\section{SANDIA REPORT}

SAND97-2381 • UC-703

Unlimited Release

Printed October 1997

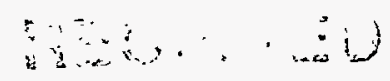

OCT 15 ing

OSTI

\title{
Comparison of M46 Broad-Band Visible Data with ELF Data from the Sprites '96 Campaign
}

Emily A. Mitchell

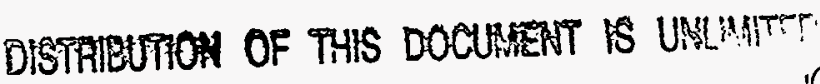

Prepared by

Sandia National Laboratories

Albuquerque, Now Mexico 87185 and Livermore, California 94550

Sandia is a multiprogram laboratory operated by Sandia

Corporation, a Lockheed Martin Company, for the United States

Department of Energy under Contract DE-AC04-94AL85000.

Approved for public release; distribution is unlimited.

\section{Sandia National Laboratories}


Issued by Sandia National Laboratories, operated for the United States Department of Energy by Sandia Corporation.

NOTICE: This report was prepared as an account of work sponsored by an agency of the United States Government. Neither the United States Government nor any agency thereof, nor any of their employees, nor any of their contractors, subcontractors, or their employees, makes any warranty, express or implied, or assumes any legal liability or responsibility for the accuracy, completeness, or usefulness of any information, apparatus, product, or process disclosed, or represents that its use would not infringe privately owned rights. Reference herein to any specific commercial product, process, or service by trade name, trademark, manufacturer, or otherwise, does not necessarily constitute or imply its endorsement, recommendation, or favoring by the United States Government, any agency thereof, or any of their contractors or subcontractors. The views and opinions expressed herein do not necessarily state or reflect those of the United States Government, any agency thereof, or any of their contractors.

Printed in the United States of America. This report has been reproduced directly from the best available copy.

Available to DOE and DOE contractors from Office of Scientific and Technical Information P.O. Box 62

Oak Ridge, TN 37831

Prices available from (615) 576-8401, FTS 626-8401

Available to the public from National Technical Information Service

U.S. Department of Commerce

5285 Port Royal Rd

Springfield, VA 22161

NTIS price codes

Printed copy: A07

Microfiche copy: A01 


\title{
Comparison of M46 Broad-Band Visible Data with ELF Data from the Sprites '96 Campaign
}

\author{
Emily A. Mitchell \\ Sandia National Laboratories \\ P.O. Box 5800 \\ Albuquerque, NM 87185-0980
}

\begin{abstract}
Lightning data, recorded with satellite optical sensors, are compared with extremely low frequency (ELF) and Schumann resonance (SR) data from the Sprites '96 Campaign. The satellite data are broad-band visible events recorded by the M46 satellite payload. Full width at half maximum and optical tail durations from the satellite data are compared with ELF slow tail features and Schumann resonance spectral color. In addition, continuing current estimates were computed for several positive cloud-toground (PCG) strokes. These estimates were derived using relative optical intensities from the satellite data and a peak current measurement from National Lightning Detection Network (NLDN) data. This assessment of M46 lightning data supports correlations between visible and ELF signatures. More data must be studied for compelling proof.
\end{abstract}


This page intentionally left blank. 


\section{DISCLAMVER}

Portions of this document may be illegible in electronic image produets. Images are produced from the best available original document. 


\section{Contents}

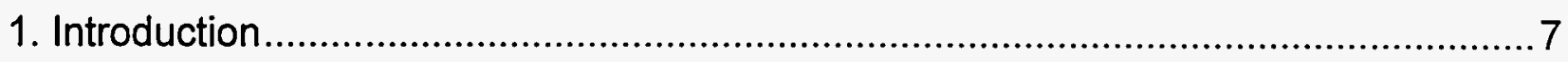

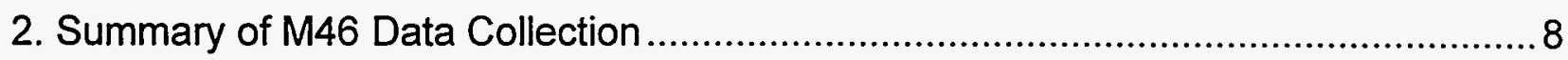

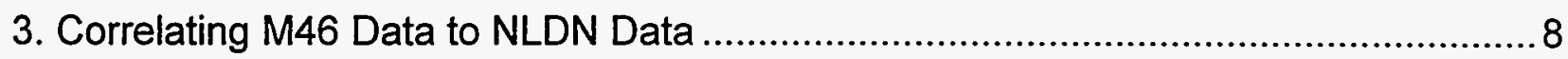

4. Full Width at Half Maximum Durations of M46 Optical Data......................................

5. Comparison of M46 Optical Data and ELF Slow Tail Data .....................................10

6. Comparison of M46 Optical Data and Schumann Resonance Data.........................11

6.1 A Brief Description of Schumann Resonance Data .......................................... 12

6.2 M46 Optical Data, Schumann Resonance Data, and Sprites........................... 13

6.2.1 Signal at 7/19/96 04:50:29.255 ......................................................... 13

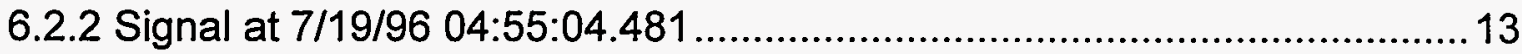

6.3 Relationships between M46 Optical Data and Schumann Resonances.............. 14

6.3.1 Comparison of M46 Optical FWHMs with Schumann Resonances ............ 14

6.3.2 Comparison of M46 Optical Full Durations and Schumann

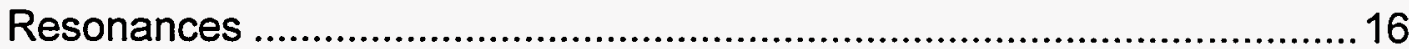

6.3.3 M46 PCG Events with Long Optical Tails Not Detected by

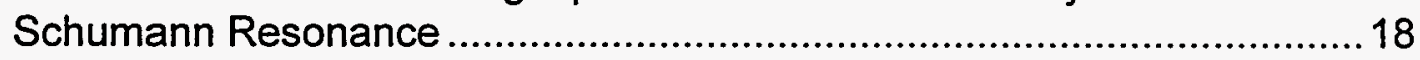

6.3.4 Other M46 Optical Tail Events ................................................................ 19

6.3.5 Estimating Values for Continuing Current................................................20

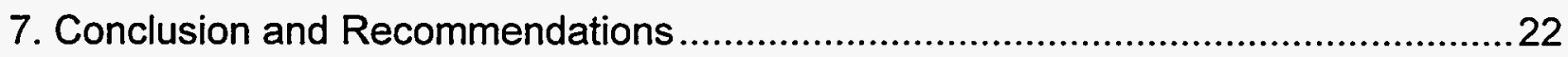

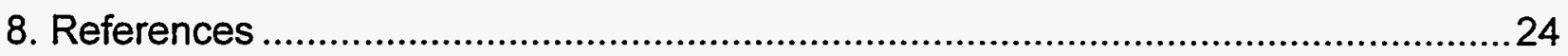




\section{Appendices}

A. Data Matches between M46 Optical Signals and NLDN Cloud-to-Ground Flashes.

B. M46 Full Width at Half Maximum Statistics from 7/16/96

C. Tables Comparing M46 Optical Data with ELF Data

D. M46 Broad-Band Visible Waveforms

E. Examples of M46 Optical Signal Ratio Calculations 129

\section{Figures and Drawings}

1. Number of M46 Optical Tail Type vs Schumann Resonance Spectral

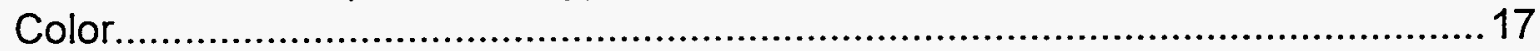

2. Frequency of Linear Current Estimates for M46 Monotonic Optical Tails ............21

3. Frequency of Linear Current Estimates for M46 Optical Secondary

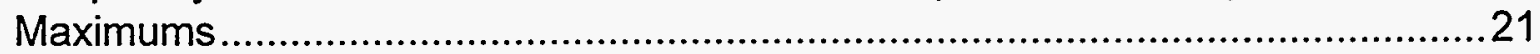

C-1. M46 Optical FWHMs vs Marx Brook ELF Slow Tails ............................................ 39

C-2. M46 Optical Full Durations vs Marx Brook ELF Slow Tails ....................................40

C-3. M46 Optical FWHMs vs Schumann Resonance Spectral Color ..........................41

C-4. M46 Minimum Optical Full Durations vs Schumann Resonance Spectral

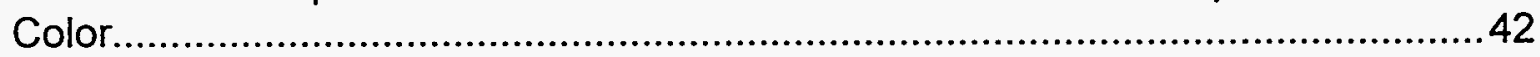

C-5. M46 Maximum Optical Full Durations vs Schumann Resonance

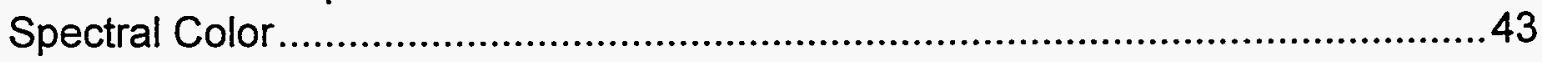

\section{Tables}

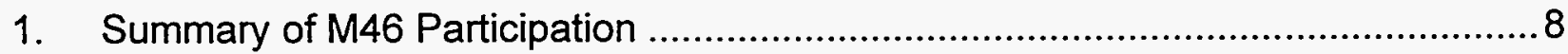

2. M46 Events with Full Durations of $60 \mathrm{~ms}$ or more .............................................18

3. Examples of M46 PCG Matches not Detected by Schumann Resonance ............. 19

C-1. PCG Matches Between M46 Broad-Band Visible Data and ELF Data for

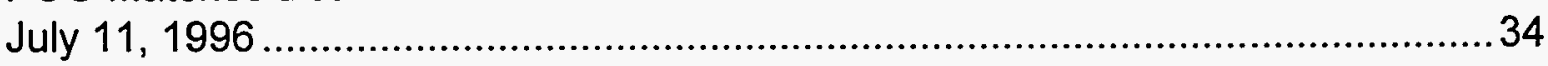

C-2. PCG Matches Between M46 Broad-Band Visible Data and ELF Data for

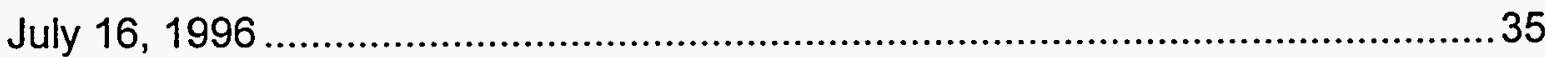

C-3. NCG Matches Between M46 Broad-Band Visible Data and ELF Data for July 16,1996 36

C-4. PCG Matches Between M46 Broad-Band Visible Data and ELF Data for July 19,1996 .37

C-5. PCG Matches Between M46 Broad-Band Visible Data and ELF Data for July 20, 1996 


\section{Waveforms}

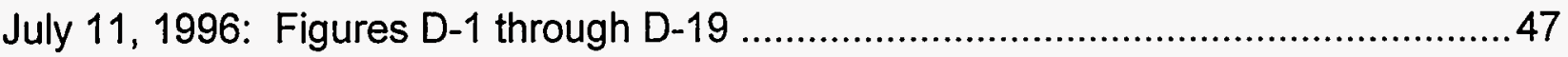

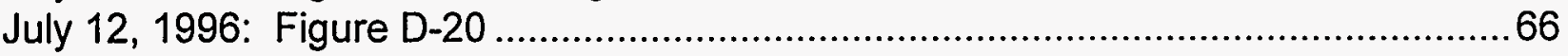

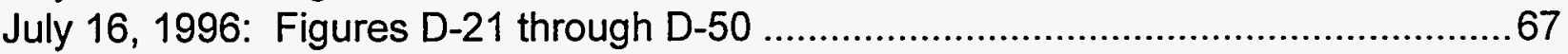

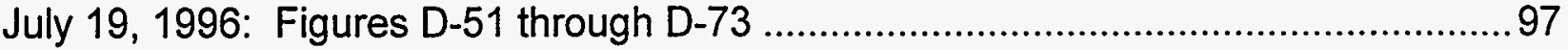

July 20, 1996: Figures D-74 through D-81 ............................................... 120 
This page intentionally left blank. 


\section{Introduction}

The Sprites 1996 Campaign was an experiment conducted during the summer of 1996 to study sprites, elves, and other upper-atmospheric lightning phenomena. ${ }^{1}$ Campaign participants collected ground-based data using low-light video cameras, photometers, extremely low frequency (ELF) and very low frequency (VLF) equipment, and mobile radar. Under the M46 program, optical satellite sensor data were collected over a period of two weeks during the campaign. ${ }^{2}$ M46 recorded data for the days of July $11,12,16,17,18,19$ and 20, 1996. The campaign was coordinated from $\mathrm{Ft}$. Collins, $\mathrm{CO}^{3}$

This document is a report covering portions of a limited analysis of M46 data with particular emphasis on the comparison of M46 optical data with ELF data. This document contains

- A summary of M46 data collection

- A comparison of M46 broad-band visible data with ELF slow tail data

- A comparison of M46 broad-band visible data with ELF Schumann resonance (SR) data

- Appendices of M46 broad-band visible data

The analysis revealed supporting evidence for a positive correlation between M46 broadband visible full width at half maximum values and ELF slow tails. Also, some possible relationships were supported between M46 optical data and Schumann resonance data. Finally, this analysis indicates that continuing current levels for mesoscale convective systems may be five to ten times the levels found in ordinary thunderstorms.

\footnotetext{
${ }^{1}$ Sponsored by Phillips Laboratory/Geophysics Dictorate and Air Force Office for Scientific Research.

${ }^{2}$ Mission 46 (M46) is a satellite sensor payload operated by Air Force Technical Application Center.

${ }^{3}$ At Yucca Ridge Field Station, owned and operated by Walt Lyons, FMA Research, Inc., Ft. Collins.
} 


\section{Summary of M46 Data Collection}

Table 1 summarizes M46 data collection for the campaign. The storms under study during the Sprites '96 Campaign were typically mesoscale systems - those most conducive to sprite production - as opposed to isolated thunderstorms. Unfortunately, video data were not available for most days of M46 participation due to local weather conditions at Ft. Collins.

Table 1. Summary of M46 Participation

\begin{tabular}{|c|c|c|c|}
\hline Date & Video Data & Storm Location & $\begin{array}{c}\text { M46 Time } \\
\text { Correction } \\
\text { Error }\end{array}$ \\
\hline $7 / 11 / 96$ & yes & ND / SD & $\pm 1.5 \mathrm{~ms}$ \\
\hline $7 / 12 / 96$ & no & $\begin{array}{c}\text { Atlantic Ocean } \\
\text { (Hurricane Bertha) }\end{array}$ & $\pm 1.0 \mathrm{~ms}$ \\
\hline $7 / 16 / 96$ & no & $\begin{array}{c}\text { southern NE / } \\
\text { northern KS }\end{array}$ & $\pm 1.6 \mathrm{~ms}$ \\
\hline $7 / 17 / 96$ & no & eastern NE / IA & - \\
\hline $7 / 18 / 96$ & no & ND, IN, MN & - \\
\hline $7 / 19 / 96$ & yes & northeastern CO & $\pm 1.8 \mathrm{~ms}$ \\
\hline $7 / 20 / 96$ & 2 sprites & $\begin{array}{c}\text { southern NE / } \\
\text { northern KS }\end{array}$ & $\pm 1.7 \mathrm{~ms}$ \\
\hline
\end{tabular}

\section{Correlating M46 Data to NLDN Data}

M46 optical events were statistically correlated in time with National Lightning Detection Network (NLDN) data for the days of July 11,12,16,19, and 20,1996. The correlation results were then used to derive millisecond time corrections for M46 data on those days (see Table 1). The time correction errors are plus or minus three standard deviations from the statistical fit (M46 data from July 17 and 18 were not corrected at the time of this report).

The NLDN detects only cloud-to-ground (CG) flashes. The NLDN determines the number of strokes in a flash (multiplicity), the polarity of the flash (positive or negative), the location of the flash, the peak current, and the time of the first stroke in a flash. The NLDN times are rounded to the nearest millisecond. Positive cloud-to-ground flashes are commonly referred to as PCGs and negative cloud-to-ground flashes as NCGs.

A statistical match of an M46 optical event with an NLDN CG flash means that the optical signal corresponded to the NLDN time. The matching optical signal may have contributions from the CG flash, cloud flashes, and possibly even sprites or elves. Presumably due to cloud geometry, M46 does not detect signals for all NLDN CG flashes. Furthermore, due to an above- 
cloud perspective, M46 may be more likely to record cloud flashes or upper atmospheric flashes than CG flashes.

Finally, this analysis assumes that the secondary maximums and optical tails following a M46/NLDN-matching peak are from the same electrical process as the NLDN CG flash. This may not always be the case, since there could be an unrelated lightning flash in the same field of view. All NLDN flashes occurring during the M46 recording periods studied were noted during the analysis. However, there is no ground truth at this time to determine if unrelated intracloud flashes might have occurred. Assuming such dual events are infrequent, then enlarging the data set size should help reduce the effect of this type of occurrence on the results.

\section{Full width at Half Maximum Durations of M46 Optical Data}

Full width at half maximum (FWHM) calculations were done for the M46 broad-band visible recordings matched with PCGs and single-stroke NCGs from July 16, 1996 (see Appendix B). Full width at half maximum values are a measurement of the duration of the optical pulse at $50 \%$ of its peak after an estimated background is subtracted.

One must consider that signals recorded by M46 are broader than they would have been if recorded from below the clouds. Empirical results by Christian, Blakeslee, and Goodman show that the major affect of a cloud on optical signals from lightning is a blurring effect, leading to time broadening of the waveforms from scattering by typically $150 \mu$ s.[1] In Monte Carlo simulations run by Brower, the broadening effect of clouds varied considerably by cloud optical thickness.[2] For example, consider Monte Carlo simulations run for cumulous clouds with 26 meter scattering distances in a tropical maritime environment of $80 \%$ relative humidity. For a moderate cloud of optical thickness 30 ( 780 meters thick), the pulse width would be broadened by a few tens of microseconds. For a very thick cloud of optical thickness 500 (13 kilometers thick), the pulse width would be broadened by about $2 \mathrm{~ms}$. In the second case, the amplitude of the signal could be severely attenuated by the scattering. These Monte Carlo simulations assumed that the cloud was of uniform thickness and type over the entire earth, and that the pulse originated from below the clouds. Cloud-to-ground lightning may originate inside of the cloud, and cloud geometries are often not uniform. Thus, in a more rigorous study of M46-observed lighting, one should strive to evaluate specific cloud properties.

The average M46 FWHM value for PCGs for this day was $1.10 \mathrm{~ms}$ (median was $1.30 \mathrm{~ms}$ ). The average FWHM value for the single stroke NCGs was $0.95 \mathrm{~ms}$ (median was $1.4 \mathrm{~ms}$ ). The histograms show that the distribution of the FWHM values for the PCG flashes peaked in the 1 to $2 \mathrm{~ms}$ range, while the distribution for the FWHM values for the single stroke NCG flashes peaked in the 0 to $0.5 \mathrm{~ms}$ range. Despite its small size, the data set indicates that the NCG flashes were slightly shorter than the PCG flashes, as expected. 
These M46 pulses are on the average longer than those seen by Goodman and Christian, who measured optical data with a narrow-band filter at $777.4 \mathrm{~nm}$ above the clouds from a U2 airplane.[3] They found the following mean FWHMs:

$\begin{array}{ll}\text { All CG flashes: } & 422 \mu \mathrm{s} \\ \text { First strokes: } & 407 \mu \mathrm{s} \\ \text { Second strokes: } & 494 \mu \mathrm{s} \\ \text { Intracloud flashes (ICs): } & 346 \mu \mathrm{s} \\ \text { IC part of CG flashes: } & 400 \mu \mathrm{s}\end{array}$

This discrepancy might be explained by the Sprites '96 Campaign concentrating on larger mesoscale convective systems, rather than on isolated thunderstorms. The larger FWHM values observed here, may be due to larger charge reservoirs in these systems or to broadening effects due to cloud scattering. More data needs to be analyzed before further conclusions can be made.

\section{Comparison of M46 Optical Data and ELF Slow Tail Data}

ELF field change antenna data from Socorro, NM, were matched with M46 events for the days of interest. ${ }^{4}$ The bandwidth of the ELF equipment was set at $360 \mathrm{~Hz}$ to $1 \mathrm{MHz}$ for the storms under consideration. For the Sprites '96 Campaign, the ELF equipment at Socorro was adjusted to trigger on PCG flashes, causing most NCG flashes to be ignored. For July 11 data, no matches to M46 PCG flashes were found. There were storms close to Socorro that night, dominating the triggering. ELF data were not collected from Socorro on July 12 . On July 16, the ELF instruments had many triggers, but only three data matches with M46. The M46 CG flash data list was minimal that day due to shortened collection times. On July. 19, a number of matches to M46 PCG flashes were identified. Four matches were found for July 20.

Most matching ELF data from Socorro exhibited "slow tail" features. ELF slow tail features have durations on the order of milliseconds and are observable with ELF bandwidth regions on the order of a few hundred hertz to one kilohertz. ELF slow tail detection drops off with distance from the source. The storms from the three days considered were close to the same distance from Socorro, reducing this source of error. Estimates of ELF slow tails durations are included in Tables C-1 through C-5, where they are compared with M46 optical data.

Figure C-1 is a plot of M46 broad-band visible FWHM data versus ELF slow tail data. FWHM values for this data set are on the order of a few milliseconds or a little less. Continuing current durations on the order of milliseconds might be expected to produce slow tails.[4] Despite the fact that this is a small data set and there is uncertainty in the ELF slow tail values

\footnotetext{
${ }^{4}$ Marx Brook, New Mexico Tech, Socorro, NM
} 
and some of the M46 FWHM values ${ }^{5}$, the plot indicates a positive correlation between ELF slow tail durations and M46 broad-band visible FWHMs.

There is one anomalous event in this data set: July 20 at 05:58:44.655 (all times are Zulu). For this event, the M46 broad-band visible recording had a large FWHM value (1.54 ms) while the ELF event showed no slow tail. This event may be a bad data point but was not anomalous with respect to M46 full duration data. More data needs to be examined to be sure.

Figure C-2 shows a plot of M46 broad-band visible full durations versus ELF slow tail data. This plot weakly indicates a positive correlation between slow tail length and M46 full duration. In all cases where M46 detected a long optical tail, the Socorro ELF instruments also detected a long slow tail. However, the relationship is not as strong as in the FWHM case for several reasons. The full duration of the M46 waveform includes the main peak along with any optical tail. These optical tails often have low magnitudes, tapering down into the noise at the background level (see data in Appendix D). Thus, the optical tail durations are difficult to measure. ${ }^{6}$ Also, because they are often low intensity, one can assume that M46 does not detect optical tails in all cases, even when they exist. Moreover, the M46 full duration values are tens to hundreds of milliseconds, where ELF slow tails are produced by millisecond time-scale effects. Thus, a relationship between long M46 optical full durations and ELF slow tails may be a side effect of a possible relationship between optical FWHM values and the production of longer lower-intensity optical tails.

Empirical results supporting a relationship between the width of the source pulse and the length of the ELF slow tail are significant to the scientific community. In 1960 Wait predicted that there would be a positive relationship between the square root of the slow-tail separation (separation between the first oscillatory peak and the maximum of the ELF slow tail) and the source pulse width.[4] Although Wait's relationship is not the same as the relationship discussed here, Wait's article demonstrates a theory predicting a relationship between the ELF slow tail and the pulse source width. Furthermore, the existence of Wait's article implies that the scientific community would be very interested in empirical evidence supporting a relationship between source pulse width and slow tail behavior.

\section{Comparison of M46 Optical Data and Schumann Resonance Data}

Earle Williams (MIT and Lincoln Laboratories) is a principal contributor to the analysis and conclusions that are discussed in this section.

\footnotetext{
${ }^{5}$ Any M46 signals that are weak may have a large uncertainty in their computed FWHM value. This is due to errors in the estimation of the background level.

${ }^{6}$ A more rigorous method for determining the background of the M46 broad-band visible signals has not been established (this will require more extensive studies). Currently, a visual estimate of the highest and lowest level for the background is made. Then, the minimum and maximum ranges for the optical signal riding on this background are estimated.
} 
ELF Schumann resonance data were collected for all of the days that M46 collected data. ${ }^{7}$ Using the list of M46/NLDN data matches, numerous M46-Schumann resonance matches were found for PCG flashes from July 11, 16, and 19, $1996{ }^{8}$ Data from July 11, 1996, contained some of the best examples of M46 signals with secondary maximums and long optical tails (not all of the sprite video ground truth data have been analyzed for this day). July 16, 1996, showed some good secondary maximums and long optical tails but was a short data collection period for M46. The M46 data for July 19, 1996, did not have the frequency of long optical tails and secondary maximums as the data from July 11,1996, although this day had the highest number of confirmed sprites (this does not imply that a relationship is lacking between optical tails and sprites, however, because the storms from July 11 were very distant from Ft. Collins, making sprites difficult to detect using video cameras at that location).

Schumann resonance measurements study the same basic phenomena as ELF measurements; the frequencies measured are lower (less than $50 \mathrm{~Hz}$ ) for Schumann resonance than for ELF instruments. For this reason, Schumann resonance data do not have the same slow tail characteristics seen in ELF data. ELF slow tails are thought to be produced by the millisecond time scale features of the continuing current. Millisecond time scales are prominent in the M46 optical data, as evidenced by the FWHM calculations, but a strong relationship between M46 optical FWHM durations and Schumann resonances is not expected. When comparing M46 optical data with Schumann resonance data, some fundamental questions were studied:

- How are M46 optical tails and secondary optical maximums related to Schumann resonance spectra?

- Do very short optical tails imply white spectra?

- Do very long optical tails imply Q-bursts with very red Schumann resonance spectra?

- How do M46 optical tails relate to sprites?

- How do M46 optical tails relate to continuing current?

\subsection{A Brief Description of Schumann Resonance Data}

Schumann resonance data are fairly complex to evaluate. A relatively simple explanation of the data follows. The Schumann resonance frequencies under consideration are as follows: 8,14 , $20,26,32,38$, and $44 \mathrm{~Hz}$. Primarily, one examines the Fast Fourier Transform (FFT) of the magnetic field and the FFT of the electric field. Then, one examines the frequency spectrum of the current amplitude derived using the normal mode equations. Red spectra are spectra whose amplitudes are larger for low frequencies than for high frequencies. White spectra are spectra whose amplitudes are flat over frequency. Red spectra are thought to indicate continuing current, because continuing currents are prominent in millisecond and longer time scales. White spectra

\footnotetext{
${ }^{7}$ Schumann resonance data were collected by Earle Williams using instruments at West Greenwich, RI.

${ }^{8}$ As of this report, Earle has not had time to evaluate the NCGs from 7/16. Also, M46 data analysis to cover comparisons for $7 / 12,7 / 17,7 / 18$ and $7 / 20$ was beyond the scope of this limited analysis effort.
} 
indicate an impulse function (no continuing current). The NLDN does not have bandwidth below $1000 \mathrm{~Hz}$; therefore, NLDN cannot detect slow tail features or Schumann modes.

"Quiet" bursts (Q-bursts), are very red ELF signals. These signals are characterized by a prominence in the $8 \mathrm{~Hz}$ Schumann resonance frequency. They are considered "quiet" because of the lack of high frequency components. Q-bursts have been connected with the occurrence of sprite-producing PCG flashes.[5] However, according to Earle Williams, Q-bursts may not be essential for producing sprites. For this analysis, an event is designated as a Q-burst when the 8 $\mathrm{Hz}$ component is three times in amplitude or an order of magnitude in power stronger than the higher frequency modes.

Discrimination of the Schumann resonance spectra between white, pink, red, and very red is fairly subjective; there is no quantitative method developed for discrimination at this time. Earle Williams is in the process of acquiring a direct measurement of the current that will allow for quantitative comparisons.

\subsection{M46 Optical Data, Schumann Resonance Data, and Sprites}

There were two three-way data matches with confirmed sprites, good broad-band visible M46 optical data, and good Schumann resonance data. These were both from July 19, 1996: 04:50:29.255 and 04:55:04.481. Both of these data points had red spectra and long optical durations, supporting a possible correlation between the two features.

\subsubsection{Signal at 7/19/96 04:50:29.255}

A cluster of comb-sprites (c-sprites) ${ }^{9}$ was identified on video at this time. M46 recorded a broad-band visible signal showing a distinct, monotonically decreasing tail of duration 35 to 180 ms (see Appendix D). FWHM was $2.40 \mathrm{~ms}$. The PCG flash measured by NLDN had a peak current of $+34 \mathrm{kA}$ with a multiplicity of 1 . A linear estimate of the continuing current (method discussed in Section 6.3.5) was 1.5 kA based on a measurement of the optical signal level $23 \mathrm{~ms}$ after the optical peak. This is an extremely large value for a continuing current. Schumann resonance data showed a very red spectrum.

\subsubsection{Signal at 7/19/96 04:55:04.481}

M46 recorded a broad-band visible signal for this event with a strong secondary maximum (see Appendix D). Unfortunately, the event occurred far enough out in the log-mode recording to have poor time resolution. Schumann resonance data showed a clean red spectrum. ELF instruments at Socorro recorded a slow tail of about $0.85 \mathrm{~ms}$.

\footnotetext{
${ }^{9}$ Comb-sprites are a cluster of thin sprites that on video resemble the teeth of a comb. This particular cluster was recorded on video by Keith Groves (Phillips Laboratory).
} 
This M46 recording is particularly interesting because of the placement of the sprite relative to the secondary maximum. Video fine times ${ }^{10}$ for this sprite showed that the sprite was brightest during the secondary maximum of the M46 signal. The video recording showed a small sprite lasting five video fields $(16.7 \mathrm{~ms}$ each). There were three small spikes. The sprite was part of a rather long cloud flash. During the first field in which the sprite appeared, the cloud flash became bright. The sprite was brightest in the second field, but the cloud flash also remained bright. The maximum duration for the sprite is from 04:55:04.481 to 04:55:04.564. The minimum duration is from 04:55:04.498 to $04: 55: 04.548$. The M46 secondary maximum could be from the cloud flash and/or the sprite and may be related in some way to a continuing current on the PCG stroke.

\subsection{Relationships between M46 Optical Data and Schumann Resonances}

The data set for comparing M46 optical "tails" to Schumann resonances was small. Although many waveforms were considered, only those with good broad-band visible M46 recordings and good Schumann resonance recordings were utilized. All of these were PCG flashes from the days of July 11,16 and 19, 1996. There were

- 4 events with white spectra

- 6 events with pink ( $(-)$ spectra

- 3 events with red ( $\mathrm{r}$ ) spectra

- 3 events with very red $(\mathrm{r}+)$ spectra

The data tables for this study are located in Appendix C. The final data set is too small to make any absolute conclusions; however, several possible relationships can be implied.

\subsubsection{Comparison of M46 Optical FWHMs with Schumann Resonances}

A strong correlation between M46 FWHM values and Schumann resonances was not expected because the FWHM values are prominent in the millisecond time scale. Schumann resonance frequencies are much lower than $1 \mathrm{kHz}$ and therefore would favor longer time-scale phenomena. There may be some relationship between optical FWHM values and longer optical full durations. If such a relationship exists, it may show up as a relationship between M46 FWHM values and Schumann resonances, provided that longer optical full durations produce red Schumann resonances. To check expectations, the following questions were posed:

- Do longer M46 optical FWHM values imply red (r-, r, or r+) Schumann resonance spectra?

For this data set, all M46 optical signals with FWHM above $1.1 \mathrm{~ms}$ had red $(\mathrm{r}-, \mathrm{r}, \mathrm{r}+)$ Schumann resonance spectra. This might imply that there exists an optical FWHM value

\footnotetext{
${ }^{10}$ Provided by Walt Lyons, FMA Research, Inc.
} 
above which all single-stroke PCG flashes have some degree of redness in their Schumann resonance spectra.

- Does redness in the Schumann resonance spectra imply a longer optical FWHM?

This appears to be true on the average, but not for all cases. The average values for M46 optical FWHM are larger for red ( $\mathrm{r}-, \mathrm{r}, \mathrm{r}+$ ) events than for white events (see Figure C-3). However, the minimum FWHM values were just as small (or smaller) for red spectrum as for white. Red events with smaller FWHMs may have long optical tails (possibly detected by M46).

- Do shorter $(<1 \mathrm{~ms})$ optical FWHM imply white Schumann resonance spectra?

No. All four spectral groups had at least one event with FWHM less than $1 \mathrm{~ms}$. In fact, the event with the shortest optical FWHM (0.76 ms from July 11, 1996, at 05:24:47) in the group had a red (r) spectrum. However, this particular event had a full optical duration of 30 to $40 \mathrm{~ms}$ due to a long optical tail.

- What does the degree of redness of Schumann resonance spectra imply about the optical FWHM?

There appears to be a very weak correlation between the degree of Schumann resonance spectral color and M46 optical FWHM values. On the average, red (r-, r, r+) events had longer FWHM values than white events. However, red (r) events had shorter FWHM values on the average than pink or very red events. This latter observation is probably an artifact of the small data set.

Studying single-stroke NCG strokes in this fashion may help determine a relationship of FWHM to Schumann resonances because single-stroke NCG strokes are thought to rarely have long continuing currents. Earle Williams has done studies evaluating his Schumann resonance detection of NLDN NCG strokes. He found that his equipment only triggers on the larger of these. However, Earle has the capability of lowering his thresholds for a short study for the purposes of detecting more of the NCG strokes.

In conclusion, these results demonstrate that when comparing M46 durations with Schumann resonances, one can not treat the effects of the optical FWHM values as statistically independent of the effects of the optical full durations. In fact, full durations of the optical signals should show a stronger relationship to Schumann resonances than the FWHM values. The relationship of optical FWHM to ELF characteristics are better pursued with higher frequency ELF measurements than the Schumann resonance bands, such as with ELF instruments at Socorro. 


\subsubsection{Comparison of M46 Optical Full Durations and Schumann Resonances}

Many of the M46 recordings featured long optical tails. Full duration measurements of these signals provided a quantitative measure of these optical tails. However, due to noise levels and low optical tail intensities, M46 full duration measurements are imprecise. In an attempt to quantify the uncertainty, minimum and maximum values for each full duration measurement were estimated. Then, the average, minimum, and maximum for all of the minimum (and then all of the maximum) full duration values were plotted using bar graphs (see Appendix C). Again, some possible implications were formulated:

- Do M46 optical "tails" imply red (r-, r, or r+) Schumann resonance spectra?

On the average, this appears to be true. Figure 1 shows the number of events with various types of optical tail features compared to their Schumann resonance spectral colors. Figures C-4 and C-5 plot the minimum, average, and maximum values for the M46 FWHM and full durations, respectively, versus Schumann resonance color. For this data set, all but one of the M46 optical PCG flash events which had distinct, long ( $>5 \mathrm{~ms}$ for minimum) optical tails produced red $(r-, r, r+)$ spectra.

The one exception was an event on July 11,1996 at 05:23:10.874. The full duration of this event was from 9 to $19 \mathrm{~ms}$ with a distinct monotonic optical tail and a small secondary maximum. Schumann resonance data for this event had a white spectrum. If the optical tail was produced by continuing current in the PCG flash channel, then this would not agree with a white spectrum. Further examination of the Schumann resonance data revealed that there was some enhancement of the spectrum at mid-band, meaning that the event did not have a clean white spectrum. This example emphasizes the need for a more quantitative measurement for the Schumann resonance characteristics. (Earle Williams has plans in the near future to provide for a direct current extraction from the Schumann resonance measurements. This would assist quantitative interpretation of future Schumann resonance data.) Unfortunately, ELF instruments at Socorro did not record this event. If the event indeed has a white spectra, then there was possibly some other process involved here; for example, an independent cloud flash or an upper atmospheric flash. A cloud flash would not be detected by the ELF.

- Do red ( $r-, r$, or $r+)$ Schumann resonance spectra imply that there will always be a broadband visible optical tail?

The available data are not at variance with this concept (see Figure 1 and the tables and figures in Appendix C). However, this question can not be determined completely by M46 because M46 may not see all optical tails. Many of these often dim continuing optical emissions could be obscured by clouds. Thus, an M46 optical full duration of 2 ms from a red spectral event does not necessarily mean that the event stopped producing optical emissions after $2 \mathrm{~ms}$. 
Optical tail type:

\begin{tabular}{|c|c|c|c|c|}
\hline $\begin{array}{c}\text { delayed } \\
\text { secondary max. }\end{array}$ & & & & 1 \\
\hline secondary max. & $0.5 ?$ & 1 & 2 & \\
\hline monotonic & 0.5 & 2 & 2 & 1 \\
\hline no tail & 2 & 2 & & \\
\hline spectral color: & white & pink & red & \\
\hline
\end{tabular}

Data from $7 / 11 / 96,7 / 16 / 96,7 / 19 / 96$

Note: Signals with very short ( $<5 \mathrm{~ms}$ "minimum" full duration) monotonic tails were considered no-tail values. Values that had multiple categories were noted as fractional amounts in both categories. For example, if an event had a monotonic tail and a secondary maximum, then 0.5 was added to the secondary maximum category and 0.5 was

$\therefore \quad$ added to the monotonic tail category.

\section{Figure 1. Number of M46 Optical Tail Type vs Schumann Resonance Spectral Color}

- Does the length of M46 broad-band visible optical tails imply the degree of redness of the Schumann resonance spectra?

Although the data appear to support the feasibility of such a relationship, verifying this premise is more difficult. Assume that the duration of the optical tail implies the duration of the continuing current. Then, the uncertainty in the M46 quantitative full duration optical measurements implies that much ambiguity still exists in determining where the continuing current actually ceases.

The continuing current duration for primary Schumann resonance excitation is one quarter to one half of the period of the fundamental Schumann resonance mode, 30 to 60 ms. Thus, continuing currents in this region should have spectra dominant at $8 \mathrm{~Hz}$. One might also expect events with continuing currents outside of this range to be less red than those falling within this range. 
However, due to the uncertainties involved, these points should be noted:

- One can not establish true maximum durations for optical emissions of events based on M46 optical full duration measurements. For example, one can not say that events with M46 maximum optical durations of less than $30 \mathrm{~ms}$ are truly this short. Thus, one can not conclude that these events are below the fundamental 30 to $60 \mathrm{~ms}$ region.

- M46 minimum duration measurements may be more useful. For example, if M46 records a minimum duration of $30 \mathrm{~ms}$, then the optical emission was at least that long. However, since the maximum durations are unknown, one still can not pinpoint events to have optical durations within the range of 30 to $60 \mathrm{~ms}$.

There is one event with good Schumann resonance data whose minimum M46 optical full duration is greater than or equal to $60 \mathrm{~ms}$. There is one other event close to this range with a minimum optical duration of $57 \mathrm{~ms}$. These two events at least do not contradict the statement that continuing currents longer than $60 \mathrm{~ms}$ would lead to less red Schumann resonance spectra (see Table 2).

In order to better explore the premise that the length of the optical tail implies a particular degree of spectral color, more quantitative measurements of the M46 optical tail durations and of the Schumann resonance spectral colors are needed. From the M46 standpoint this means that a better understanding of the noise levels is necessary. From the Schumann resonance standpoint, the ability to directly measure the current for the Schumann resonance data would help.

Table 2. M46 Events with Full Durations of $60 \mathrm{~ms}$ or More

\begin{tabular}{|c|c|c|c|c|c|c|c|}
\hline date & NLDN time & $\begin{array}{c}\text { NLDN } \\
\text { peak } \\
\text { current } \\
(\mathbf{k A})\end{array}$ & $\begin{array}{c}\text { NLDN } \\
\text { multi- } \\
\text { plicity }\end{array}$ & $\begin{array}{c}\text { M46 } \\
\text { FWHM } \\
\text { (ms) }\end{array}$ & $\begin{array}{c}\text { M46 } \\
\text { Full } \\
\text { Duration } \\
\text { (ms) }\end{array}$ & $\begin{array}{c}\text { M46 optical tail } \\
\text { comment }\end{array}$ & $\begin{array}{c}\text { EW } \\
\text { Schumann. } \\
\text { resonance spectral } \\
\text { color }\end{array}$ \\
\hline $7 / 11 / 96$ & $05: 36: 55.693$ & +79 & 1 & 1.44 & $60-80$ & monotonic & red \\
\hline $7 / 16 / 96$ & $04: 14: 35.382$ & +45 & 4 & 2.25 & $57-200$ & monotonic & pink \\
\hline
\end{tabular}

\subsubsection{M46 PCG Events with Long Optical Tails Not Detected by Schumann Resonance}

On July 11, 1996 there were some M46 PCG-matched events that had long optical tails but whose PCG flashes were not detected by Earle Williams' Schumann resonance equipment. Some of these events had large NLDN peak currents. Searching for an explanation for why the instruments did not detect these events, it was noticed that these events fell in a time interval where none of the Schumann resonance data matched any of the M46-NLDN PCG flashes (from 
about 04:16:43 to 05:23:10). One possible cause is that local storms in New England could have interfered with Schumann resonance data collection of these more remote storms. ${ }^{11}$

Table 3 describes three of those events. Plots of the three events are located in Appendix D. These events have particularly interesting optical tails and secondary maximum. Schumann resonance data might have been helpful in understanding the source lightning that produced these three events.

\section{Table 3. Examples of M46 PCG Matches Not Detected by Schumann Resonance}

\begin{tabular}{|c|c|c|c|c|c|}
\hline NLDN time & $\begin{array}{c}\text { NLDN } \\
\text { Peak } \\
\text { Current } \\
(\mathrm{kA})\end{array}$ & $\begin{array}{c}\text { NLDN } \\
\text { mult- } \\
\text { plicity }\end{array}$ & $\begin{array}{c}\text { M46 } \\
\text { FWHM } \\
\text { (ms) }\end{array}$ & $\begin{array}{c}\text { M46 } \\
\text { Full } \\
\text { Duration } \\
\text { (ms) }\end{array}$ & M46 optical tail comment \\
\hline $04: 23: 38.367$ & +68 & 1 & 2.45 & $60-110$ & $\begin{array}{l}\text { very prominent monotonic } \\
\text { tail and secondary } \\
\text { maximum }\end{array}$ \\
\hline $04: 35: 28.831$ & +79 & 1 & 0.820 & $3.5 / 45-50$ & $\begin{array}{l}\text { two secondary maximums } \\
\text { beginning after primary } \\
\text { pulse ended. }\end{array}$ \\
\hline $04: 47: 47.578$ & +51 & 1 & 1.50 & $80-130$ & $\begin{array}{l}\text { monotonic tail with } \\
\text { prominent secondary } \\
\text { maximum }\end{array}$ \\
\hline & & & & &
\end{tabular}

\subsubsection{Other M46 Optical Tail Events}

During the Sprites '96 Campaign, M46 recorded some broad-band visible optical events with long optical tails and secondary maximums that do not statistically correlate with NLDN CG flashes and that were not detected by ELF. Presumably, these events are cloud flashes or upper atmospheric events. Alternatively, they may be CG events not detected by NLDN or the other ELF equipment.

One example is the event on July 11,1996, at approximately 05:45:50.565 (see Appendix D). This event reveals a primary pulse with a long monotonic tail and a secondary maximum (full duration of 90 to $150 \mathrm{~ms}$ ). The recording also indicates a later small fluctuation in intensity close to an NLDN PCG flash at 05:45:50.809. There was no sprite associated with the PCG flash. The source of the prominent first pulse is unknown. M46 recordings of this type demonstrate that much still needs to be learned about satellite optical lightning data. Converting the M46 data to geophysical units would be a step towards this understanding.

\footnotetext{
"Schumann resonance instruments are located in Rhode Island.
} 


\subsubsection{Estimating Values for Continuing Current}

Assuming that the optical tails are a product of the continuing current, Earle Williams suggested that the M46 optical tail intensities appeared larger than expected in comparison to the optical peaks for the Sprites '96 Campaign data. This is based on the expectation that continuing currents are a few hundred amperes for $\mathrm{CG}$ flashes in ordinary thunderstorms. With this in mind, ratios of the optical tail and secondary maximums to the optical peak for a few of the M46 broadband visible optical events were computed (see Tables C-1 through C-5). This ratio was computed as follows:

1. For events with monotonical optical tails, this is the ratio of the intensity of the optical tail relative to the intensity at the peak with estimated background removed. (The intensity of the optical tail is measured at approximately two-thirds of the distance from the peak to the minimum duration point of the optical tail.)

2. For events with secondary maximums, this is the ratio of the peak intensity of the secondary maximum relative to the peak intensity of the larger primary peak with estimated background removed.

Tables $\mathrm{C}-1$ through $\mathrm{C}-5$ show the time from the primary peak measurement point to the optical tail measurement point. Appendix E shows two examples of the ratio calculations.

\subsubsection{Linear Current Estimate}

For a first approximation of the channel currents that produced the optical tail emissions, a linear relationship between channel current and optical emission was assumed (a quadratic relationship is discussed in Section 6.3.5.2). These linear estimates were computed by multiplying the optical ratio (optical tail to peak intensity) by NLDN peak current; they are listed in Tables $\mathrm{C}-1$ through $\mathrm{C}-5$. These calculations make several assumptions:

1. That the relationship between the optical signature and the continuing current is linear. (This is probably not the case. More likely, the optical measurements are related to power, or the square of the current.)

2. That the optical signal from the secondary maximums and the optical tail are from the same cloud and channel geometry as the optical signature of the main pulse. (This may not be a valid assumption in some cases, especially if cloud components are present.)

3. That the optical signal is dominated by the $\mathrm{CG}$ channel.

4. That the electromagnetically determined peak current for the return stroke data is coincident with the M46 optical peak. 
The uncertainty of the ratios is high in some cases, especially for the smaller ratios (table values with very high uncertainty are marked with $a \sim$ ). These ratios are based on the ability to estimate the M46 background and noise level. A better understanding of the noise level needs to be developed along with the effect of the data averaging over the sampling period in order to improve the estimates for the background. The larger the ratio, the more accurate it is, provided that all the other assumptions are correct. Improving these measurements and determining their uncertainty would require a detailed study of all the waveforms from the session.

These ratio computations indicate that the PCG flashes from the Sprites '96 Campaign could have much higher continuing currents than those from ordinary PCG flashes: 1 to $5 \mathrm{kA}$ as compared to a few hundreds of amps, as shown in Figure 2. Larger continuing currents might be expected from these storms, however, because charge reservoirs of mesoscale convective systems are larger than those of ordinary thunderstorms.

The current estimates derived from M46 optical secondary maximums were even larger (2 to $10 \mathrm{kA}$ ), as shown in Figure 3. These secondary maximums could have contributions from other sources (possibly cloud flashes or sprites).

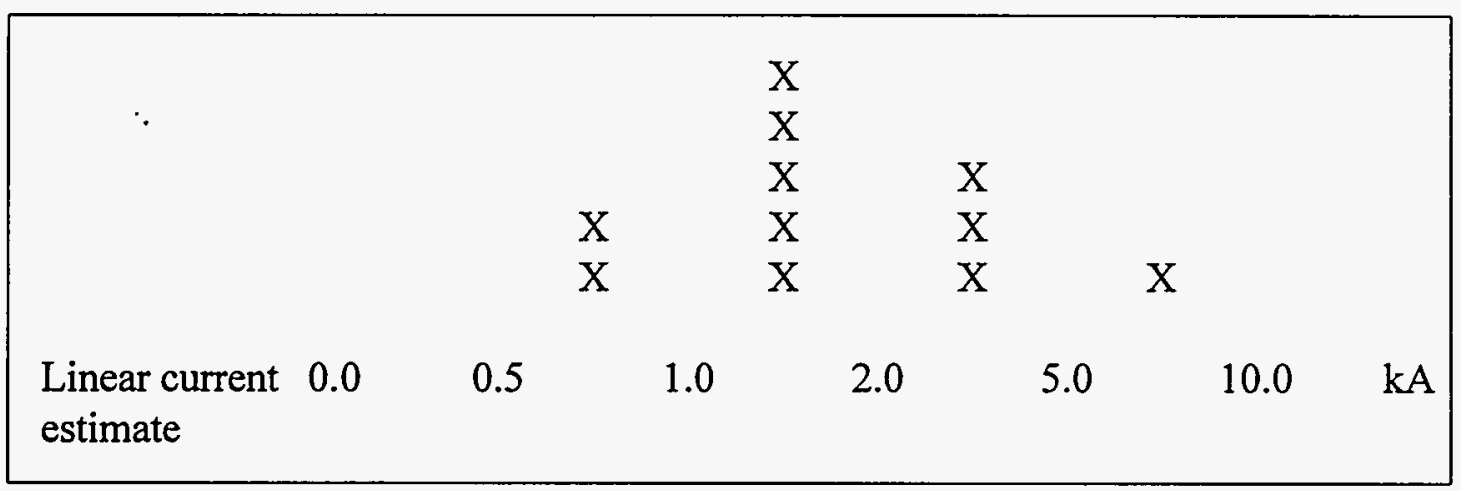

Figure 2. Frequency of Linear Current Estimates for M46 Monotonic Optical Tails

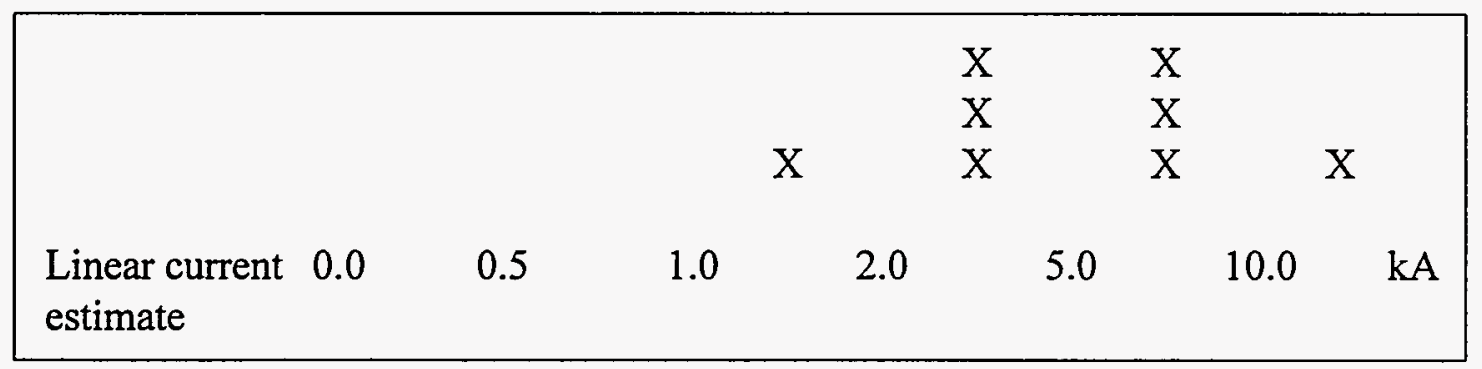

Figure 3. Frequency of Linear Current Estimates for M46 Optical Secondary Maximums 


\subsubsection{Quadratic Current Estimate}

The relationship between continuing current and optical emissions is not linear, however.[6] Colvin et al. derived a relationship between channel current and brightness for the 0.50 to 0.70 micron region:

$$
B=a I+b I^{2}
$$

where $a$ and $b$ are $4.6119 \mathrm{e}-4$ and $4.0748 \mathrm{e}-6, I$ is the discharge current in $\mathrm{kA}$, and $B$ is the radiation in $4 \pi \mathrm{sr}$ in units of $10^{8} \mathrm{~W} \mathrm{~m}^{-1}$ of channel length. [6] This implies that optical intensity has a quadratic, rather than a linear relationship with channel current. For comparison purposes the quadratic estimate of the continuing current was computed for two examples.

1. Consider the event on July 19, 1996 at 04:50:29.255 (see Table C-4). This event had an optical ratio of 0.044 . The PCG flash had a peak current of $34 \mathrm{kA}$. Using the linear relationship, the continuing current at the optical tail was predicted to be $1.5 \mathrm{kA}$. Colvin's formula predicts a source peak brightness of $2.04 \mathrm{e}^{\mathrm{W} \mathrm{m}} \mathrm{m}^{-1}$ for this PCG flash. Assuming that the channel and cloud geometry are the same (from the M46 perspective) for the optical peak intensity and for the optical tail, then, at the continuing current measurement point, the

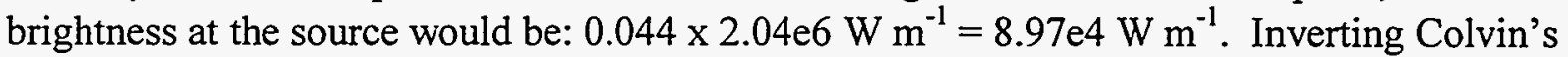
formula, this would imply a current level of $\sim 1.9 \mathrm{kA}$. This is slightly larger than the linearlyderived value.

2. Consider another event on July 11,1996 at 03:46:32.419 (see Table C-1). This event had a ratio of 0.32 at the first secondary maximum relative to the optical peak. The PCG flash had a peak current of $114 \mathrm{kA}$. Using the linear relationship, the continuing current was predicted to be $36 \mathrm{kA}$. Colvin's formula predicts a source peak brightness of $1.06 \mathrm{e} 7 \mathrm{~W} \mathrm{~m}^{-1}$ for this PCG flash. Assuming that the channel and cloud geometry are the same for the optical peak and the optical tail intensities, then, at the secondary maximum, the brightness at the source would be: $0.32 \times 1.06 \mathrm{e} 7 \mathrm{~W} \mathrm{~m}^{-1}=3.38 \mathrm{e} 6 \mathrm{~W} \mathrm{~m}^{-1}$. Inverting Colvin's formula, this would imply a current level of $\sim 51 \mathrm{kA}$. This is considerably larger than the linear estimate.

This indicates that the linear estimates are conservative estimates, provided that the assumptions regarding the channel are true. The larger-than-expected continuing currents indicated by these results could be significant. Further studies should be done to understand these data.

\section{Conclusion and Recommendations}

In conclusion, the analysis of M46 broad-band visible data with ELF data revealed several results. First, the results show that a positive correlation between M46 broad-band visible FWHM values and ELF slow tails is likely to exist. Second, although not conclusive, the data suggests that long optical tails are related to $C G$ flashes with red optical spectra. Finally, this 
analysis indicates that continuing current levels for mesoscale convective systems may be considerably larger than those present in ordinary thunderstorms.

More data needs to be collected in order to further investigate the relationship between M46 optical FWHM values and ELF slow tail durations to determine if the positive relationship between them continues to be supported. The M46 data from the days of July 12, 17, and 18 were from distant storms that can not be directly compared to data from July 19 and 20, 1996, because slow tails are thought to attenuate with distance from the source. If Marx Brook's equipment is to be used, storms proximate to Socorro should be studied.

The following analysis topics could be pursued using currently unevaluated Sprites '96 Campaign data:

- Continue analysis of continuing current estimates based on optical tails, encouraging theorists to propose theories explaining these results.

- Analyze M46 noise levels in order to reduce the uncertainty of the full duration measurements and to improve background estimations and continuing current calculations.

- Continue to pursue the indication that data with red Schumann resonance spectra will also typically have broad-band visible optical tails.

- Continue comparisons with Schumann resonance data to determine if there exists an optical FWHM value above which all single-stroke PCG flashes have some degree of redness in their Schumann resonance spectra.

- Perform conversion of the M46 data to geophysical units, providing additional information about the source signals and their continuing currents.

- Compare M46 optical FWHMs with full durations to determine any relationships.

- Evaluate FWHM and full duration measurements for M46 optical data from isolated thunderstorms and for the rest of the Sprites '96 campaign days to determine if there are significant differences in values between mesoscale systems and ordinary thunderstorms. (M46 data from isolated thunderstorms are archived.)

This analysis is only a beginning. There is much to be learned regarding the relationships between optical and ELF signals. More data need to be studied in order to confirm or contradict the results indicated by this introductory analysis. 


\section{References}

1. Christian, H.J., R.J. Blakeslee, and S.J. Goodman, "The Detection of Lightning from Geostationary Orbit," Journal of Geophysical Research, Vol. 94, No. D11, pp. 13329-13337, September 30, 1989.

2. Brower, K.L., "Optical Transmission of Light through Clouds," Sandia Report SAND971139, UC-703, Specified Dissemination, May 1997.

3. Goodman, S.J., H.J. Christian, and W.D. Rust, "A Comparison of the Optical Pulse Characteristics of Intracloud and Cloud-to-Ground Lightning as Observed above Clouds," Journal of Applied Meteorology, Vol. 27, pp. 1369-1381, December 1988.

4. Wait, J.R., "On the Theory of the Slow-Tail Portion of Atmospheric Waveforms," Journal of Geophysical Research, Vol. 65, No. 7, pp. 1939-1946, July 1960.

5. Boccippio, D.J., E.R. Williams, W.A. Lyons, I. Baker and R. Boldi, "Sprites, Q-Bursts and Positive Ground Strokes," Science, 1995, Vol. 269, pp. 1088-1091.

6. Colvin, J.D., C.K. Mitchell, J.R. Greig, D.P. Murphy, R.E. Pechacek, and M. Raleigh, "An Empirical Study of the Nuclear Explosion-Induced Lightning Seen on IVY-MIKE,", Journal of Geophysical Research, Vol. 92, No. D5, pp. 5696-5712, May 20, 1987. 


\section{Appendix A: \\ Data Matches between M46 Optical Signals and NLDN Cloud-to-Ground Flashes}

M46 - NLDN PCG Matches for July 11, 1996

\begin{tabular}{|c|c|c|c|c|c|}
\hline & & & & $\begin{array}{l}\text { peak } \\
\text { current }\end{array}$ & \\
\hline date & time & Lat. & Long. & $\mathrm{kA} / 0.185$ & multiplicity \\
\hline $07 / 11 / 96$ & $03: 46: 32.419$ & 48.672 & -98.363 & +614.4 & 1 \\
\hline $07 / 11 / 96$ & $03: 51: 42.196$ & 48.766 & -98.375 & +465.6 & 1 \\
\hline $07 / 11 / 96$ & $04: 03: 01.321$ & 45.595 & -100.332 & +142.7 & 1 \\
\hline $07 / 11 / 96$ & $04: 11: 23.177$ & 48.374 & -98.654 & +63.9 & 1 \\
\hline $07 / 11 / 96$ & $04: 13: 44.300$ & 48.369 & -98.283 & +233.9 & 1 \\
\hline $07 / 11 / 96$ & $04: 14: 53.098$ & 49.139 & -98.405 & +341.6 & 1 \\
\hline $07 / 11 / 96$ & $04: 16: 43.900$ & 48.192 & -98.694 & +144.7 & 1 \\
\hline $07 / 11 / 96$ & $04: 20: 15.622$ & 47.969 & -98.985 & +104.7 & 2 \\
\hline $07 / 11 / 96$ & $04: 21: 11.752$ & 46.607 & -98.932 & +59.4 & 1 \\
\hline $07 / 11 / 96$ & $04: 23: 38.367$ & 48.789 & -98.817 & +368.9 & 1 \\
\hline $07 / 11 / 96$ & $04: 27: 59.314$ & 48.328 & -98.104 & +298.7 & 1 \\
\hline $07 / 11 / 96$ & $04: 35: 28.831$ & 48.416 & -98.073 & +424.6 & 1 \\
\hline $07 / 11 / 96$ & $04: 38: 28.771$ & 47.023 & -98.329 & +309.9 & 1 \\
\hline $07 / 11 / 96$ & $04: 47: 47.578$ & 48.877 & -98.063 & +273.9 & 1 \\
\hline $07 / 11 / 96$ & $04: 51: 11.405$ & 48.391 & -97.830 & +642.5 & 1 \\
\hline $07 / 11 / 96$ & $04: 52: 36.576$ & 48.729 & -97.904 & +477.5 & 1 \\
\hline $07 / 11 / 96$ & $04: 53: 56.874$ & 48.462 & -97.588 & +257.5 & 1 \\
\hline $07 / 11 / 96$ & $04: 58: 38.264$ & 48.776 & -97.945 & +332.9 & 1 \\
\hline $07 / 11 / 96$ & $05: 00: 33.064$ & 48.427 & -97.923 & +304.1 & 1 \\
\hline $07 / 11 / 96$ & $05: 03: 16.418$ & 48.371 & -97.805 & +181.1 & 1 \\
\hline $07 / 11 / 96$ & $05: 07: 46.029$ & 48.578 & -97.628 & +527.1 & 1 \\
\hline 07/11/96 & $05: 09: 11.564$ & 48.398 & -97.707 & +392.7 & 1 \\
\hline $07 / 11 / 96$ & $05: 14: 05.716$ & 47.926 & -98.369 & +111.5 & 1 \\
\hline $07 / 11 / 96$ & $05: 14: 59.165$ & 48.672 & -97.563 & +873.3 & 1 \\
\hline $07 / 11 / 96$ & $05: 18: 25.532$ & 48.259 & -97.422 & +290.6 & 1 \\
\hline $07 / 11 / 96$ & $05: 19: 02.605$ & 48.460 & -98.172 & +109.0 & 1 \\
\hline $07 / 11 / 96$ & $05: 19: 07.332$ & 48.544 & -97.532 & +560.7 & 1 \\
\hline $07 / 11 / 96$ & $05: 20: 39.827$ & 48.295 & -97.494 & +125.8 & 1 \\
\hline $07 / 11 / 96$ & $05: 23: 10.874$ & 48.540 & -97.463 & +430.6 & 1 \\
\hline $07 / 11 / 96$ & $05: 24: 47.302$ & 48.835 & -98.074 & +522.8 & 1 \\
\hline $07 / 11 / 96$ & $05: 27: 52.925$ & 48.559 & -97.496 & +468.2 & 1 \\
\hline $07 / 11 / 96$ & $05: 29: 08.804$ & 48.444 & -97.671 & +126.0 & 1 \\
\hline $07 / 11 / 96$ & $05: 29: 10.354$ & 48.904 & -97.990 & +490.3 & 2 \\
\hline $07 / 11 / 96$ & $05: 30: 53.461$ & 48.272 & -97.436 & +166.3 & 1 \\
\hline $07 / 11 / 96$ & $05: 35: 41.241$ & 48.028 & -97.809 & +50.9 & 1 \\
\hline $07 / 11 / 96$ & $05: 36: 55.693$ & 48.900 & -97.553 & +426.0 & 1 \\
\hline $07 / 11 / 96$ & $05: 40: 13.138$ & 48.699 & -97.435 & +212.3 & 1 \\
\hline $07 / 11 / 96$ & $05: 40: 52.652$ & 47.559 & -99.107 & +73.6 & 1 \\
\hline $07 / 11 / 96$ & $05: 41: 56.653$ & 48.448 & -97.465 & +156.4 & 1 \\
\hline $07 / 11 / 96$ & $05: 45: 50.809$ & 48.990 & -97.611 & +499.6 & 1 \\
\hline $07 / 11 / 96$ & $05: 52: 32.747$ & 48.321 & -97.183 & +391.1 & 1 \\
\hline $07 / 11 / 96$ & $05: 52: 51.614$ & 48.529 & -97.365 & +218.1 & 1 \\
\hline $07 / 11 / 96$ & $05: 54: 51.280$ & 47.870 & -97.855 & +211.3 & 1 \\
\hline $07 / 11 / 96$ & $05: 56: 31.595$ & 48.498 & -97.284 & +239.3 & 1 \\
\hline $07 / 11 / 96$ & $06: 00: 44.950$ & 47.911 & -97.625 & +202.7 & 1 \\
\hline $07 / 11 / 96$ & $06: 00: 54.849$ & 45.086 & -98.973 & -220.4 & 2 \\
\hline $07 / 11 / 96$ & $06: 03: 43.510$ & 47.933 & -97.641 & +163.9 & 1 \\
\hline $07 / 11 / 96$ & $06: 14: 40.029$ & 47.383 & -98.327 & +60.8 & 1 \\
\hline $07 / 11 / 96$ & $06: 40: 15.795$ & 46.370 & -97.608 & +33.6 & 1 \\
\hline $07 / 11 / 96$ & $07: 02: 54.017$ & 44.948 & -97.533 & +175.2 & 1 \\
\hline $07 / 11 / 96$ & $07: 06: 02.119$ & 44.647 & -98.424 & +161.4 & 1 \\
\hline $07 / 11 / 96$ & $07: 10: 23.627$ & 44.625 & -98.491 & +84.3 & 1 \\
\hline $07 / 11 / 96$ & $07: 10: 23.733$ & 44.871 & -97.875 & +303.4 & 1 \\
\hline $07 / 11 / 96$ & $07: 12: 23.106$ & 44.598 & -97.997 & +656.5 & 3 \\
\hline
\end{tabular}


M46 - NLDN PCG Matches for July 12, 1996

$\begin{array}{cccccl}\text { date } & \text { time } & \text { Lat. } & \text { Long. } & \begin{array}{c}\text { purrent } \\ \text { kA } / 0.185\end{array} & \text { multiplicity } \\ 07 / 12 / 96 & 04: 07: 35.718 & 30.238 & -76.378 & +281.1 & 1 \\ 07 / 12 / 96 & 04: 14: 51.144 & 30.439 & -76.421 & +347.2 & 1 \\ 07 / 12 / 96 & 04: 18: 28.324 & 30.423 & -76.694 & +204.3 & 1 \\ 07 / 12 / 96 & 04: 21: 10.407 & 30.126 & -76.364 & +226.2 & 1 \\ 07 / 12 / 96 & 04: 22: 38.807 & 30.410 & -76.482 & +195.7 & 1 \\ 07 / 12 / 96 & 04: 29: 54.845 & 30.500 & -76.468 & +330.0 & 1 \\ 07 / 12 / 96 & 04: 32: 37.858 & 30.530 & -76.398 & +230.6 & 1 \\ 07 / 12 / 96 & 04: 38: 55.324 & 30.428 & -76.391 & +189.3 & 1 \\ 07 / 12 / 96 & 04: 45: 05.307 & 30.119 & -76.434 & +111.6 & 1 \\ 07 / 12 / 96 & 04: 47: 02.050 & 30.230 & -76.338 & +284.1 & 1 \\ 07 / 12 / 96 & 04: 51: 01.073 & 30.749 & -76.378 & +221.1 & 1 \\ 07 / 12 / 96 & 04: 56: 03.092 & 30.749 & -76.407 & +119.8 & 1 \\ 07 / 12 / 96 & 05: 01: 44.899 & 30.691 & -76.366 & +150.3 & 1 \\ 07 / 12 / 96 & 05: 12: 08.114 & 30.403 & -76.260 & +415.8 & 2 \\ 07 / 12 / 96 & 05: 32: 25.658 & 29.773 & -76.414 & +195.5 & 1 \\ 07 / 12 / 96 & 05: 35: 07.378 & 30.860 & -76.416 & +344.7 & 1 \\ 07 / 12 / 96 & 06: 20: 54.676 & 30.738 & -76.563 & +266.4 & 1 \\ 07 / 12 / 96 & 06: 22: 52.906 & 30.697 & -76.917 & +471.3 & 1 \\ 07 / 12 / 96 & 06: 30: 48.247 & 30.918 & -76.827 & +269.3 & 1 \\ 07 / 12 / 96 & 06: 33: 07.632 & 30.853 & -76.651 & +181.5 & 1 \\ 07 / 12 / 96 & 06: 33: 25.647 & 30.998 & -76.438 & +223.5 & 1 \\ 07 / 12 / 96 & 06: 34: 24.610 & 30.885 & -76.818 & +100.7 & 1\end{array}$


M46 - NLDN PCG Matches for July 16, 1996

peak

current

date time Lat. Long. $\mathrm{kA} / 0.185$ multiplicity

07/16/96 03:11:32.111 39.755 - $100.151+297.42$

$07 / 16 / 96 \quad 03: 16: 29.525 \quad 39.994-100.132+886.6 \quad 2$

$07 / 16 / 96 \quad 03: 16: 34.92341 .273-98.702+442.8 \quad 1$

$07 / 16 / 9603: 25: 41.09640 .277-100.429+609.72$

$07 / 16 / 96 \quad 03: 29: 59.708 \quad 40.064-100.494+335.8 \quad 1$

$07 / 16 / 96 \quad 03: 39: 15.78540 .061-100.815+328.4 \quad 1$

$07 / 16 / 96 \quad 03: 58: 01.628 \quad 39.729-100.289+894.4 \quad 2$

07/16/96 $03: 58: 35.970 \quad 40.793 \quad-99.071+252.8 \quad 1$

$07 / 16 / 96 \quad 04: 11: 20.59239 .436-100.218+81.01$

$07 / 16 / 9604: 12: 30.80539 .379-100.710+184.11$

$07 / 16 / 96 \quad 04: 14: 35.382 \quad 40.299 \quad-99.543+244.3 \quad 4$

$07 / 16 / 96 \quad 04: 22: 42.410 \quad 40.434 \quad-99.099+186.3 \quad 1$

$07 / 16 / 96 \quad 04: 28: 25.293 \quad 39.417-100.957+170.7 \quad 1$

M46 - NLDN NCG Matches for July 16, 1996

\begin{tabular}{|c|c|c|c|c|c|}
\hline & & & & $\begin{array}{l}\text { peak } \\
\text { current }\end{array}$ & \\
\hline date & time & Lat. & Long. & $\mathrm{kA} / 0.185$ & multiplicity \\
\hline $07 / 16 / 96$ & $03: 09: 05.008$ & 40.340 & -99.972 & -226.2 & 2 \\
\hline $07 / 16 / 96$ & $03: 14: 17.190$ & 42.674 & -98.461 & -250.4 & 2 \\
\hline $07 / 16 / 96$ & $03: 23: 25.745$ & 40.234 & -99.872 & -139.1 & 1 \\
\hline $07 / 16 / 96$ & $03: 24: 28.497$ & 40.654 & -99.312 & -245.9 & 2 \\
\hline $07 / 16 / 96$ & $03: 32: 07.907$ & 40.301 & -99.715 & -285.3 & 4 \\
\hline $07 / 16 / 96$ & $03: 38: 52.856$ & 39.408 & -101.419 & -147.9 & 2 \\
\hline $07 / 16 / 96$ & $03: 39: 52.951$ & 39.829 & -100.057 & -91.5 & 1 \\
\hline $07 / 16 / 96$ & $03: 39: 58.316$ & 41.106 & -99.452 & -404.6 & 5 \\
\hline $07 / 16 / 96$ & $0.3: 40: 43.265$ & 39.396 & -101.397 & -106.3 & 3 \\
\hline $07 / 16 / 96$ & $03: 48: 20.469$ & 40.000 & -99.885 & -242.5 & 2 \\
\hline $07 / 16 / 96$ & $03: 48: 23.168$ & 40.550 & -99.719 & -136.2 & 1 \\
\hline $07 / 16 / 96$ & $03: 51: 51.886$ & 40.303 & -99.622 & -100.7 & 4 \\
\hline $07 / 16 / 96$ & $03: 53: 36.693$ & 39.440 & -101.301 & -120.8 & 1 \\
\hline $07 / 16 / 96$ & $03: 54: 00.333$ & 39.172 & -101.583 & -111.4 & 1 \\
\hline $07 / 16 / 96$ & $03: 54: 50.892$ & 39.144 & -101.625 & -180.7 & 2 \\
\hline $07 / 16 / 96$ & $03: 55: 16.616$ & 40.453 & -99.959 & -109.2 & 1 \\
\hline $07 / 16 / 96$ & $03: 57: 58.815$ & 39.152 & -101.572 & -80.8 & 1 \\
\hline $07 / 16 / 96$ & $03: 58: 33.030$ & 40.518 & -99.466 & -210.9 & 1 \\
\hline $07 / 16 / 96$ & $03: 59: 22.876$ & 39.201 & -101.596 & -127.2 & 2 \\
\hline $07 / 16 / 96$ & $04: 00: 58.306$ & 39.203 & -101.552 & -132.5 & 1 \\
\hline $07 / 16 / 96$ & $04: 00: 58.129$ & 39.713 & -100.090 & -103.1 & 1 \\
\hline $07 / 16 / 96$ & $04: 08: 14.833$ & 39.583 & -99.667 & -131.7 & 2 \\
\hline $07 / 16 / 96$ & $04: 12: 26.364$ & 40.224 & -99.865 & -193.8 & 1 \\
\hline $07 / 16 / 96$ & $04: 16: 49.823$ & 39.721 & -99.933 & -138.3 & 1 \\
\hline $07 / 16 / 96$ & $04: 20: 47.985$ & 40.121 & -100.619 & -113.6 & 1 \\
\hline $07 / 16 / 96$ & $04: 22: 43.878$ & 40.252 & -99.803 & -519.8 & 3 \\
\hline $07 / 16 / 96$ & $04: 23: 12.811$ & 39.202 & -101.385 & -137.4 & 1 \\
\hline $07 / 16 / 96$ & $04: 25: 33.033$ & 40.019 & -99.697 & -301.6 & 3 \\
\hline $07 / 16 / 96$ & $04: 25: 59.088$ & 39.191 & -101.411 & -120.8 & 1 \\
\hline $07 / 16 / 96$ & $04: 28: 45.567$ & 40.012 & -99.685 & -389.0 & 1 \\
\hline $07 / 16 / 96$ & $04: 29: 52.780$ & 39.199 & -101.432 & -93.2 & 1 \\
\hline
\end{tabular}


M46 - NLDN PCG Matches for July 19, 1996

peak

current

date time Lat. Long. $\mathrm{kA} / 0.185$ multiplicity

$07 / 19 / 9602: 48: 53.572 \quad 39.277-102.698+264.7 \quad 2$

$07 / 19 / 96 \quad 02: 49: 30.905 \quad 39.657-102.388+181.8 \quad 1$

$07 / 19 / 9602: 50: 41.94139 .072-101.921+253.0 \quad 1$

$07 / 19 / 9602: 53: 04.78639 .432-102.589+367.9 \quad 1$

$07 / 19 / 96 \quad 02: 53: 09.944 \quad 39.148-102.495+168.0 \quad 1$

$07 / 19 / 96 \quad 02: 53: 40.845 \quad 39.015-101.076 \quad+286.4 \quad 1$

$07 / 19 / 96 \quad 02: 55: 03.097 \quad 39.411-102.561+172.7 \quad 1$

$07 / 19 / 96 \quad 03: 06: 42.78240 .961-102.454+86.6 \quad 1$

$07 / 19 / 96 \quad 04: 50: 00.07140 .641-102.481+572.0 \quad 2$

$07 / 19 / 96 \quad 04: 50: 29.25541 .010-102.376+181.6 \quad 1$

$07 / 19 / 96 \quad 04: 51: 55.07540 .666-102.457+309.1 \quad 1$

$07 / 19 / 96 \quad 04: 52: 12.697 \quad 40.049-101.900+102.5 \quad 1$

$07 / 19 / 96 \quad 04: 52: 20.793 \quad 40.657-102.420+580.8 \quad 1$

$07 / 19 / 96 \quad 04: 52: 54.243 \quad 41.049-102.359+250.0 \quad 1$

$07 / 19 / 96 \quad 04: 53: 13.493 \quad 40.719-102.360+264.0 \quad 1$

$07 / 19 / 96 \quad 04: 53: 36.987 \quad 40.542-102.436+148.3 \quad 1$

$07 / 19 / 96 \quad 04: 54: 14.920 \quad 40.718-102.408+520.8 \quad 1$

$07 / 19 / 96 \quad 04: 55: 03.93340 .056-101.870+182.8 \quad 1$

$07 / 19 / 96 \quad 04: 55: 04.481 \quad 40.103-102.113+450.4 \quad 1$

$07 / 19 / 96 \quad 04: 55: 06.57540 .909-102.341+138.1 \quad 1$

$07 / 19 / 96 \quad 04: 55: 32.787 \quad 40.540-102.452+307.3 \quad 1$

$07 / 19 / 96 \quad 05: 02: 17.346 \quad 40.094-101.978+308.7 \quad 1$

$07 / 19 / 96 \quad 05: 06: 51.14040 .753-102.356+819.0 \quad 1$

$07 / 19 / 96 \quad 05: 41: 02.31940 .899-102.160+219.01$

$07 / 19 / 96 \quad 05: 46: 21.494 \quad 40.772-101.820+575.4 \quad 1$

$07 / 19 / 96 \quad 05: 47: 47.590 \quad 40.791-102.217+299.11$

$07 / 19 / 96 \quad 05: 48: 38.748 \quad 40.367-101.718+314.4 \quad 1$

$07 / 19 / 96 \quad 05: 53: 56.73640 .960-102.268+409.2 \quad 1$

$07 / 19 / 96 \quad 05: 57: 58.567 \quad 40.888-102.037+434.1 \quad 1$

$07 / 19 / 96 \quad 06: 05: 36.718 \quad 40.450-101.849+195.0 \quad 1$

$07 / 19 / 96 \quad 06: 07: 59.623 \quad 40.514-101.865+271.8 \quad 1$

$07 / 19 / 96 \quad 06: 11: 54.00940 .724-101.842+250.4 \quad 1$

$07 / 19 / 96 \quad 06: 16: 00.375 \quad 40.742-101.826+275.9 \quad 2$

$07 / 19 / 9606: 16: 25.47141 .026-102.005+336.4 \quad 1$

$07 / 19 / 96 \quad 06: 22: 05.037 \quad 40.823-101.545+565.92$

$07 / 19 / 96 \quad 06: 23: 33.96040 .706-102.494+234.6 \quad 1$

$07 / 19 / 96 \quad 06: 34: 04.63140 .885-101.672+537.31$

07/19/96 06:35:22.410 41.010 $-101.589+565.6 \quad 1$

$07 / 19 / 9606: 38: 30.15141 .056-101.560+633.0 \quad 2$ 
M46 - NLDN PCG Matches for July 20, 1996

\begin{tabular}{|c|c|c|c|c|c|}
\hline date & time & Lat. & Long. & $\mathrm{kA} / 0.18$ & 5 multiplicity \\
\hline $07 / 20 / 96$ & $03: 19: 15.327$ & 40.447 & -98.816 & +413.3 & 1 \\
\hline $07 / 20 / 96$ & $03: 27: 57.085$ & 40.519 & -98.722 & +295.9 & 1 \\
\hline $07 / 20 / 96$ & $03: 37: 25.969$ & 40.193 & -98.532 & +149.4 & 1 \\
\hline $07 / 20 / 96$ & $03: 43: 58.935$ & 40.333 & -98.490 & +376.2 & 1 \\
\hline $07 / 20 / 96$ & $03: 48: 46.880$ & 40.445 & -98.580 & +302.7 & 1 \\
\hline $07 / 20 / 96$ & $03: 50: 32.946$ & 40.602 & -98.950 & +116.1 & 1 \\
\hline $07 / 20 / 96$ & $03: 52: 31.174$ & 40.417 & -98.511 & +187.1 & 1 \\
\hline $07 / 20 / 96$ & $03: 55: 29.234$ & 40.588 & -98.569 & +342.1 & 1 \\
\hline $07 / 20 / 96$ & $03: 58: 02.213$ & 40.405 & -98.497 & +161.4 & 1 \\
\hline $07 / 20 / 96$ & $04: 01: 47.567$ & 40.172 & -98.285 & +109.2 & 1 \\
\hline $07 / 20 / 96$ & $04: 02: 02.574$ & 40.425 & -98.442 & +178.5 & 1 \\
\hline $07 / 20 / 96$ & $04: 03: 05.405$ & 40.584 & -98.569 & +246.6 & 2 \\
\hline $07 / 20 / 96$ & $04: 03: 49.456$ & 40.180 & -98.481 & +122.4 & 1 \\
\hline $07 / 20 / 96$ & $04: 11: 47.636$ & 39.911 & -98.037 & +93.7 & $I$ \\
\hline $07 / 20 / 96$ & $04: 19: 30.488$ & 40.330 & -98.212 & +207.6 & 1 \\
\hline $07 / 20 / 96$ & $04: 23: 50.040$ & 40.344 & -98.204 & +151.5 & 1 \\
\hline $07 / 20 / 96$ & $04: 27: 56.213$ & 40.205 & -98.136 & +132.7 & 1 \\
\hline $07 / 20 / 96$ & $04: 45: 46.195$ & 37.238 & -100.738 & +370.3 & 1 \\
\hline $07 / 20 / 96$ & $04: 47: 36.717$ & 39.612 & -98.120 & +111.2 & 1 \\
\hline $07 / 20 / 96$ & $04: 53: 25.640$ & 40.089 & -98.003 & +46.2 & 1 \\
\hline $07 / 20 / 96$ & $05: 01: 32.311$ & 39.828 & -98.066 & +162.2 & 1 \\
\hline $07 / 20 / 96$ & $05: 01: 33.752$ & 39.525 & -98.162 & +426.5 & 1 \\
\hline $07 / 20 / 96$ & $05: 03: 38.954$ & 39.811 & -98.055 & +178.1 & 1 \\
\hline $07 / 20 / 96$ & $05: 09: 34.187$ & 39.888 & -97.987 & +359.7 & 2 \\
\hline $07 / 20 / 96$ & $05: 11: 05.436$ & 40.764 & -98.527 & +194.9 & 1 \\
\hline $07 / 20 / 96$ & $05: 11: 59.264$ & 40.712 & -98.385 & +209.2 & 1 \\
\hline $07 / 20 / 96$ & $05: 18: 43.823$ & 39.261 & -96.691 & +359.7 & 1 \\
\hline $07 / 20 / 96$ & $05: 18: 54.341$ & 39.063 & -97.232 & +184.0 & 1 \\
\hline $07 / 20 / 96$ & $05: 21: 50.797$ & 39.711 & -97.455 & +85.9 & 1 \\
\hline $07 / 20 / 96$ & $05: 22: 38.764$ & 39.082 & -97.173 & +203.7 & 1 \\
\hline $07 / 20 / 96$ & $05: 25: 12.669$ & 39.050 & -97.055 & +189.1 & 1 \\
\hline $07 / 20 / 96$ & $05: 27: 06.471$ & 39.101 & -97.659 & +119.6 & 1 \\
\hline $07 / 20 / 96$ & $05: 28: 32.194$ & 40.282 & -98.033 & +260.3 & 1 \\
\hline $07 / 20 / 96$ & $05: 29: 01.132$ & 38.414 & -98.285 & +341.9 & 2 \\
\hline $07 / 20 / 96$ & $05: 31: 15.334$ & 38.413 & -98.229 & +164.7 & 1 \\
\hline $07 / 20 / 96$ & $05: 36: 53.526$ & 40.039 & -97.203 & +146.8 & 1 \\
\hline $07 / 20 / 96$ & $05: 40: 51.654$ & 40.100 & -97.164 & +154.6 & 1 \\
\hline $07 / 20 / 96$ & $05: 58: 44.655$ & 39.878 & -96.184 & +236.9 & 1 \\
\hline $07 / 20 / 96$ & $06: 02: 14.146$ & 40.622 & -98.025 & +239.7 & 1 \\
\hline $07 / 20 / 96$ & $06: 05: 47.459$ & 40.636 & -97.793 & +310.7 & 1 \\
\hline $07 / 20 / 96$ & $06: 06: 31.122$ & 40.640 & -97.995 & +251.6 & 1 \\
\hline $07 / 20 / 96$ & $06: 06: 58.996$ & 40.669 & -97.373 & +105.6 & 1 \\
\hline $07 / 20 / 96$ & $06: 07: 04.466$ & 40.787 & -97.865 & +404.9 & 1 \\
\hline $07 / 20 / 96$ & $06: 13: 58.735$ & 40.633 & -97.645 & +267.1 & 1 \\
\hline $07 / 20 / 96$ & $06: 14: 01.631$ & 40.830 & -97.877 & +143.8 & 1 \\
\hline $07 / 20 / 96$ & $06: 17: 12.548$ & 40.659 & -97.684 & +149.8 & 1 \\
\hline $07 / 20 / 96$ & $06: 18: 48.882$ & 40.670 & -97.645 & +129.4 & 1 \\
\hline $07 / 20 / 96$ & $06: 21: 39.708$ & 40.657 & -97.693 & +349.7 & 1 \\
\hline $07 / 20 / 96$ & $06: 23: 02.836$ & 40.478 & -97.476 & +278.1 & 1 \\
\hline $07 / 20 / 96$ & $06: 25: 19.681$ & 40.741 & -97.462 & +340.3 & 1 \\
\hline $07 / 20 / 96$ & $06: 27: 17.914$ & 40.735 & -97.486 & +301.7 & 1 \\
\hline $07 / 20 / 96$ & $06: 31: 12.550$ & 39.371 & -96.514 & +235.2 & 1 \\
\hline $07 / 20 / 96$ & $06: 31: 55.866$ & 38.120 & -98.979 & +33.2 & 1 \\
\hline $07 / 20 / 96$ & $06: 33: 36.539$ & 39.778 & -97.222 & +153.1 & 1 \\
\hline $07 / 20 / 96$ & $06: 36: 24.185$ & 39.346 & -97.427 & +162.6 & 1 \\
\hline $07 / 20 / 96$ & $06: 37: 02.500$ & 39.061 & -96.440 & +74.2 & 1 \\
\hline $07 / 20 / 96$ & $06: 44: 04.932$ & 40.099 & -96.273 & +141.4 & 1 \\
\hline $07 / 20 / 96$ & $06: 55: 13.254$ & 40.112 & -95.905 & +320.7 & 1 \\
\hline
\end{tabular}


This page intentionally left blank. 


\title{
Appendix B: M46 FWHM Statistics from 7/16/96
}

\author{
Statistics for \\ M46/NLDN Positive Cloud-to-Ground Flash Matches \\ July 16, 1996
}

\begin{tabular}{llrlccc} 
date & time & \multicolumn{3}{c}{ kA mult } & FWHM (ms) & Full Dur. (ms) \\
$07 / 16 / 96$ & $03: 11: 32.111$ & +55 & 2 & 1.1 & 3 & \\
$07 / 16 / 96$ & $03: 16: 29.525$ & +164 & 2 & 1.1 & $2.5-5$ & \\
$07 / 16 / 96$ & $03: 16: 34.923$ & +82 & 1 & 1.3 & 2.3 & \\
$07 / 16 / 96$ & $03: 25: 41.096$ & +113 & 2 & 0.90 & $2-5$ & \\
$07 / 16 / 96$ & $03: 29: 59.708$ & +62 & 1 & 0.70 & $2.5-4$ & \\
$07 / 16 / 96$ & $03: 39: 15.785$ & +61 & 1 & 1.85 & 3 & \\
$07 / 16 / 96$ & $03: 58: 01.628$ & +166 & 2 & 1.1 & $3-4$ & \\
$07 / 16 / 96$ & $03: 58: 35.970$ & +47 & 1 & 0.950 & 50 & secondary max \\
$07 / 16 / 96$ & $04: 11: 20.592$ & +15 & 1 & 0.350 & $1-2.5$ & \\
$07 / 16 / 96$ & $04: 12: 30.805$ & +34 & 1 & 0.650 & 1.5 & \\
$07 / 16 / 96$ & $04: 14: 35.382$ & +45 & 4 & 2.25 & $100-200$ & \\
$07 / 16 / 96$ & $04: 22: 42.410$ & +34 & 1 & 0.98 & $3-8$ & $100 \mathrm{~ms}$ delayed 2nd max \\
$07 / 16 / 96$ & $04: 28: 25.293$ & +32 & 1 & 1.10 & $7-15$ &
\end{tabular}

FWHM Histogram

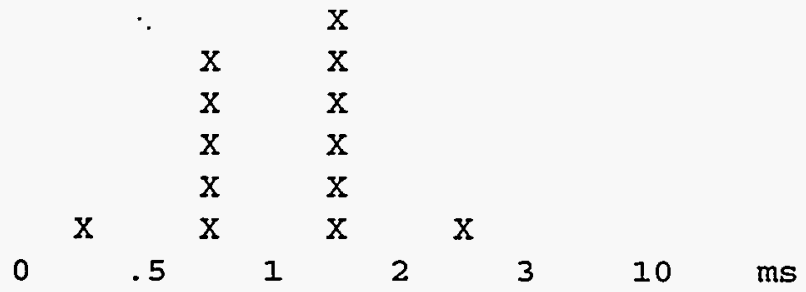

Full Duration Histogram

(Those labeled with + are for ambiguous values.)

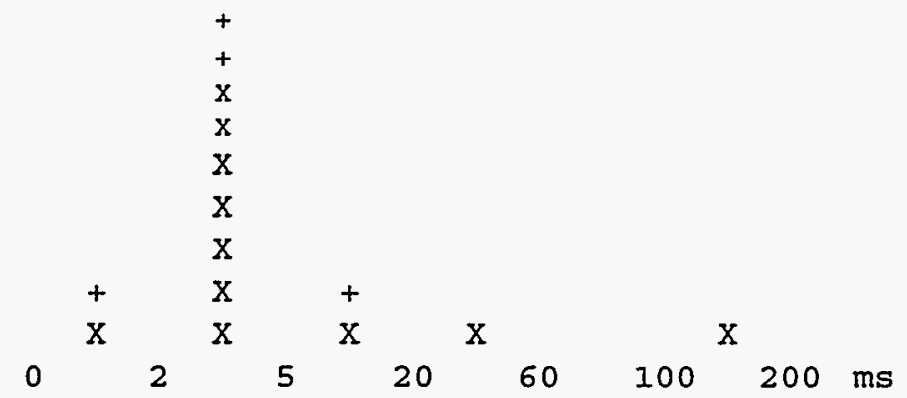




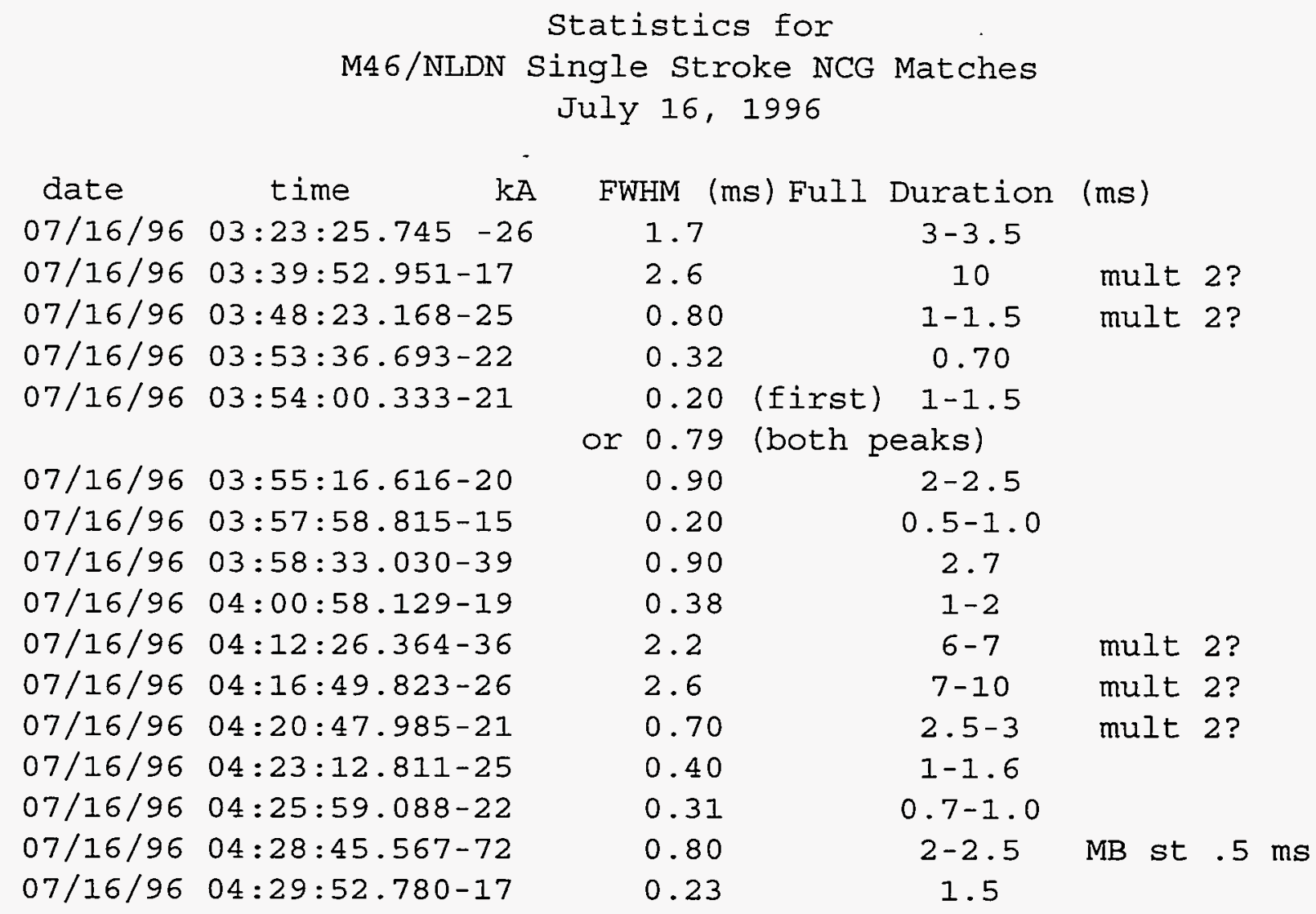

FWHM Histogram

(The "+" is for the bimodal event.)

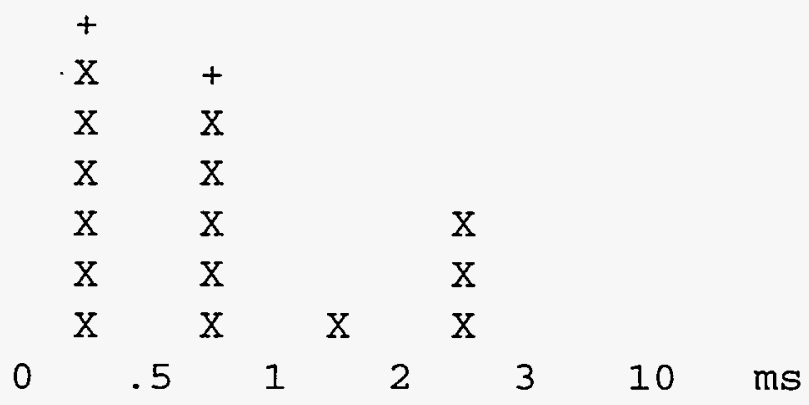




\section{Appendix C: Tables Comparing M46 Optical Data with ELF Data}

\section{Key to Data Notation}

In the column $M 46$ ratio, a " $"$ implies a large uncertainty in this measurement.

The ratios with "-" can't be measured with any certainty.

Initials key:

KG Keith Groves (Phillips Laboratory)

EW Earle Williams (MIT)

MB Marx Brook (New Mexico Tech)

MT Mike Taylor (Utah State University)

WL Walt Lyons (FMA Research, Inc.)

RA Russ Armstrong (MRC)

Comment key:

$\begin{array}{ll}\text { S } & \text { Sprite } \\ \text { E } & \text { Elve }\end{array}$

M46 optical tail key:

- weak

EW Schumann resonance spectral color key:

- noisy or otherwise ambiguous data, sometimes due to multistrokes

Explanations of the linear estimate of the current and of the M46 optical signal ratio are found in the body of this document. 
Table C-1. PCG Matches Between M46 Broad-Band Visible Data and ELF Data for July 11, 1996

6/25/97 Emily Mitchell, SNL

Earle Williams, MIT

\begin{tabular}{|c|c|c|c|c|c|c|c|c|c|c|c|}
\hline NLDN time & $\begin{array}{l}\text { NLDN } \\
\text { Peak } \\
\text { Current } \\
(\mathrm{k} \Lambda)\end{array}$ & $\begin{array}{c}\text { Linear } \\
\text { Estimate } \\
\text { of } \\
\text { Current }\end{array}$ & $\begin{array}{l}\text { NLDN } \\
\text { multi- } \\
\text { plicity }\end{array}$ & $\begin{array}{l}\text { M46 } \\
\text { FWHM } \\
\text { (ms) }\end{array}$ & $\begin{array}{c}\text { M46 } \\
\text { Full } \\
\text { Duration } \\
\text { (ms) }\end{array}$ & $\begin{array}{l}\text { M46 Optical } \\
\text { Signal Ratio } \\
\text { time: ratio } \\
\text { (ms: ratio) }\end{array}$ & $\begin{array}{l}\text { M46 Optical Tail } \\
\text { Description }\end{array}$ & $\begin{array}{l}\text { Schumann } \\
\text { Resonance } \\
\text { Spectral } \\
\text { Color }\end{array}$ & $\begin{array}{c}\text { Earle Williams } \\
\text { Schumann } \\
\text { Resonance } \\
\text { Description }\end{array}$ & $\begin{array}{c}\text { Marx Brook } \\
\text { ELF } \\
\text { Slow Tail } \\
\text { Duration (ms) }\end{array}$ & Event Comment \\
\hline \multirow[t]{3}{*}{$03: 46: 32.419$} & +114 & & $T$ & $\overline{1.36}$ & 40 & & $\begin{array}{l}\text { monotonic tail/ } \\
\text { secondary max }\end{array}$ & red & & - & \\
\hline & & +36 & & & & $5.7: 0.32$ & (at sec. $\max 1$ ) & & & & \\
\hline & & $\sim+4.6$ & & & & $25.0: \sim 0.04$ & (at sec. $\max 2)$ & & & & \\
\hline \multirow[t]{2}{*}{$04: 13: 44.300$} & +43 & & 1 & 1.91 & $20-40$ & & monotonic tail & pink & & - & \\
\hline & & -1.3 & & & & 13.3: - 0.03 & (on optical tail) & & & & \\
\hline $04: 14: 53.098$ & +63 & & 1 & 1.30 & $3-17$ & - & - & very red & & - & \\
\hline \multirow[t]{3}{*}{$05: 23: 10.874$} & +80 & & 1 & 1.00 & $9-19$ & & $\begin{array}{l}\text { monotonic tail/ } \\
\text { secondary max? }\end{array}$ & white & & - & \\
\hline & & -1.3 & & & & $6.0: \sim 0.016$ & (on optical tail) & & & & \\
\hline & & +3.5 & & & & $3.6: 0.044$ & (at sec. max?) & & & & \\
\hline \multirow[t]{3}{*}{$05: 24: 47.302$} & +97 & & 1 & 0.76 & $30-40$ & & $\begin{array}{l}\text { monotonic tail/ } \\
\text { secondary max }\end{array}$ & red & Q-burst & - & \\
\hline & & -0.87 & & & & $20.0: \sim 0.009$ & (on optical tail) & & & & \\
\hline & & +4.3 & & & & $4.7: 0.044$ & (at sec. max) & & & & \\
\hline $05: 27: 52.925$ & +87 & & 1 & 0.88 & $4-7$ & - & no tail & white & & - & \\
\hline $05: 29: 10.354$ & +91 & & 2 & 0.81 & 2 & - & no tail & pink & & - & \\
\hline \multirow[t]{2}{*}{$05: 36: 55.693$} & +79 & & 1 & 1.44 & $60-80$ & & monotonic tail & red & & - & \\
\hline & & -+0.63 & & & & $40.0: \sim .008$ & (on optical tail) & & & & \\
\hline $05: 40: 13.138$ & +39 & & $\mathrm{I}$ & 1.20 & 16 & - & - & - & noisy & - & \\
\hline $05: 45: 50.809$ & +92 & & 1 & 2.1 & - & - & - & - & noisy & - & $\begin{array}{l}\text { Possible cloud flash } \\
\text { with monotonic tail } \\
\text { prior to PCG. }\end{array}$ \\
\hline $05: 56: 31.595$ & +97 & & 1 & 1.10 & 3 & - & no tail & - & multistroke 2 & - & \\
\hline
\end{tabular}


Table C-2. PCG Matches Between M46 Broad-Band Visible Data and ELF Data for July 16, 1996

6/25/97 Emily Mitchell, SNL Earle Williams, MIT

\begin{tabular}{|c|c|c|c|c|c|c|c|c|c|c|c|}
\hline NLDN time & $\begin{array}{l}\text { NLDN } \\
\text { Peak } \\
\text { Current } \\
(\mathrm{kA})\end{array}$ & $\begin{array}{l}\text { Linear } \\
\text { Estimate } \\
\text { of } \\
\text { Current }\end{array}$ & $\begin{array}{l}\text { NLDN } \\
\text { multi- } \\
\text { plicity }\end{array}$ & $\begin{array}{c}\text { M46 } \\
\text { FWHM } \\
\text { (ms) }\end{array}$ & $\begin{array}{c}\text { M46 } \\
\text { Full } \\
\text { Duration } \\
\text { (ms) }\end{array}$ & $\begin{array}{l}\text { M46 Optical } \\
\text { Signal Ratio } \\
\text { time: ratio } \\
\text { (ms: ratio) }\end{array}$ & $\begin{array}{l}\text { M46 Optical Tail } \\
\text { Description }\end{array}$ & $\begin{array}{c}\text { Schumann } \\
\text { Resonance } \\
\text { Spectral } \\
\text { Color }\end{array}$ & $\begin{array}{c}\text { Earle Williams } \\
\text { Schumann } \\
\text { Resonance } \\
\text { Description }\end{array}$ & $\begin{array}{c}\text { Marx } \\
\text { Brook ELF } \\
\text { Slow Tail } \\
\text { Duration } \\
(\mathrm{ms})\end{array}$ & Event Comment \\
\hline $03: 11: 32.111$ & +55 & & 2 & 1.1 & 3 & - & - & - & multistroke & - & \\
\hline $03: 16: 29.525$ & +164 & & 2 & 1.1 & $2.5-5$ & - & - & white & clear & - & \\
\hline $03: 16: 34.923$ & +82 & & 1 & 1.3 & 2.3 & - & no tail & - & mulitple & - & \\
\hline $03: 25: 41.096$ & +113 & & 2 & 0.90 & $2-5$ & - & no tail & white & clear & - & \\
\hline $03: 39: 15.785$ & +61 & & 1 & 1.85 & 3 & - & no tail & - & multistroke & - & \\
\hline $03: 58: 01.628$ & +166 & & 2 & 1.1 & $3-4$ & - & - & - & 2 strokes & 0.65 & \\
\hline $03: 58: 35.970$ & +47 & & 1 & 0.950 & 50 & & secondary max & pink & $\begin{array}{l}2^{\text {nd }} \text { event } 200 \\
\text { ms after first }\end{array}$ & 0.85 & \\
\hline & & +2.3 & & & & $1.8: 0.050$ & (note 1) & & & & \\
\hline & & +7.5 & & & . & $4.5: 0.16$ & (at sec. $\max 1$ ) & & & & \\
\hline & & +6.6 & & & & $30.2: 0.14$ & (at sec. $\max 2$ ) & & & & \\
\hline $04: 14: 35.382$ & +45 & & 4 & 2.25 & $57-200$ & & monotonic tail & pink & & - & \\
\hline & & -1.7 & & & & $38.0 ; \sim 0.037$ & (on optical tail) & & & & \\
\hline $04: 22: 42.410$ & +34 & & 1 & 0.98 & $3-8$ & - & - & very red & clean & 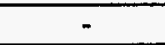 & \\
\hline & & & & & 100 & & $\begin{array}{l}\text { delayed secondary } \\
\max \end{array}$ & & & - & \\
\hline
\end{tabular}

note 1: Measured at minimum between primary peak and first secondary maximum. 
6/25/97 Emily Mitchell, SNL

\begin{tabular}{|c|c|c|c|c|c|c|c|c|c|}
\hline NLDN time & $\begin{array}{l}\text { NLDN } \\
\text { Peak } \\
\text { Current } \\
(\mathrm{kA})\end{array}$ & $\begin{array}{l}\text { Linear } \\
\text { Estimate } \\
\text { of } \\
\text { Current }\end{array}$ & $\begin{array}{c}\text { M46 } \\
\text { FWHIM } \\
(\mathrm{ms})\end{array}$ & $\begin{array}{c}\text { M46 } \\
\text { Full } \\
\text { Duration } \\
\text { (ms) }\end{array}$ & $\begin{array}{l}\text { M46 Optical } \\
\text { Signal Ratio } \\
\text { time: ratio } \\
\text { (ms: ratio) }\end{array}$ & $\begin{array}{l}\text { M46 Optical Tail } \\
\text { Description }\end{array}$ & $\begin{array}{c}\text { Schumann } \\
\text { Resonance } \\
\text { Spectral } \\
\text { Color }\end{array}$ & $\begin{array}{c}\text { Earle } \\
\text { Williams } \\
\text { Schumann } \\
\text { Resonance } \\
\text { Description }\end{array}$ & $\begin{array}{c}\text { Marx Brook } \\
\text { ELF } \\
\text { Slow Tail } \\
\text { Duration (ms) }\end{array}$ \\
\hline $03: 23: 25.745$ & -26 & & 1.7 & $3-3.5$ & - & no tail & & & - \\
\hline \multirow[t]{2}{*}{$03: 39: 52.951$} & -17 & & 2.6 & 10 & & $\begin{array}{c}\text { monotonic tail/ } \\
\text { secondary max? }\end{array}$ & & & - \\
\hline & & $\sim-2.9$ & & & $6.5: \sim 0.17$ & (on optical tail) & & & - \\
\hline $03: 48: 23.168$ & -25 & & 0.80 & $1-1.5$ & - & secondary max? & & & - \\
\hline $03: 53: 36.693$ & -22 & & 0.32 & 0.70 & - & no tail & & & - \\
\hline \multirow[t]{2}{*}{$03: 54: 00.333$} & -21 & & 0.20 (first) & $1-1.5$ & - & no tail & & & - \\
\hline & & & 0.79 (both) & & - & & & & - \\
\hline $03: 55: 16.616$ & -20 & & 0.90 & $2-2.5$ & - & - & & & - \\
\hline $03: 57: 58.815$ & -15 & & 0.20 & $0.5-1.0$ & - & no tail & & & - \\
\hline $03: 58: 33.030$ & -39 & & 0.90 & 2.7 & - & no tail & & & - \\
\hline $04: 00: 58.129$ & -19 & & 0.38 & $1-2$ & - & - & & & - \\
\hline \multirow[t]{3}{*}{$04: 12: 26.364$} & -36 & & 2.2 & $6-7$ & & $\begin{array}{c}\text { monotonic tail/ } \\
\text { secondary max? }\end{array}$ & & & - \\
\hline & & $\sim-5.0$ & & & $4.0: \sim 0.14$ & (on optical tail) & & & - \\
\hline & & $\sim-8.3$ & & & $9.0: \sim 0.23$ & (at sec. $\max$ ) & & & - \\
\hline $04: 16: 49.823$ & -26 & & 2.6 & $7-10$ & - & monotonic tail & & & - \\
\hline $04: 20: 47.985$ & -21 & & 0.70 & $2.5-3$ & - & $\begin{array}{c}\text { no tail/ } \\
\text { secondary max? }\end{array}$ & & & - \\
\hline $04: 23: 12.811$ & -25 & & 0.40 & $1-1.6$ & - & no tail & & & - \\
\hline $04: 25: 59.088$ & -22 & & 0.31 & $0.7-1.0$ & - & no tail & & & - \\
\hline $04: 28: 45.567$ & -72 & & 0.80 & $2-2.5$ & - & no tail & & & 0.50 \\
\hline $04: 29: 52.780$ & -17 & & 0.23 & 1.5 & & no tail & & & - \\
\hline
\end{tabular}


Table C-4. PCG Matches Between M46 Broad-Band Visible Data and ELF Data for July 19, 1996

6/25/97 Emily Mitchell, SNL Earle Williams, MIT

\begin{tabular}{|c|c|c|c|c|c|c|c|c|c|c|c|}
\hline NLDN time & $\begin{array}{l}\text { NLDN } \\
\text { Peak } \\
\text { Current } \\
(\mathrm{kA})\end{array}$ & $\begin{array}{l}\text { Linear } \\
\text { Estimate } \\
\text { of } \\
\text { Current }\end{array}$ & $\begin{array}{l}\text { NLDN } \\
\text { multi- } \\
\text { plicity }\end{array}$ & $\begin{array}{c}\text { M46 } \\
\text { FWHM } \\
(\mathrm{ms})\end{array}$ & $\begin{array}{c}\text { M46 } \\
\text { Full } \\
\text { Duration } \\
\text { (ms) }\end{array}$ & $\begin{array}{l}\text { M46 Optical } \\
\text { Signal Ratio } \\
\text { time: ratio } \\
\text { (ms: ratio) }\end{array}$ & $\begin{array}{l}\text { M46 Optical Tail } \\
\text { Description }\end{array}$ & $\begin{array}{l}\text { Schumann } \\
\text { Resonance } \\
\text { Spectral } \\
\text { Color }\end{array}$ & $\begin{array}{c}\text { Earle } \\
\text { Williams } \\
\text { Schumann } \\
\text { Resonance } \\
\text { Description }\end{array}$ & $\begin{array}{c}\text { Marx Brook } \\
\text { ELF } \\
\text { Slow Tail } \\
\text { Duration } \\
\text { (ms) }\end{array}$ & Event Comment \\
\hline $04: 50: 00.071$ & +106 & & 2 & 0.68 & $1.5-6$ & - & - & - & no trigger & 0.50 & \\
\hline $04: 50: 29.255$ & +34 & & $T$ & 2.40 & $35-180$ & & monotonic tail & very red & $\begin{array}{l}\text { clean } \\
\text { Q-burst }\end{array}$ & - & $\begin{array}{l}\text { S(KG) no fine times } \\
\text { MT: bright amorphous flash } \\
\text { - no sprite }\end{array}$ \\
\hline & & -+1.5 & & & & $23.0: \sim 0.044$ & (on optical tail) & & & & \\
\hline $04: 51: 55.075$ & +57 & & 1 & $\begin{array}{l}1.18- \\
1.23\end{array}$ & $2-4$ & - & - & - & no trigger & 0.78 & \\
\hline $04: 52: 54.243$ & +46 & & 1 & 2.10 & $11-27$ & - & monotonic tail & - & messy & - & $\begin{array}{l}\text { S(KG) no fine times } \\
M T: \text { bright amorphous flash - } \\
\text { no sprite }\end{array}$ \\
\hline $04: 54: 14.920$ & +96 & & 1 & 1.12 & 5 & - & - & - & no trigger & 0.45 & \\
\hline \multirow[t]{2}{*}{$04: 55: 04.481$} & +83 & & 1 & - & - & - & - & red & clean & 0.85 & S(WL,RA,MT) w/fine times \\
\hline & & & & & 60 & - & secondary max & & & & \\
\hline $04: 55: 32.787$ & +57 & & 1 & 0.48 & 1 & - & - & - & no trigger & 0.35 & \\
\hline $05: 41: 02.319$ & +40 & & 1 & 1.12 & 3 & - & - & - & messy & - & $\mathrm{S}(\mathrm{KG})$ no fine times \\
\hline $05: 46: 21.494$ & +106 & & 1 & 1.84 & 6 & - & - & pink & Q-burst? & - & S(KG) no fine times \\
\hline $05: 47: 47.590$ & +55 & & 1 & 2.1 & $4-7$ & - & - & - & no trigger & 1.10 & \\
\hline \multirow[t]{2}{*}{$05: 53: 56.736$} & +76 & & 1 & 1.44 & $13-30$ & & monotonic tail & - & no trigger & 0.88 & \\
\hline & & -+5.4 & & & & $8.3: \sim 0.071$ & (on optical tail) & & & & \\
\hline $05: 57: 58.567$ & +80 & & 1 & 1.38 & 3 & - & no tail & pink & & 1.20 & $E(W L)$ \\
\hline \multirow[t]{3}{*}{$06: 16: 25.471$} & +32 & & 1 & 1.18 & $80-160$ & & monotonic tail & - & multistroke & 1.15 & $\mathrm{~S}(\mathrm{WL}, \mathrm{MT}) \mathrm{w} / \mathrm{fine}$ times \\
\hline & & -1.4 & & & & $53.0: \sim 0.044$ & (on optical tail) & & & & \\
\hline & & $\sim 2.0$ & & & & $40.5: \sim 0.062$ & (small peak) & & & & \\
\hline $06: 22: 05.037$ & +105 & & 2 & 1.15 & 3 & - & no tail & - & no trigger & - & S(WL,RA,MT) w/fine times \\
\hline $06: 38: 30.151$ & +117 & & 2 & 1.00 & $2-2.5$ & - & - & - & $\begin{array}{l}\text { cvent later in } \\
\text { window }\end{array}$ & - & $\mathrm{E}(\mathrm{WL}, \mathrm{RA}, \mathrm{MT})$ \\
\hline
\end{tabular}


Table C-5. PCG Matches Between M46 Broad-Band Visible Data and ELF Data for July 20, 1996

6/25/97 Emily Mitchell, SNL

\begin{tabular}{|c|c|c|c|c|c|c|c|c|c|c|c|}
\hline NLDN time & $\begin{array}{l}\text { NLDN } \\
\text { Peak } \\
\text { Current } \\
(k A)\end{array}$ & $\begin{array}{c}\text { Linear } \\
\text { Estimate } \\
\text { of } \\
\text { Current }\end{array}$ & $\begin{array}{l}\text { NLDN } \\
\text { multi- } \\
\text { plicity }\end{array}$ & $\begin{array}{c}\text { M46 } \\
\text { FWHM } \\
\text { (ms) }\end{array}$ & $\begin{array}{c}\text { M46 } \\
\text { Full } \\
\text { Duration } \\
\text { (ms) }\end{array}$ & $\begin{array}{l}\text { M46 Optical } \\
\text { Signal Ratio } \\
\text { time: ratio } \\
\text { (ms: ratio) }\end{array}$ & $\begin{array}{l}\text { M46 Optical Tail } \\
\text { Description }\end{array}$ & $\begin{array}{c}\text { Schumann } \\
\text { Resonance } \\
\text { Spectral } \\
\text { Color }\end{array}$ & $\begin{array}{c}\text { Earle } \\
\text { Williams } \\
\text { Schumann } \\
\text { Resonance } \\
\text { Description }\end{array}$ & $\begin{array}{c}\text { Marx Brook } \\
\text { ELF } \\
\text { Slow Tail } \\
\text { Duration } \\
(\mathrm{ms}) \\
\end{array}$ & Event Comment \\
\hline $04: 45: 46.195$ & +68 & & I & 0.430 & $2-5$ & & no tail & & & 0.40 & \\
\hline $05: 09: 34.187$ & +66 & & 2 & 1.28 & $\begin{array}{r}35 \\
40-90 \\
75-125\end{array}$ & & $\begin{array}{c}\text { monotonic tail/ } \\
\text { secondary max } \\
\text { monotonic tail } \\
\text { monotonic tail / } \\
\text { secondary max }\end{array}$ & & & 1.20 & $\begin{array}{l}\text { first stroke } \\
\text { second stroke } \\
\text { both strokes }\end{array}$ \\
\hline $05: 29: 01.132$ & +63 & & 2 & 1.32 & $8-10$ & & monotonic tail & & & 0.65 & first stroke \\
\hline $05: 58: 44.655$ & +44 & & 1 & 1.54 & $4.5-9$ & & no tail & & & 0.15 & no MB slow tail \\
\hline
\end{tabular}




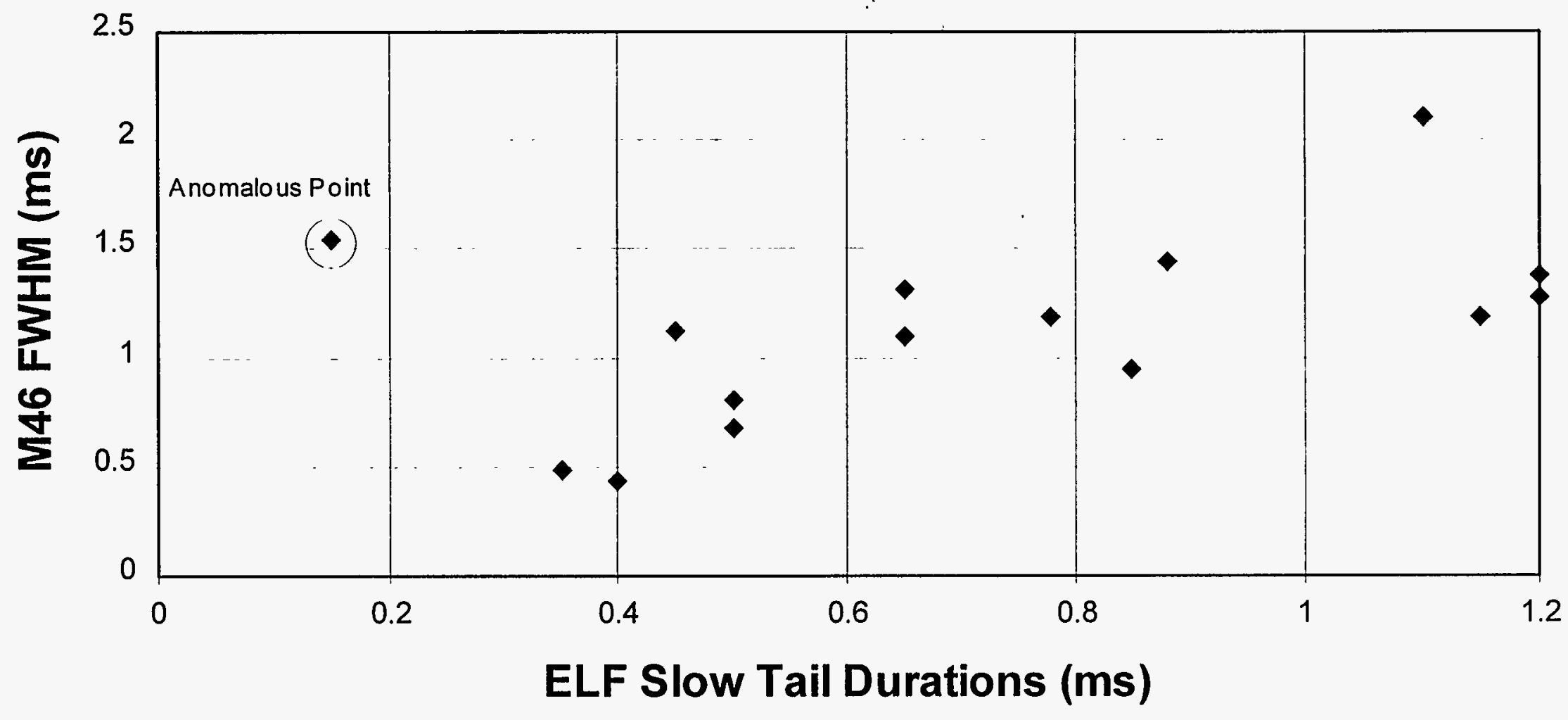

Figure C-1. M46 Optical FWHMs vs Marx Brook ELF Slow Tails 


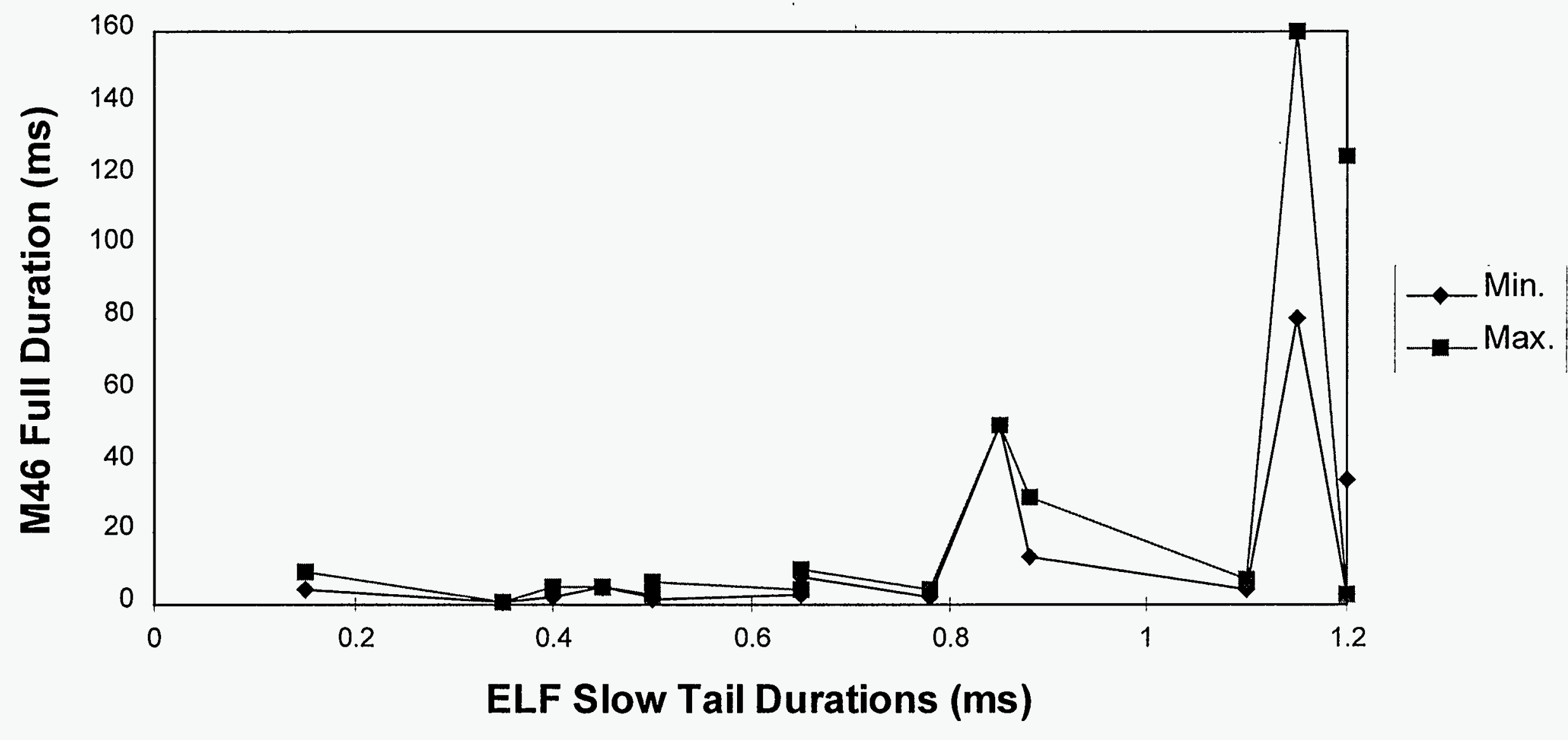

Figure C-2. M46 Optical Full Durations vs Marx Brook ELF Slow Tails 


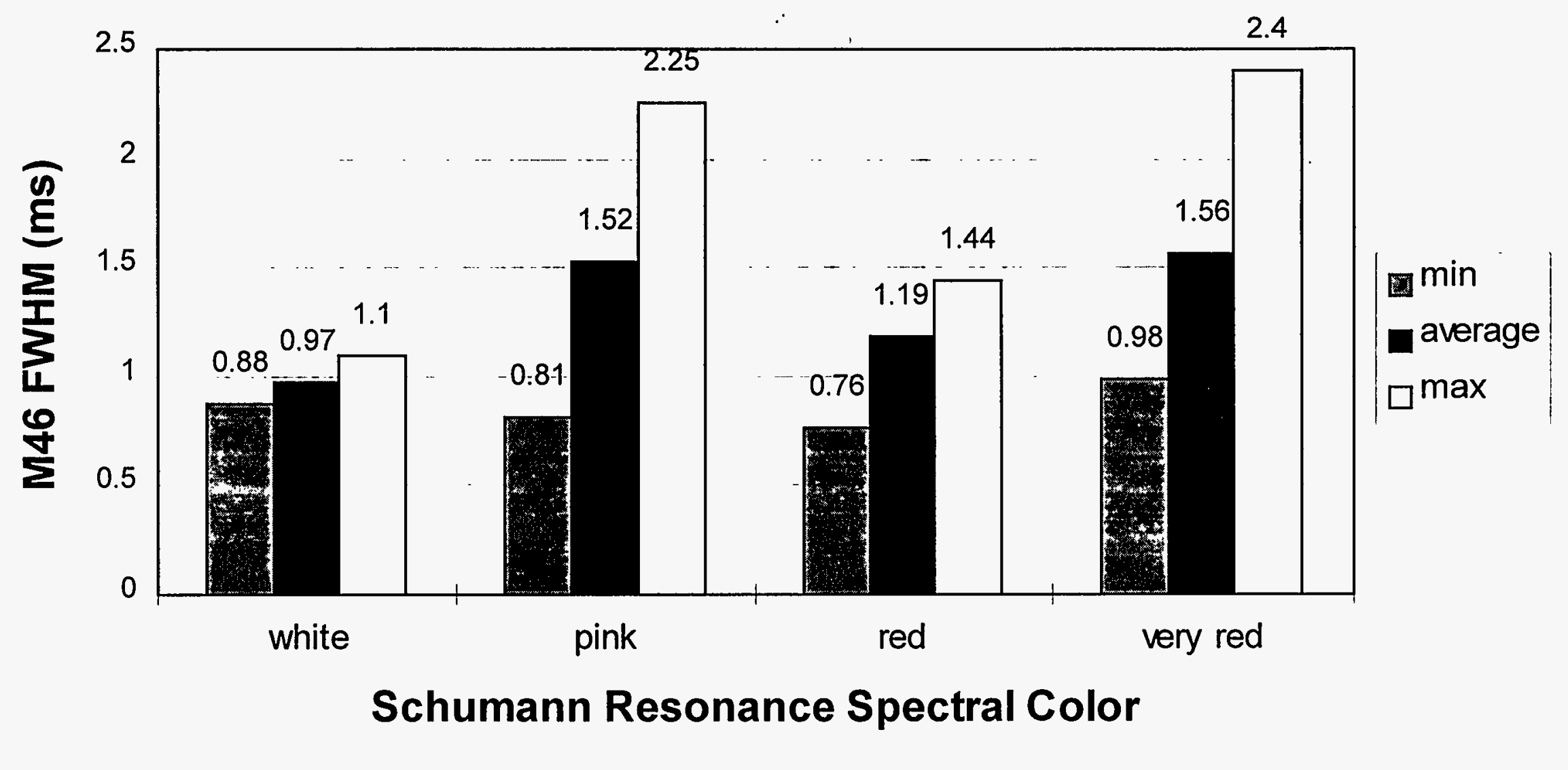

Figure C-3. M46 Optical FWHMs vs Schumann Resonance Spectral Color 

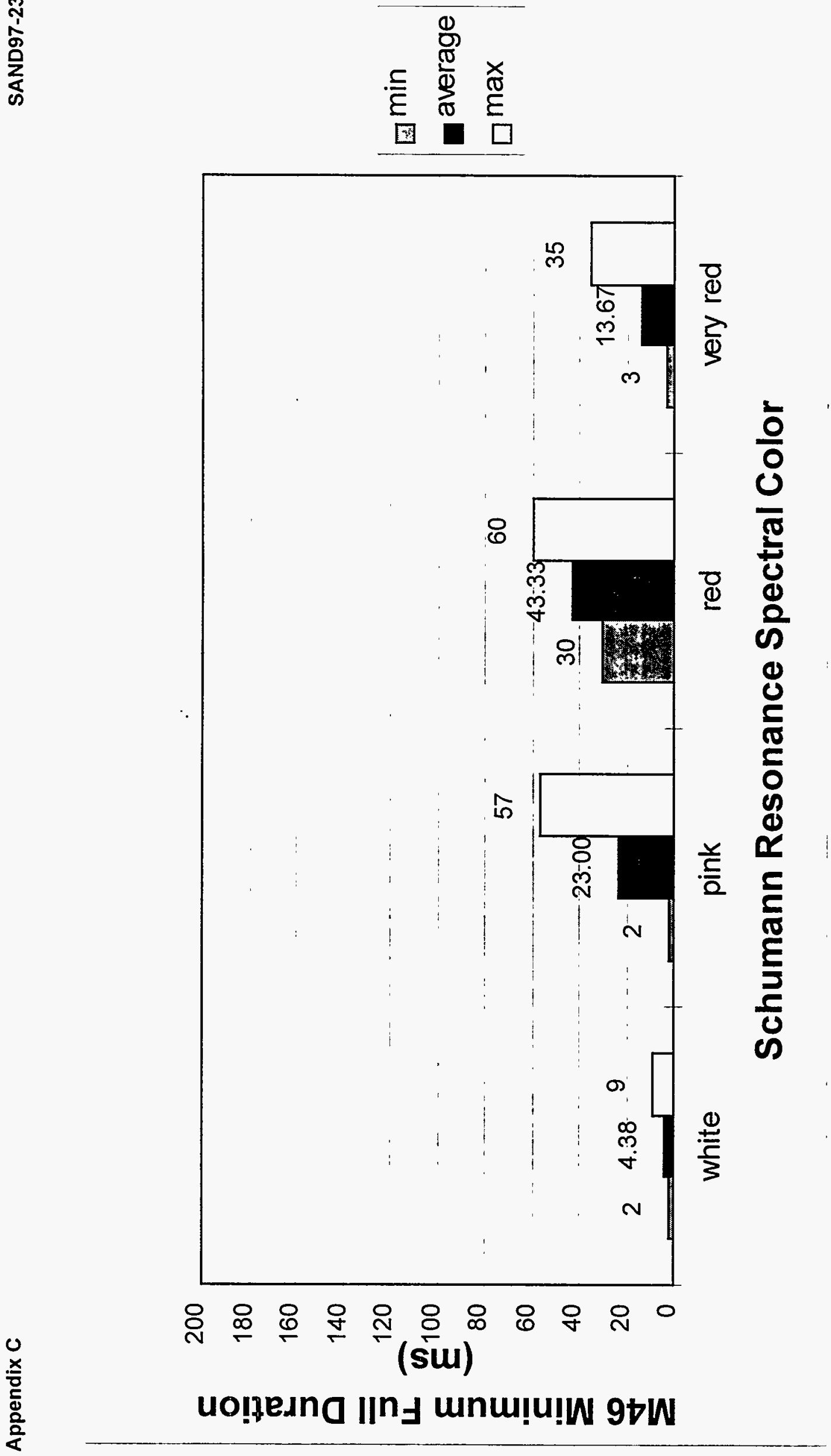

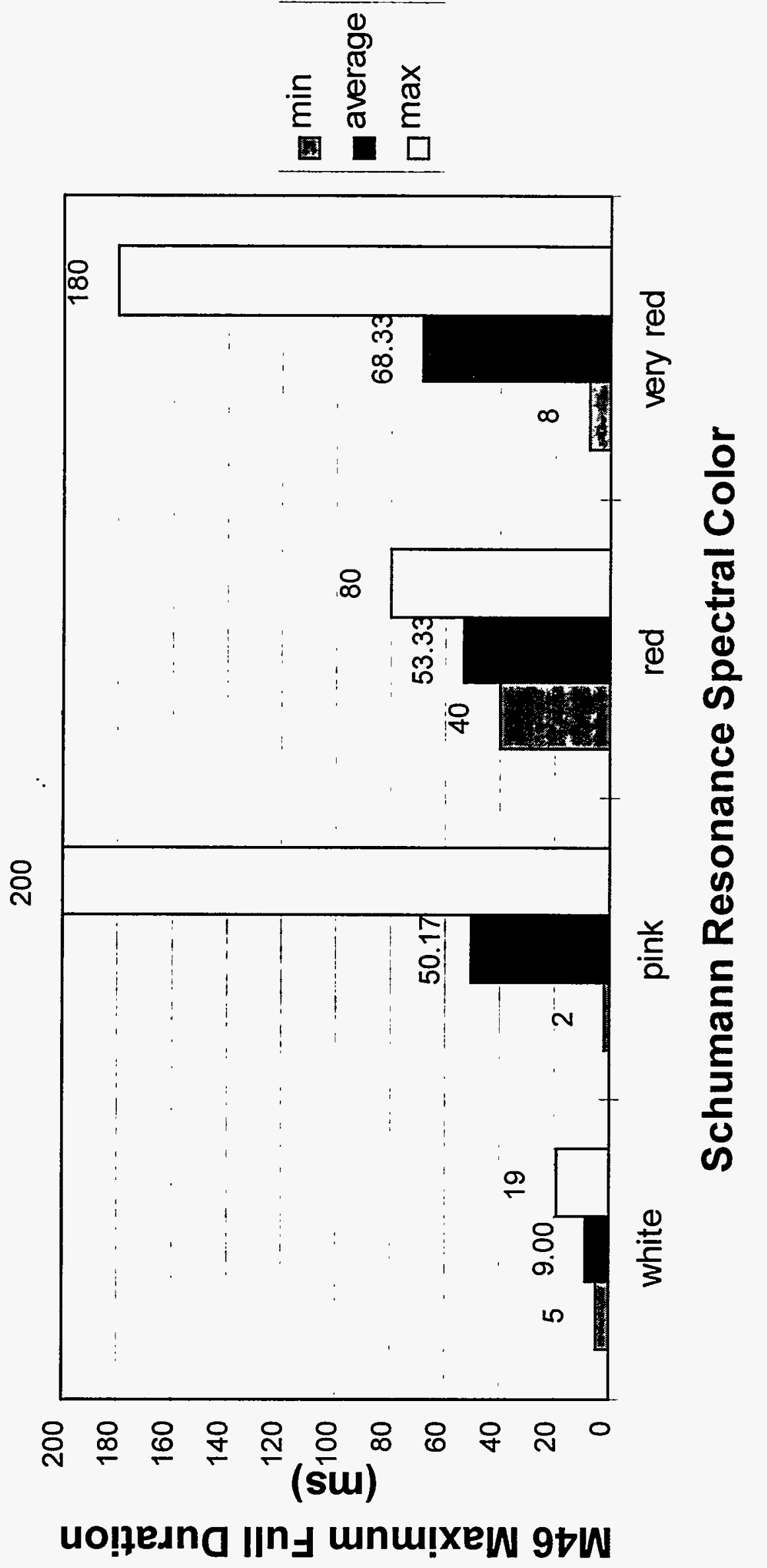

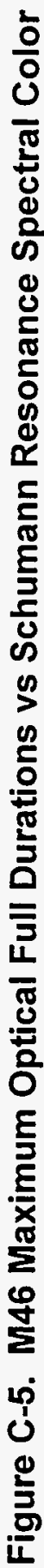


This page intentionally left blank. 


\section{Appendix D: M46 Broad-Band Visible Waveforms}

Included in this appendix are the waveforms that were utilized for data analysis. The waveforms are organized chronologically.

The data are in units of normalized intensity, rather than $\mathrm{W} / \mathrm{str} / \mathrm{micron}$. Normalized intensity values were produced as follows: (1) Nonlinearities in sensor output, if they existed, were removed from the data. (2) The minimum sensor output value measured in the recording was subtracted from each waveform. These values were then scaled to an arbitrary nominal value for each collection period.

Thus, the normalized intensity amplitudes have no direct geophysical meaning, but can be compared to each other within a given collection period. (Atmospheric propagation has not been accounted for.)

Most of the waveforms included in this appendix are not discussed specifically in the text, although many were used in this analysis (as listed in the tables in Appendix C). The remaining waveforms were included to document the variety of broad-band visible waveforms obtained during the test. 
Appendix D

SAND 97-2381

This page intentionally left blank.

46 
草

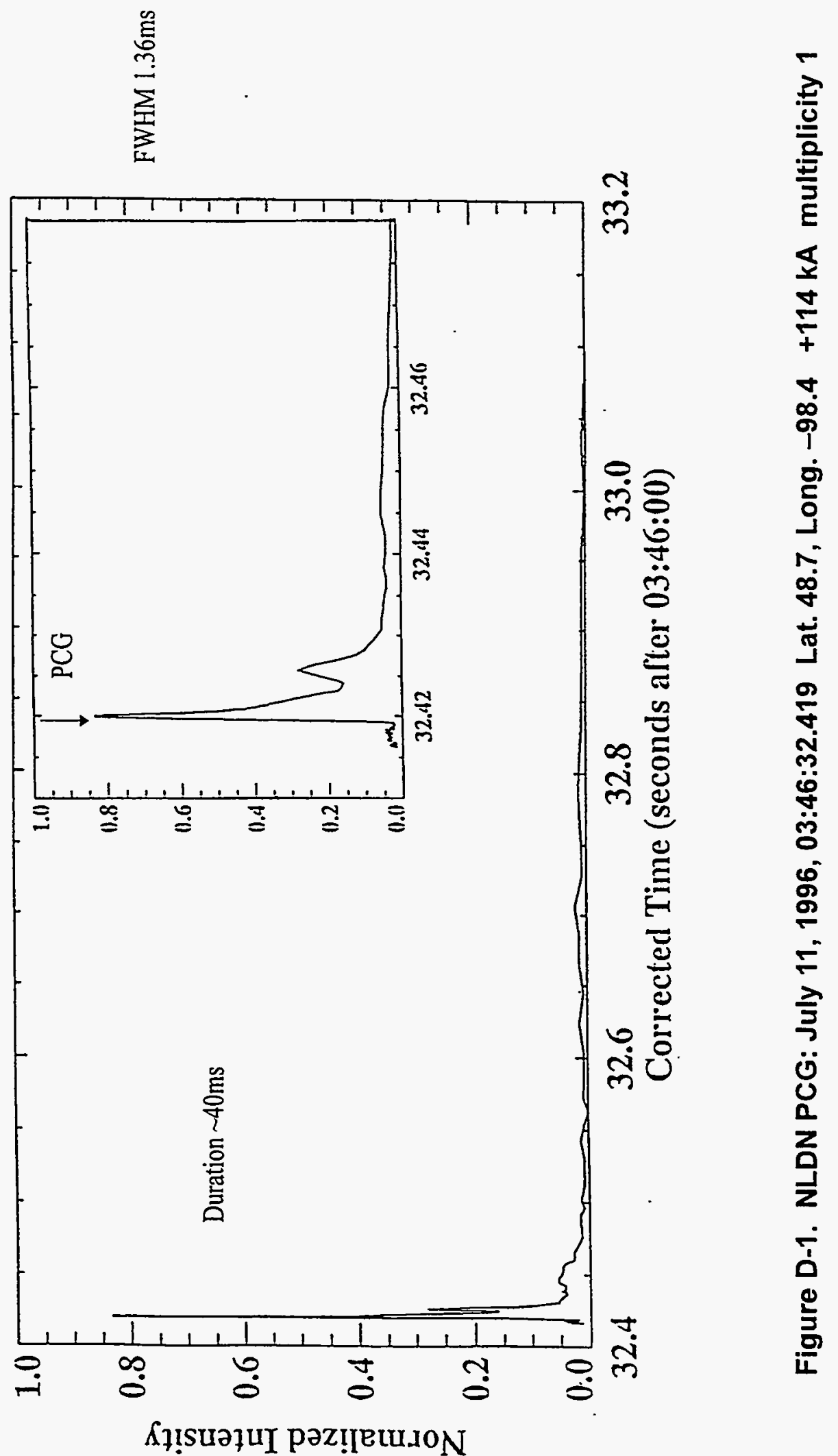




\section{Broad-Band Visible}

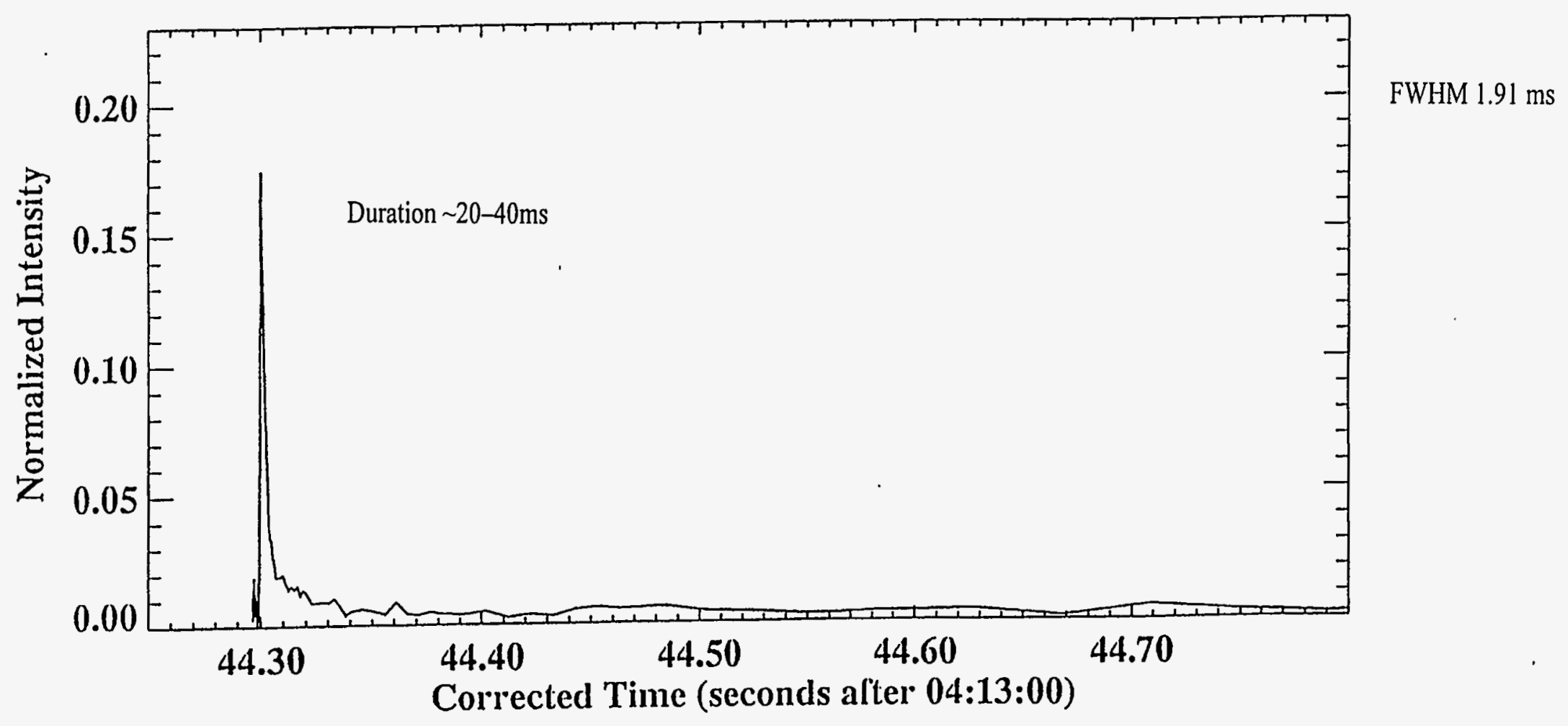

Figure D-2. NLDN PCG: July 11, 1996, 04:13:44.300 Lat. 48.4, Long. -98.3 +43 kA multiplicity 1 

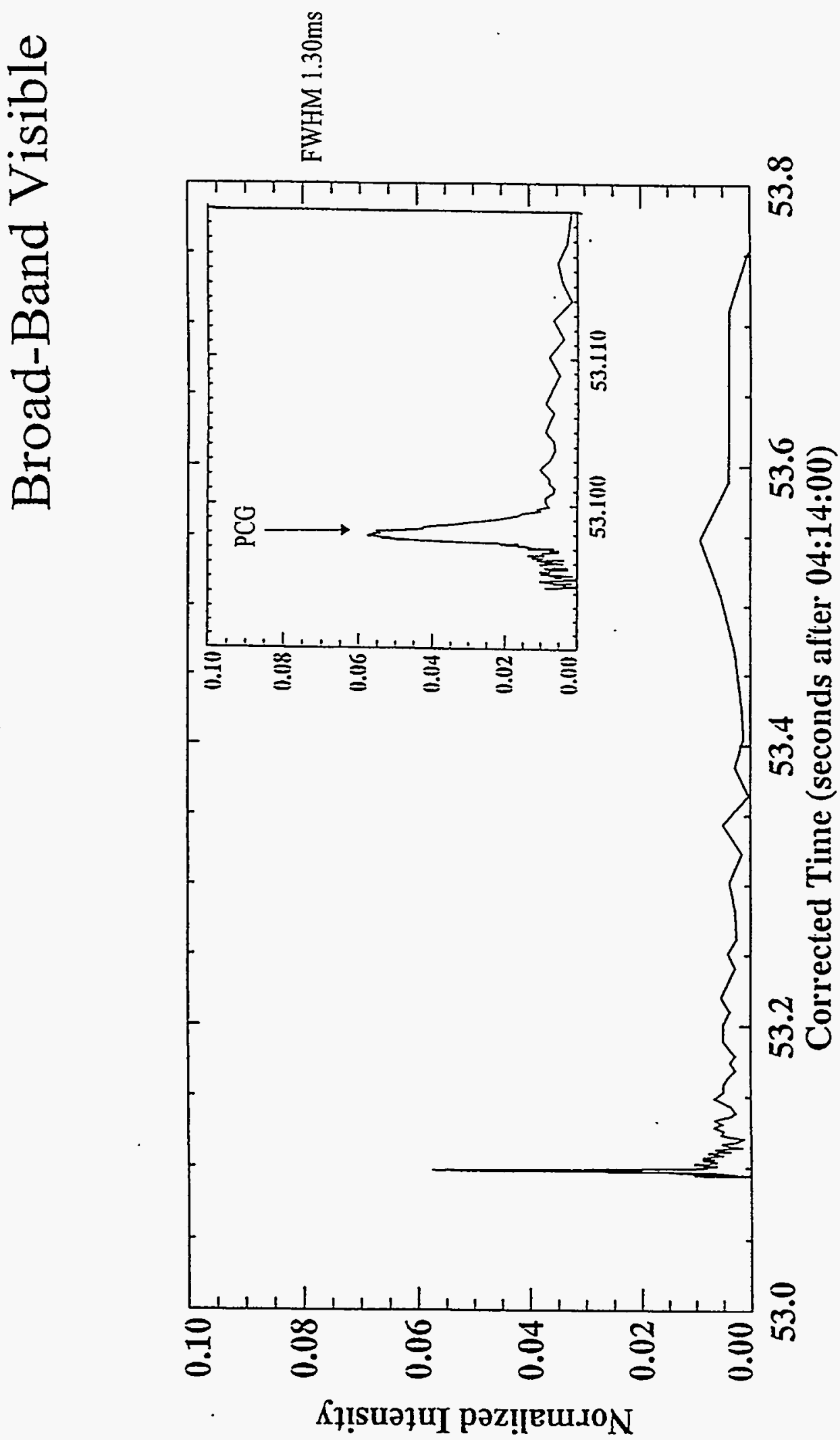

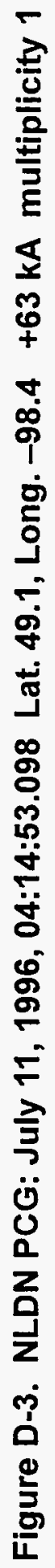




\section{Broad-Band Visible}

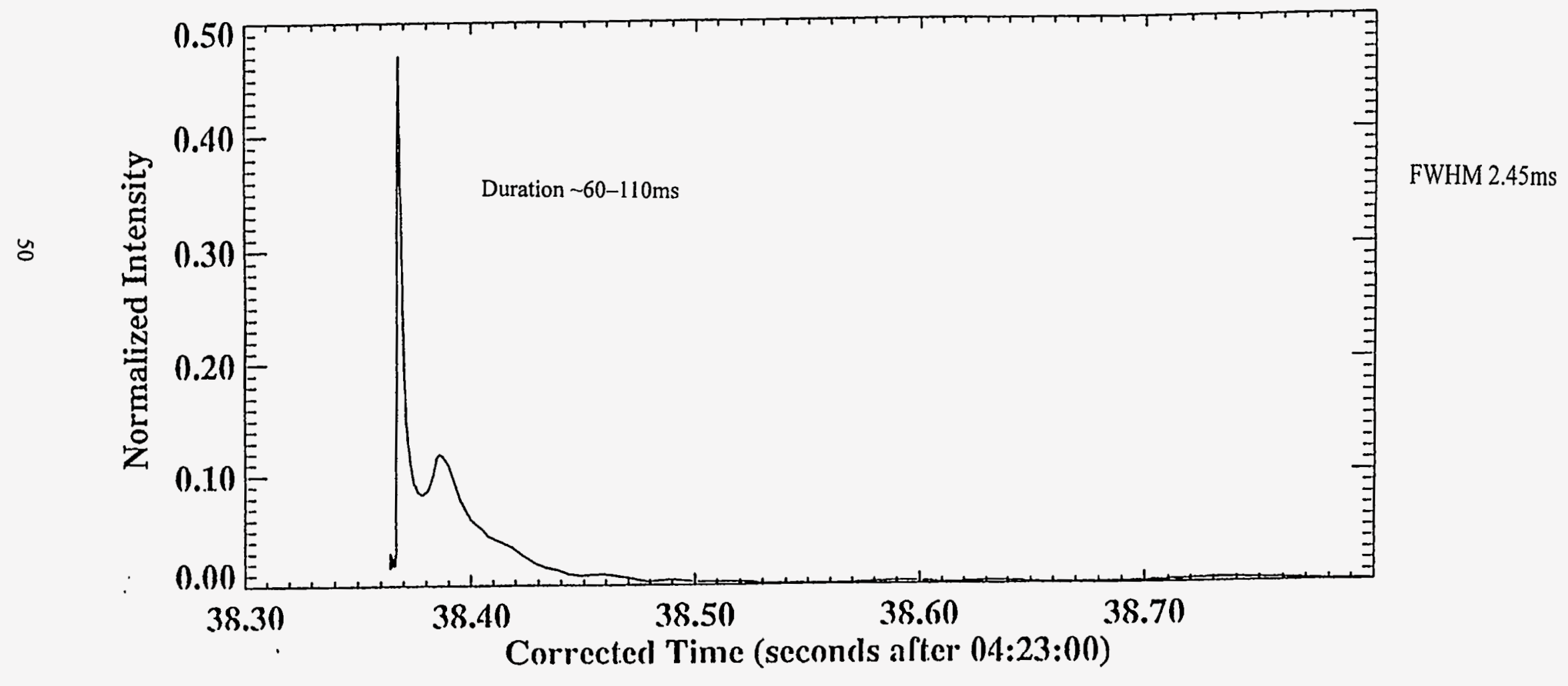

Figure D-4. NLDN PCG: July 11, 1996, 04:23:38.367 Lat. 48.8, Long. -98.8 +68 kA multiplicity 1 


\section{Broad-Band Visible}

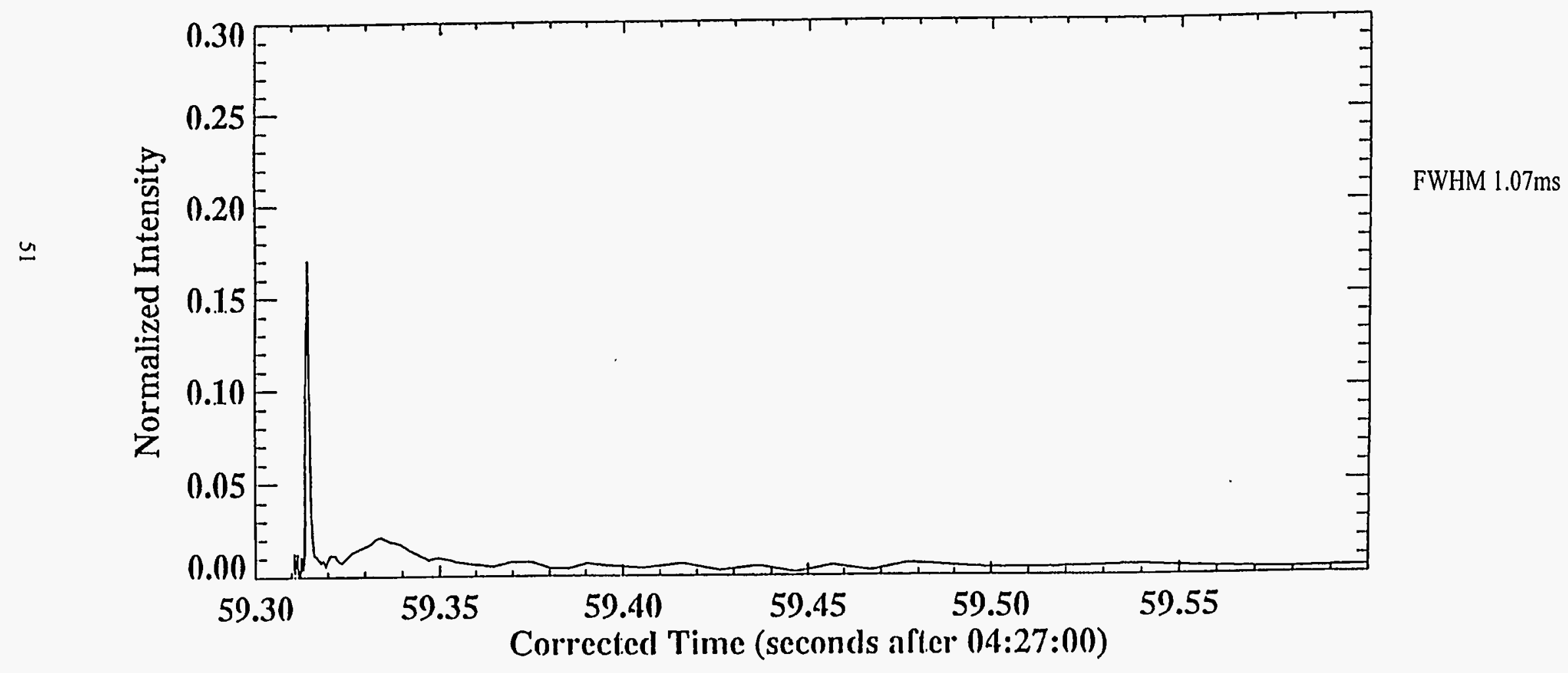

Figure D-5. NLDN PCG: July 11, 1996, 04:27:59.314 Lat. 48.3, Long. $-98.1+55$ kA multiplicity 1 


\section{Broad-Band Visible}

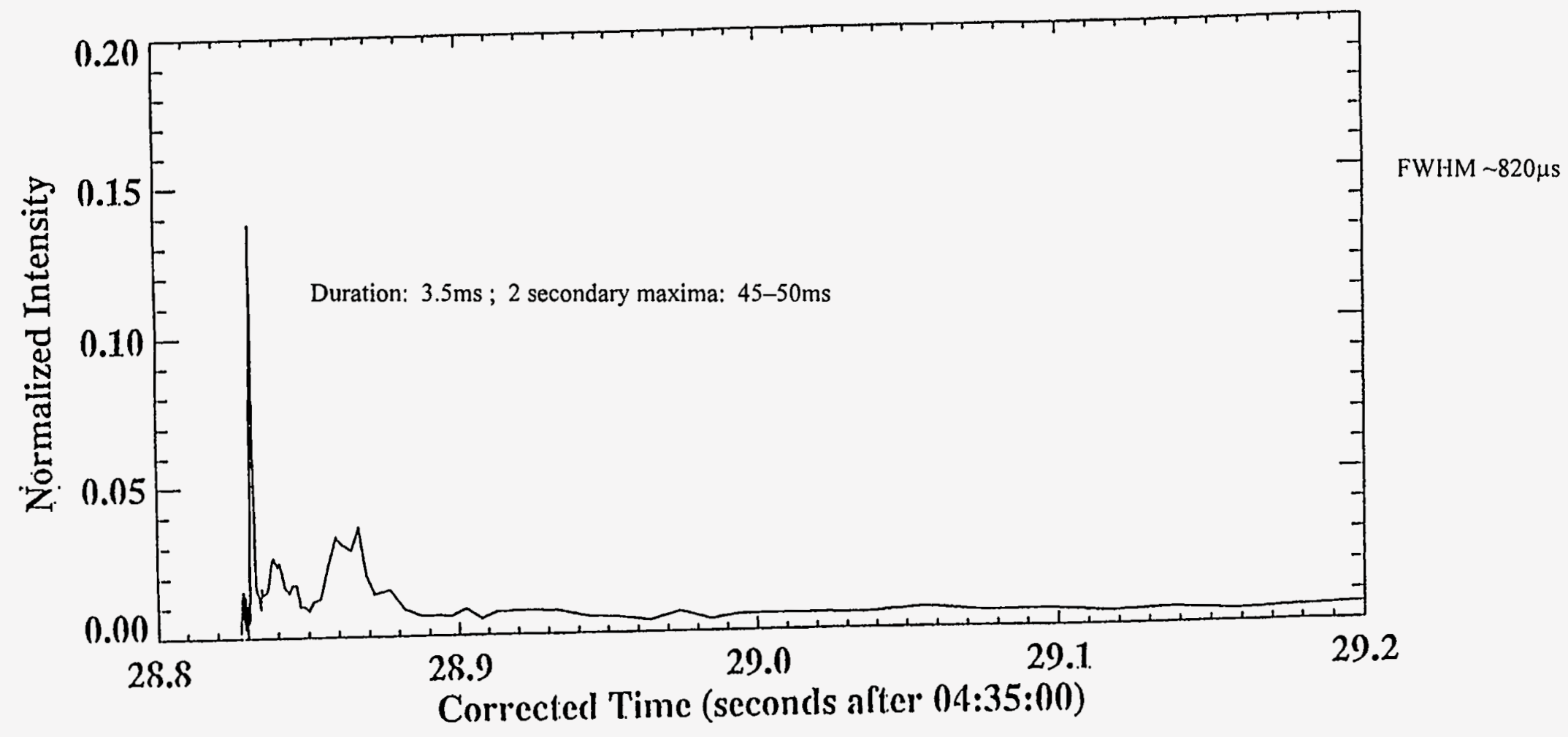

Figure D-6. NLDN PCG: July 11, 1996, 04:35:28.831 Lat. 48.4, Long. -98.1 +79 kA multiplicity 1 . 


\section{Broad-Band Visible}

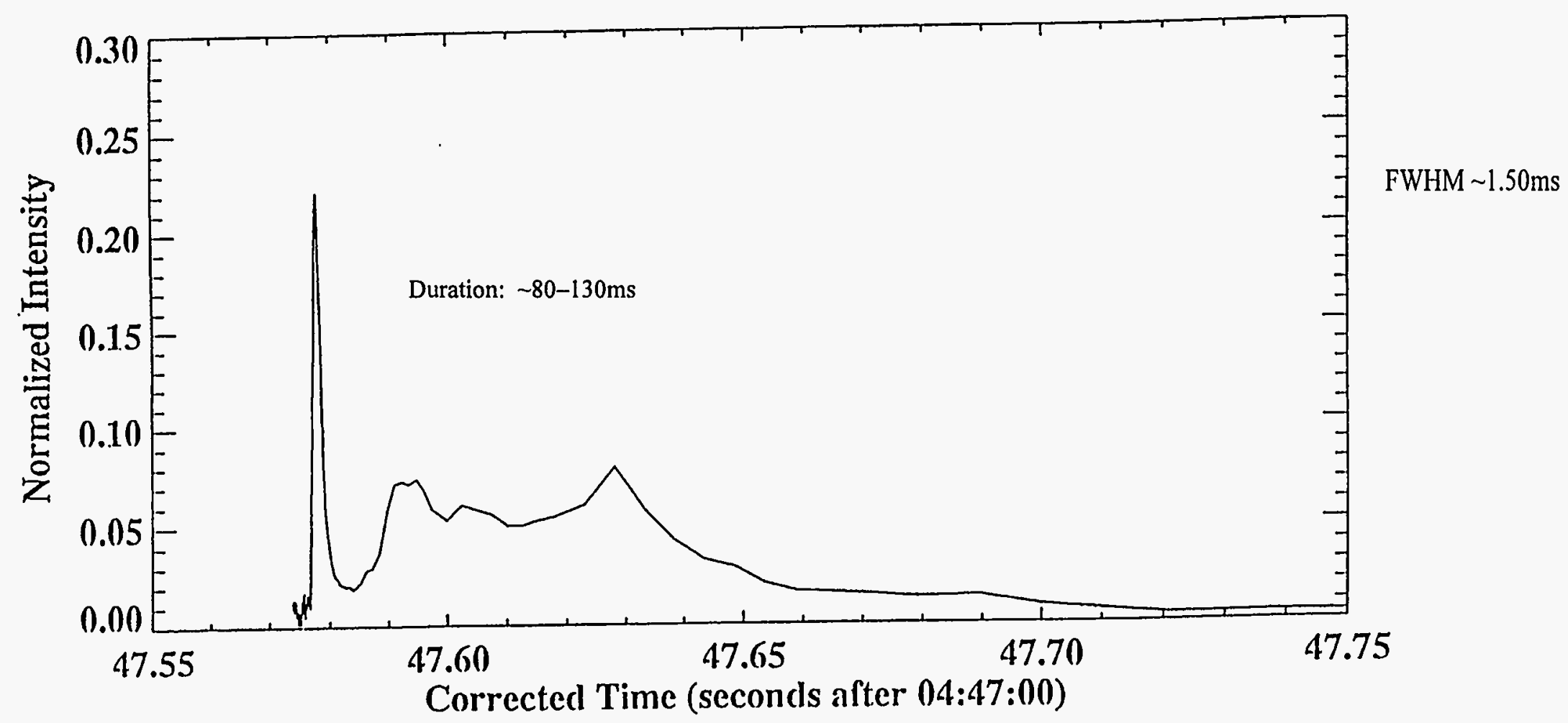

Figure D-7. NLDN PCG: July 11, 1996, 04:47:47.578 Lat. 48.9, Long. -98.1 +51 kA multiplicity 1 . 


\section{Broad-Band Visible}

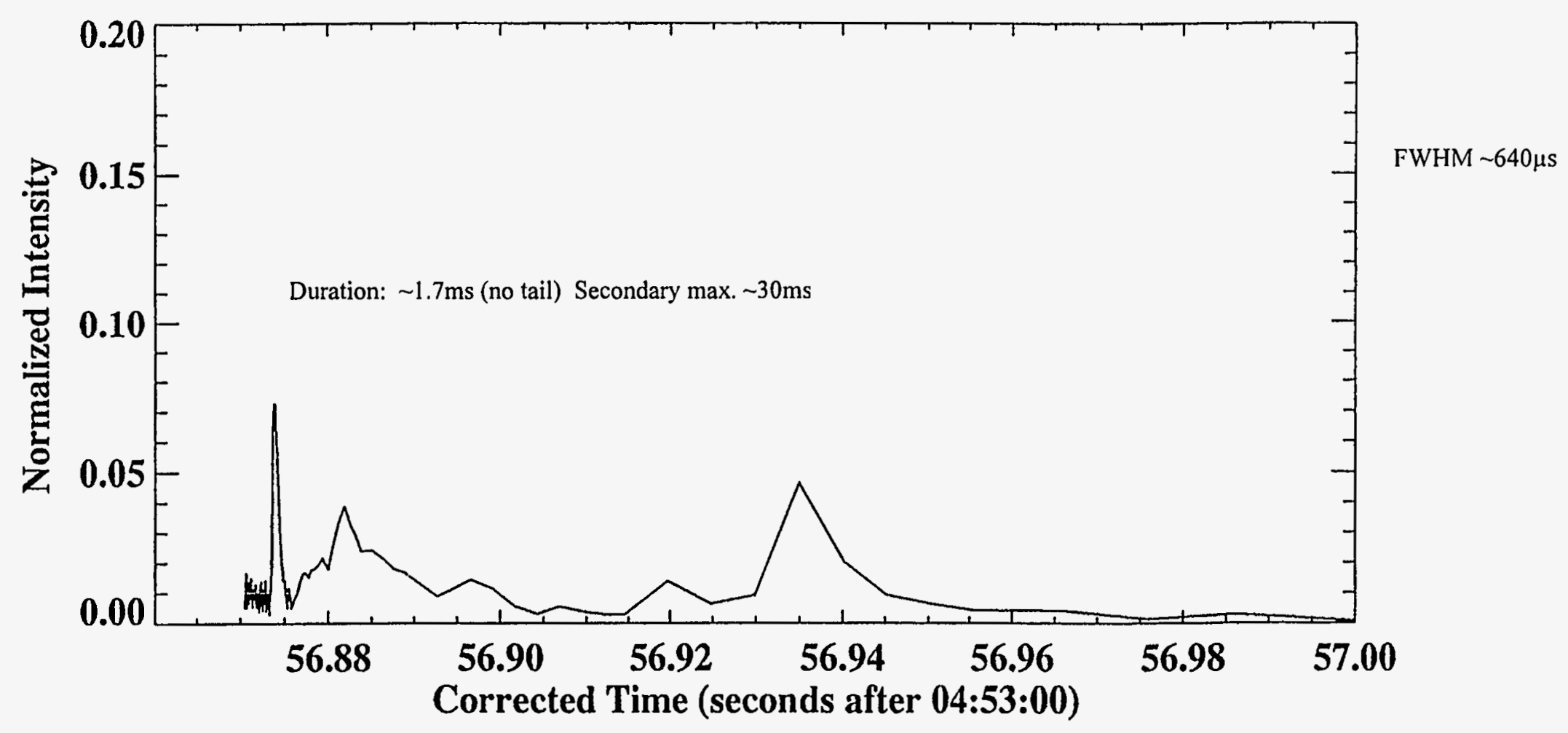

Figure D-8. NLDN PCG: July 11, 1996, 04:53:56.874 Lat. 48.5, Long. -97.6 +48 kA multiplicity 1 


\section{Broad-Band Visible}

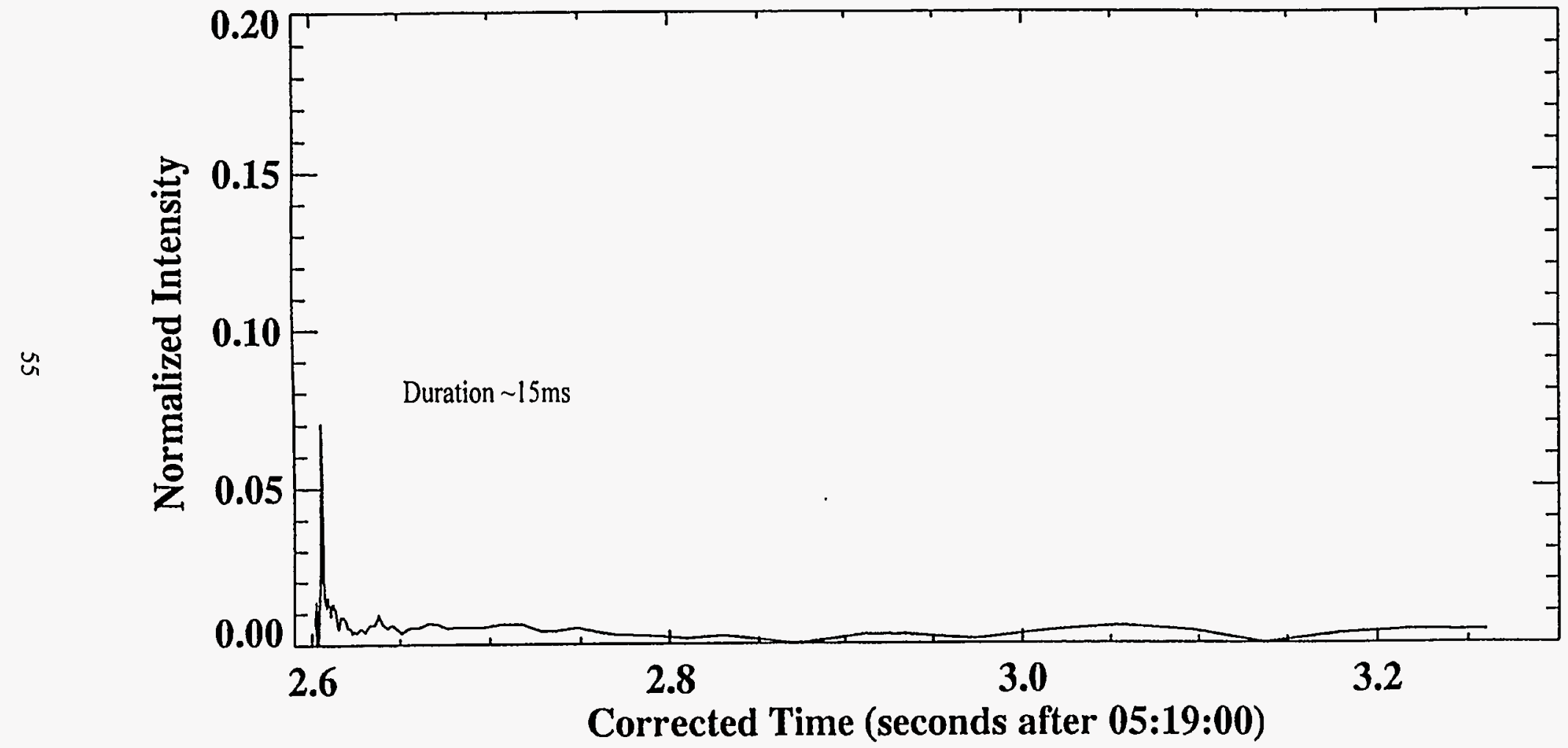

Figure D-9. NLDN PCG: July 11, 1996, 05:19:02.605 Lat. 48.5, Long. $-98.2+20$ kA multiplicity 1 


\section{Broad-Band Visible}

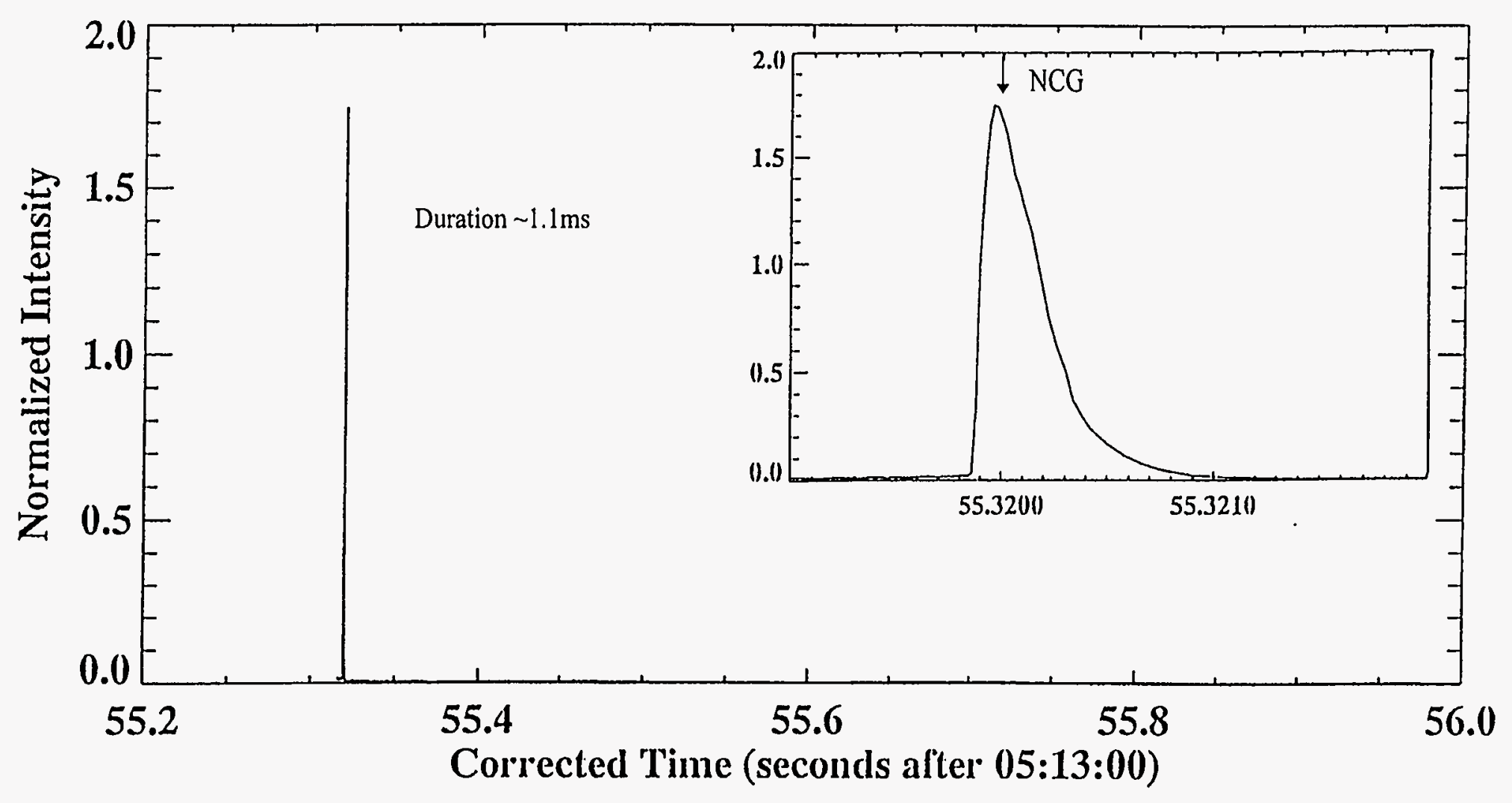

Figure D-10. NLDN NCG: July 11, 1996, 05:13:55.320 Lat. 47.5, Long. -99.3 -31 kA multiplicity 1 


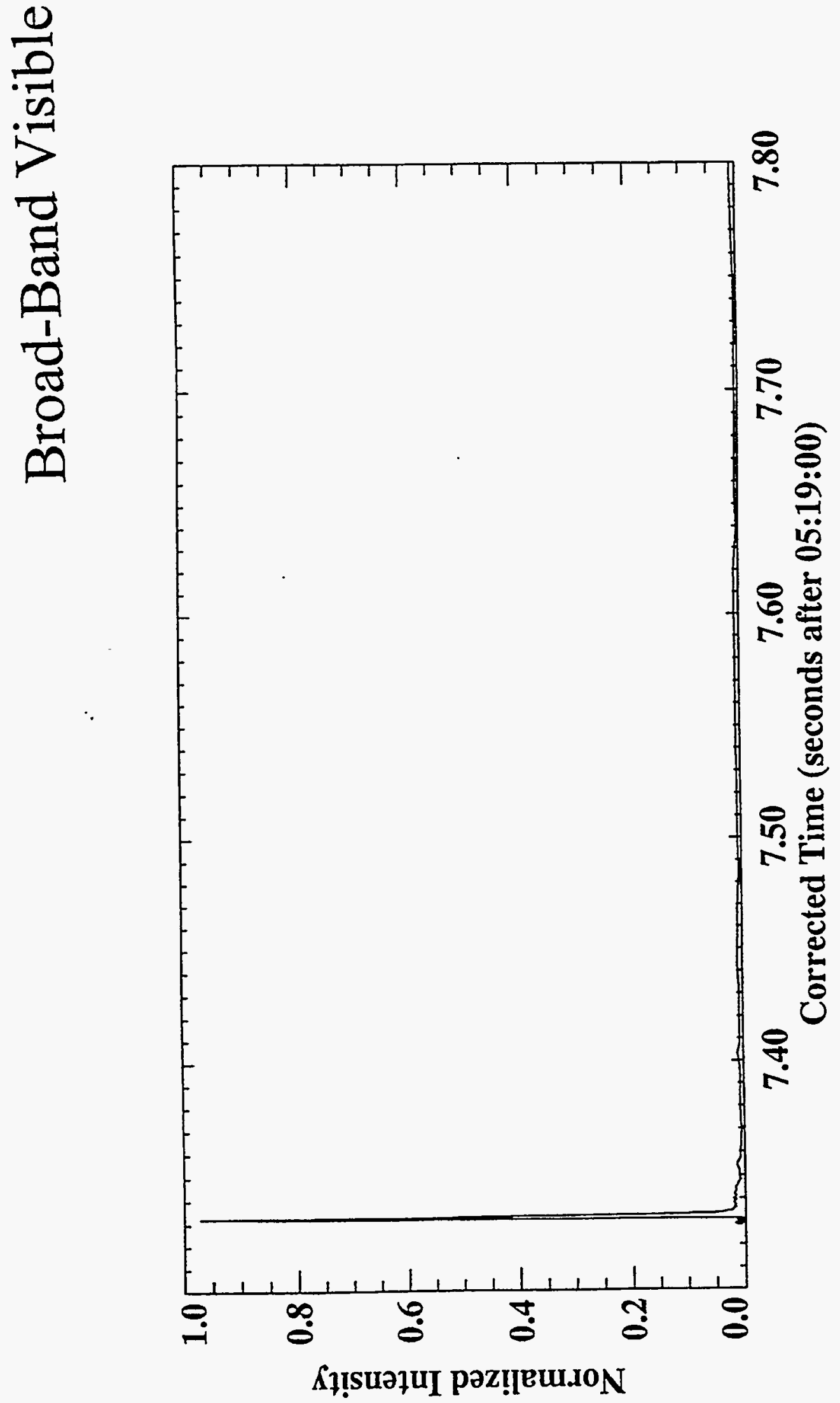

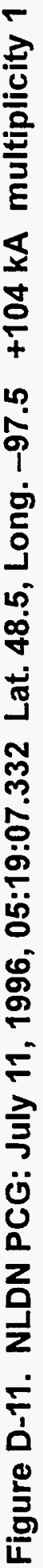



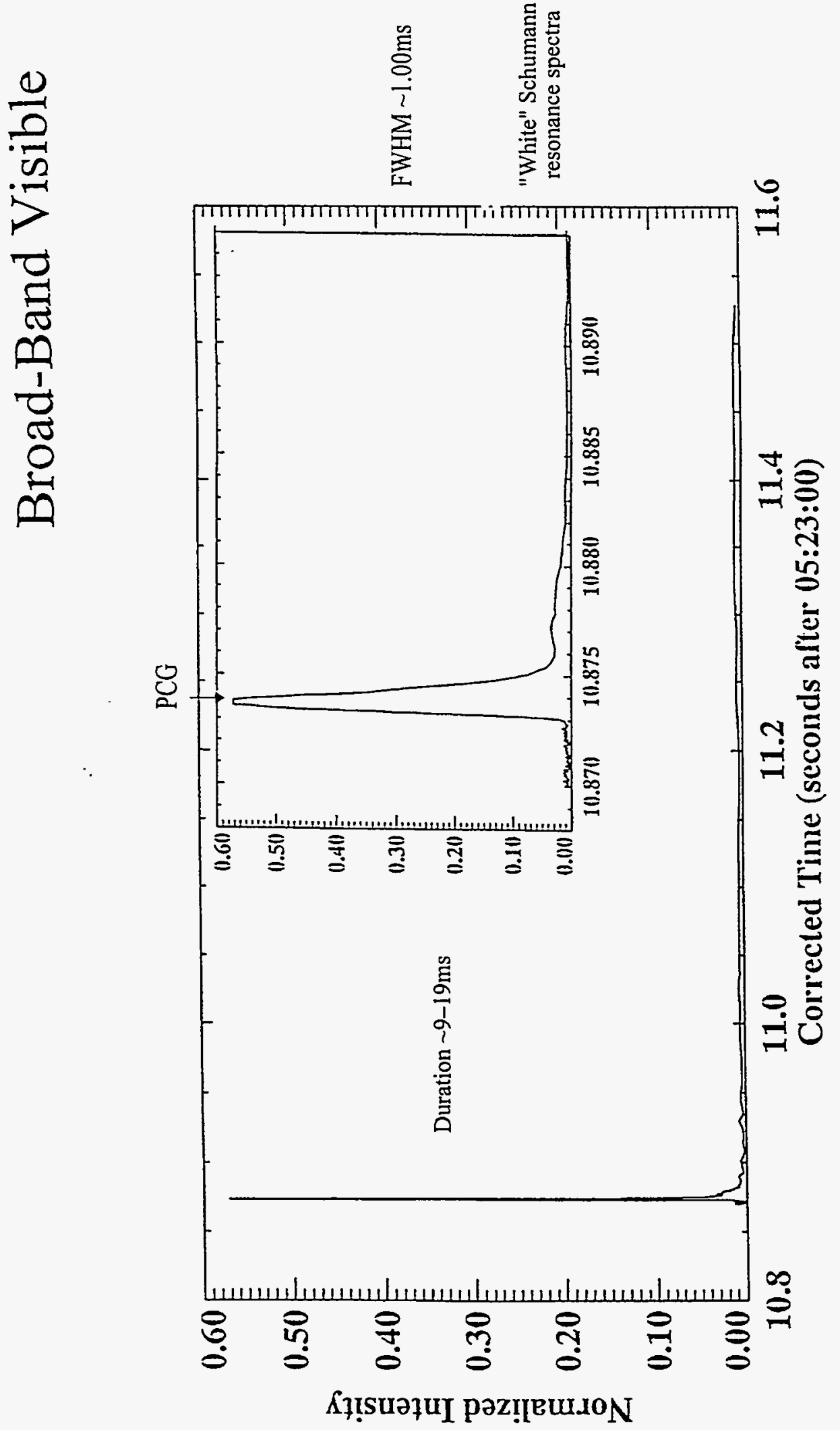

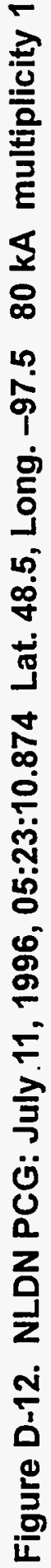



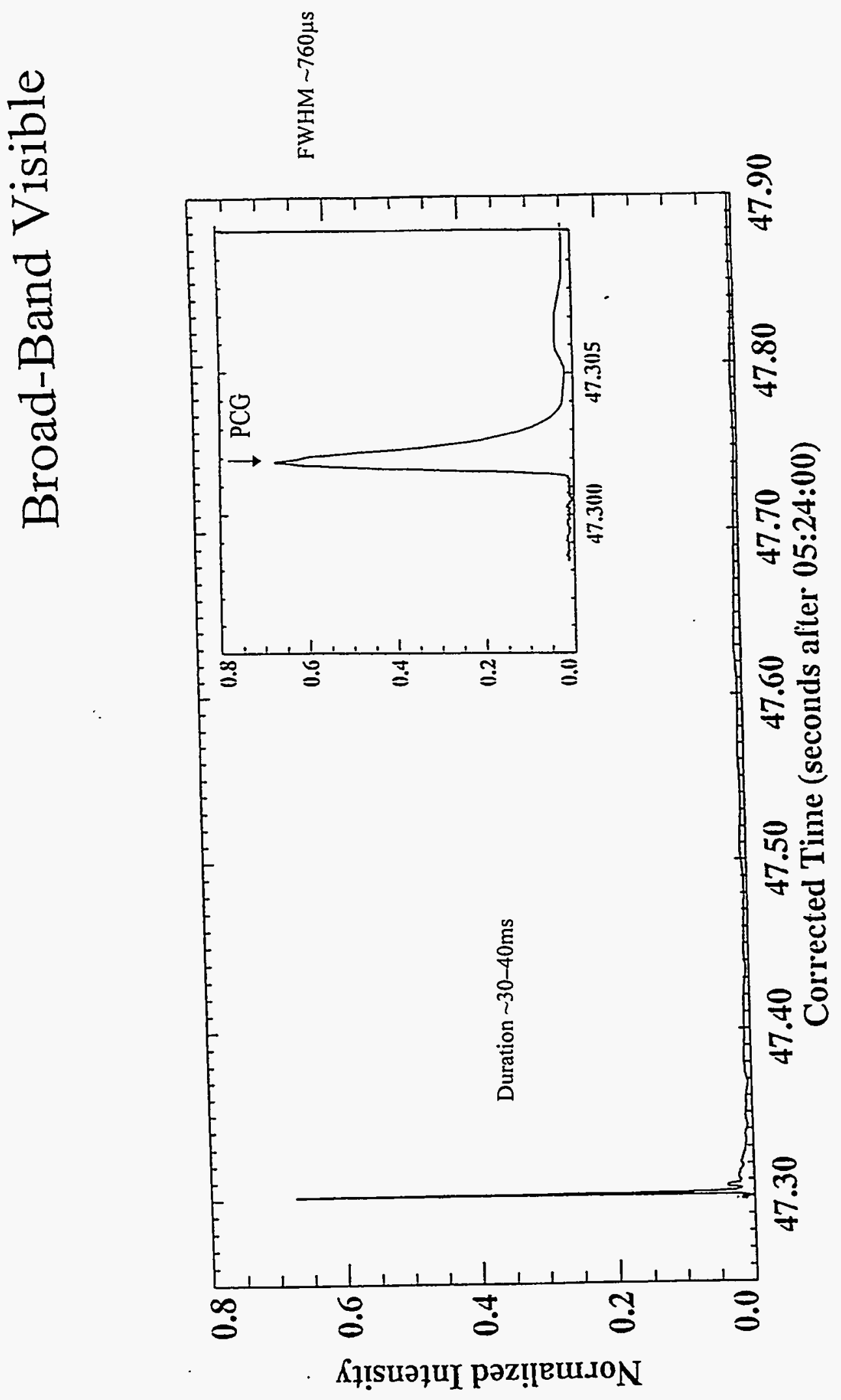

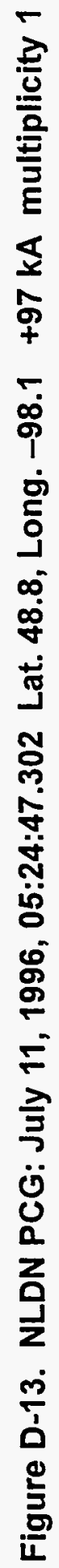



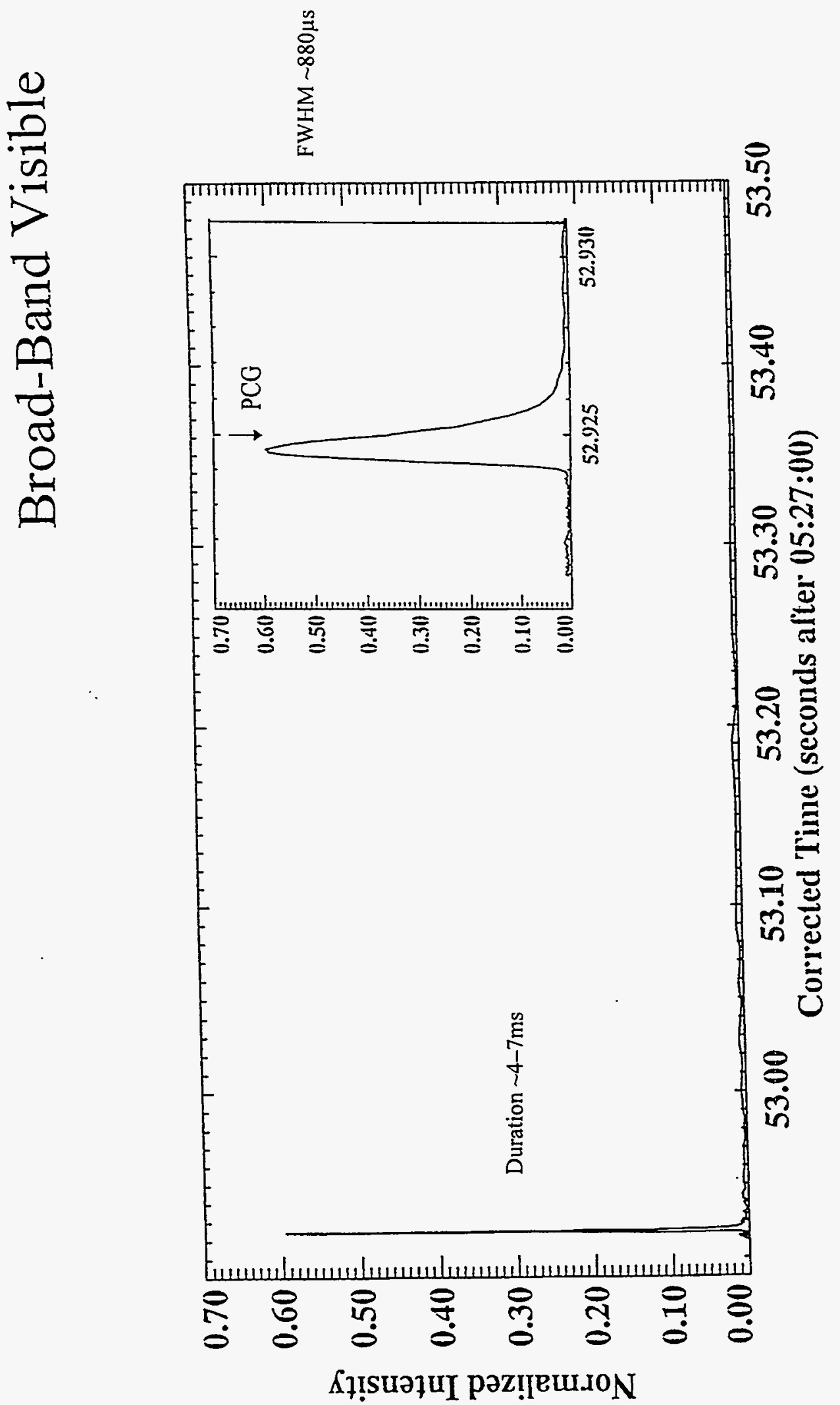

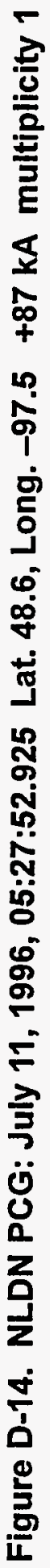




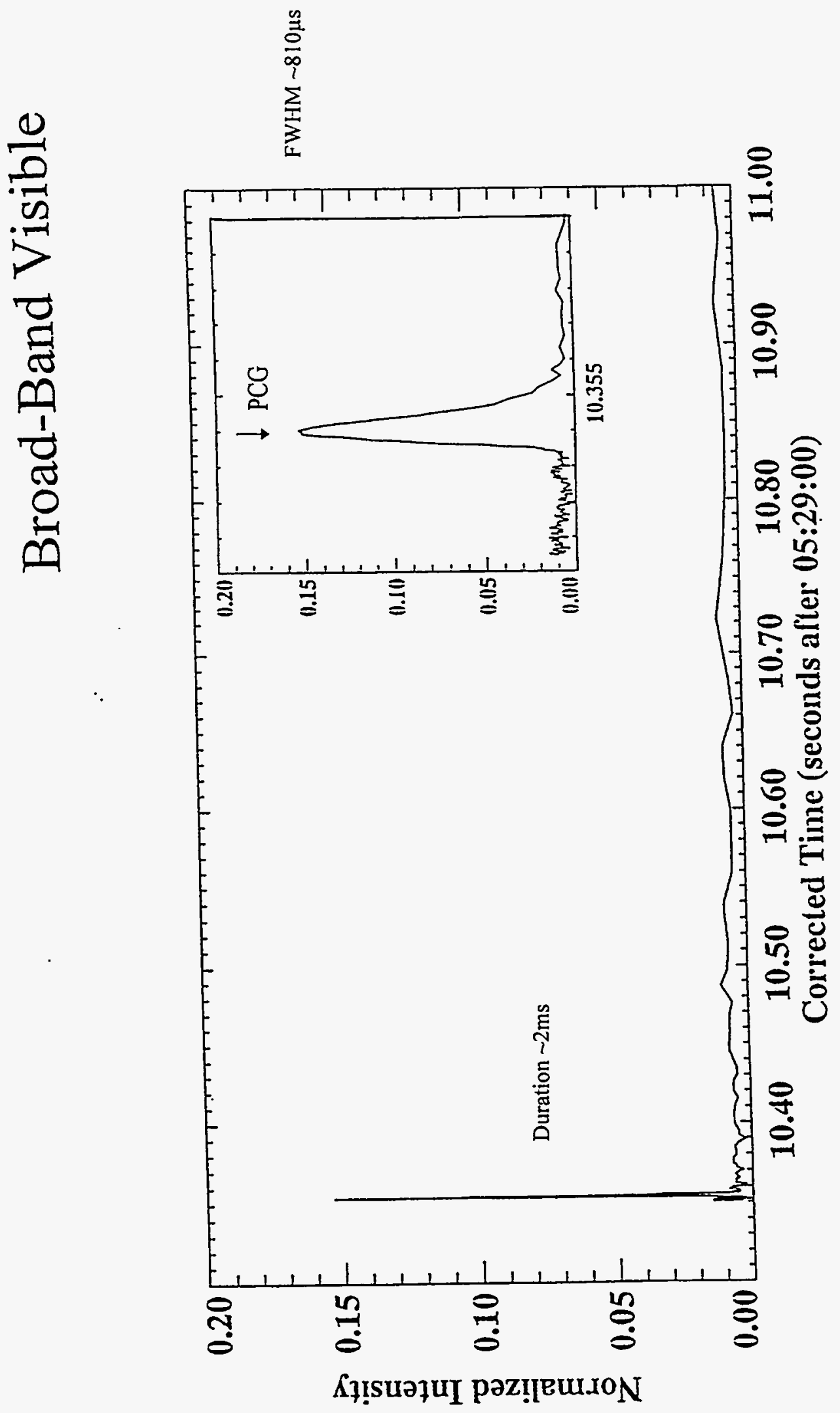

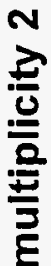

$\underline{5}$

$\stackrel{5}{+}$

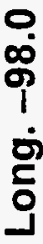

?

$\infty$

茴

苑

กำ

\%

in

\&

\%

$E$

水

$\ddot{0}$

0

z

เั่

은 

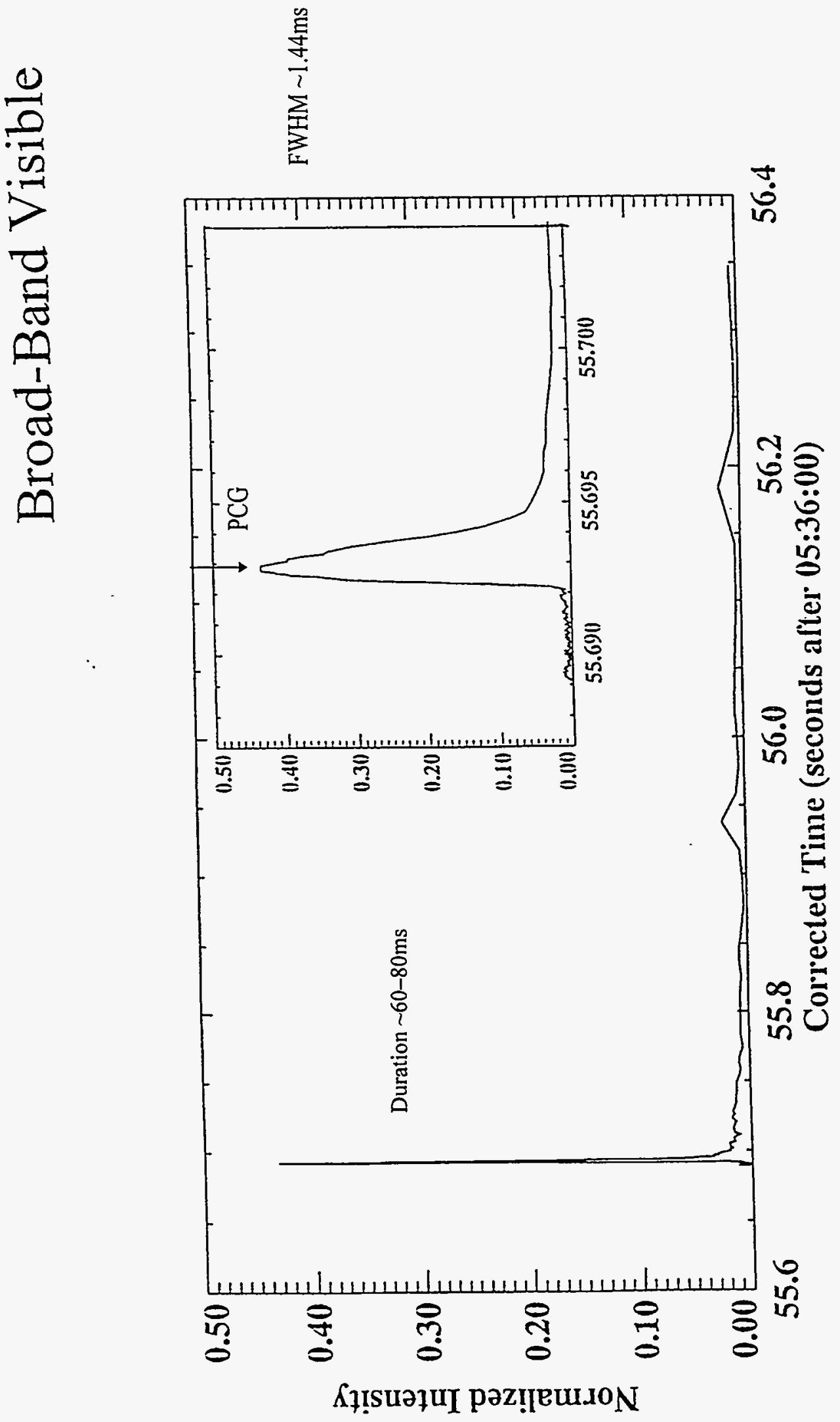

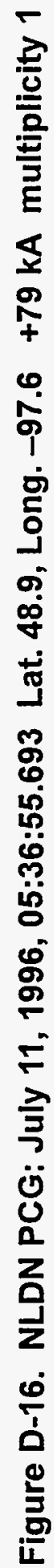


D্=

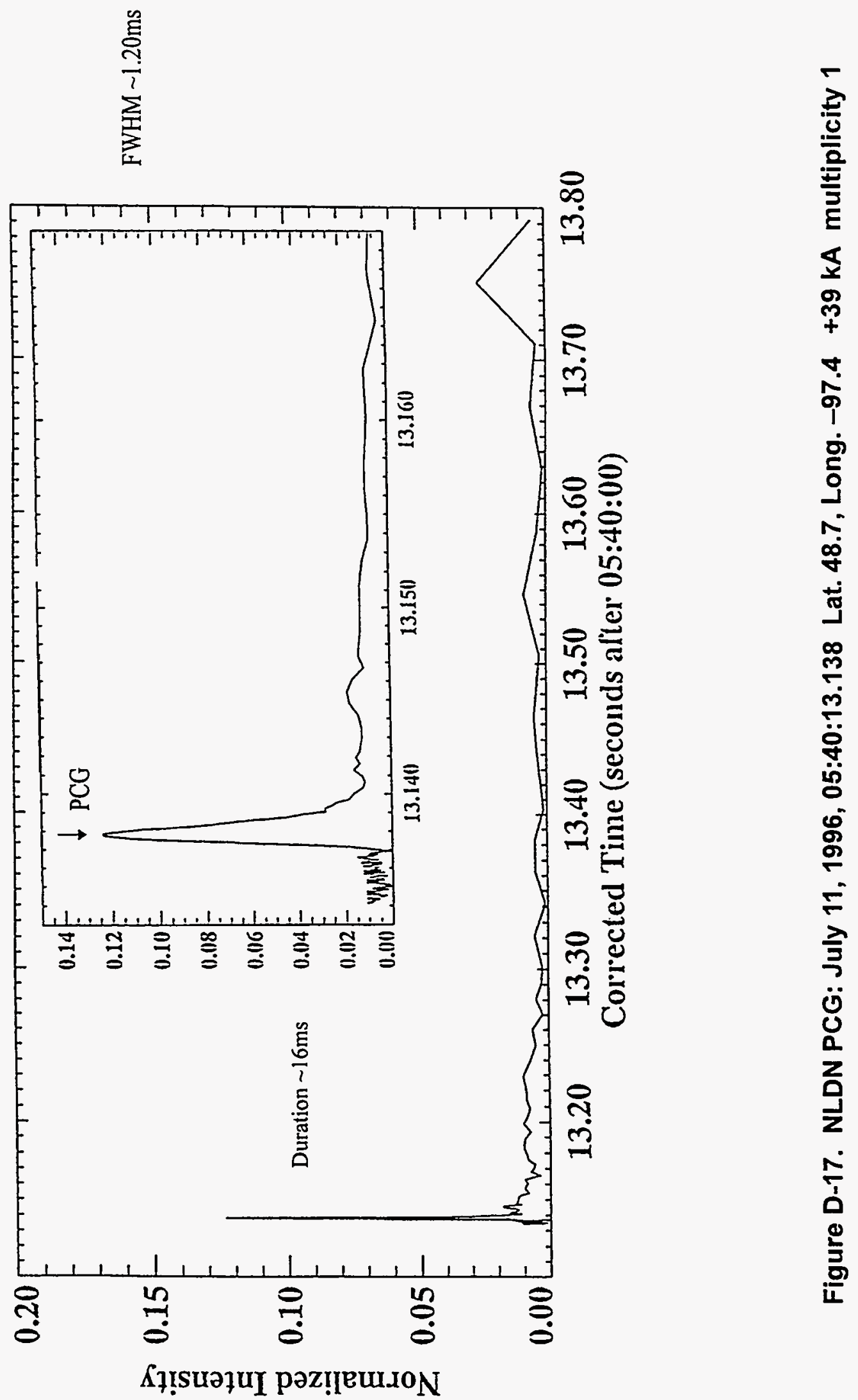




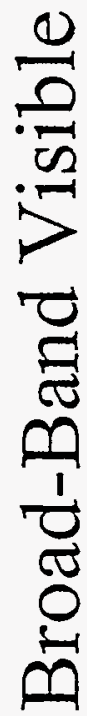

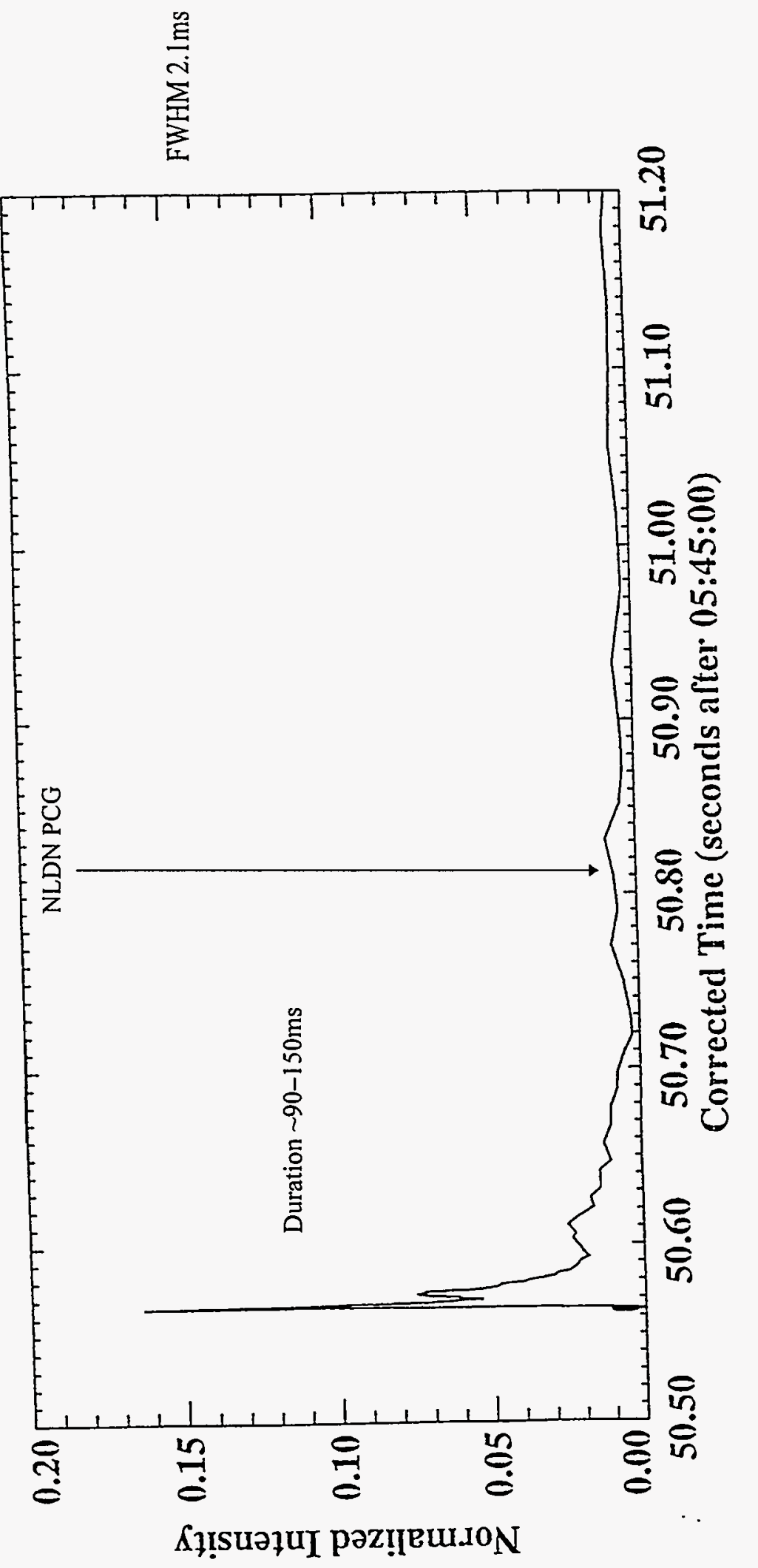

를

$\checkmark$

ণ্ণ

官

ปั

:

ษั

용

ळ.

ب⿱艹

苗

○

\%

\%

F

$\frac{2}{3}$

$\ddot{0}$

0

z

몰

잉

흔

$\infty$

ఢ

온 


\section{Broad-Band Visible}

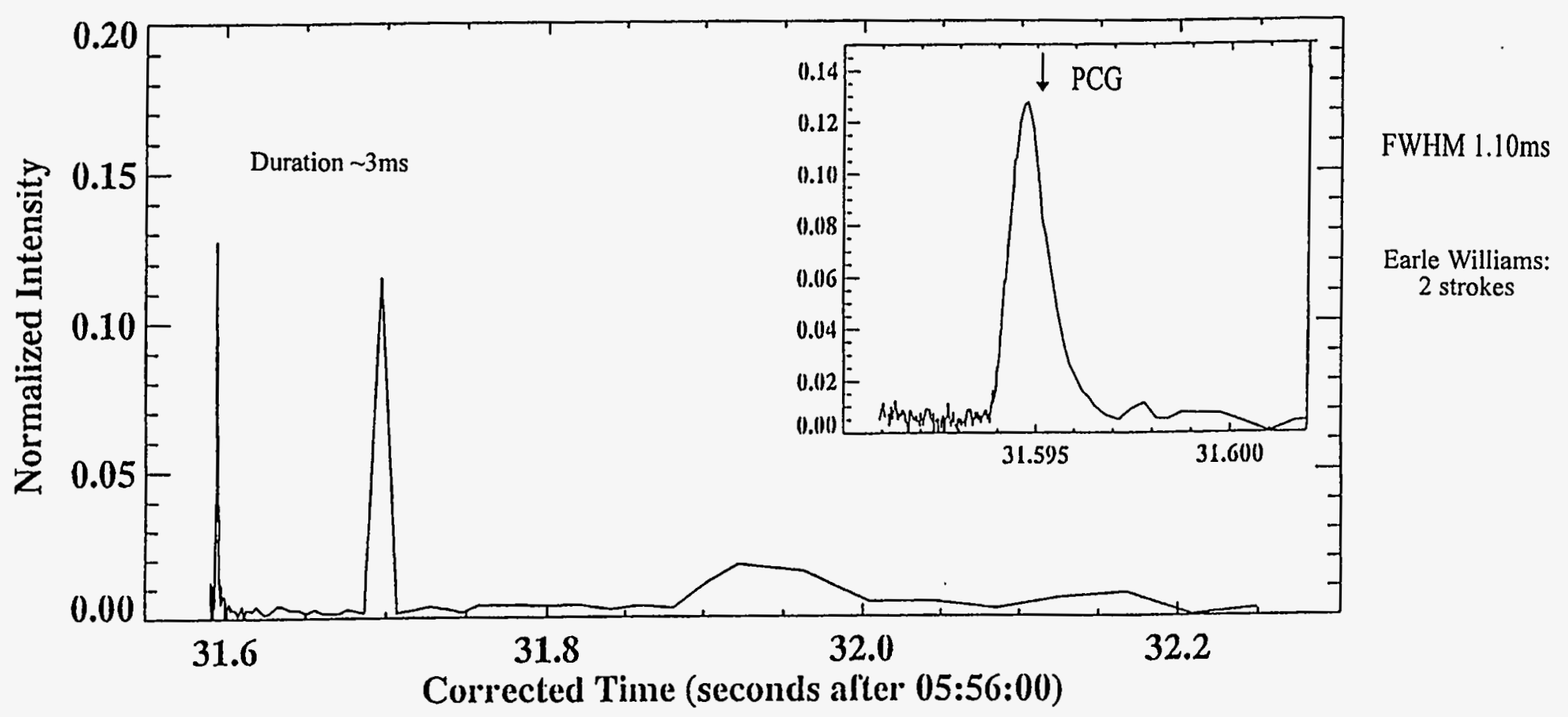

Figure D-19. NLDN PCG: July 11, 1996, 05:56:31.595 Lat. 48.5, Long. $-97.3+44$ kA multiplicity 1 

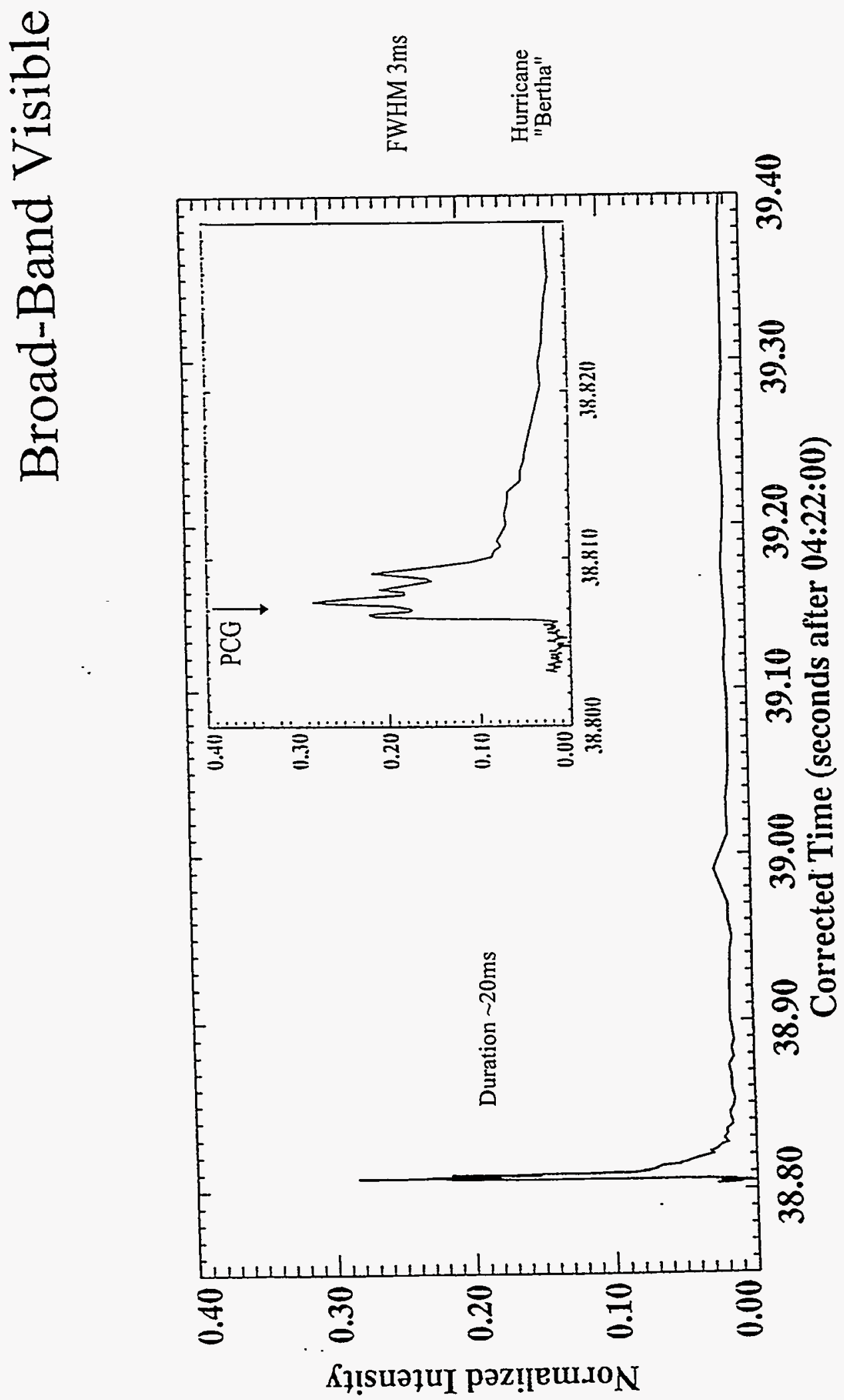

를

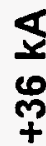

象

อุ

J

요

$\infty$

N

$\underset{8}{\mathscr{8}}$

ஜ́

욤

v

$\frac{2}{3}$

$\ddot{0}$
0
$z$
$z$
$z$

ণั่ 


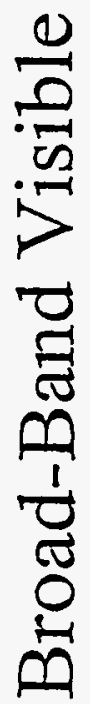

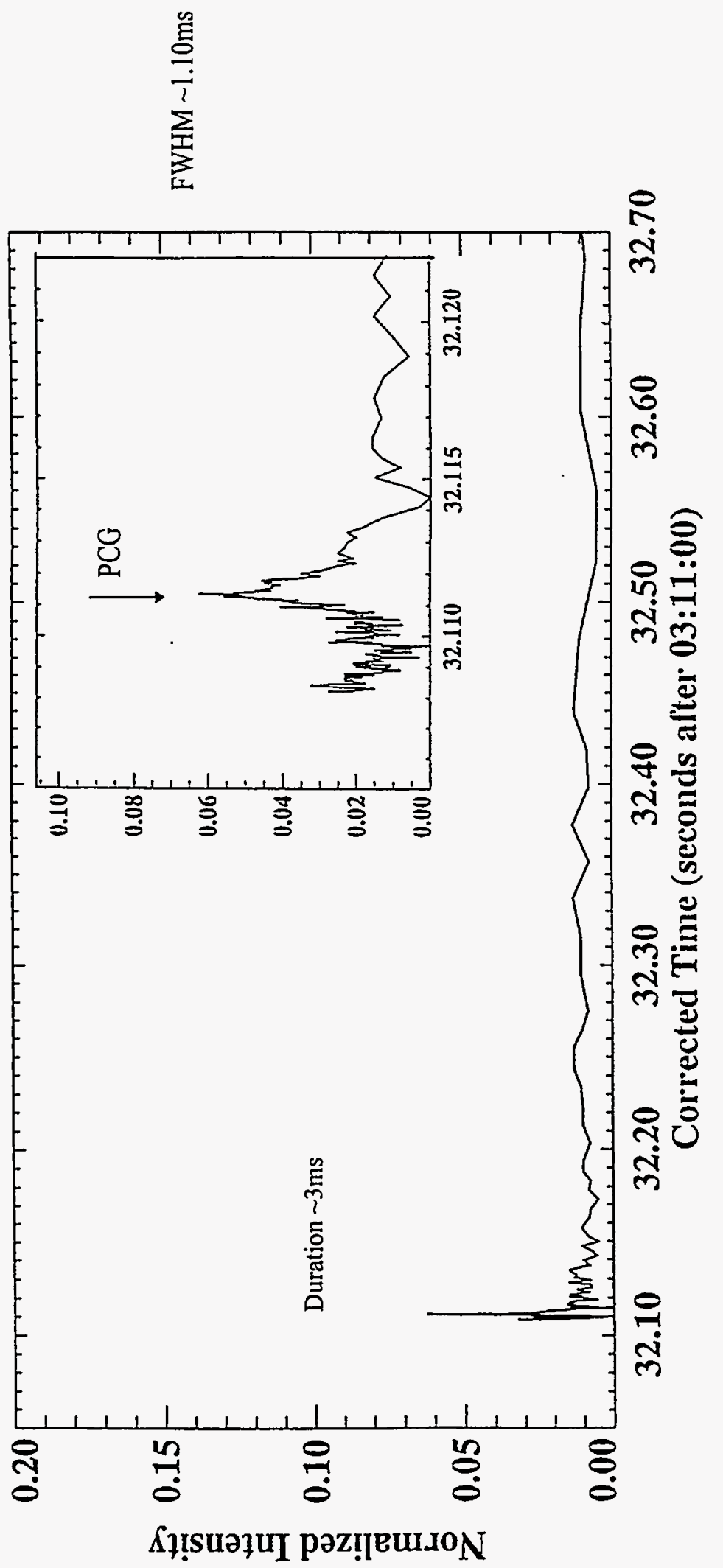

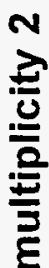

$\frac{5}{4}$

옹

ס்

$\stackrel{\infty}{\circ}$

ल

苛

$F$

ก

?ำ

ஜั

\&

6

$\frac{7}{3}$

ï

0

z

ণั่ 


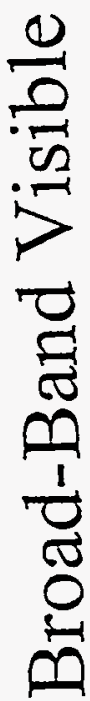

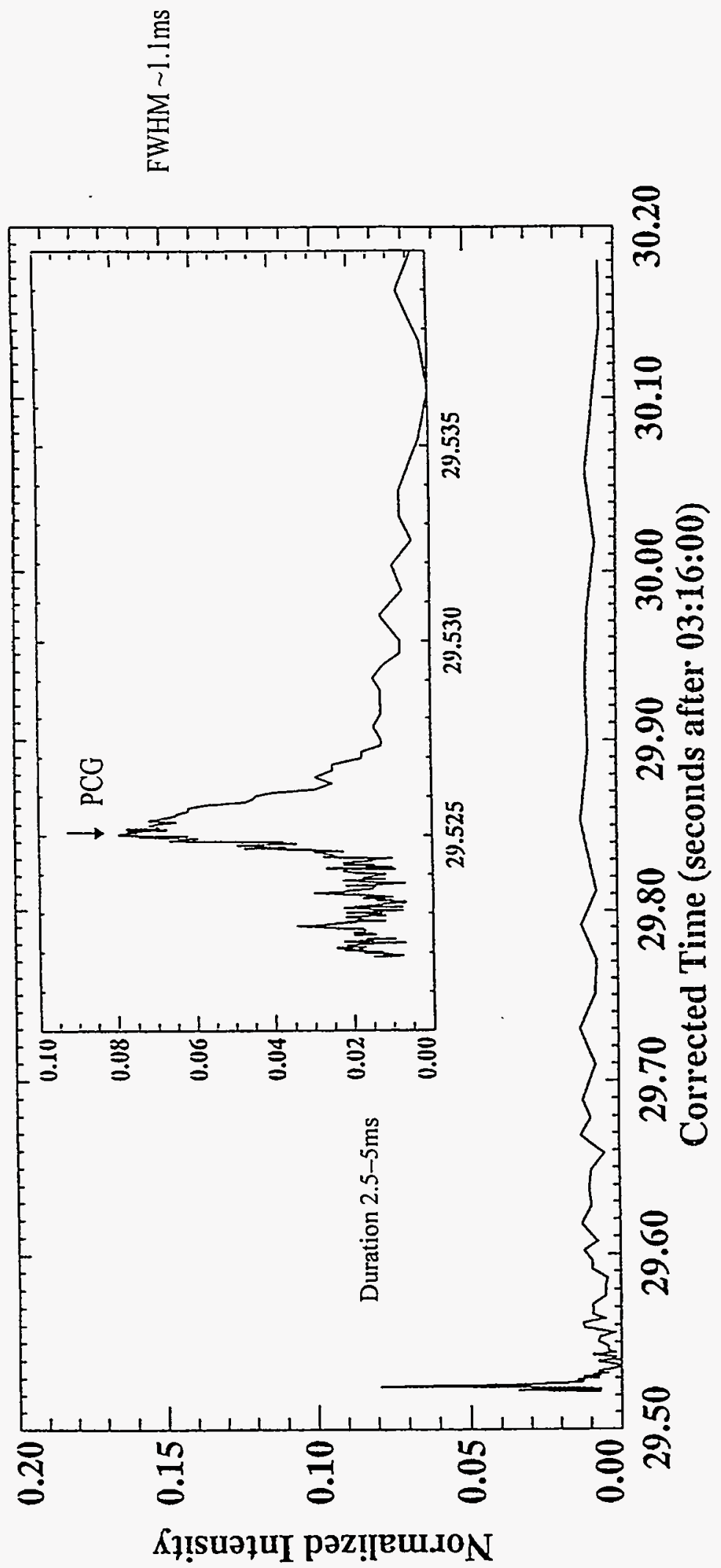

N

를

$\frac{5}{ \pm}$

홍

ᄋ.

تั

กิ

จ

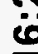

ตั

g

$\frac{6}{3}$

ï

0

z

ฟั่ 


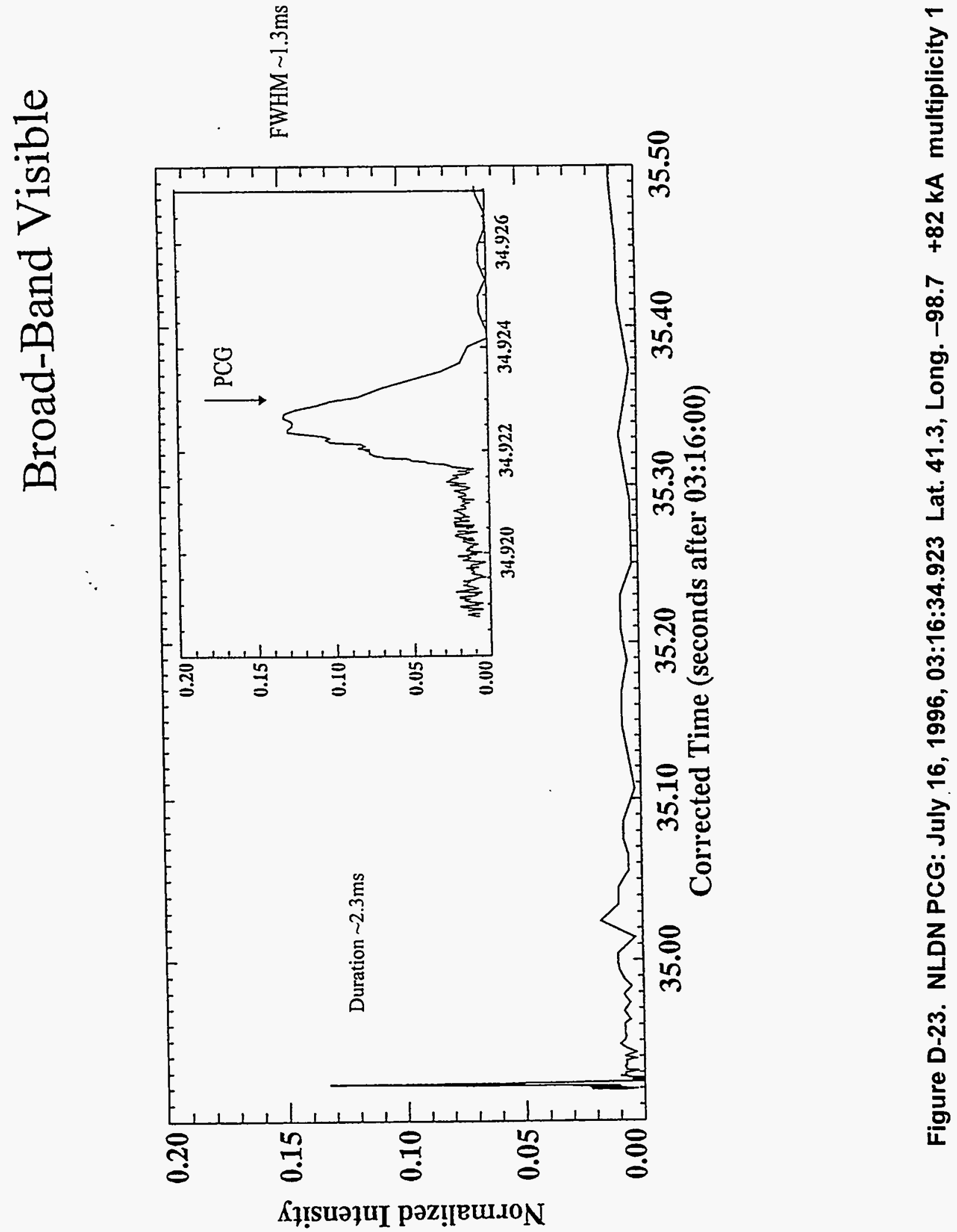



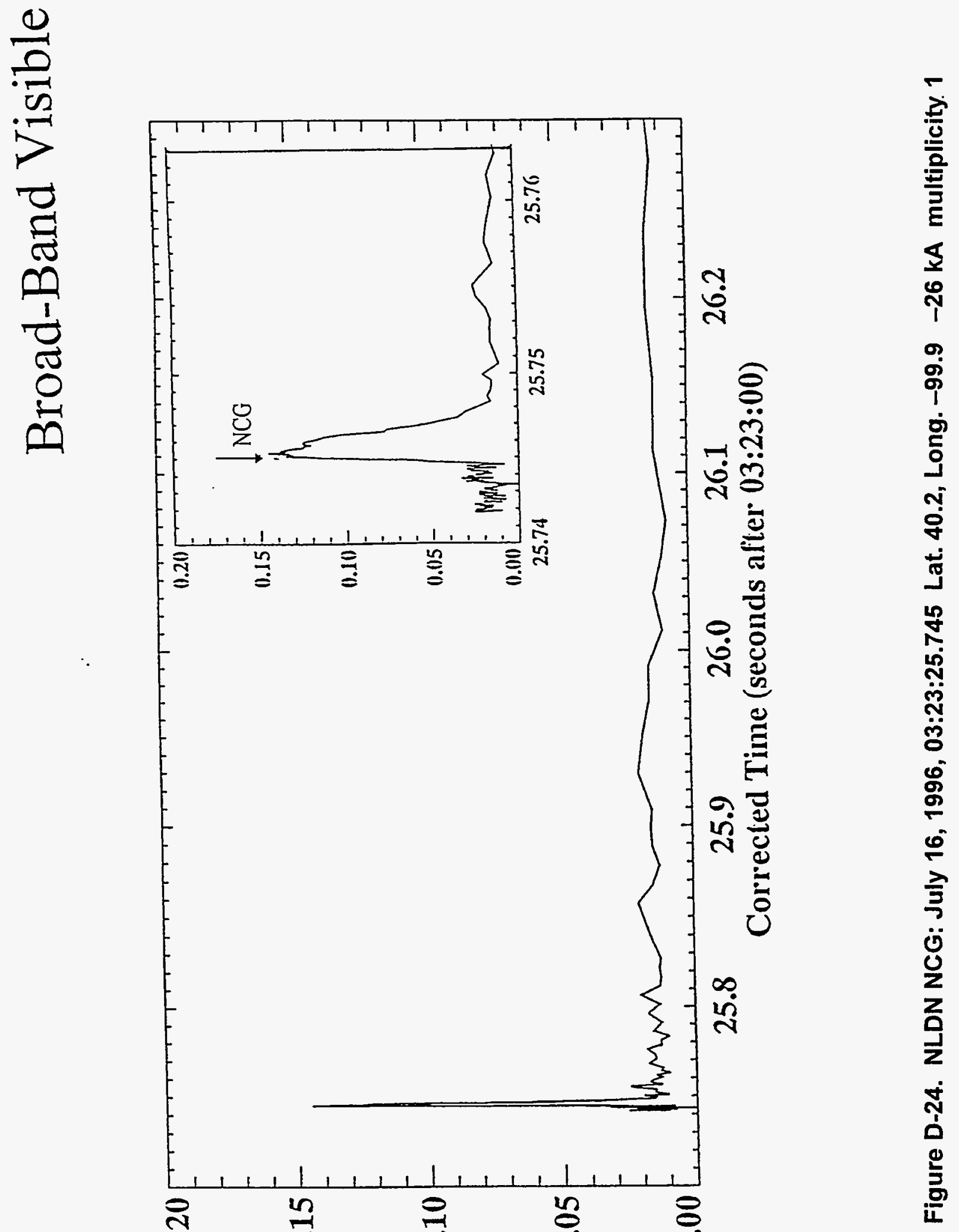


\section{Broad-Band Visible}

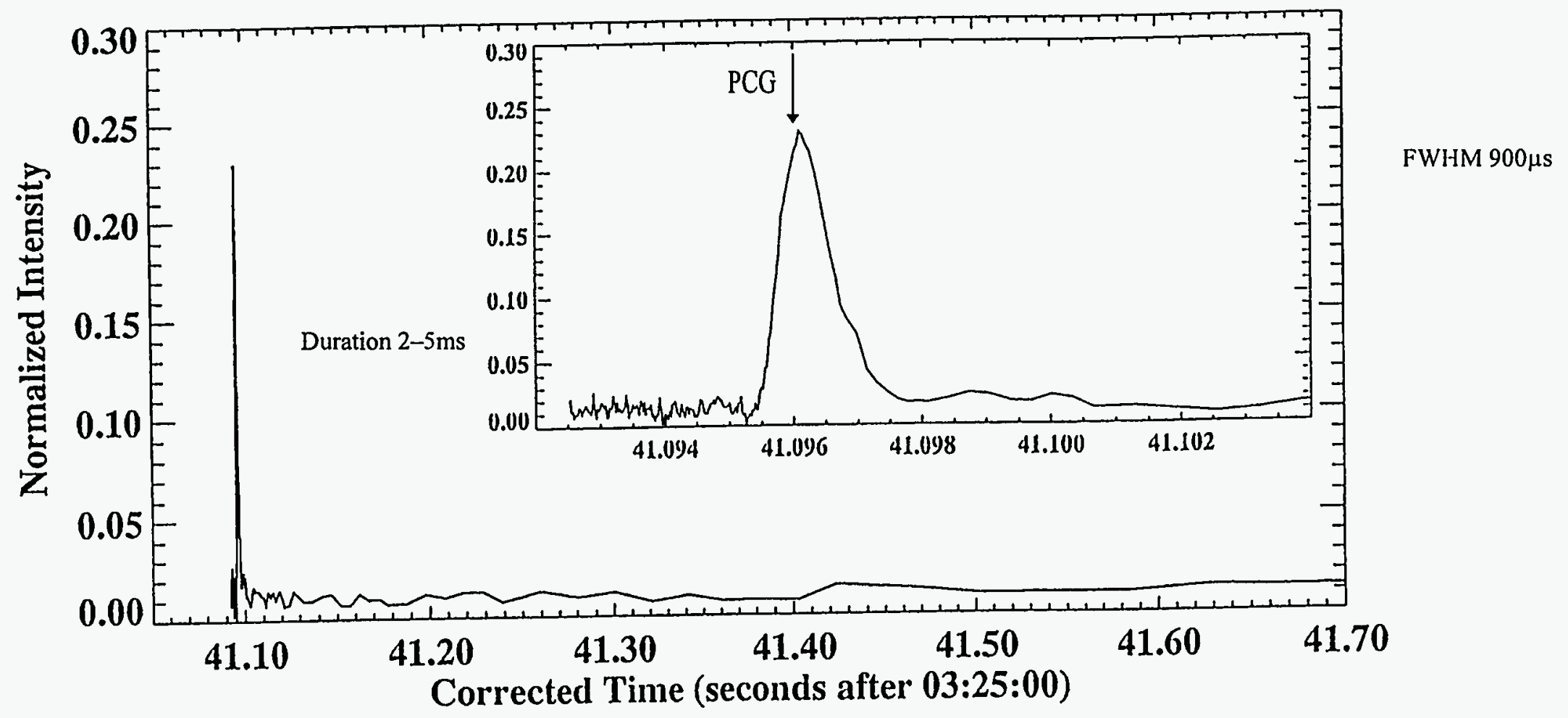

Figure D-25. NLDN PCG: July 16, 1996, 03:25:41.096 Lat. 40.3, Long. $-100.4+113$ kA multiplicity 2 
$\frac{0}{0}$

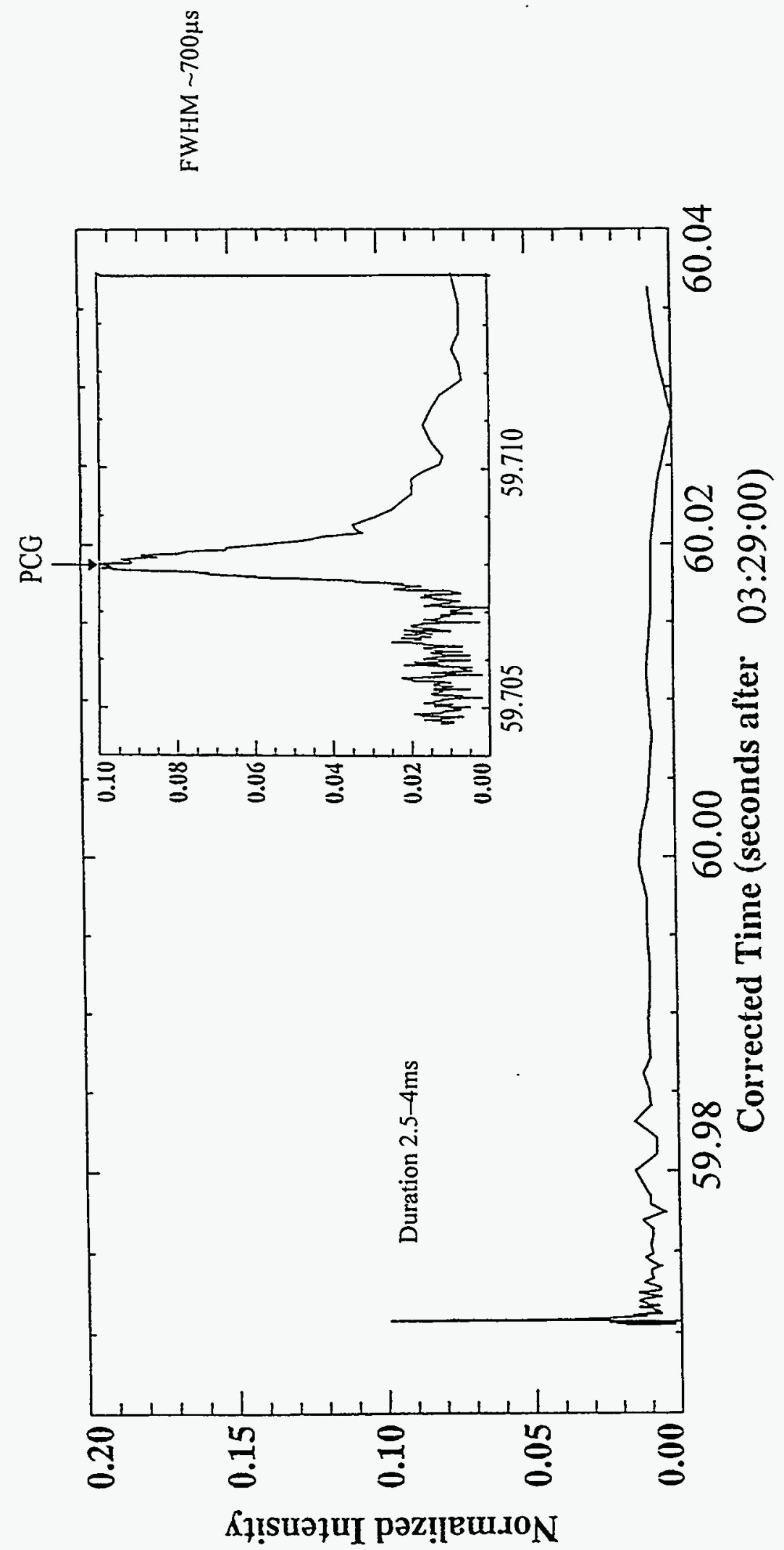




\section{Broad-Band Visible}

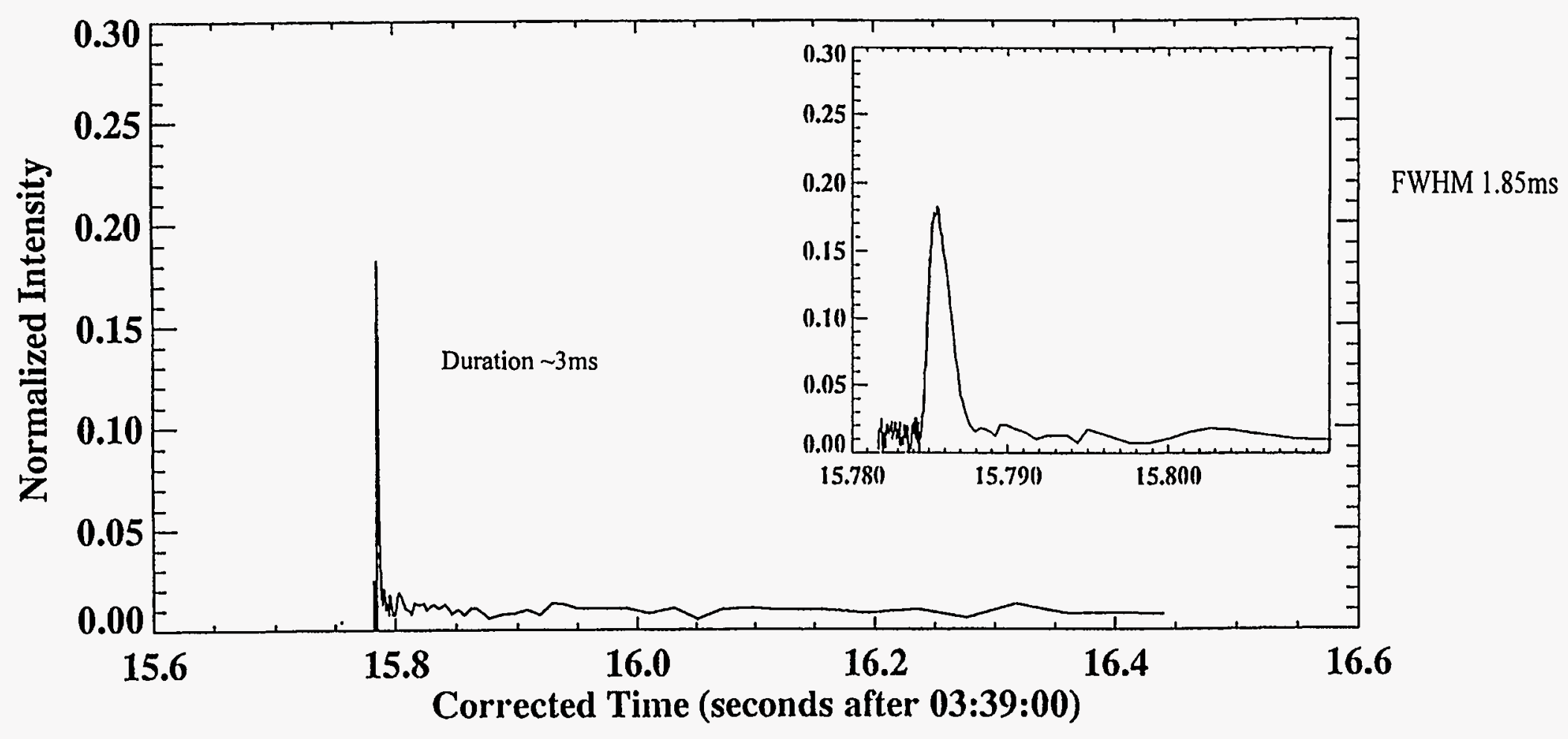

Figure D-27. NLDN PCG: July 16, 1996, 03:39:15.785 Lat. 40.1, Long. $-100.8+61$ kA multiplicity 1 

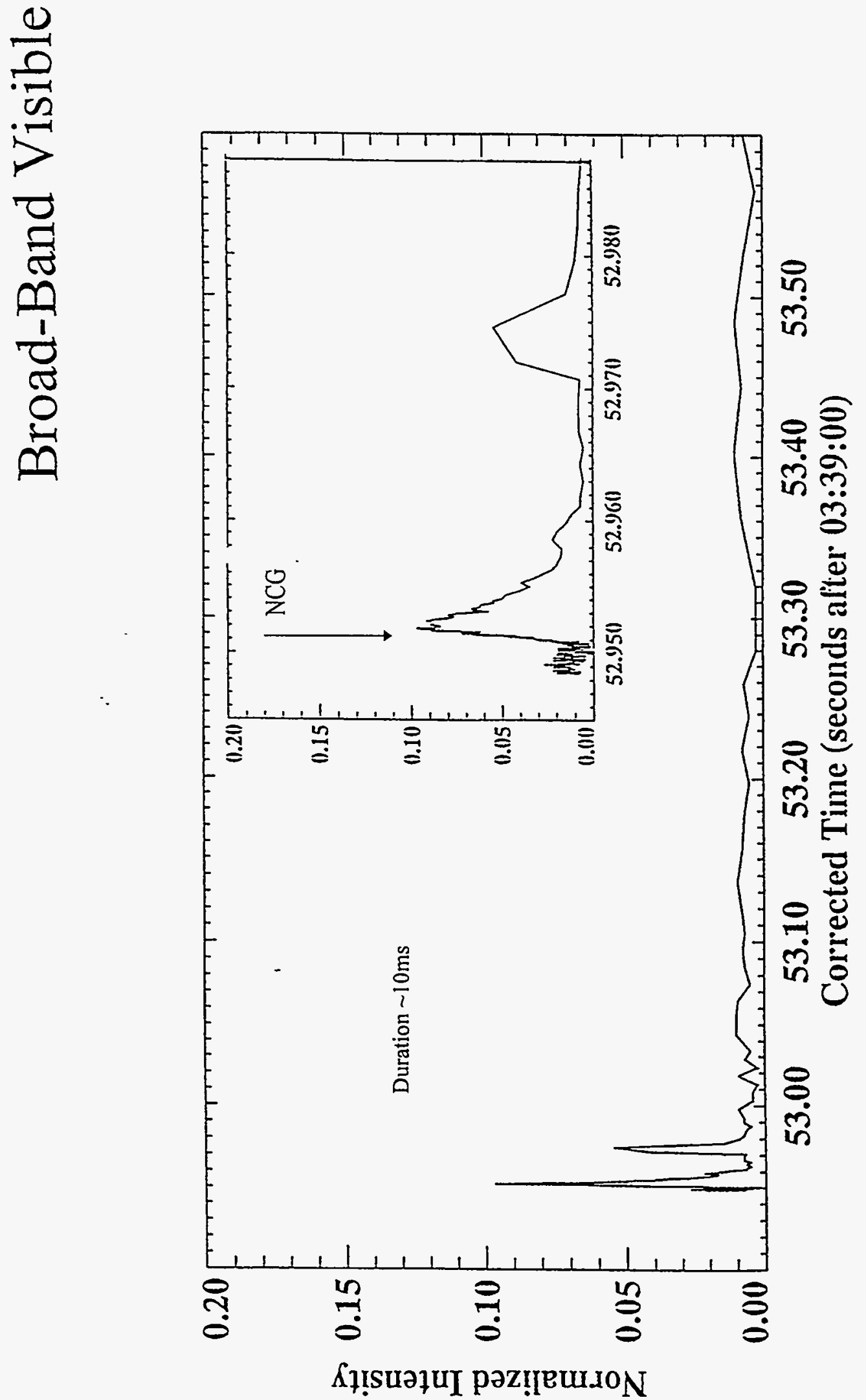

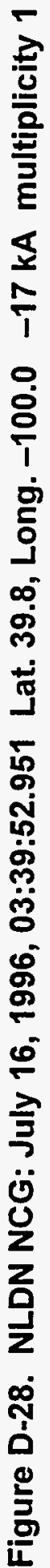




\section{Broad-Band Visible}

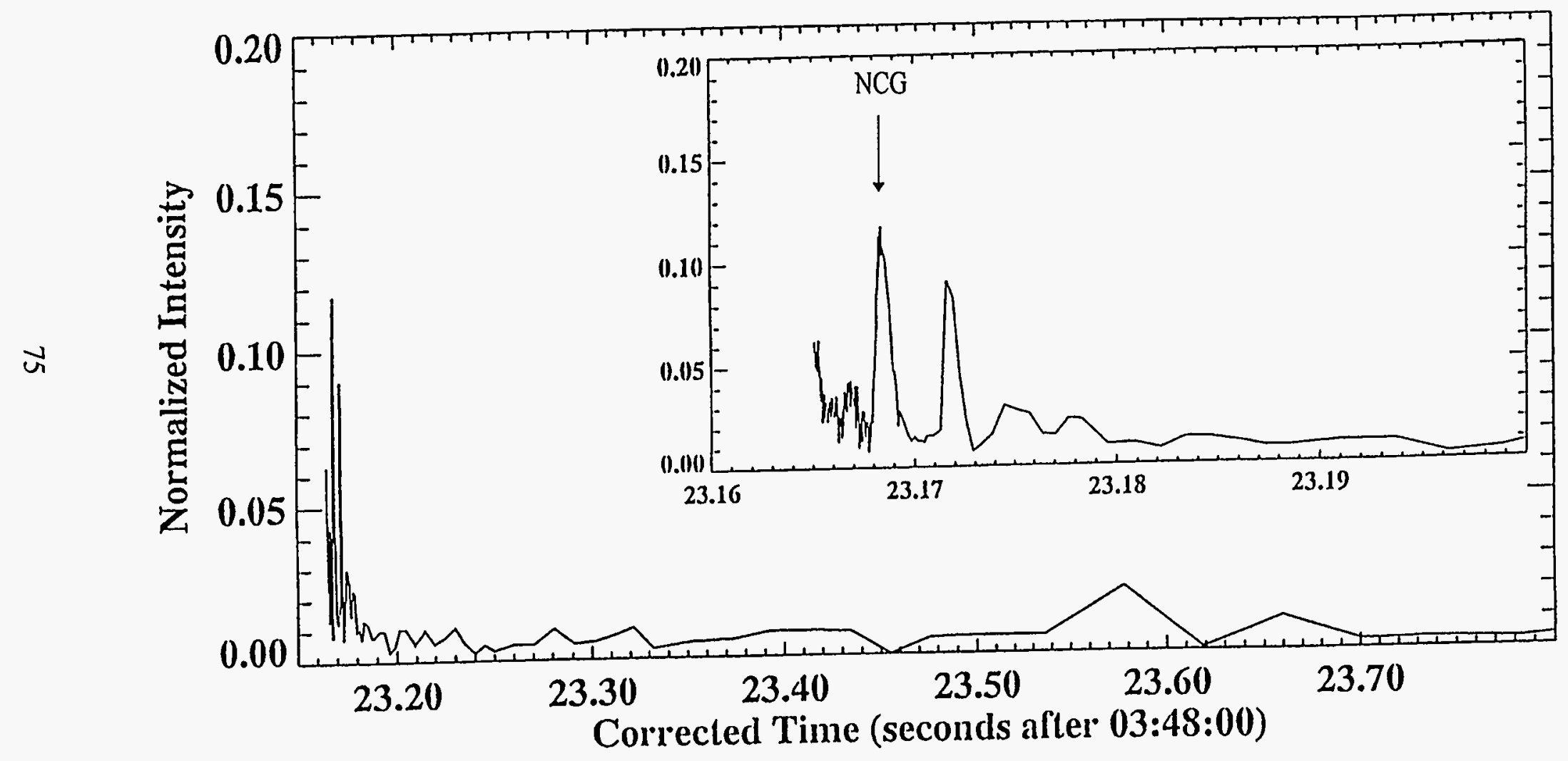

Figure D-29. NLDN NCG: July 16, 1996, 03:48:23.168 Lat. 40.6, Long. $-99.7-25$ kA multiplicity 1 

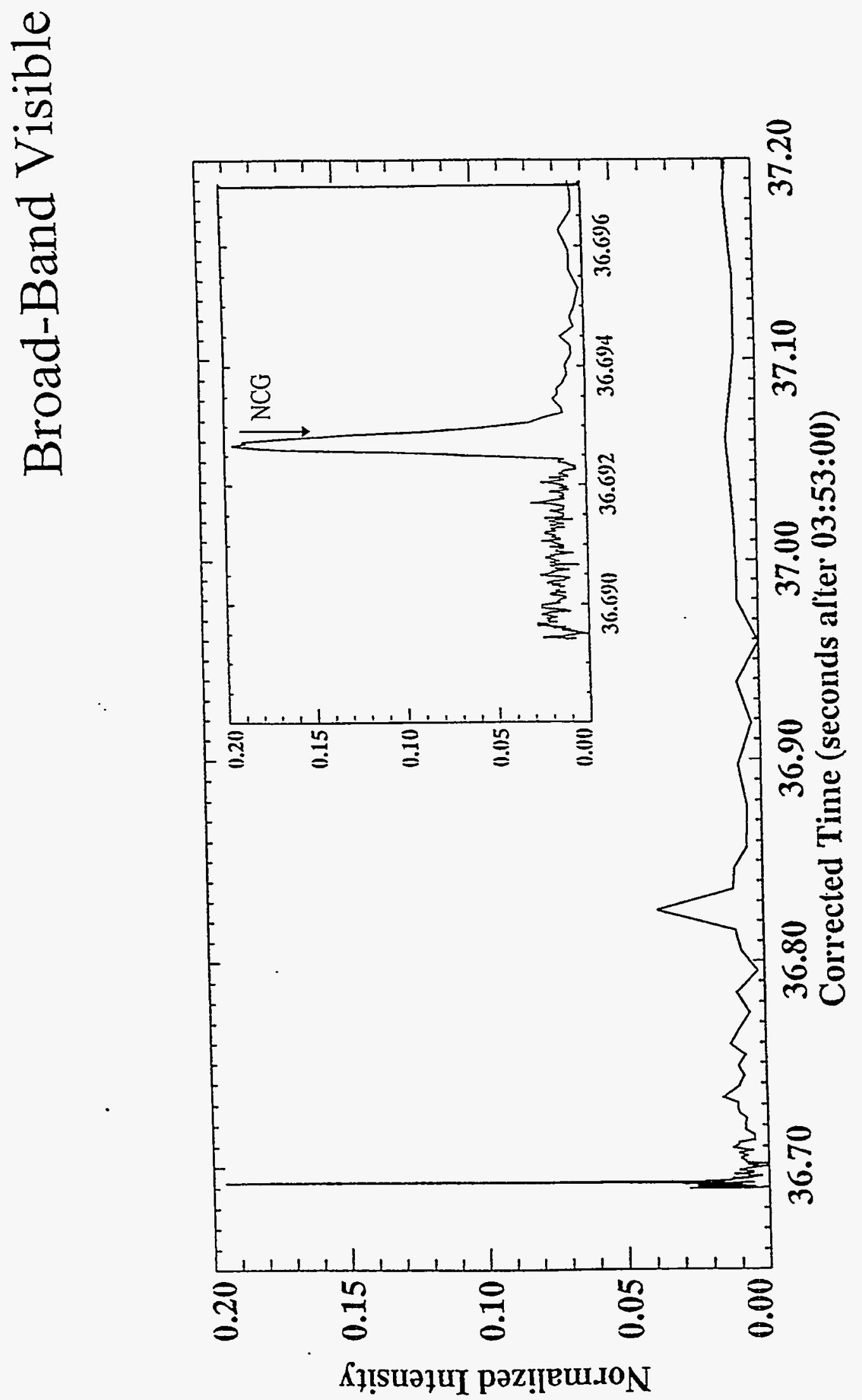

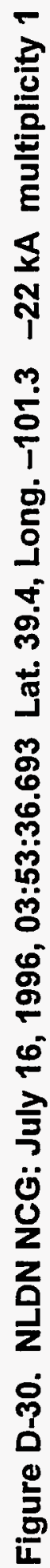



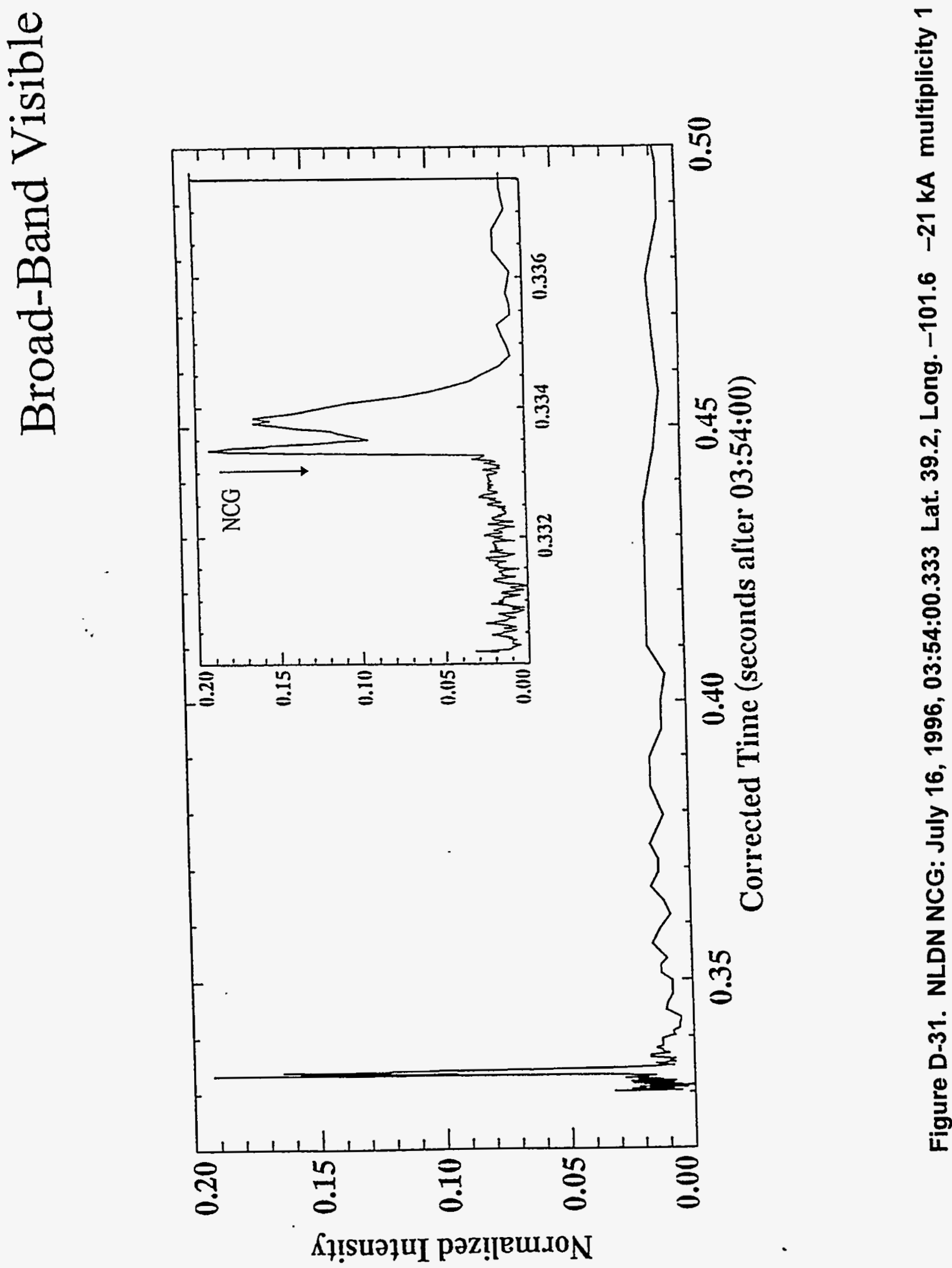

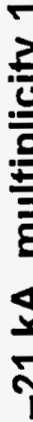

웅 

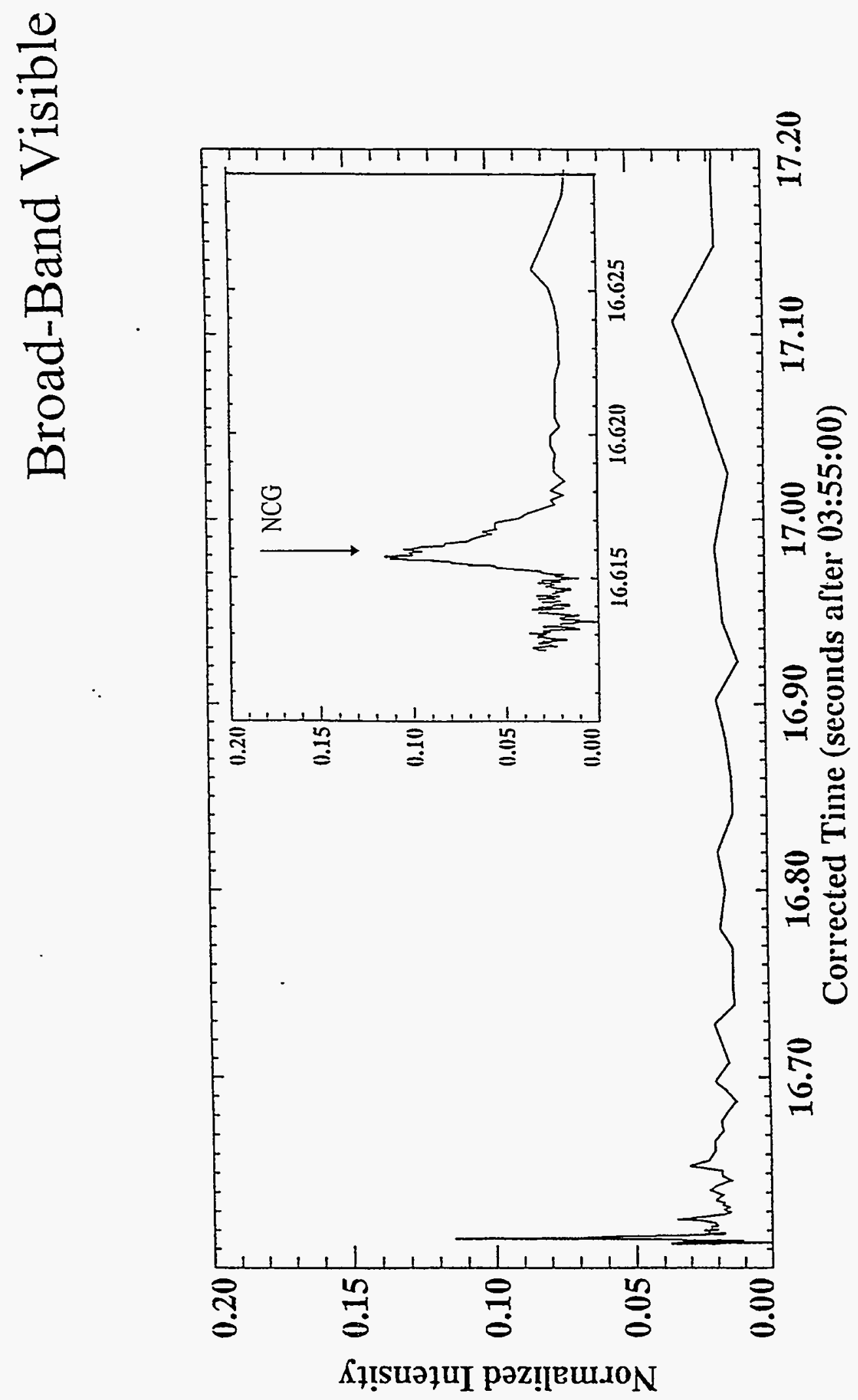

동

옹

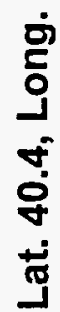

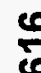

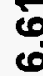

in

in

8

ตั

으

ह

$\frac{7}{3}$

$\ddot{g}$

2

ż

กั่

온 

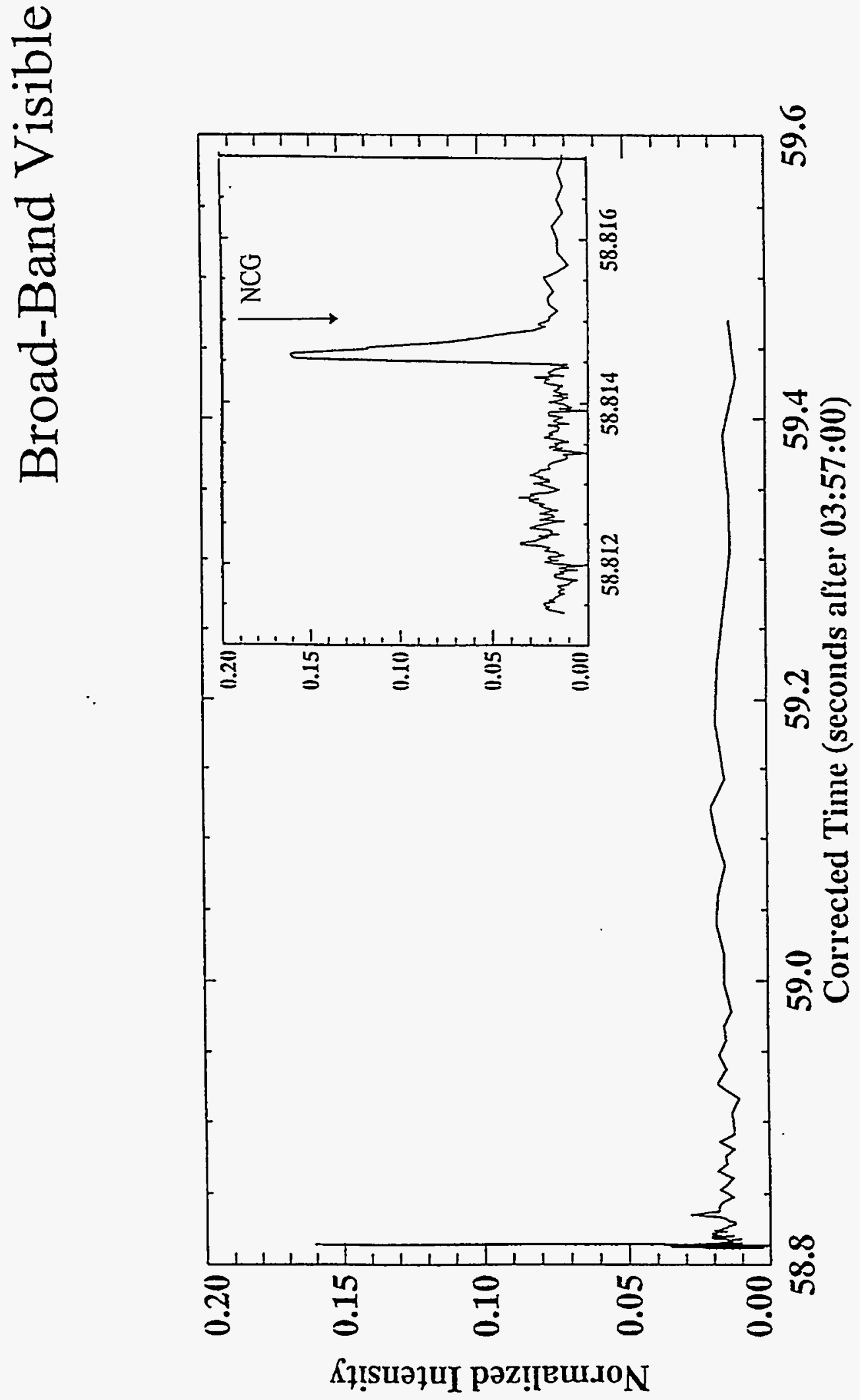

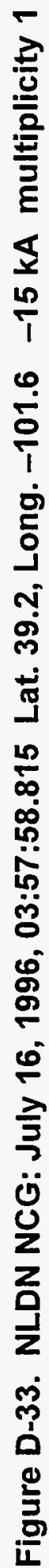




\section{Sprites '96 Campaign: M46 Lightning Data July 16,1996}

\section{S. Nebraska / NW Kansas Storm}
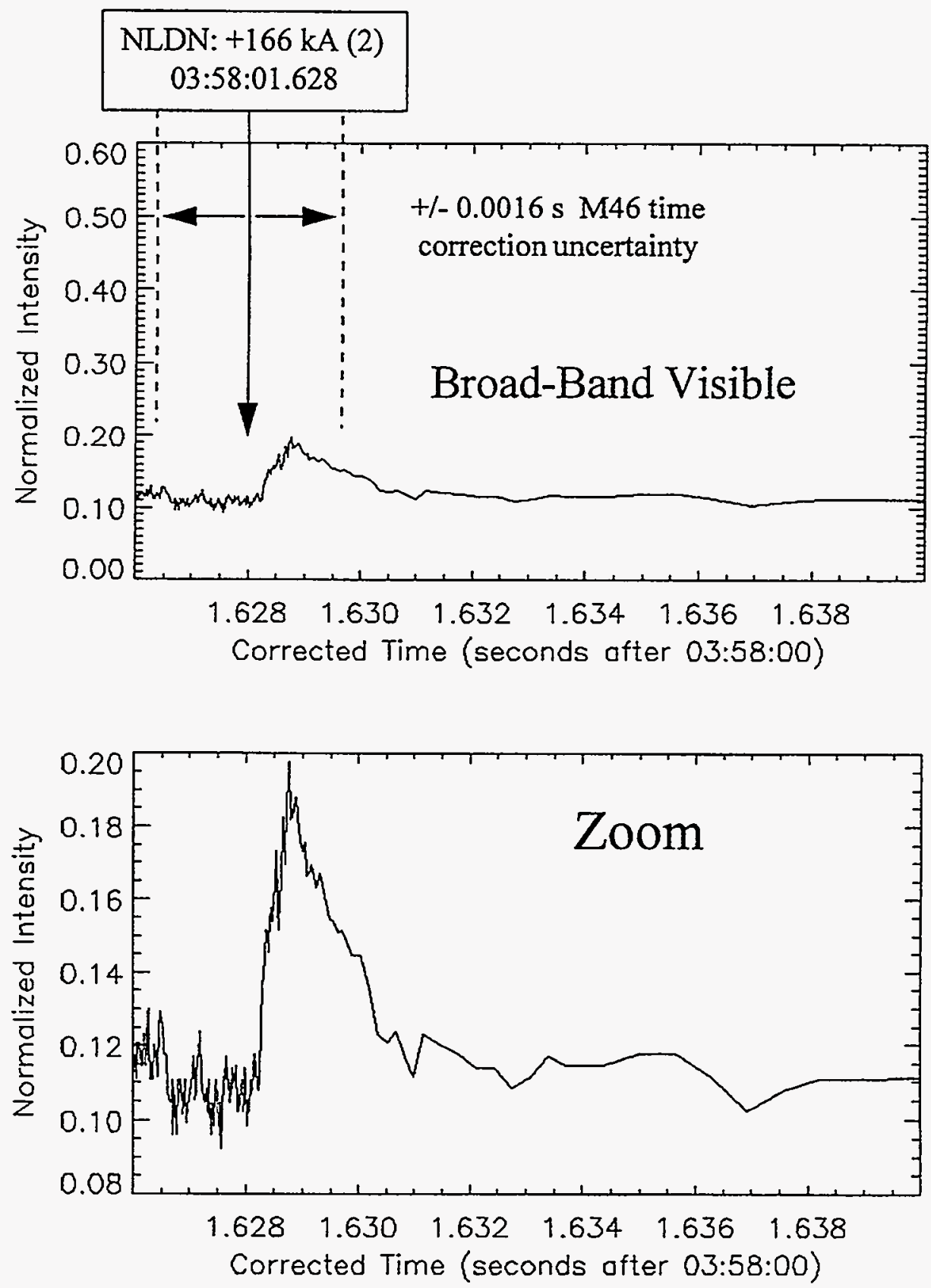

7i Sandia National Laboratories

Figure D-34. NLDN PCG: July 16, 1996, 03:58:01.628 +166 kA multiplicity 2 

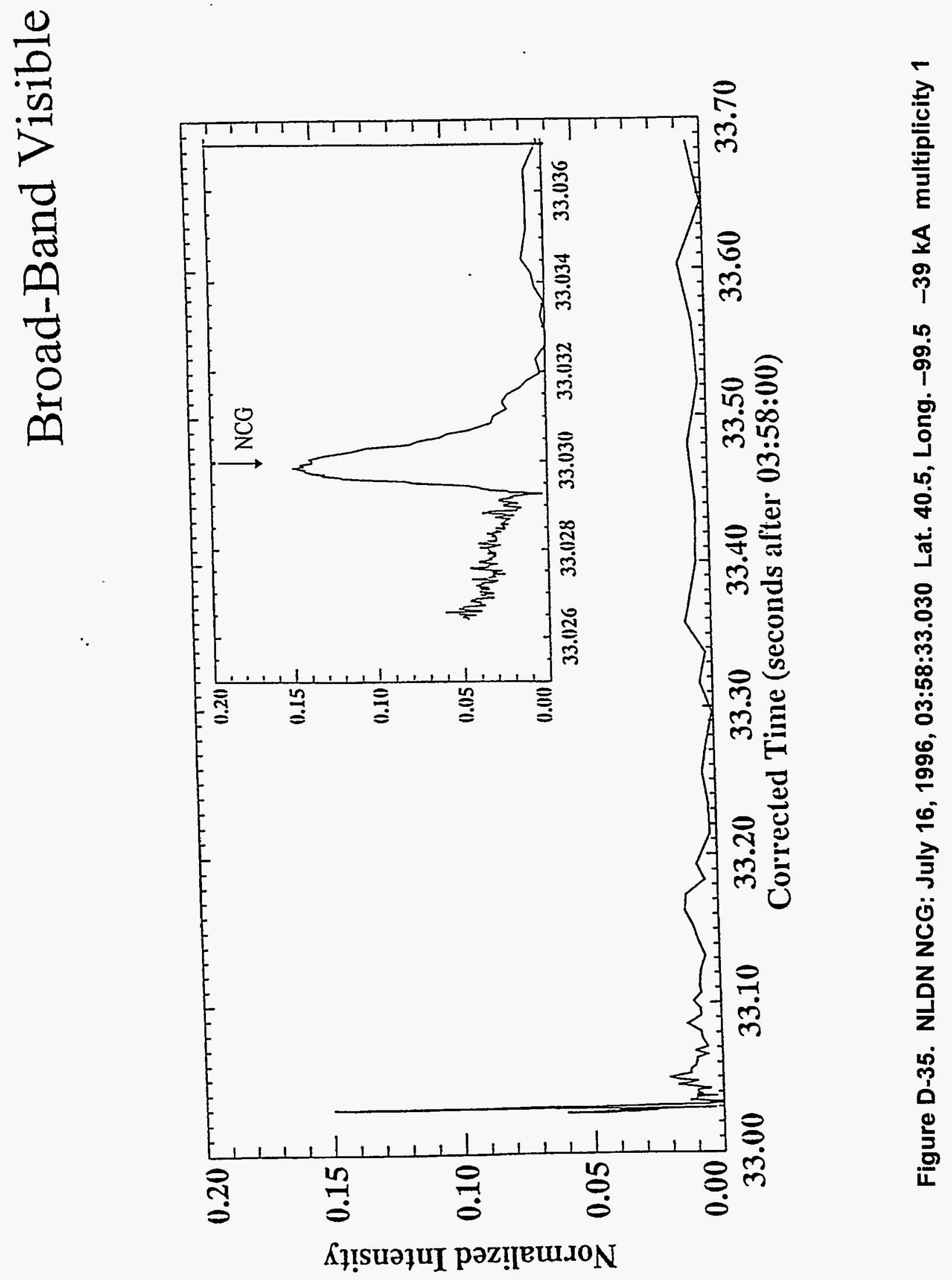

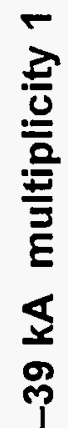

\%̊

10

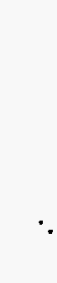




\section{Sprites '96 Campaign \\ M46 Lightning Data}

July 16, 1996: S Nebraska / NW Kansas Storm

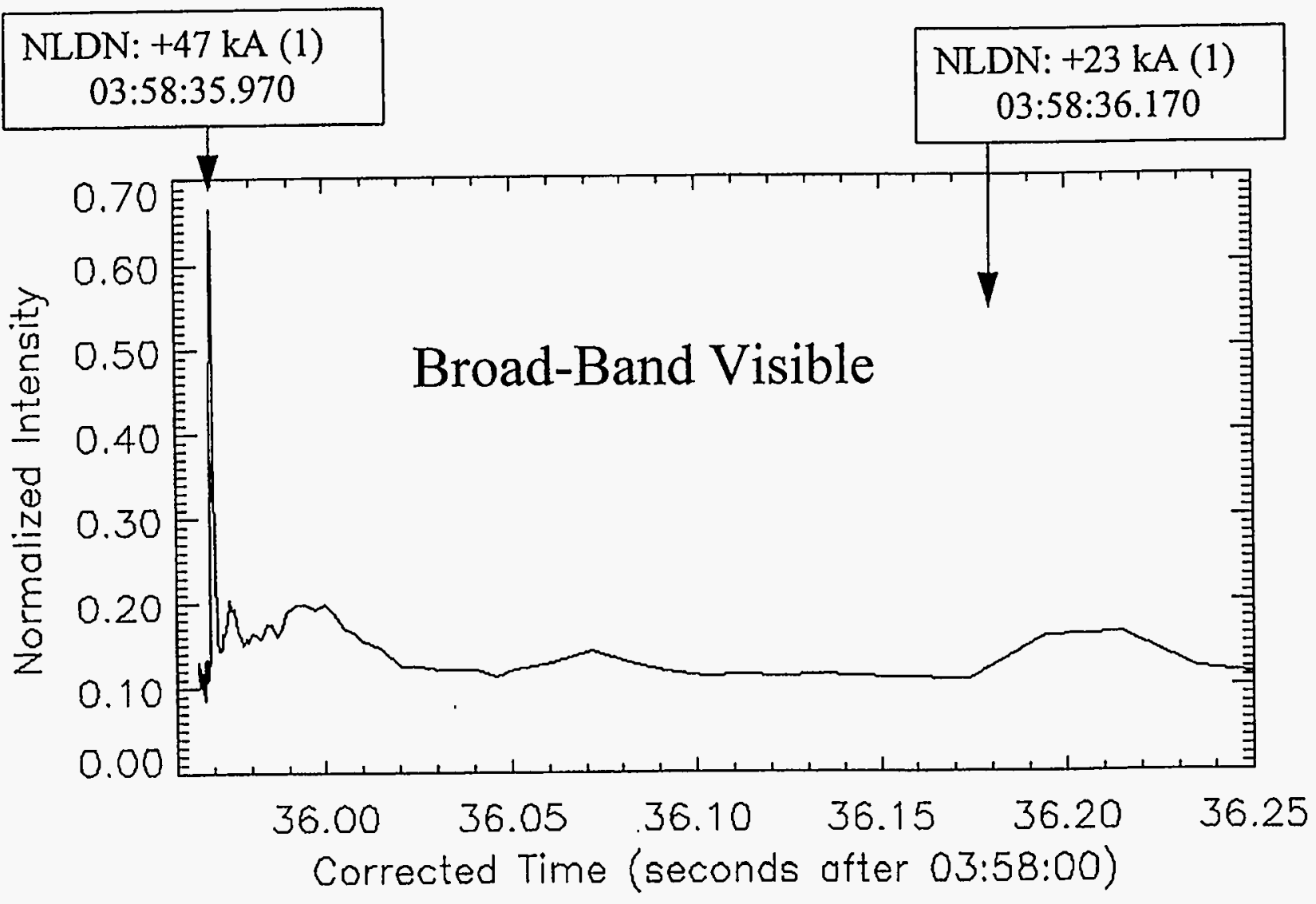

团 Sandia National Laboratories

Figure D-36. NLDN PCG: July 16, 1996, 03:58:36.970, +47 kA multiplicity 1 


\section{Sprites '96 Campaign}

\section{M46 Lightning Data}

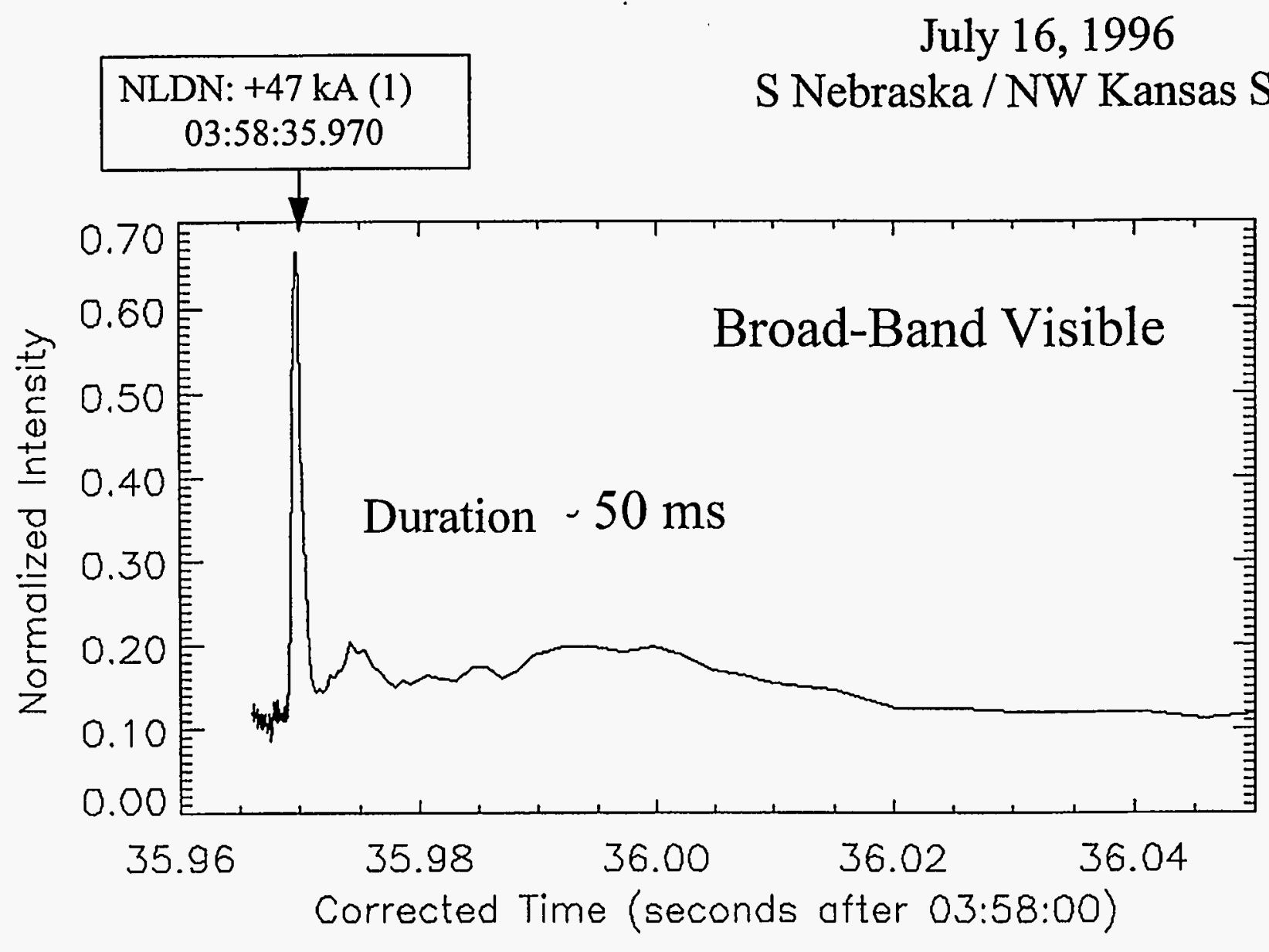

Sandia National Laboratories

Figure D-37. NLDN PCG: July 16, 1996, 03:58:35.970 +47 kA multiplicity 1 (expanded view) 


\section{Broad-Band Visible}

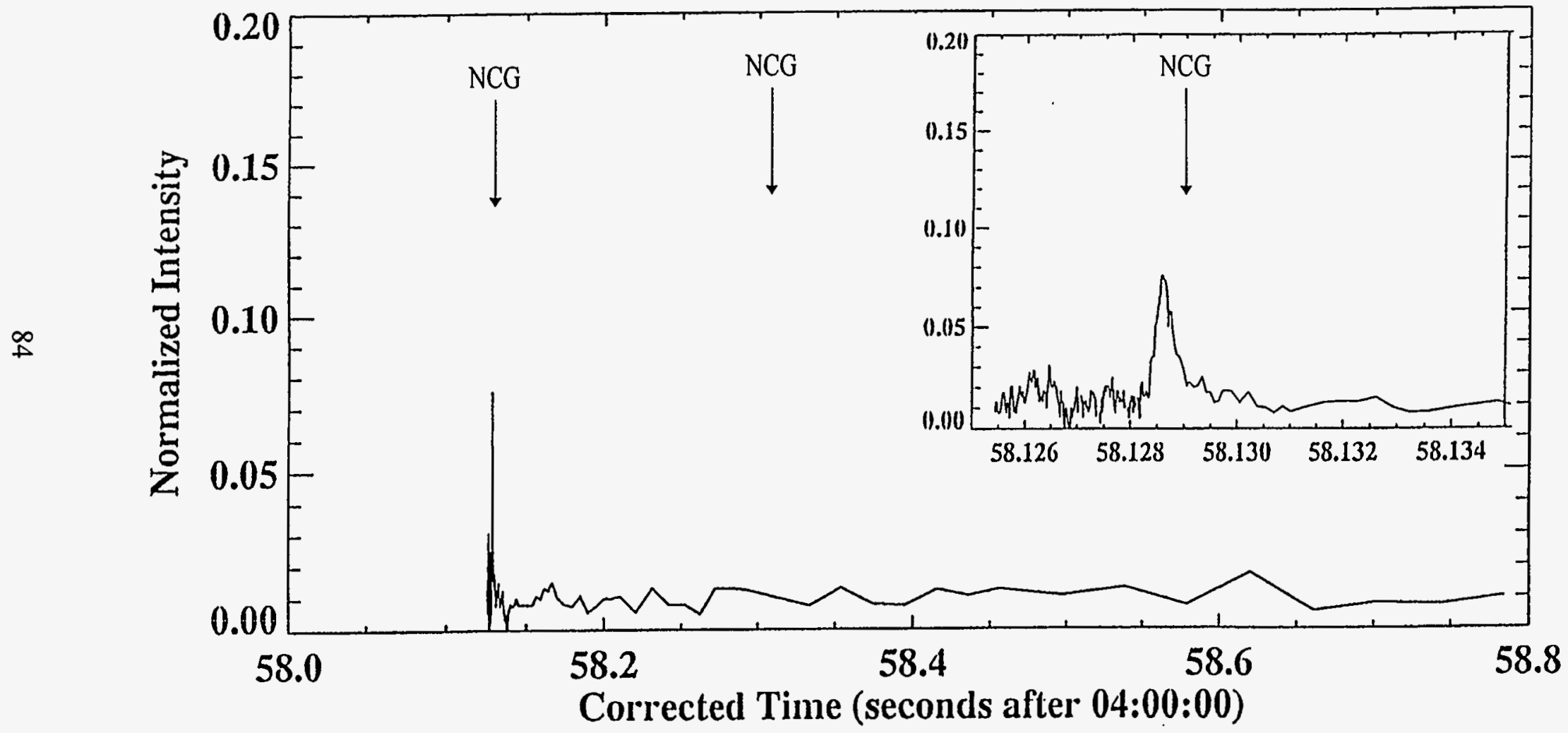

Figure D-38. NLDN NCG: July 16, 1996, 04:00:58.129 Lat. 39.7, Long. $-100.1-19$ kA multiplicity 1 NLDN NCG: July 16, 1996, 04:00:58.306 Lat. 39.2, Long. -101.6 -24 kA multiplicity 1 
0
0
0
0
0
0
0
0
0
0
0
0
0
0
0
0

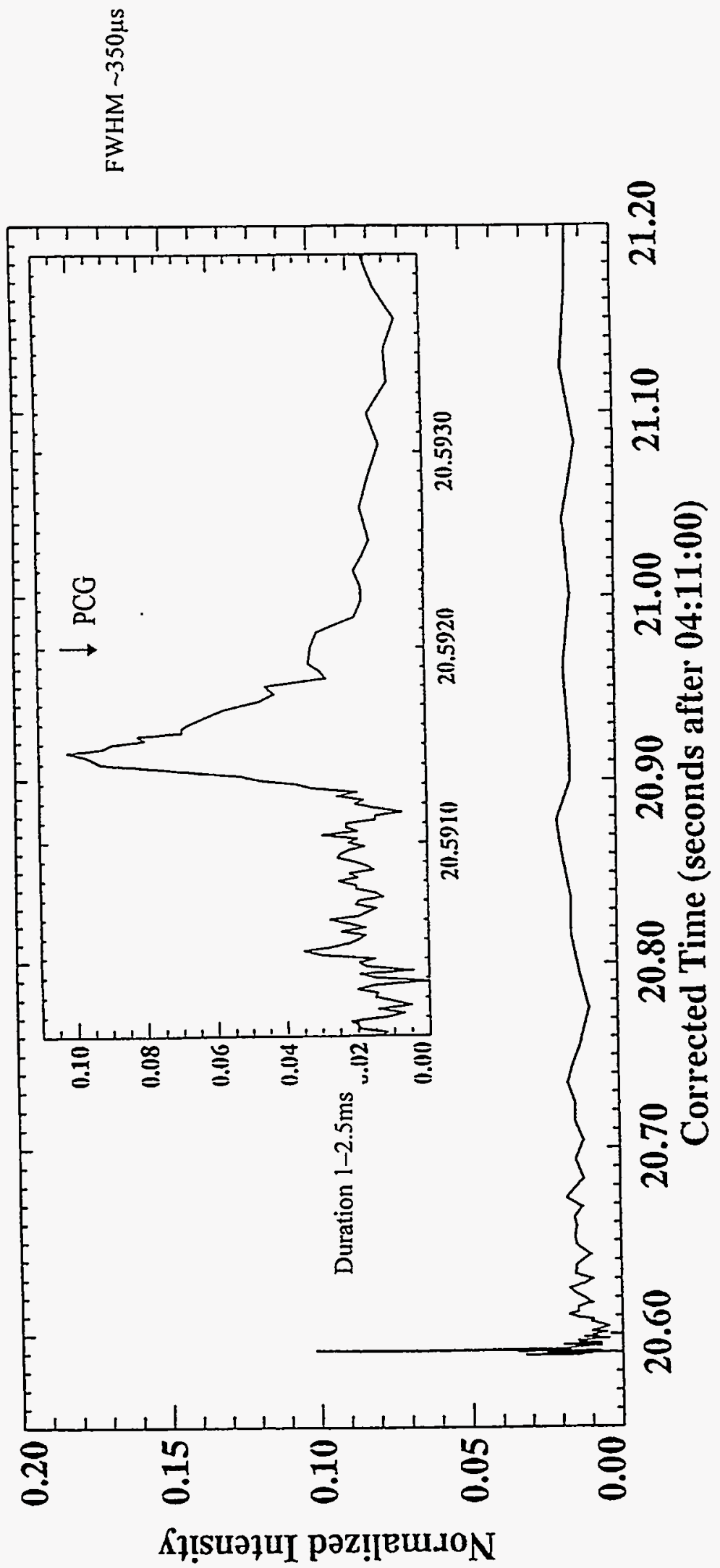

롱

$\frac{5}{5}$

ํํㅇ

ס̊

พั

เก

ก

$\stackrel{5}{\dot{8}}$

5

요

6

$\frac{2}{3}$

0
0
$z$
$z$
$z$

発 

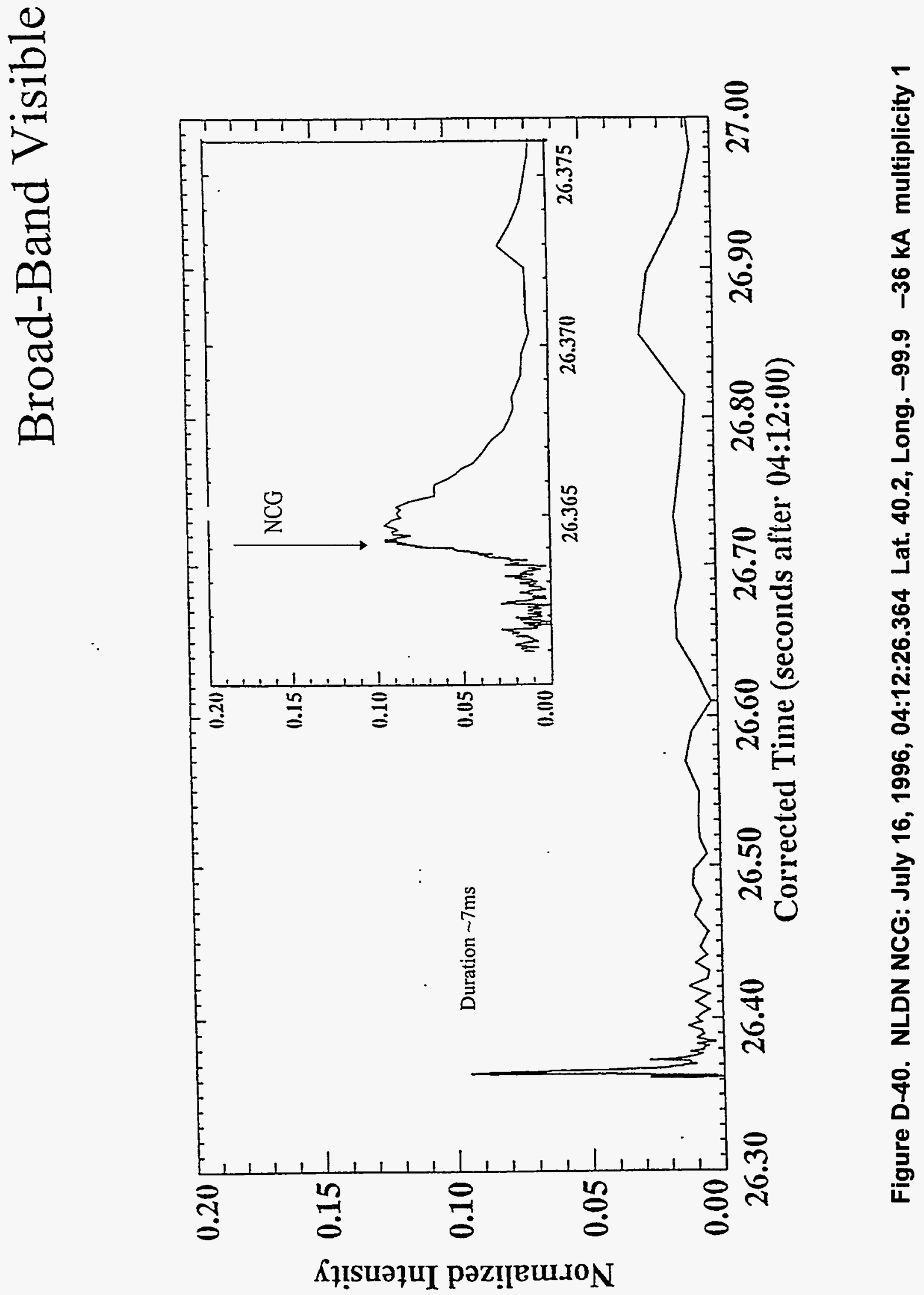


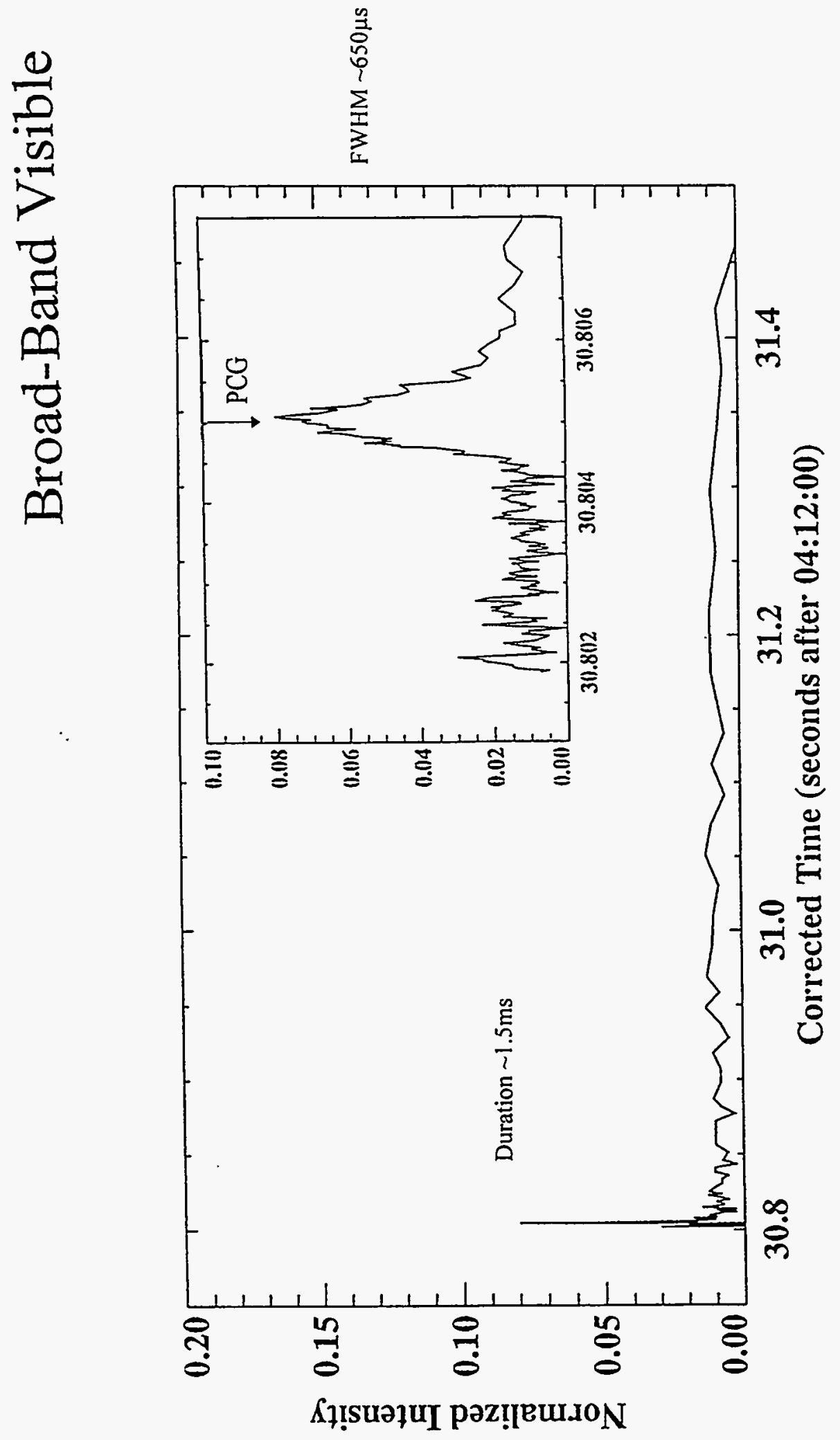

를

$\frac{\mathbb{s}}{\mathbb{f}}$

뭉

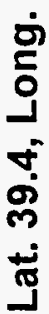

눙

○

ஸ்

뭉

क्

\%



$\frac{2}{3}$

$\ddot{0}$

0

를

广்

온 


\section{Broad-Band Visible}

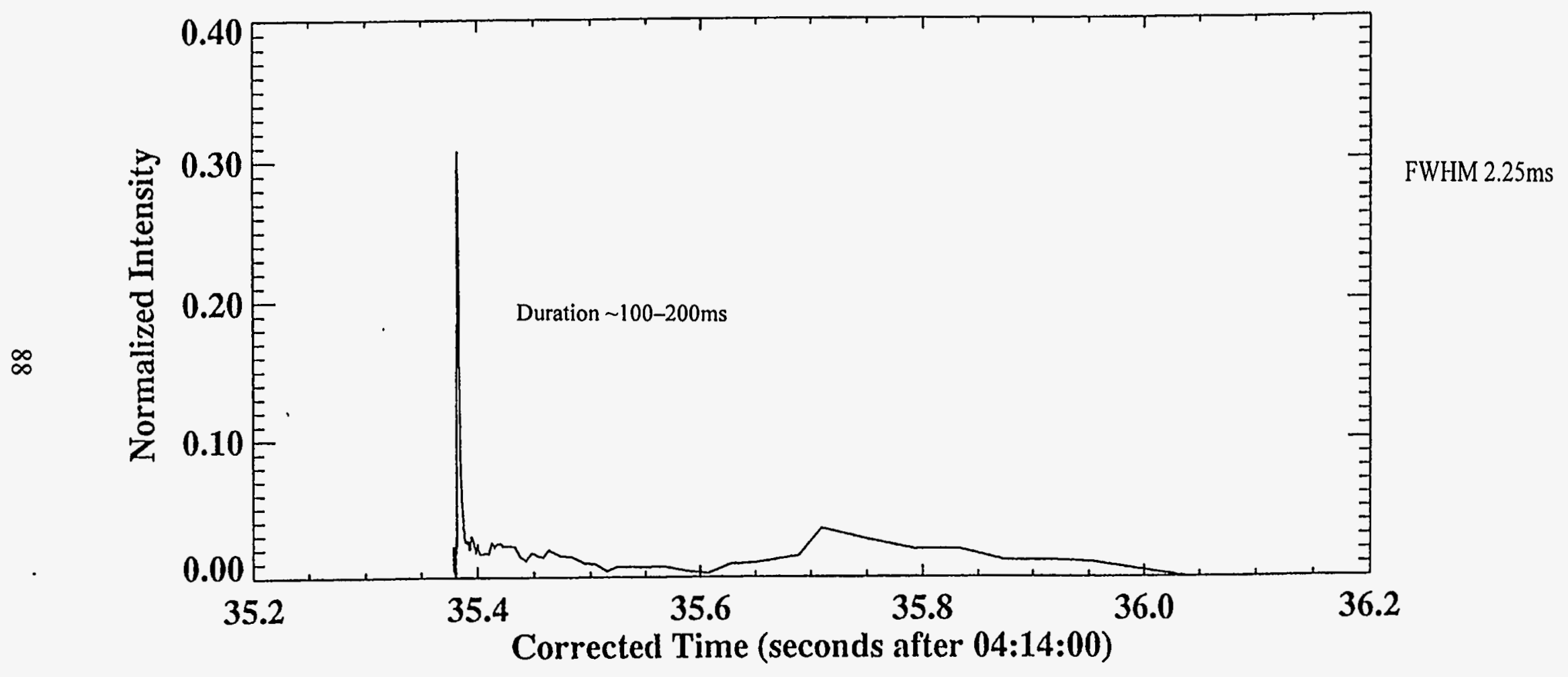

Figure D-42. NLDN PCG: July 16, 1996, 04:14:35.382 Lat. 40.3, Long. -99.5 +45 kA multiplicity 4 


\section{Broad-Band Visible}

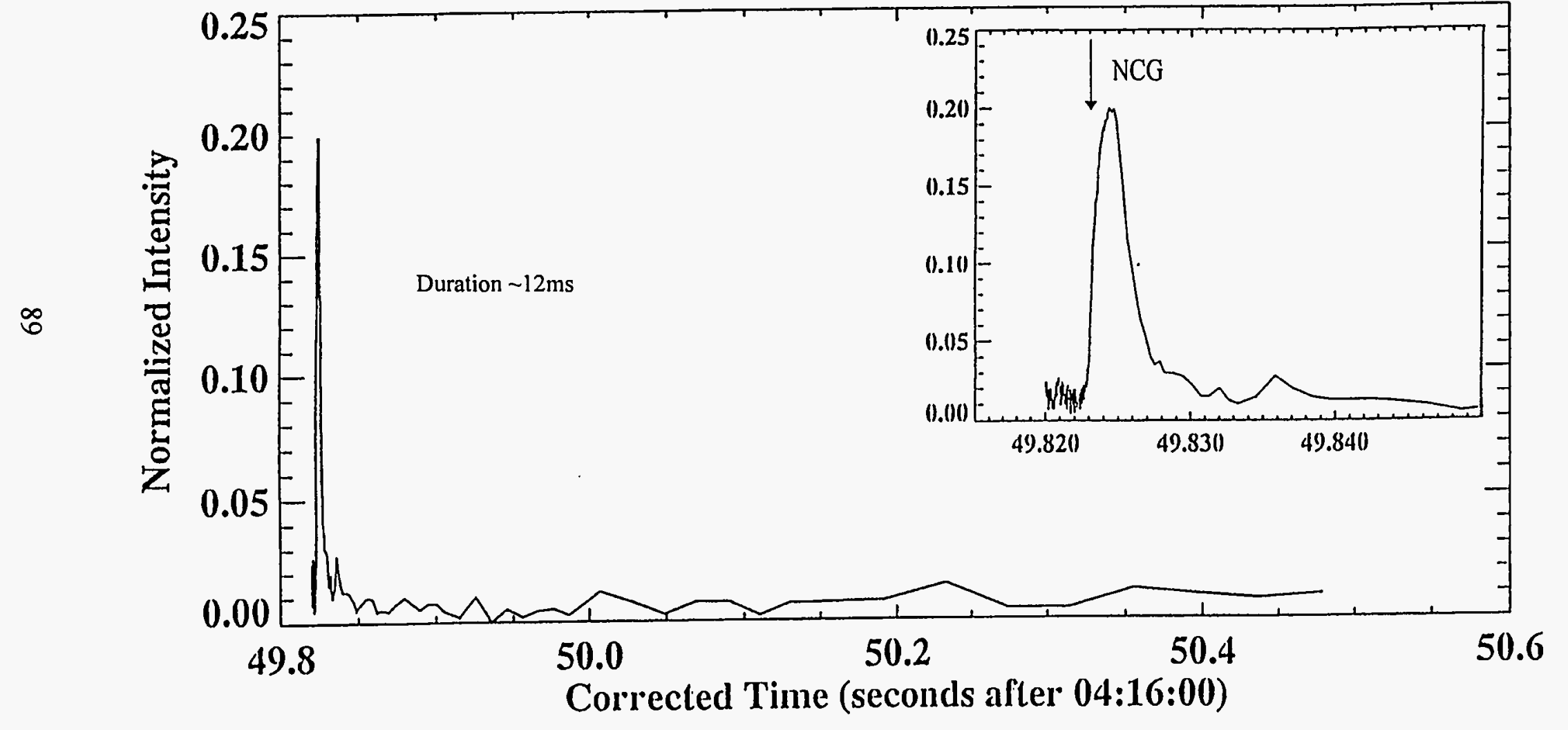

Figure D-43. NLDN NCG: July 16, 1996, 04:16:49.823 Lat. 39.7, Long. $-99.9-26$ kA multiplicity 1 

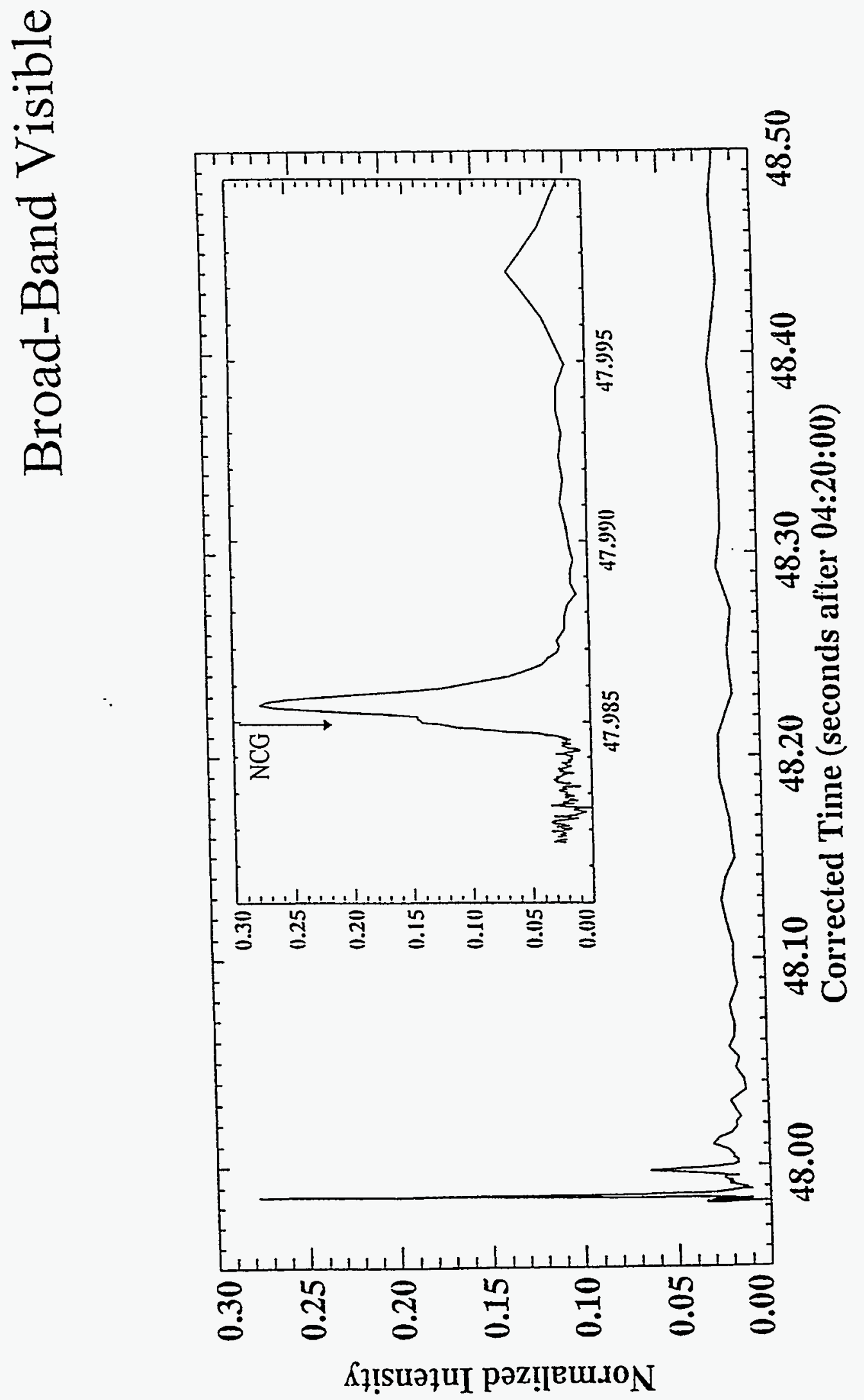

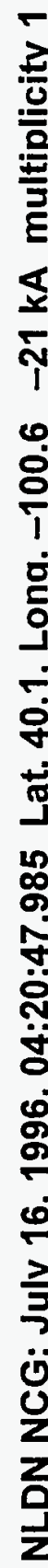

章 
0
0
0
0
0
0
0
0
0
0
0
0
0
0
0

$\sum_{\substack{1 \\ \vdots \\ 0}}^{\substack{0 \\ 0}}$

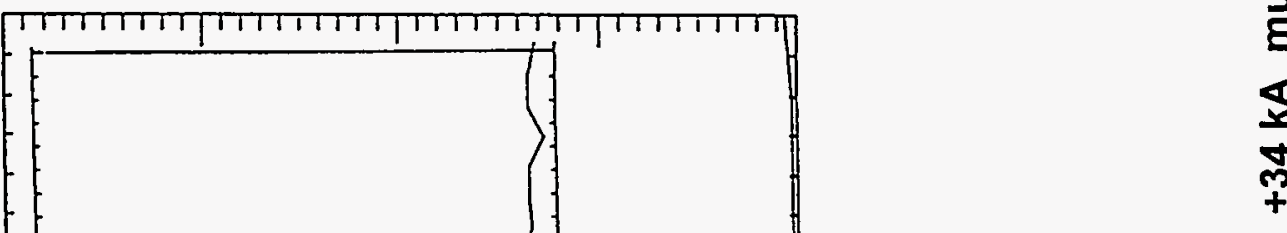

咅

g

임

$\stackrel{0}{0}$

둥

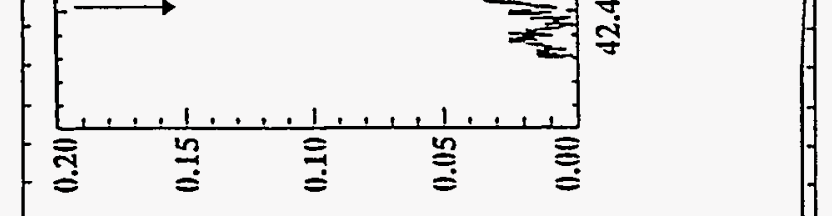

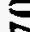

ก

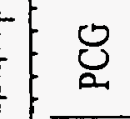

1 쿠

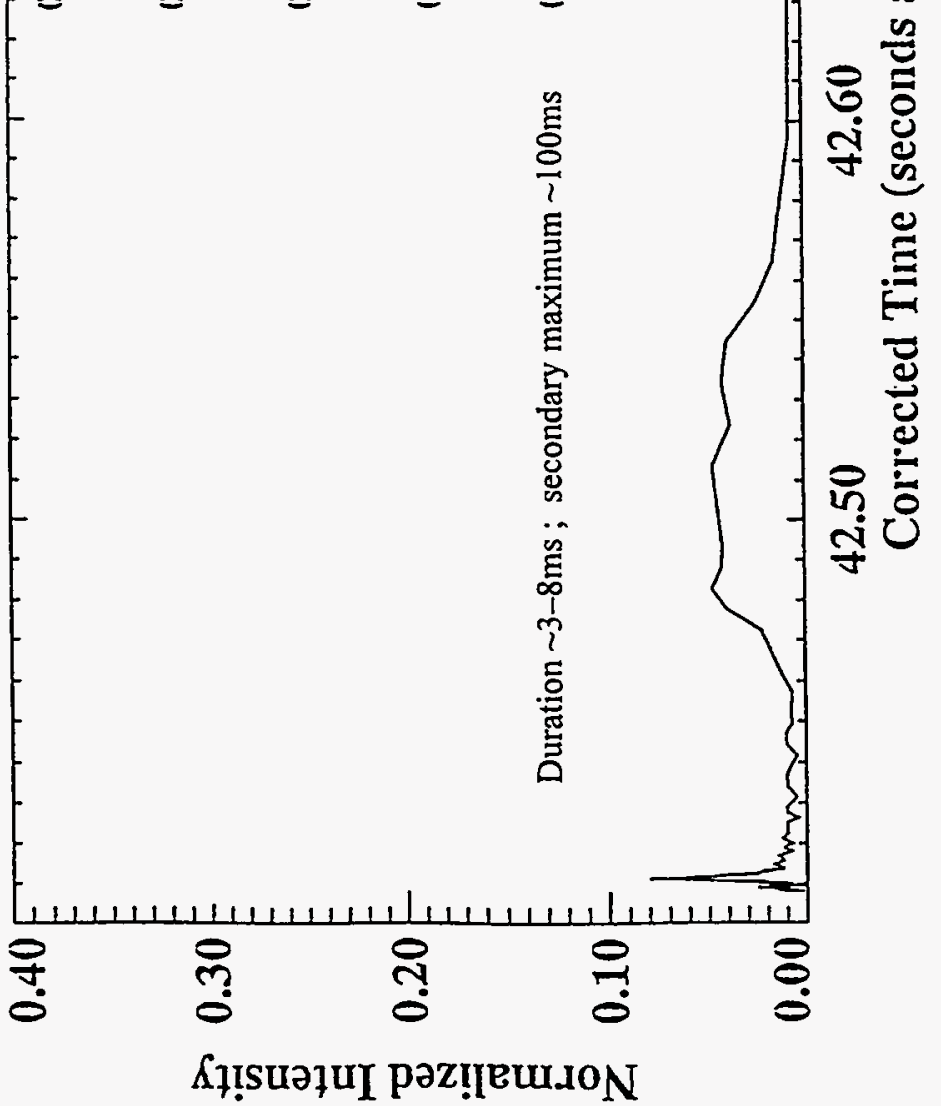

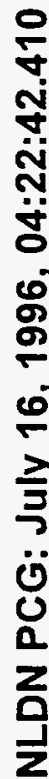

บั

온 


\section{Broad-Band Visible}

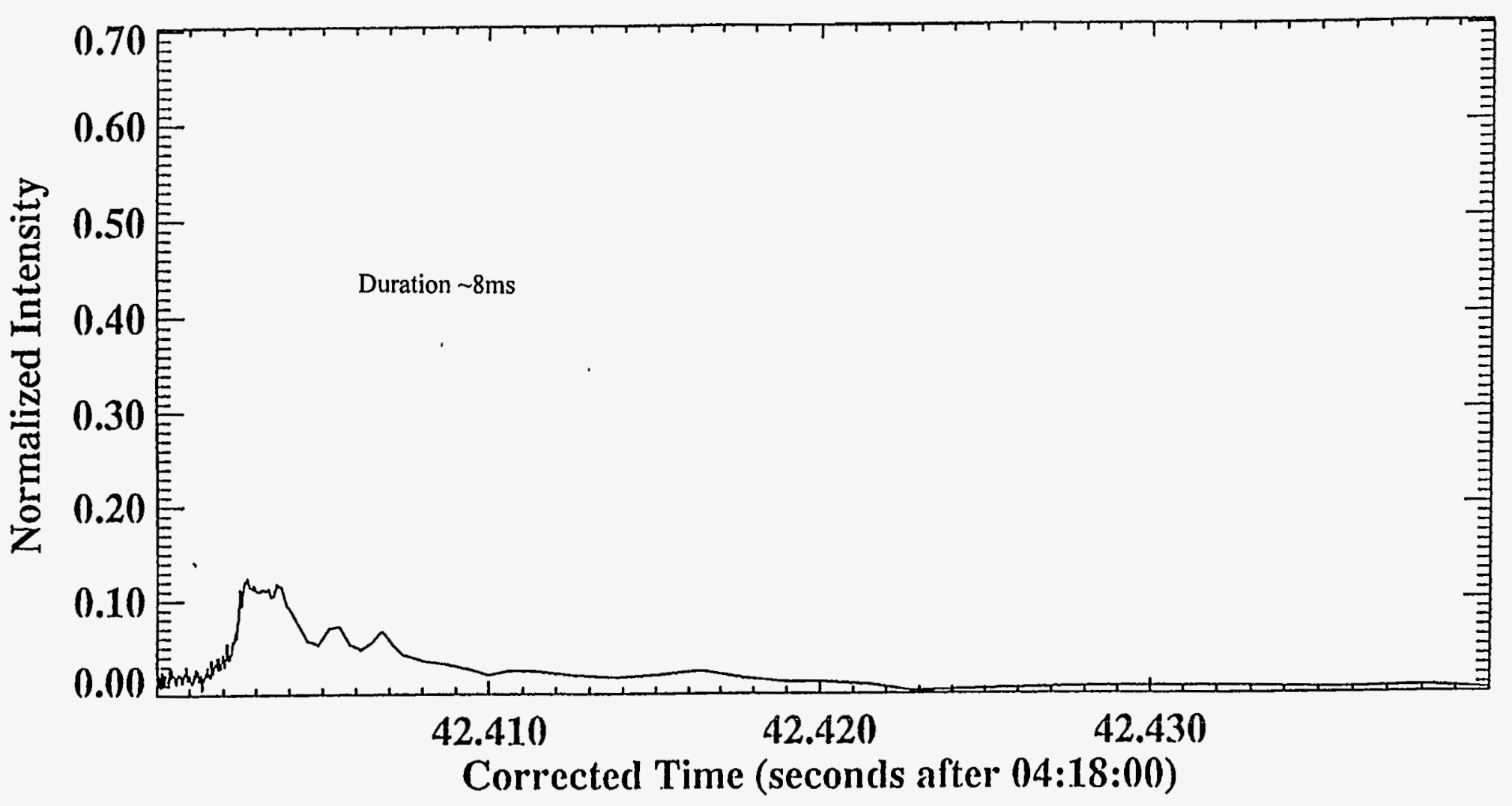

Figure D-46. No NLDN match, July 16, 1996, 04:18:42 


\section{Broad-Band Visible}

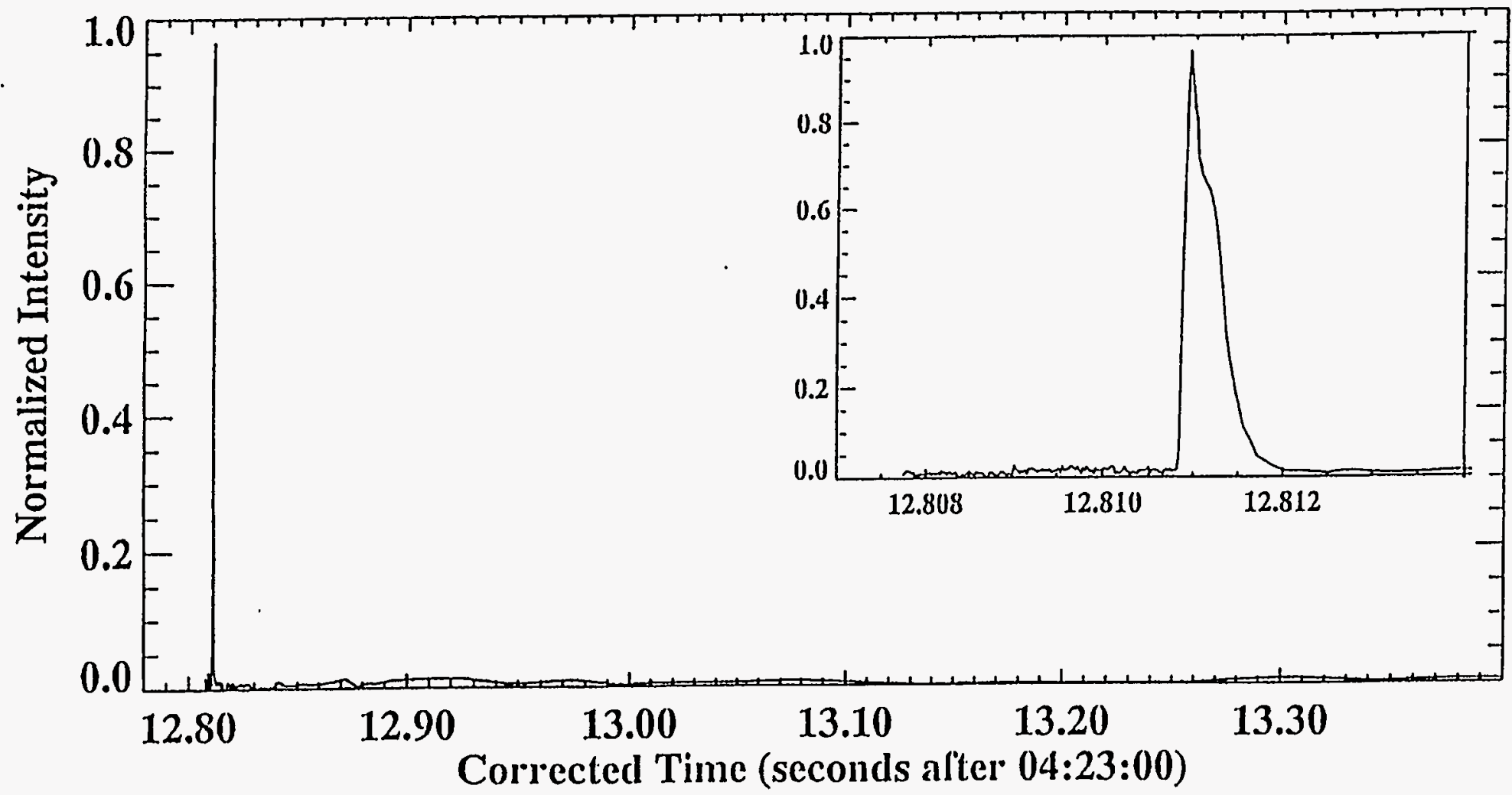

Figure D-47. NLDN NCG: July 16, 1996, 04:23:12.811 Lat. 39.2, Long. -101.4 -25 kA multiplicity 1 


\section{Broad-Band Visible}

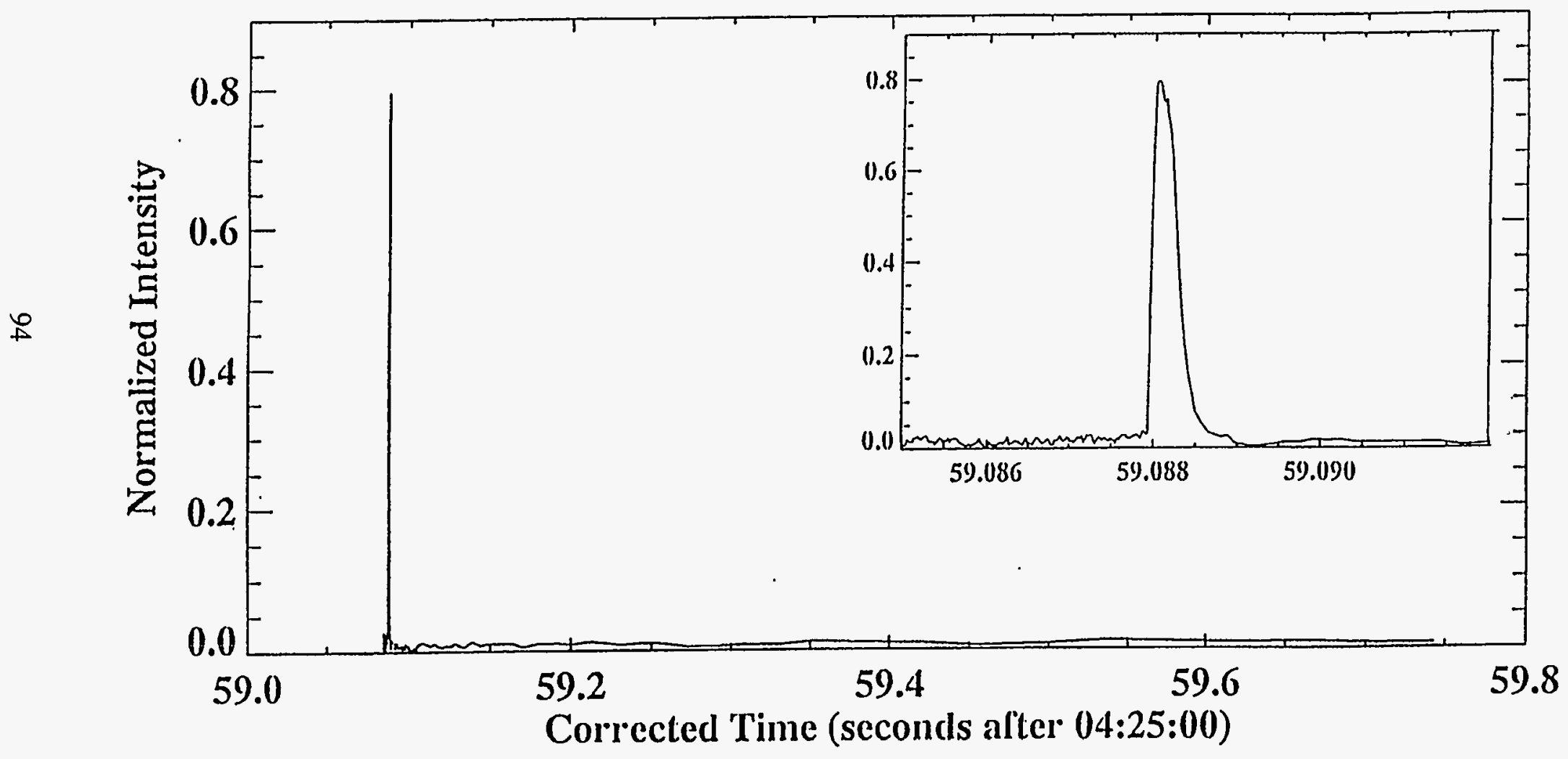

Figure D-48. NLDN NCG: July 16, 1996, 04:25:59.088 Lat. 39.2, Long. $-101.4-22$ kA multiplicity 1 

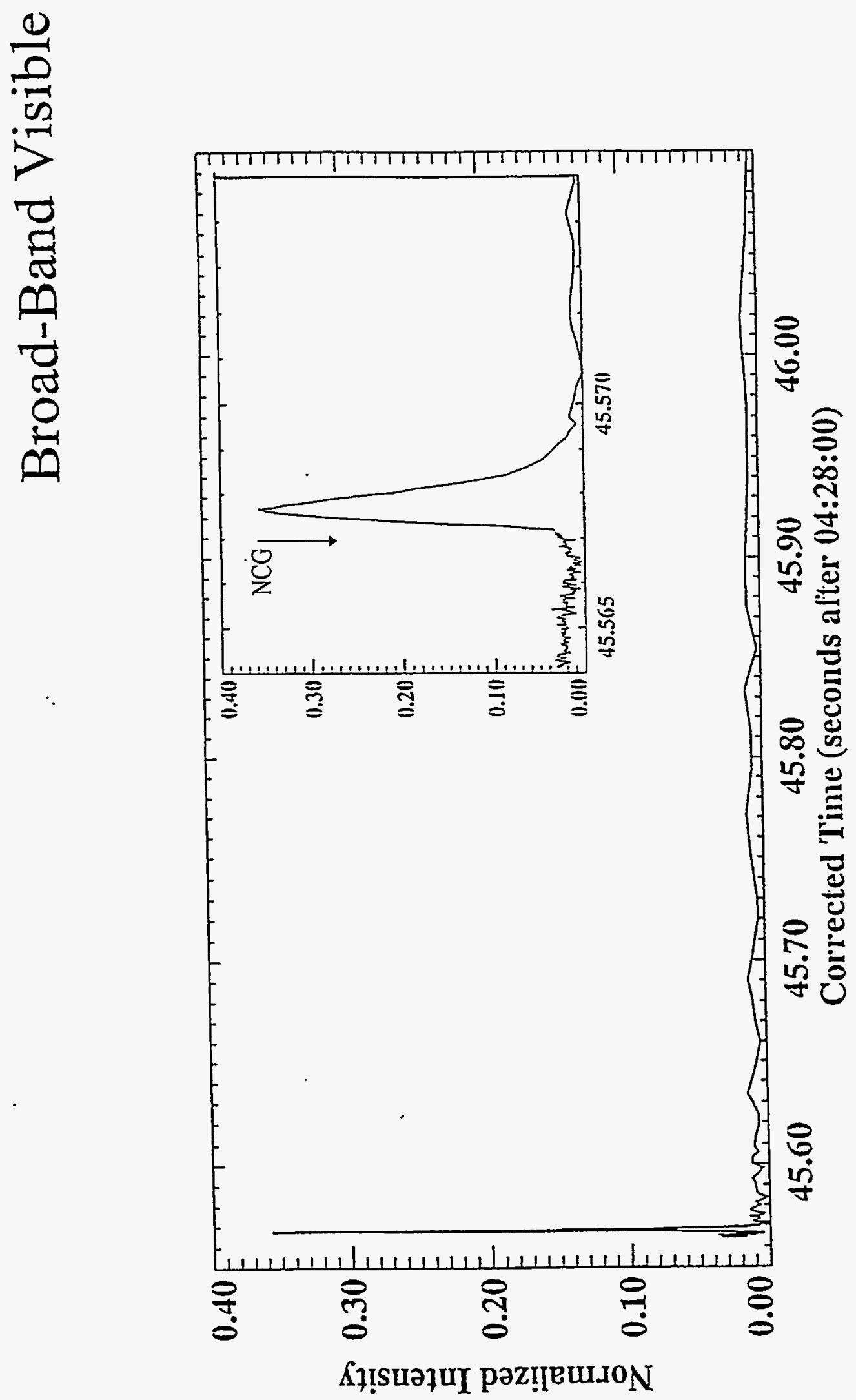

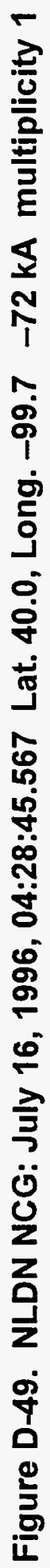




\section{Broad-Band Visible}

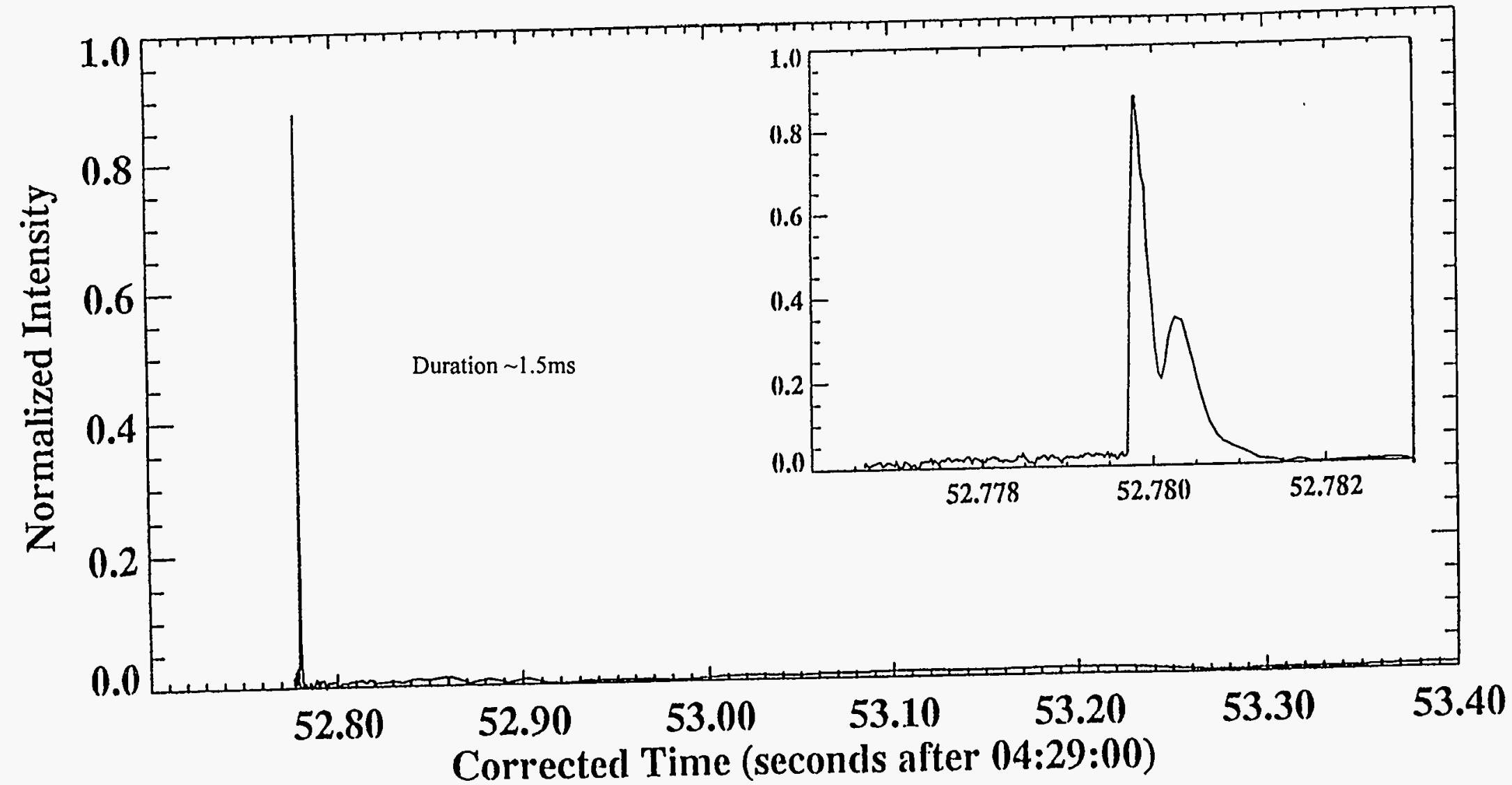

Figure D-50. NLDN NCG: July 16, 1996, 04:29:52.780 Lat. 39.2, Long. $-101.4-17$ kA multiplicity 1 


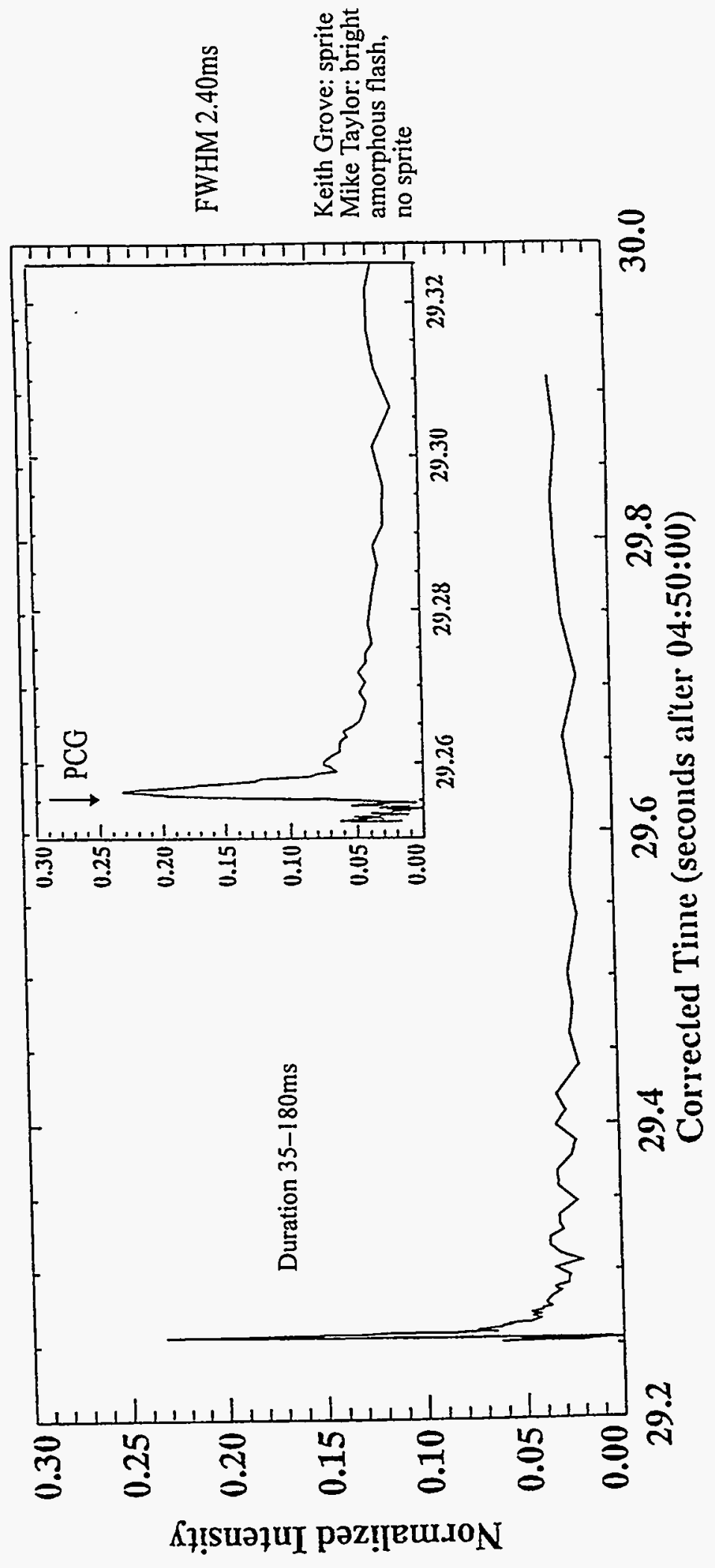

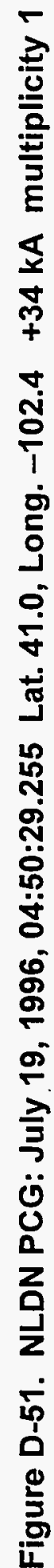




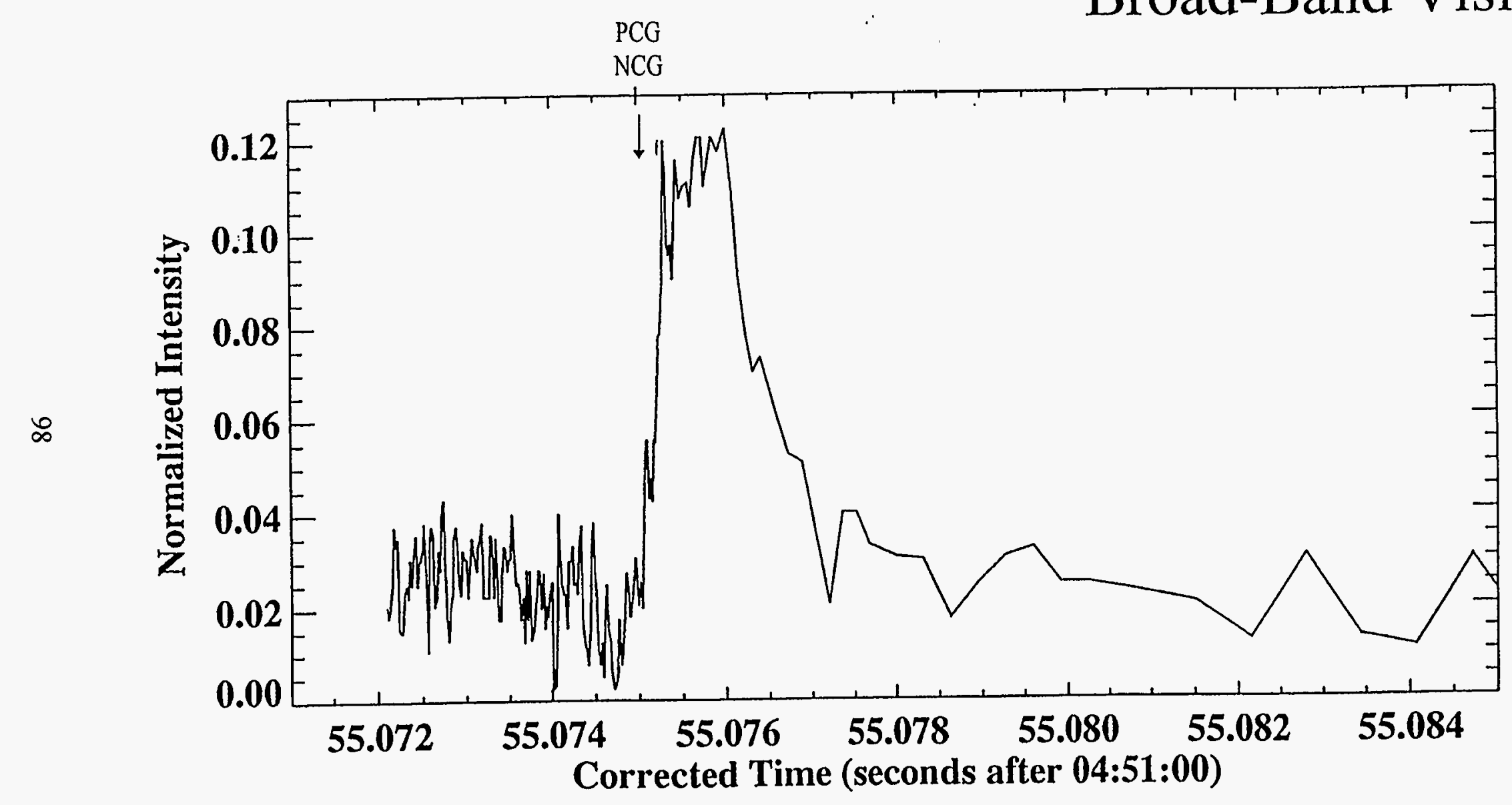

Figure D-52. NLDN PCG: July 19, 1996, 04:51:55.075 Lat. 40.7, Long. -102.4 +57 kA multiplicity 1 NLDN NCG: July 19, 1996, 04:51:55.075 Lat. 40.7, Long. $-102.6-29$ kA multiplicity 1 


\section{Broad-Band Visible}

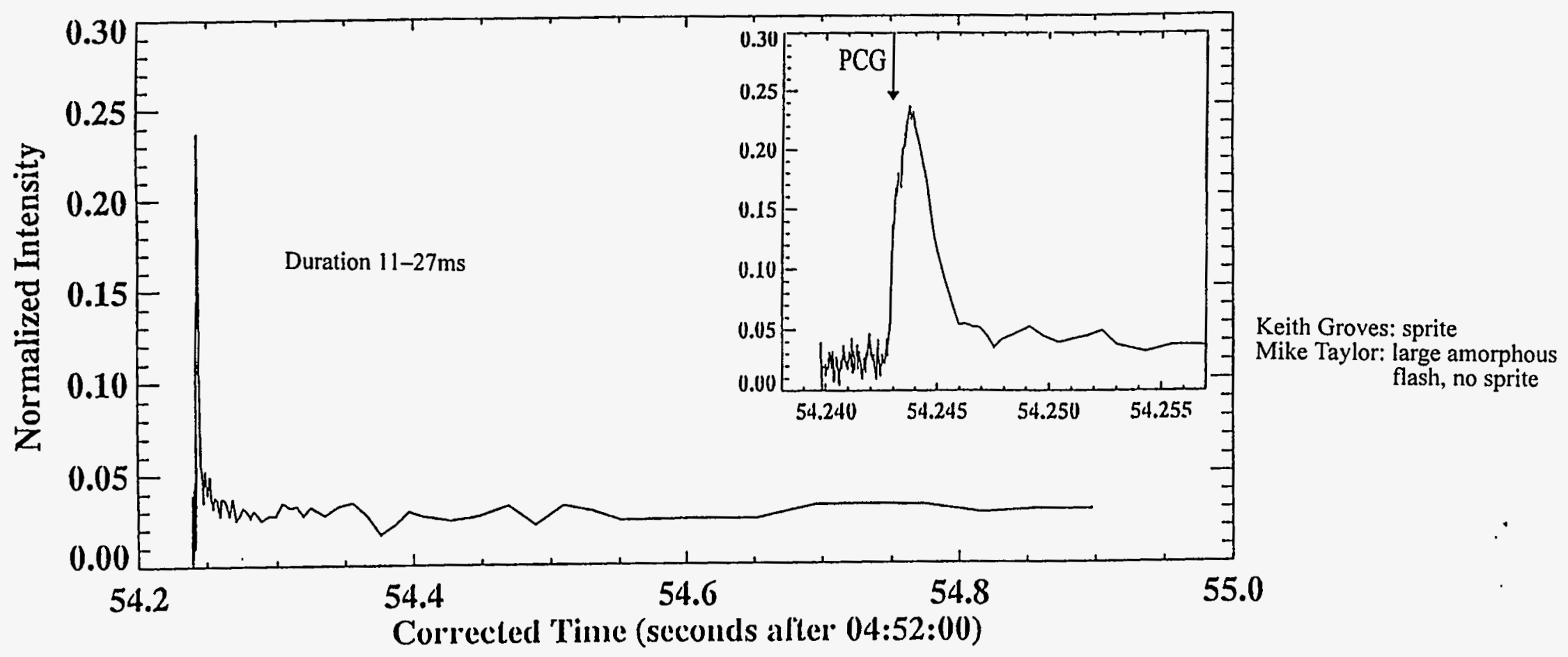

Figure D-53. NLDN PCG: July 19, 1996, 04:52:54.243 Lat. 41.0, Long. -102.4 +46 kA multiplicity 1 


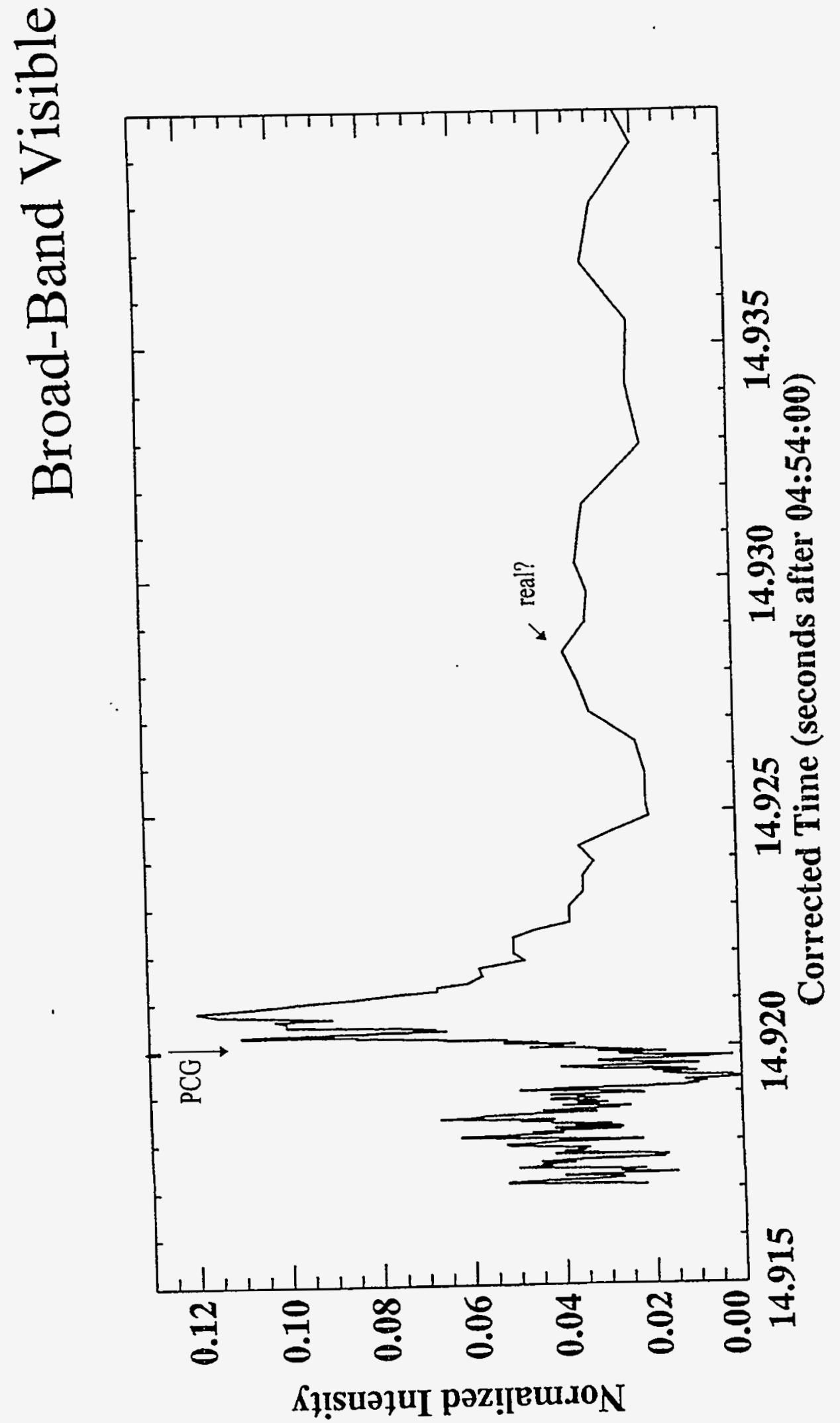

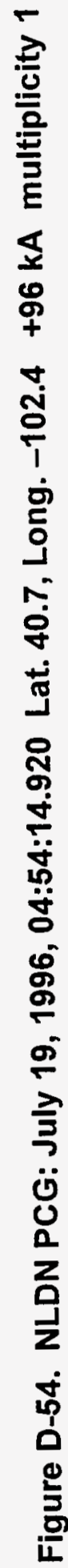




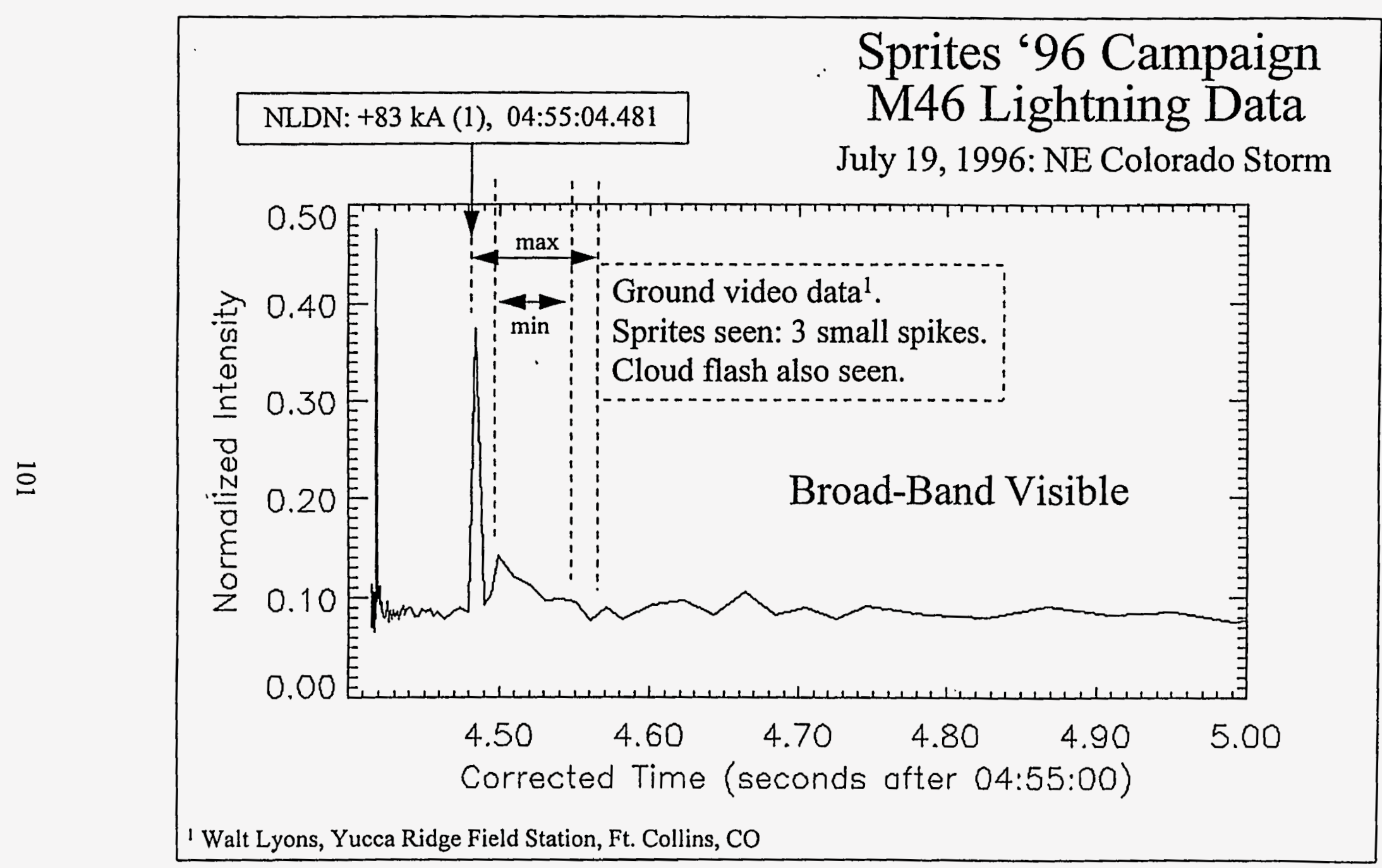

[î. Sandia National Laboratories

Figure D-55. NLDN PCG: July 19, 1996, 04:55:04.481 +83 kA multiplicity 1 


\section{Broad-Band Visible}

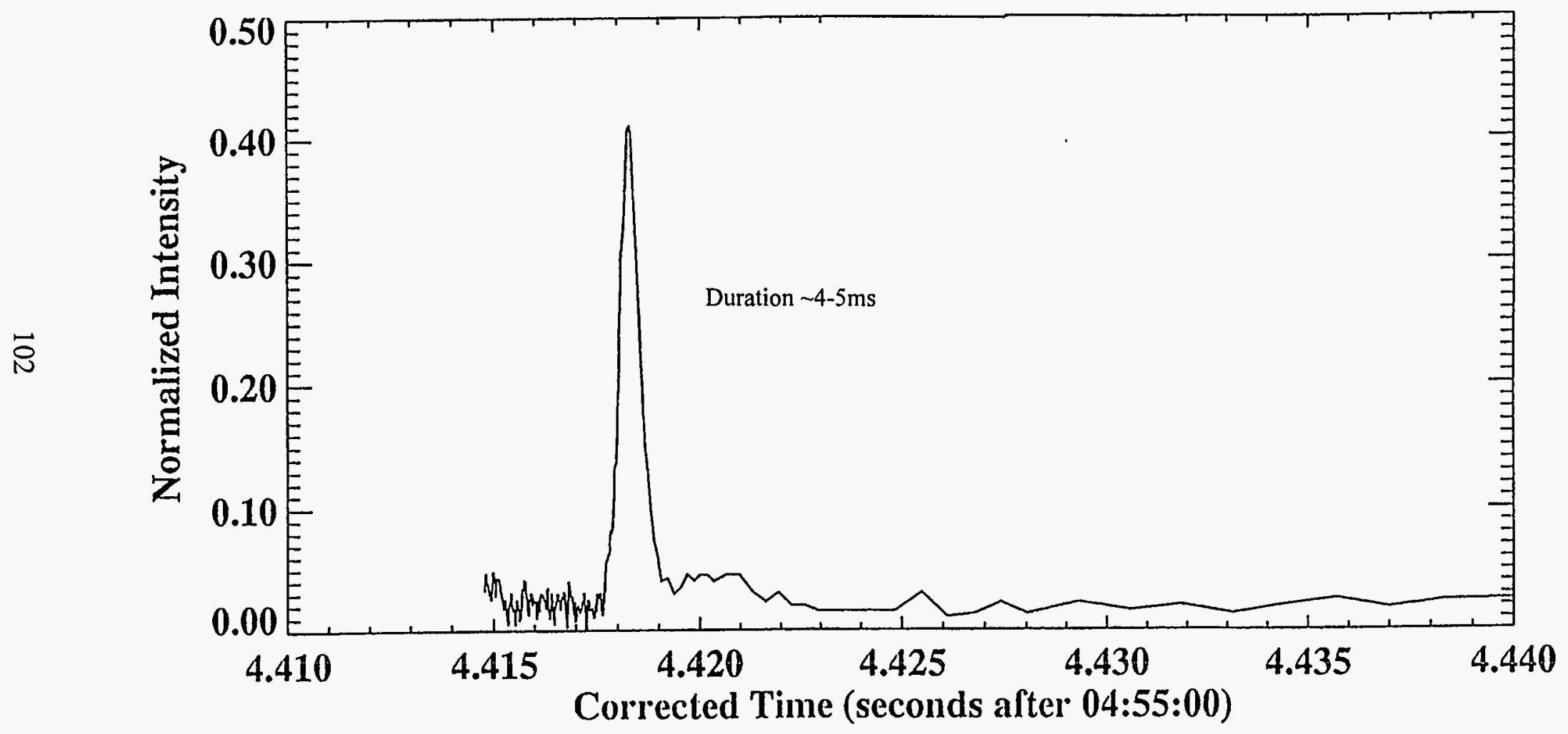

Figure D-56. Signal Prior to PCG: July 19, 1996, 04:55:04 


\section{Broad-Band Visible}

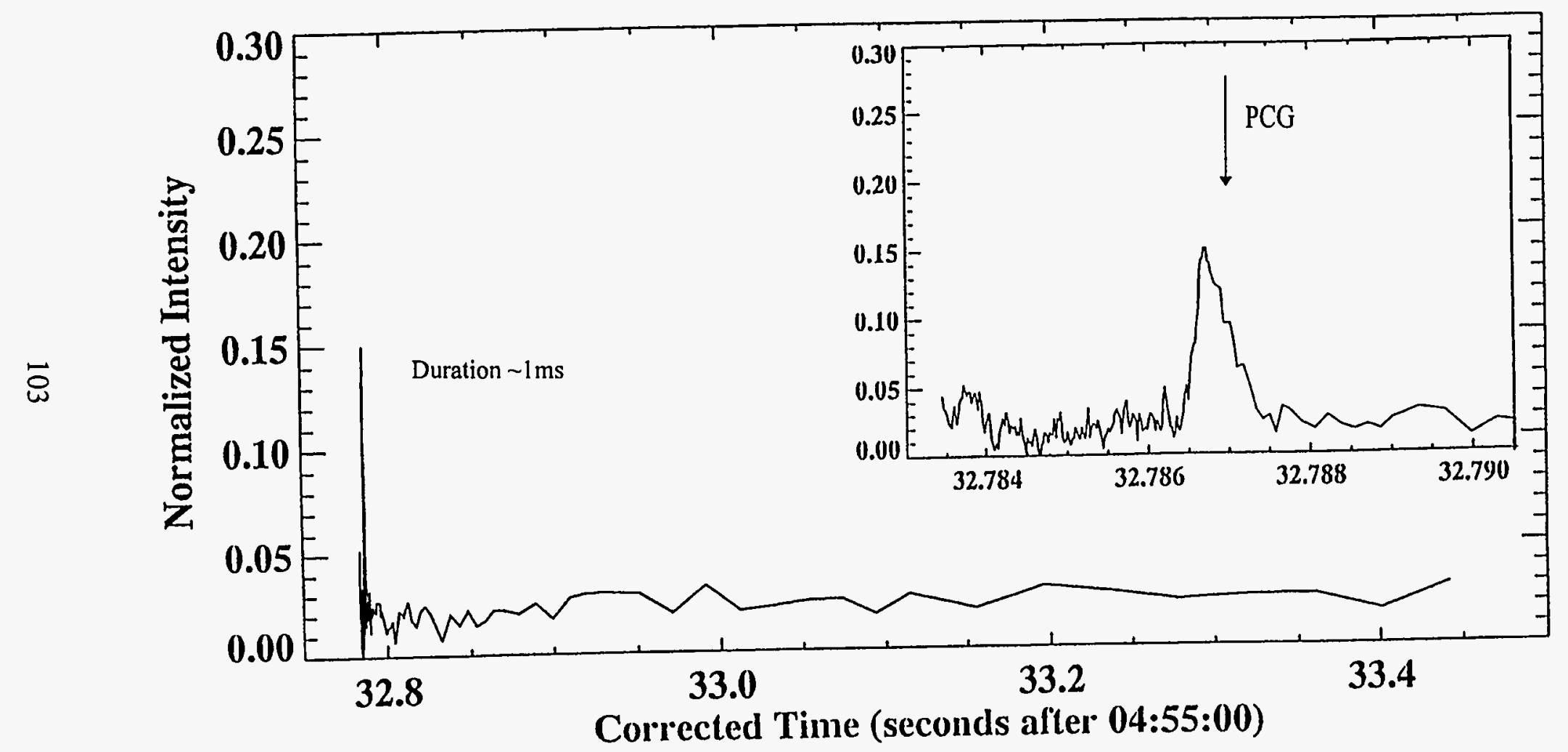

Figure D-57. NLDN PCG: July 19, 1996, 04:55:32.787 Lat. 40.5, Long. -102.4 +57 kA multiplicity 1 


\section{Broad-Band Visible}

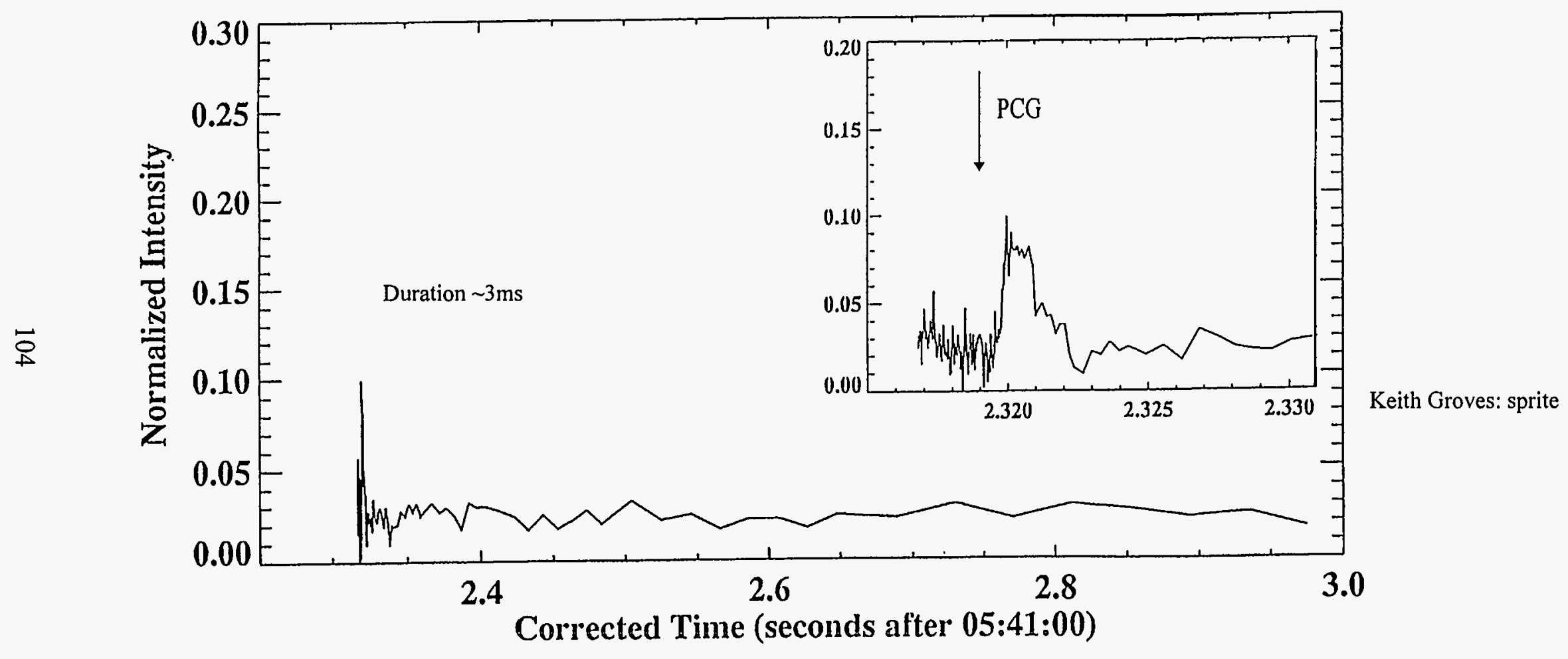

Figure D-58. NLDN PCG: July 19, 1996, 05:41:102.319 Lat. 40.9, Long. -102.2 +40 kA multiplicity 1 


\section{Broad-Band Visible}

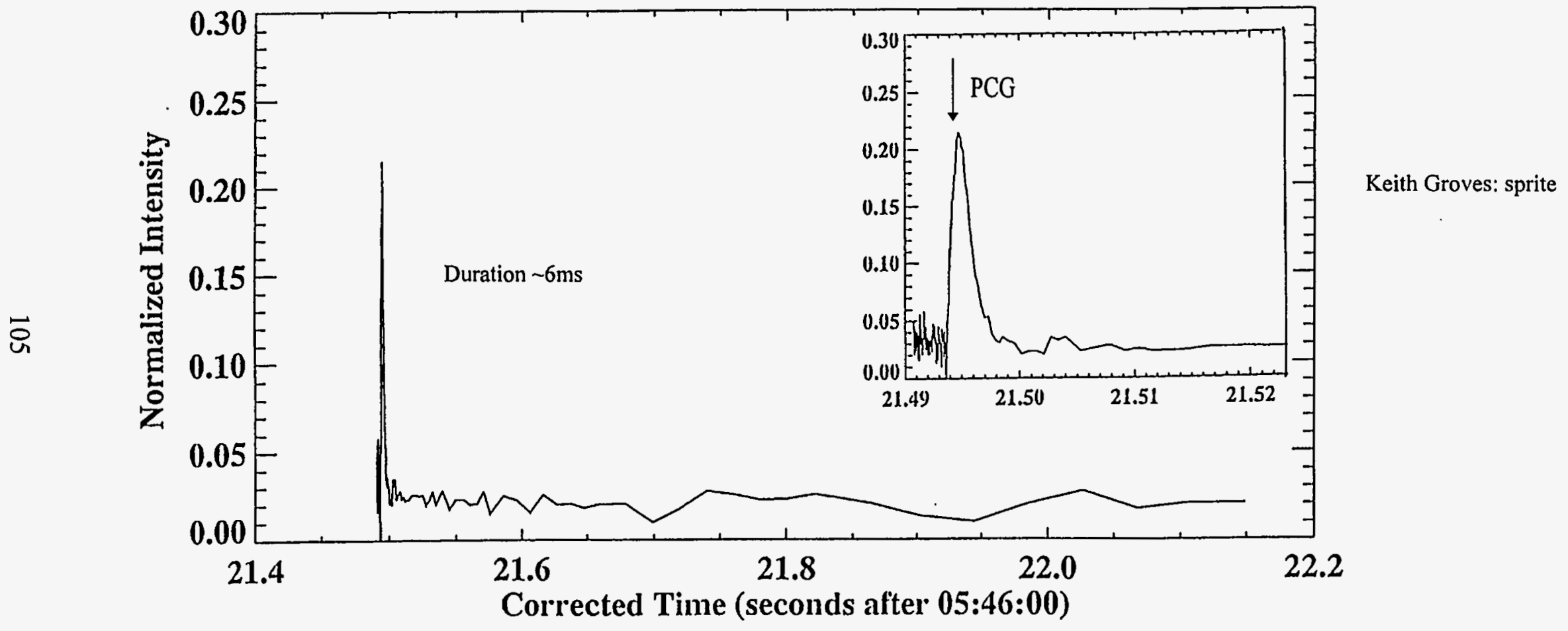

Figure D-59. NLDN PCG; July 19, 1996, 05:46:21.494 Lat. 40.8, Long. -101.8 +106 kA multiplicity 1 


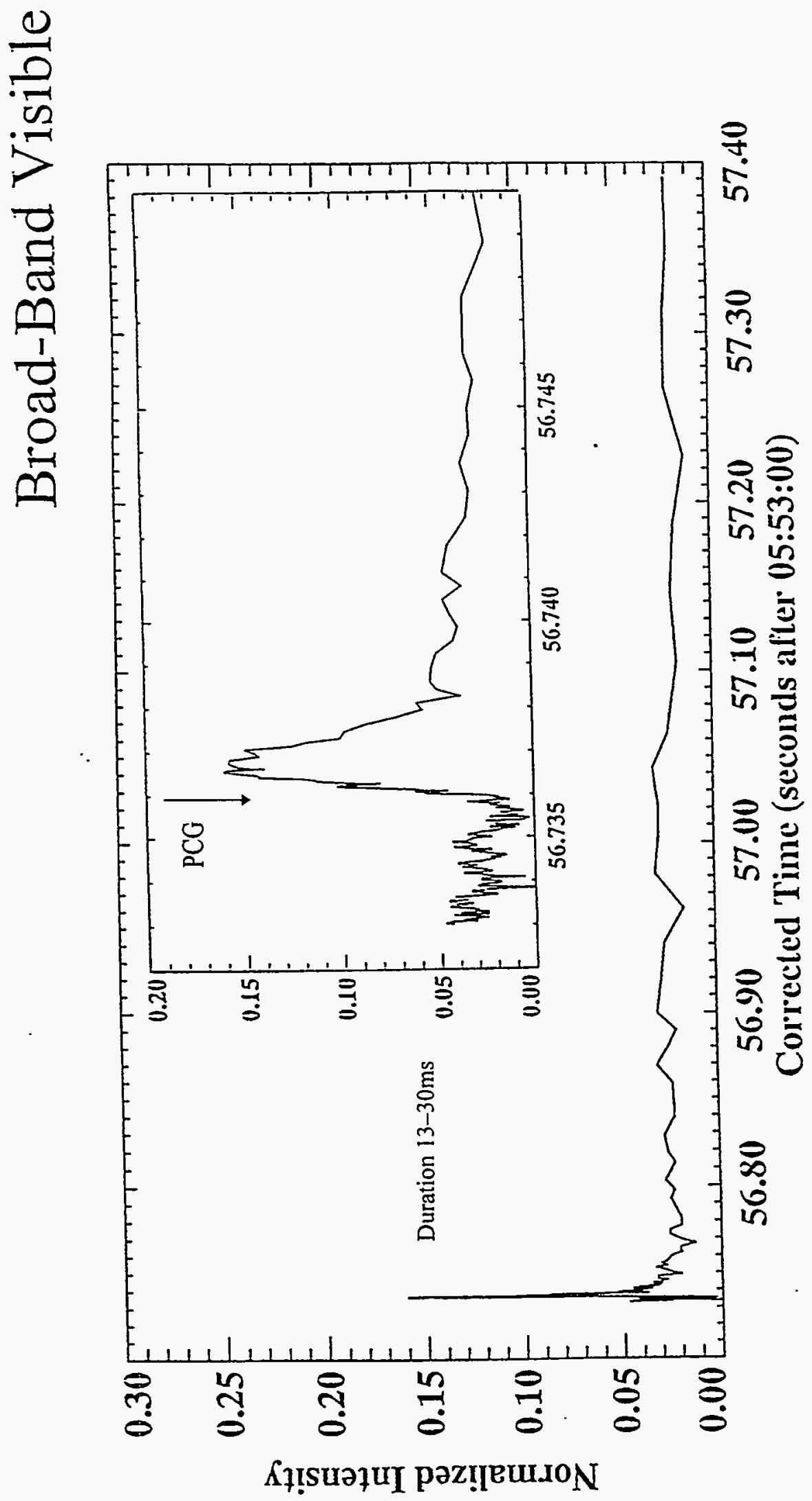

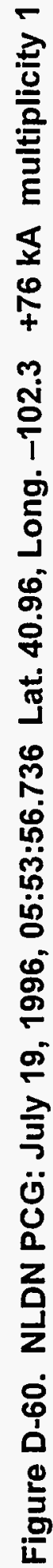




\section{Summer Sprites '96 Campaign M46 Lightning Data}

July 19, 1996: NE Colorado Storm
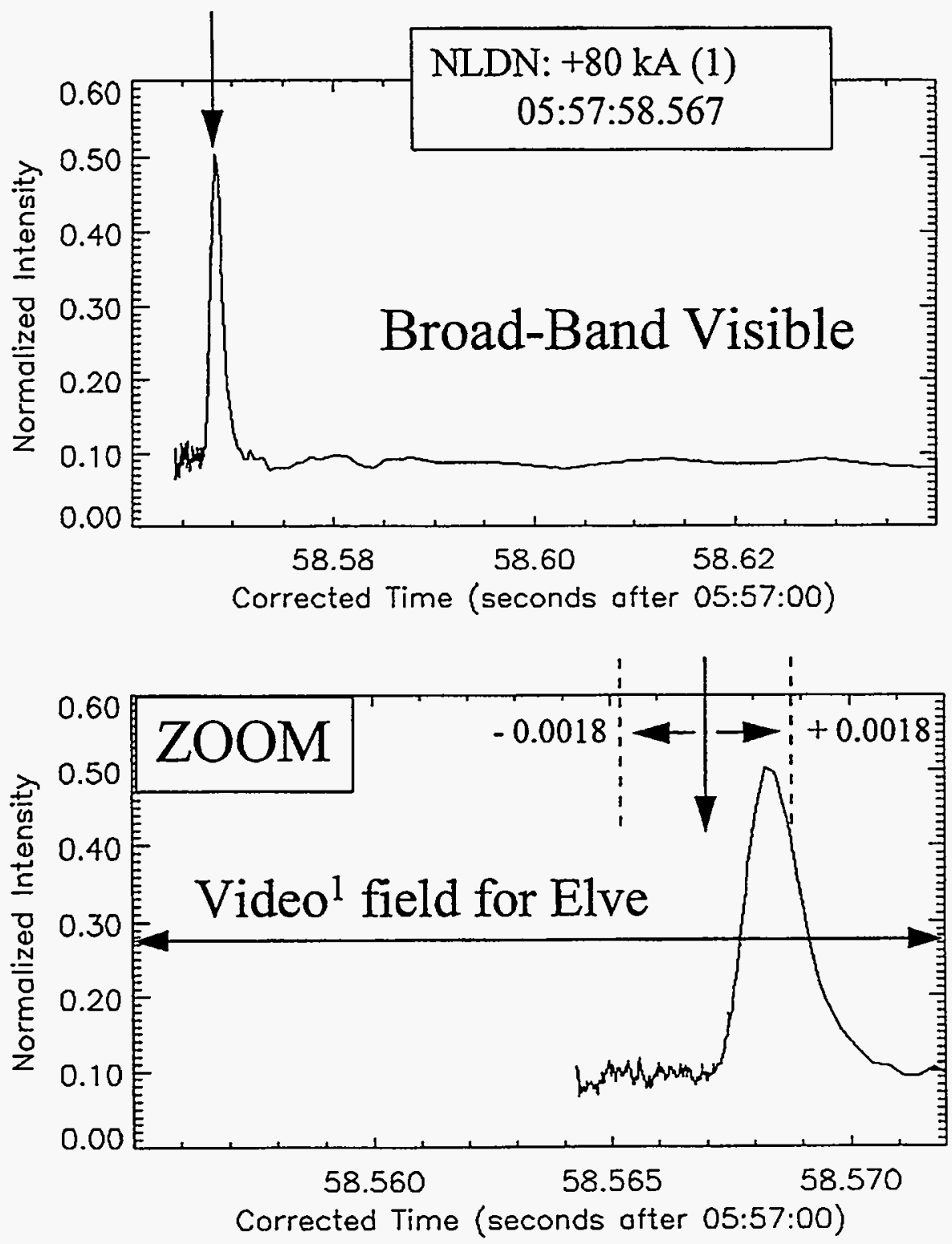

1 Walt Lyons, Yucca Ridge Field Station, Ft. Collins, CO

[1ㄱ Sandia National Laboratories

Figure 61. NLDN PCG: July 19, 1996, 05:57:58.567, +80 kA, multiplicity 1 

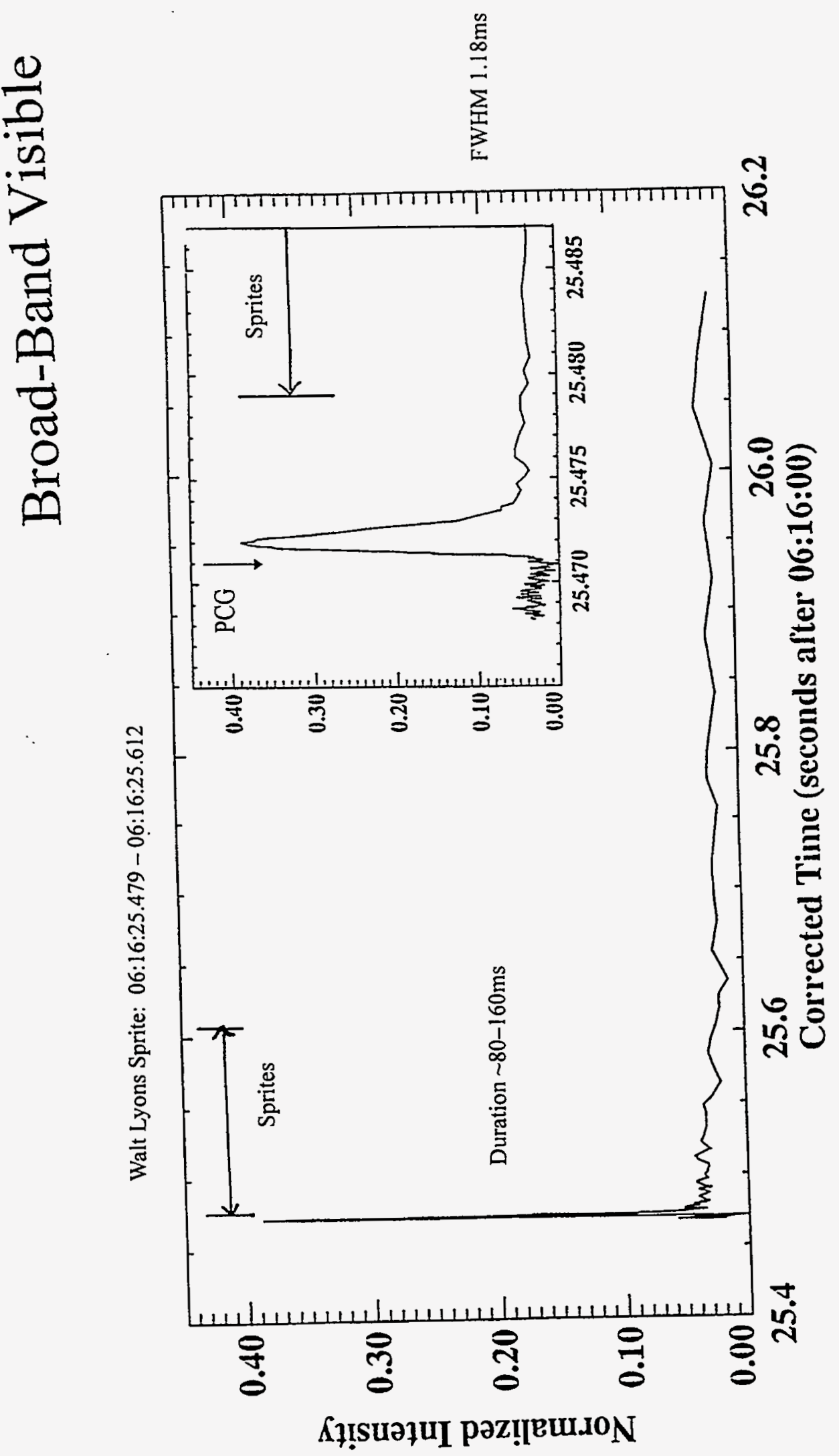

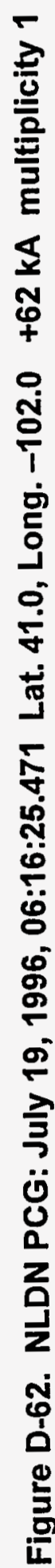


Sprites '96 Campaign M46 Lightning Data July 19, 1996: NE Colorado Storm

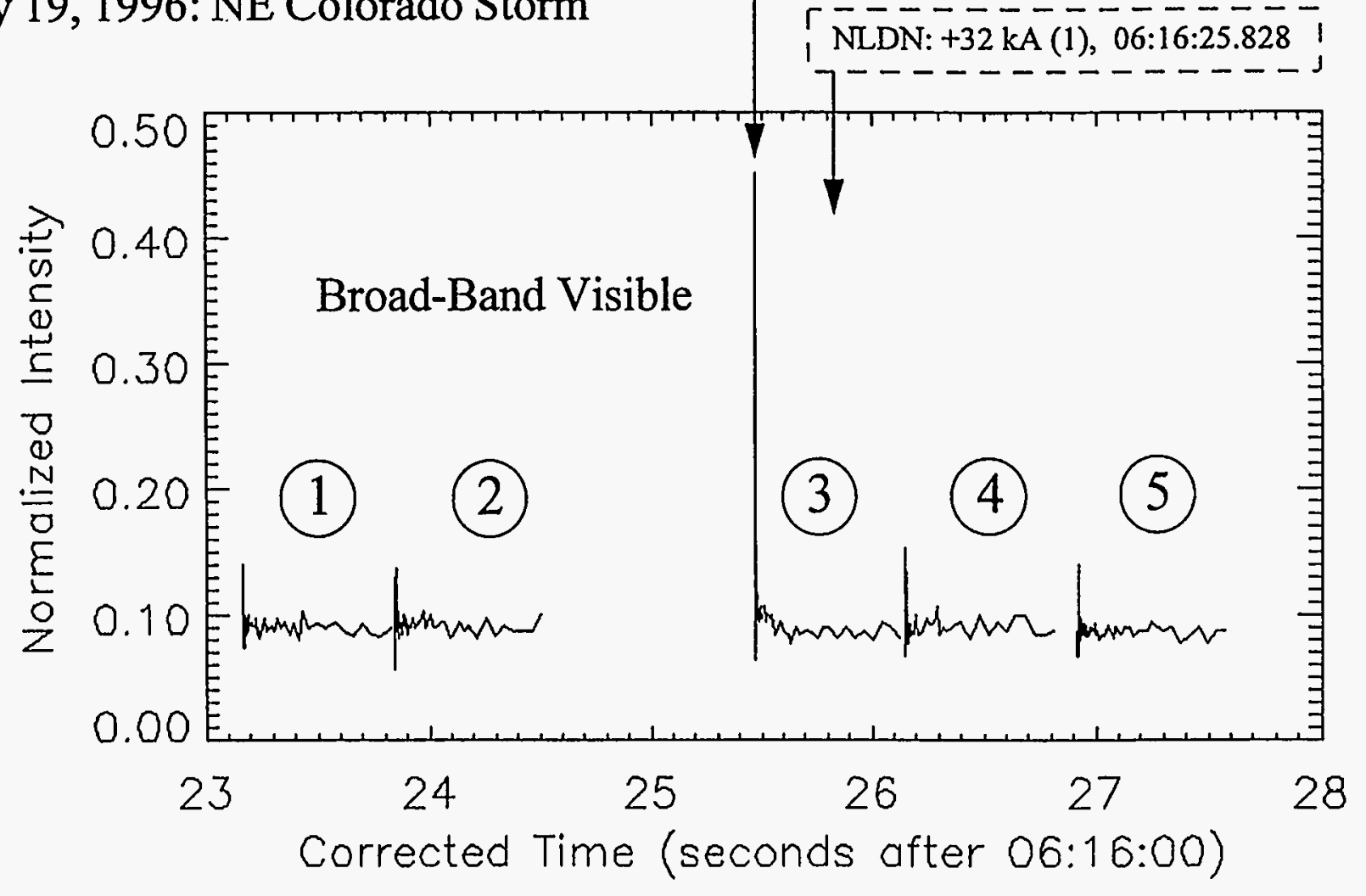

团 Sandia National Laboratories

Figure D-63. Events around NLDN PCG: July 19, 1996, 06:16:25.471 +62 kA multiplicity 1 


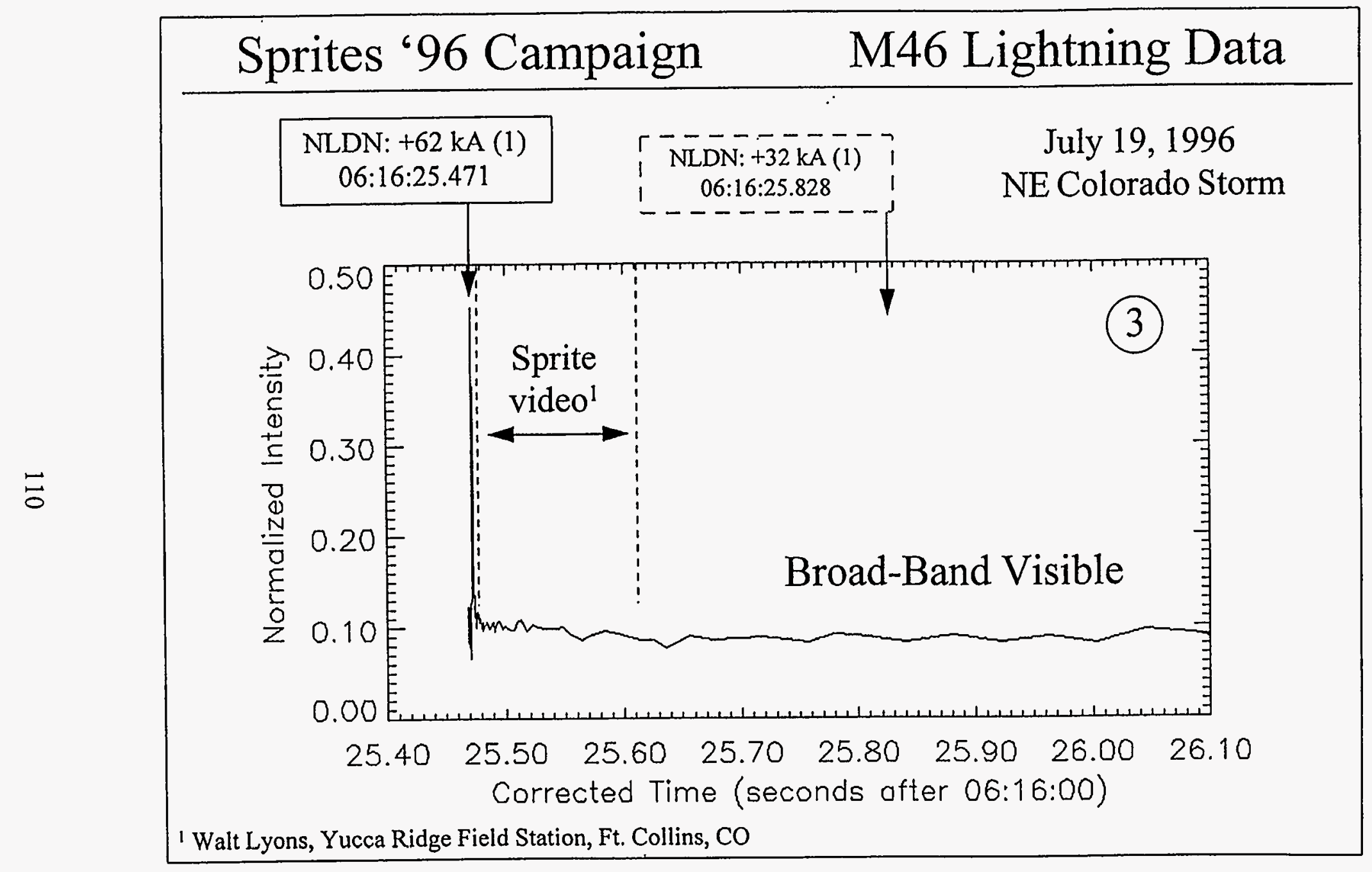

fî Sandia National Laboratories

Figure D-64. NLDN PCG: July 19, 1996, 06:16:25.471 +62 kA multiplicity 1 
Sprites '96 Campaign: M46 Lightning Data

July 19, 1996: NE Colorado Storm

Comparison to Walt Lyons' Video Data

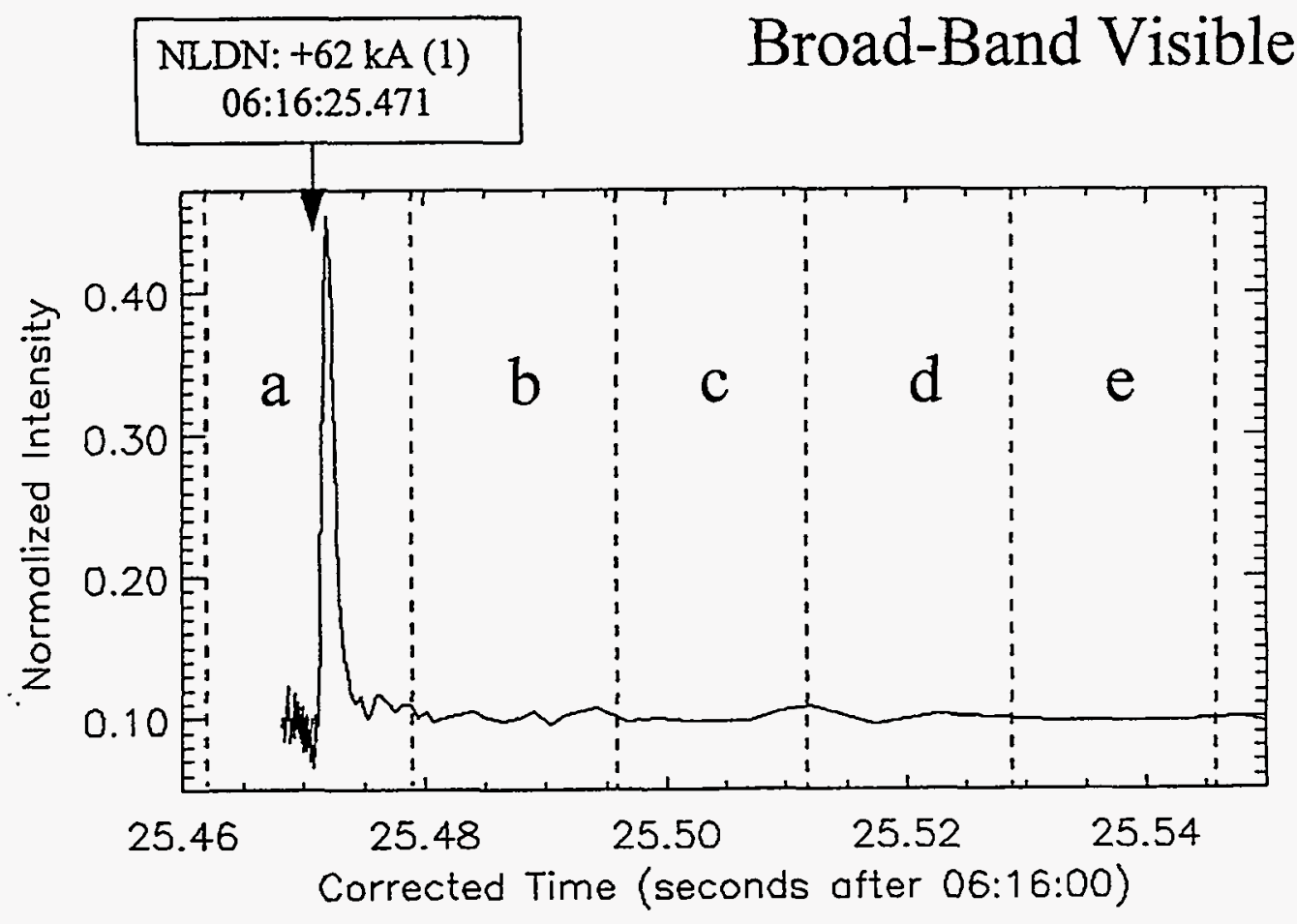

Walt Lyons' video description:

(a) 25.462-.479: CF gets brighter (+ NLDN PCG)

(b) 25.479-.496: C-sprite appears, CF slightly dimmer

(c) 25.496-.512: C-sprite brighter, CF brighter

(d) 25.512-.529: Bright carrot sprite, C-sprites dim, CF bright

(e) 25.529-.546: All features dim slightly

司 Sandia National Laboratories

Figure 65. Linear Intensity Comparison to Walt Lyon's Data: July 19, 1996, 06:16:25.471 
Sprites '96 Campaign: M46 Lightning Data

July 19, 1996: NE Colorado Storm

Comparison to Walt Lyons' Video Data

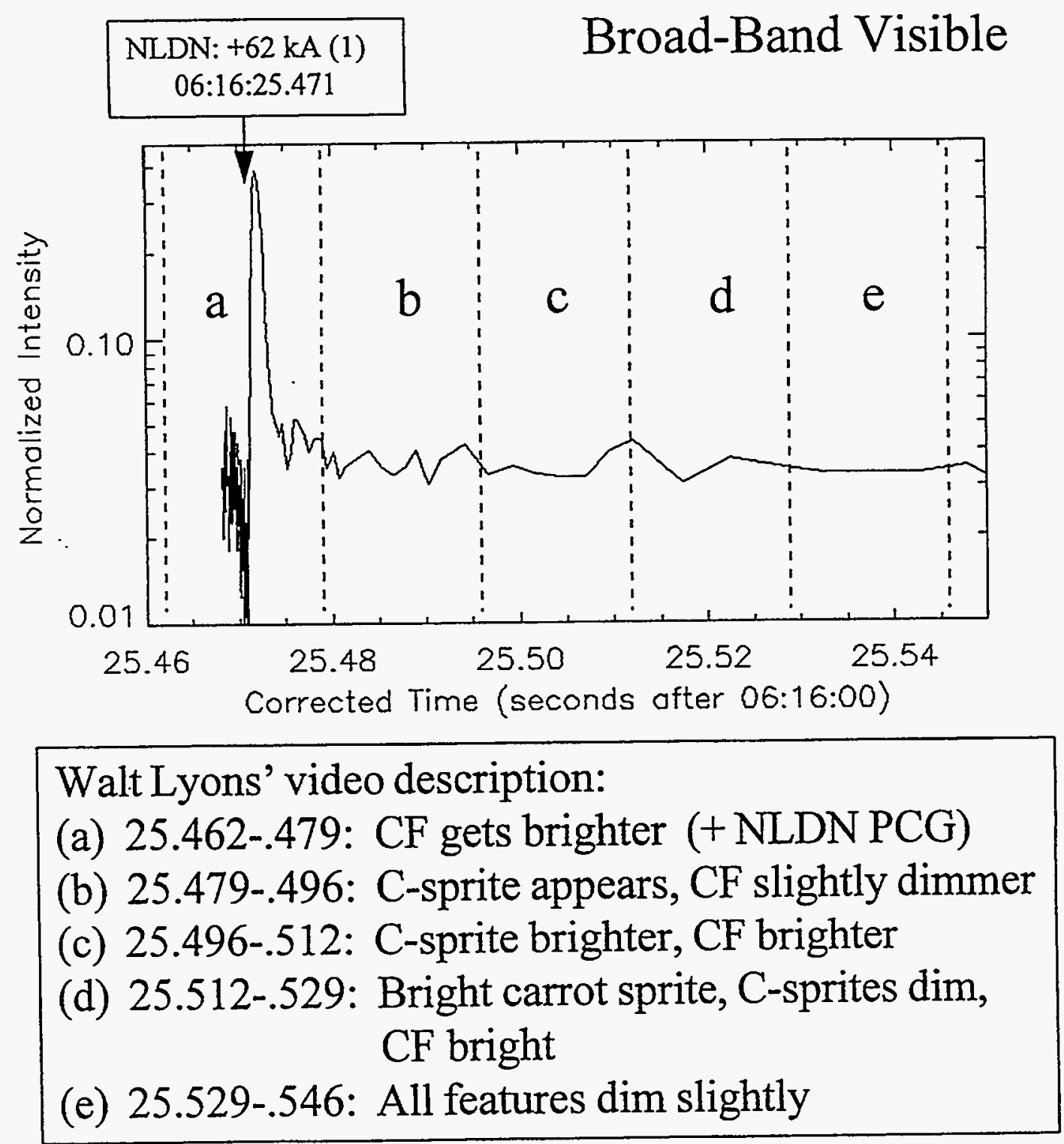

[17 Sandia National Laboratories

Figure 66. Logarithmic Intensity Comparison to Walt Lyon's Data: July 19, 1996, 06:16:25.471 

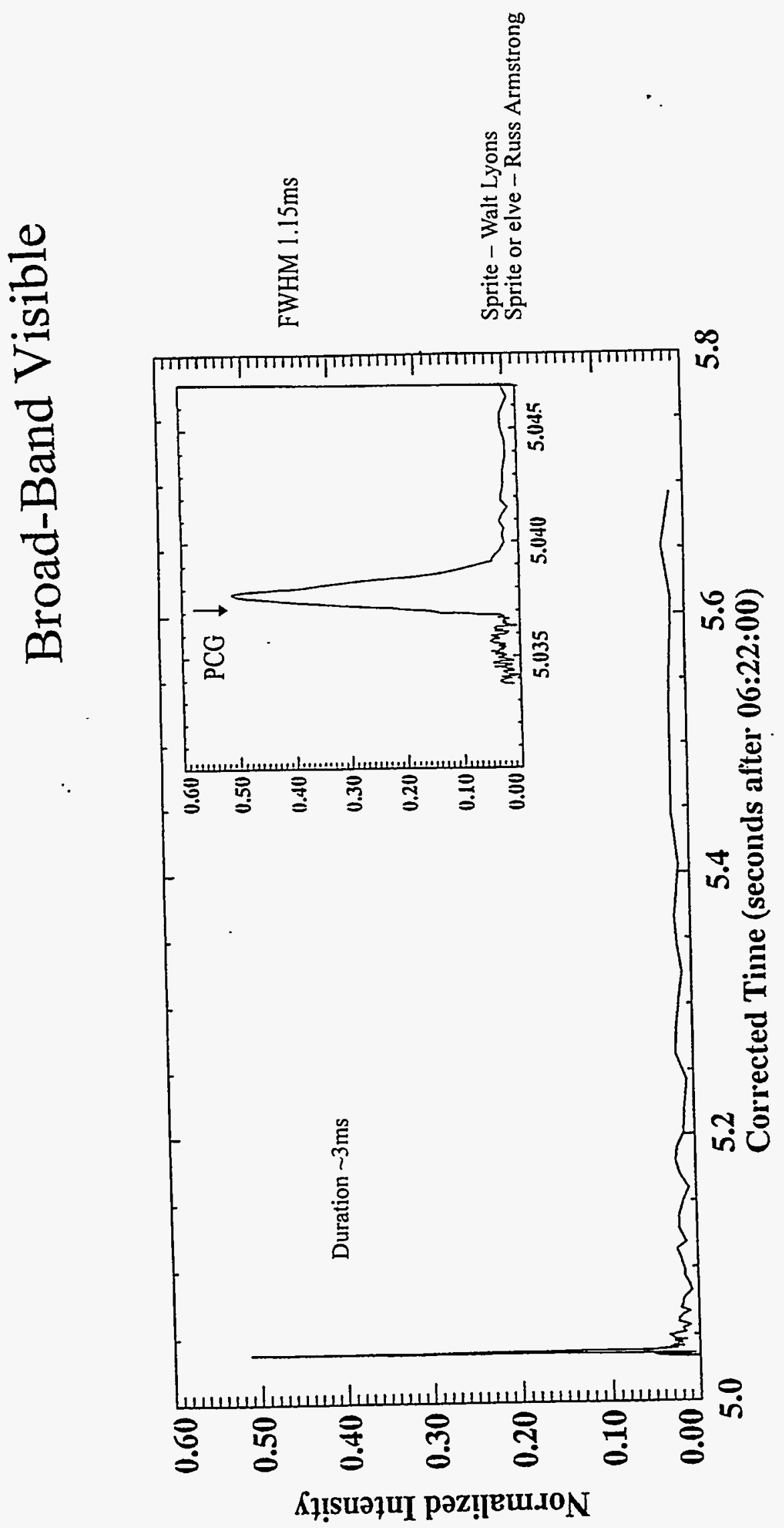

$\frac{2}{\frac{2}{2}}$

$\$$

농

훔

응

$\infty$

\&

范

ตั

4

ํํำ

$\ddot{\circ}$

5

\%

$\sigma$

$\frac{5}{3}$

$\ddot{8}$

0

곰

ํ. 


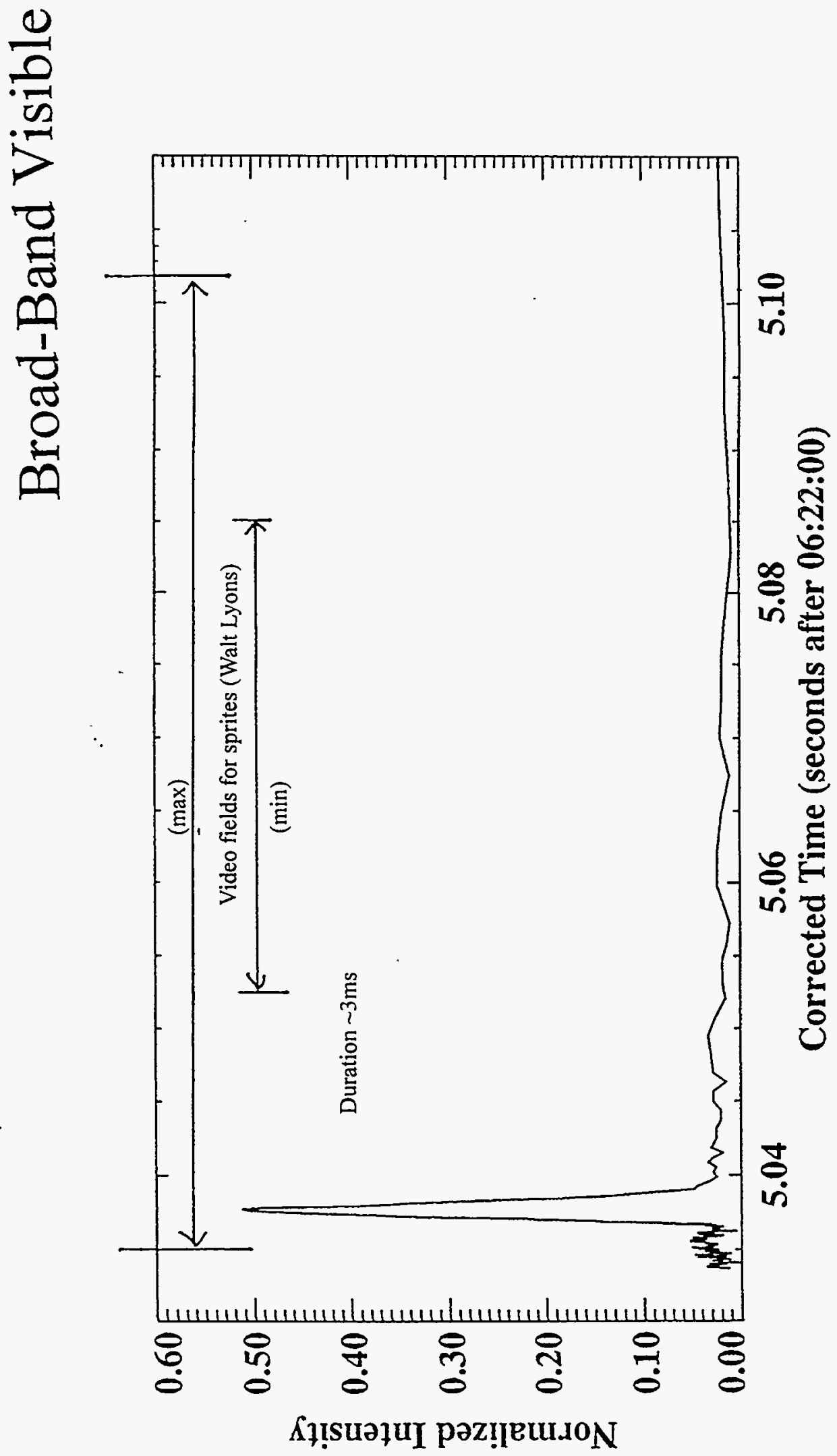

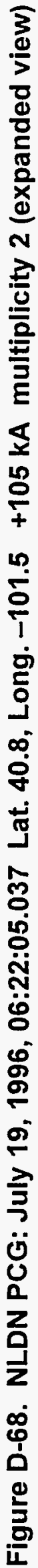




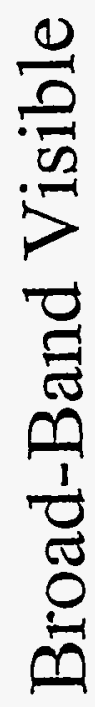

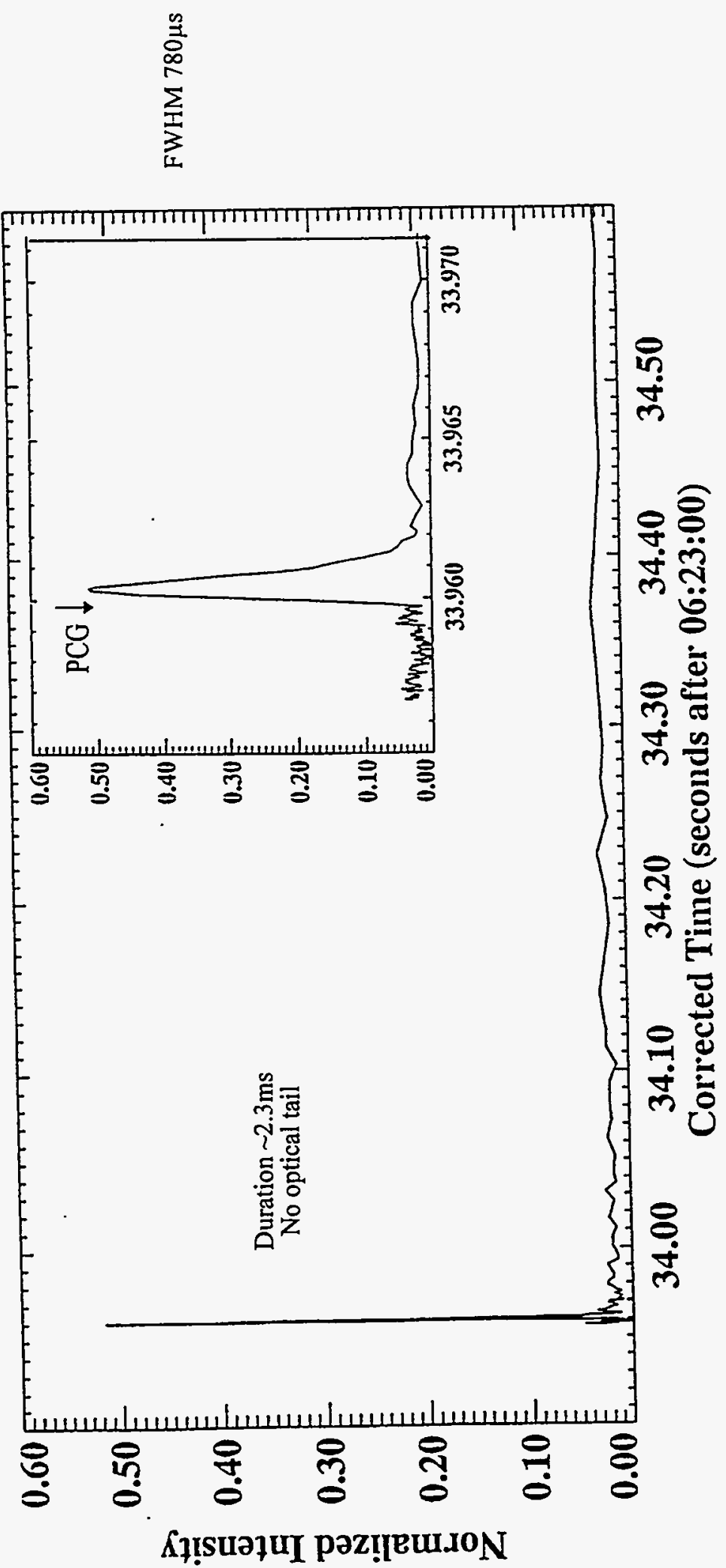

흘

$\frac{5}{9}$

$\frac{10}{3}$

뭉

تُ

8

ตे

m

$\ddot{m}$

$\ddot{\circ}$

क

\%

क

$\frac{7}{5}$

0

0

를

ஜீ

옥 


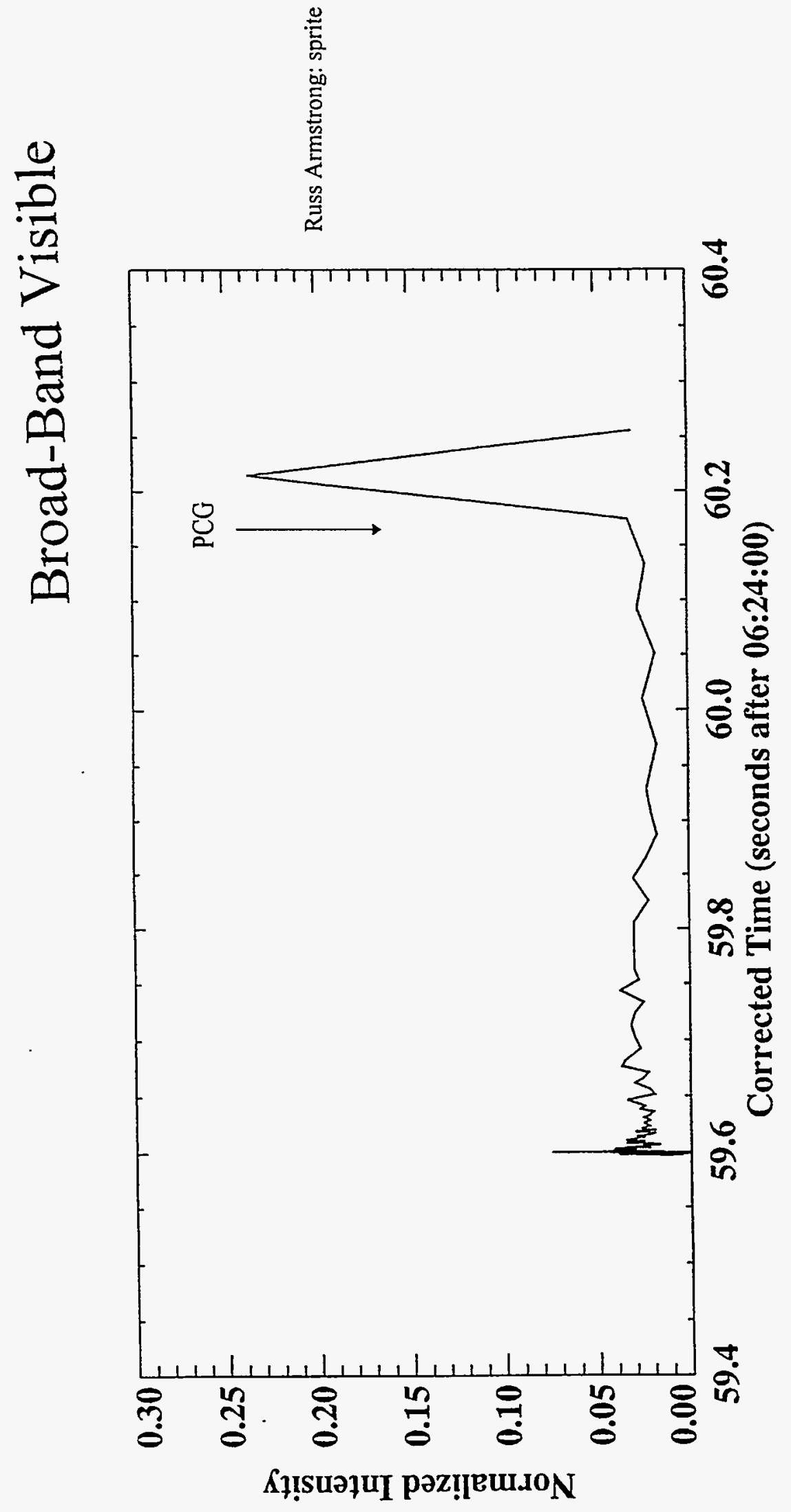

를

$\frac{5}{7}$

훙

ฮ̊

$m$

F

ํํ

in

ஜ̊

\%

\%

$\stackrel{2}{2}$

$\frac{2}{3}$

$\ddot{8}$

Q

2

ำ

는 

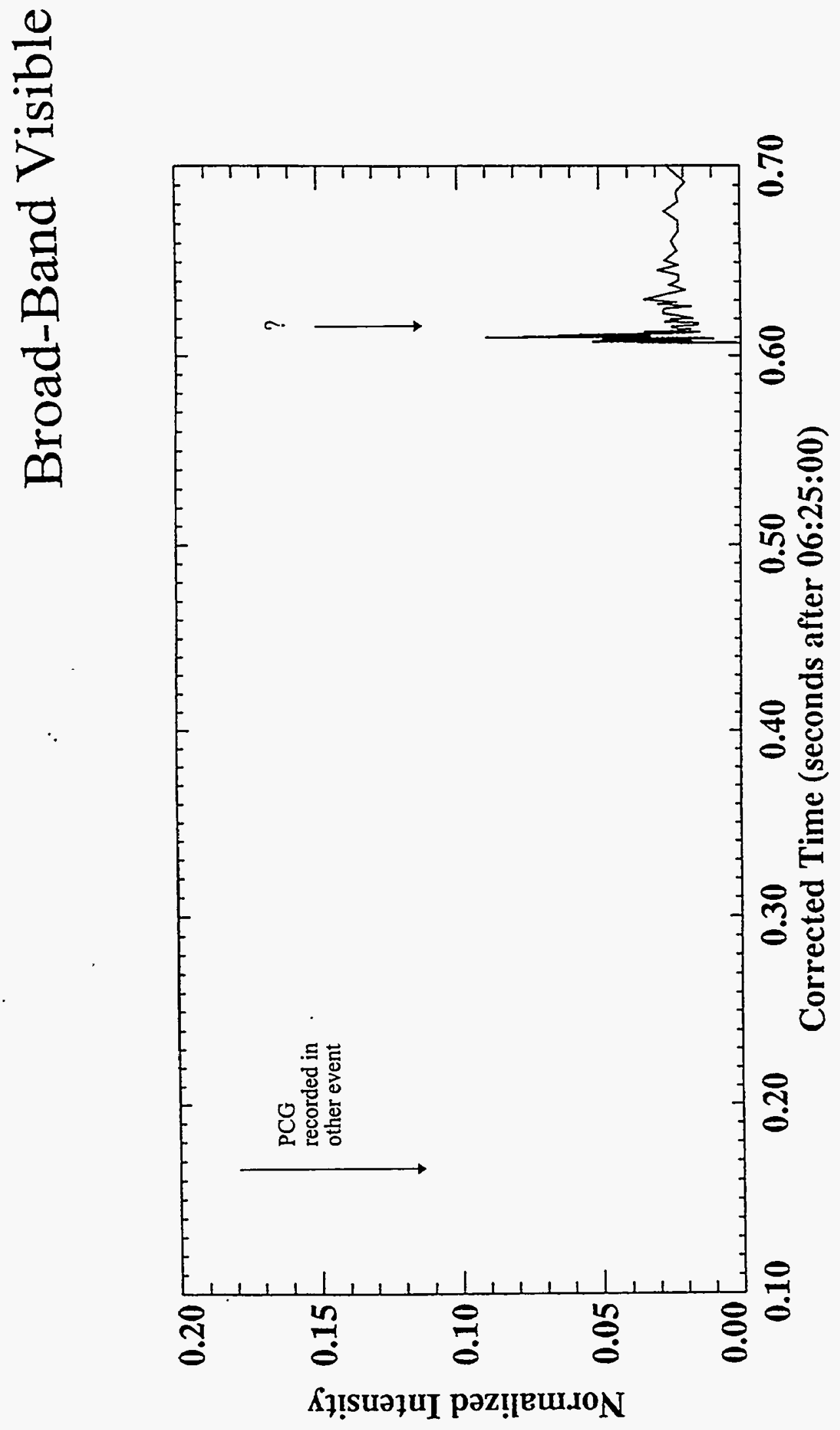

$\stackrel{p}{2}$

둥

เก่

$\ddot{\circ}$

के

g

is

$\frac{7}{5}$

$\ddot{0}$

0

2

之

을

3

응

$\bar{\pi}$

홍

定 


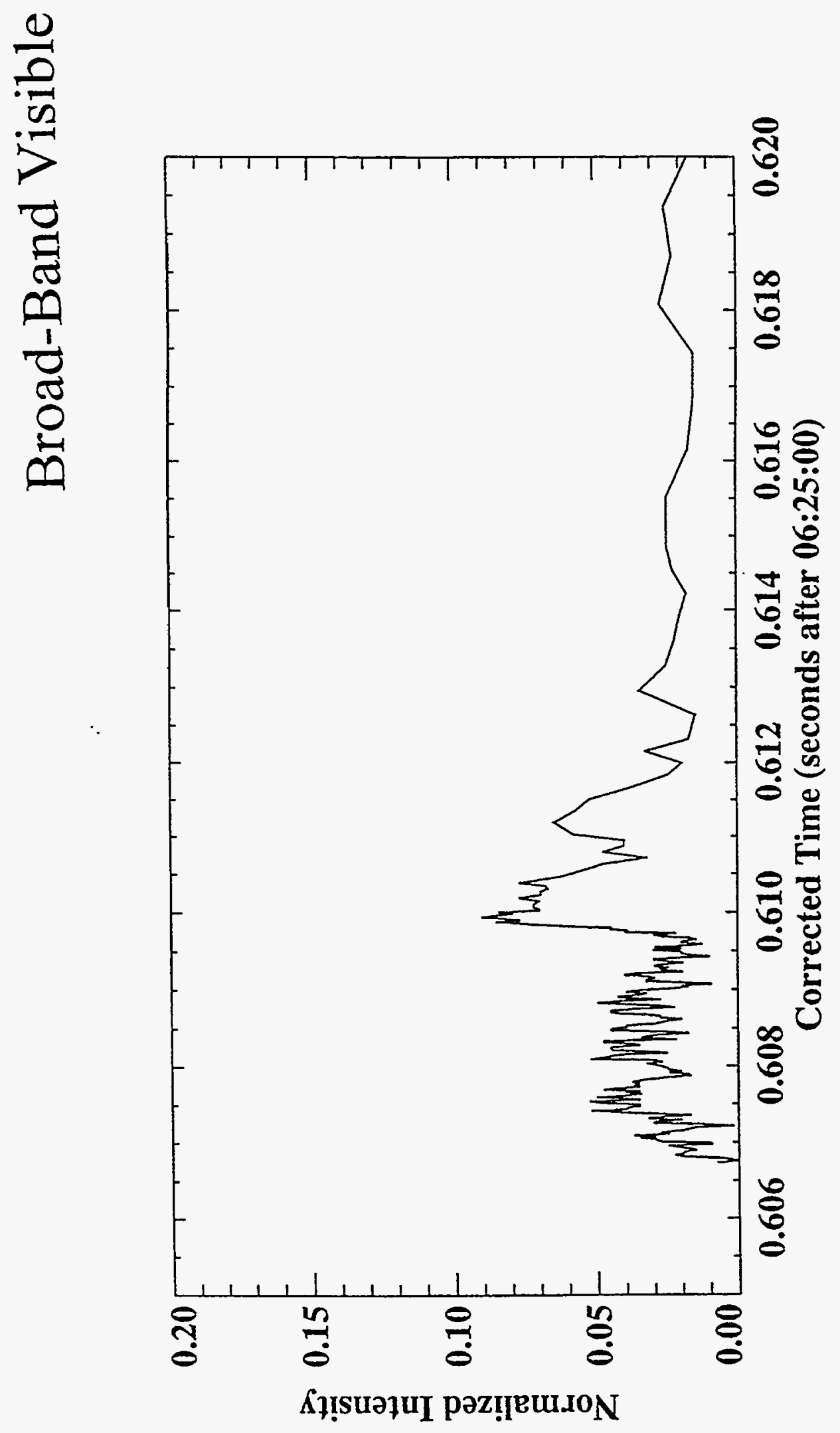

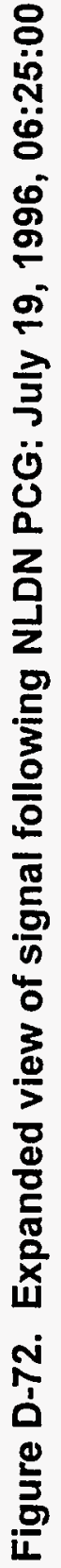




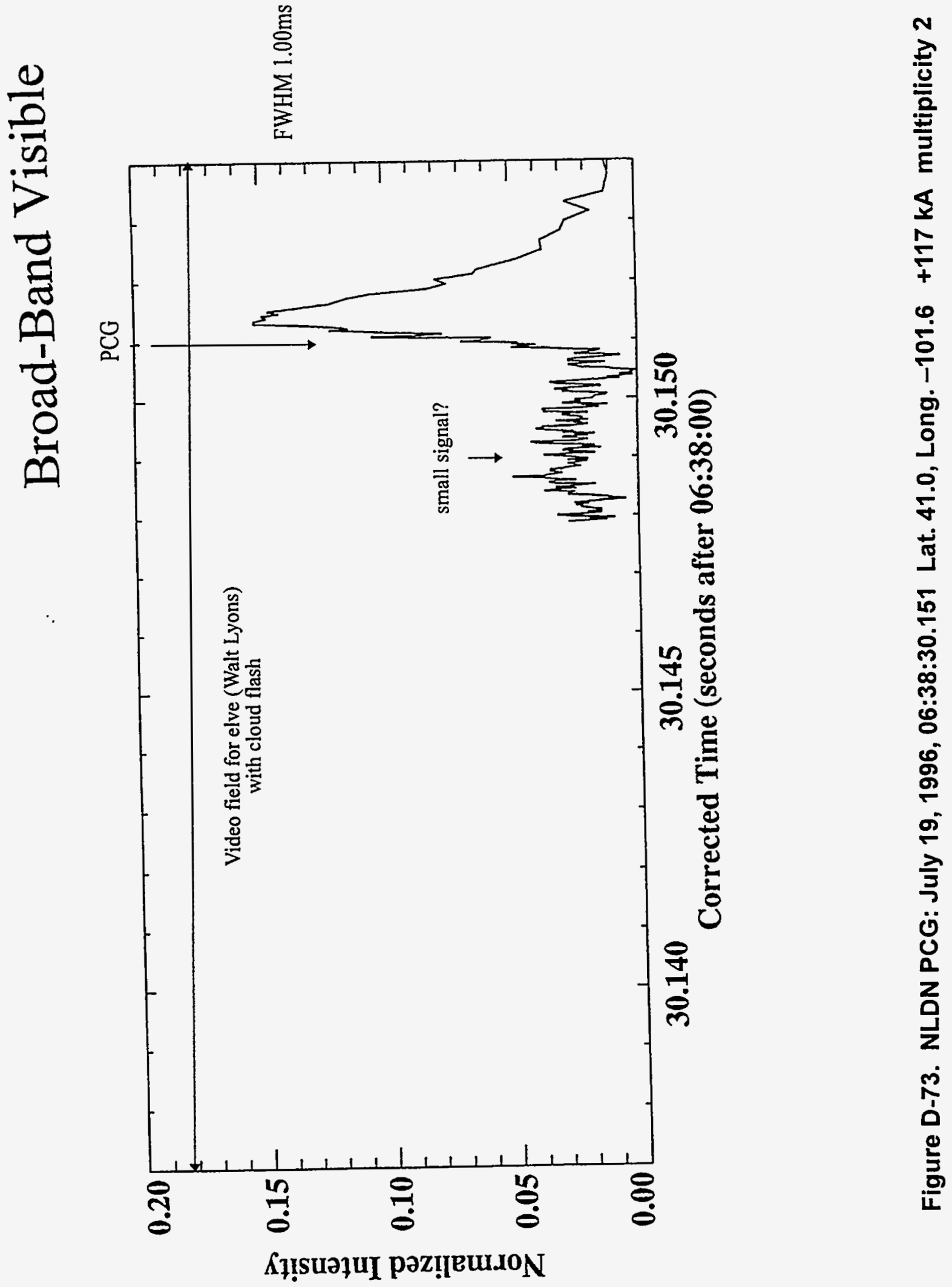



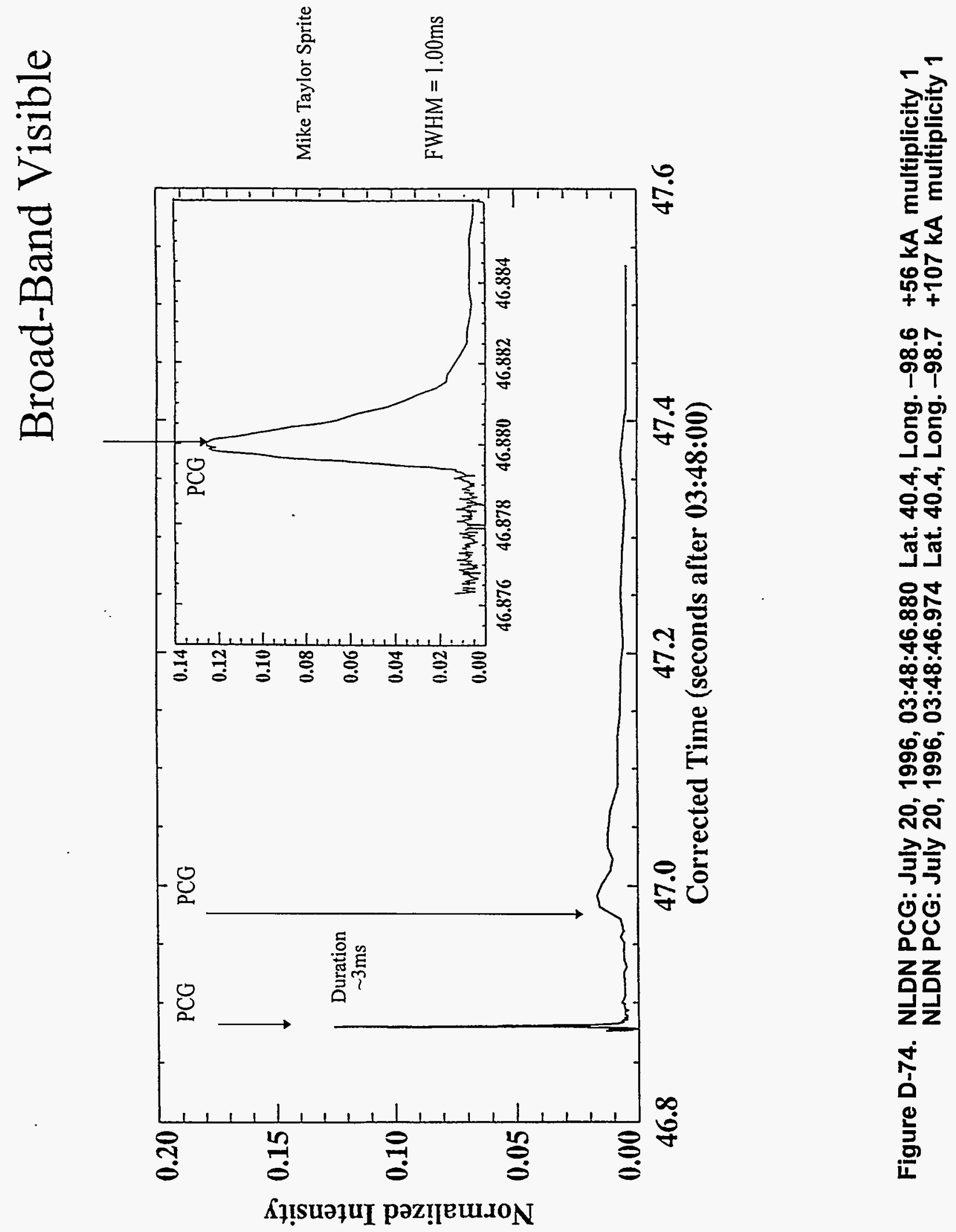

oN

$\infty$

\%

홍ํํ

48

웅요

䒕

용

o

$\ddot{\infty}$

乎

m\%

co

용

으무

จิจิ

즐즐

$\ddot{0} 0$

U.

$z z$

之是

市 


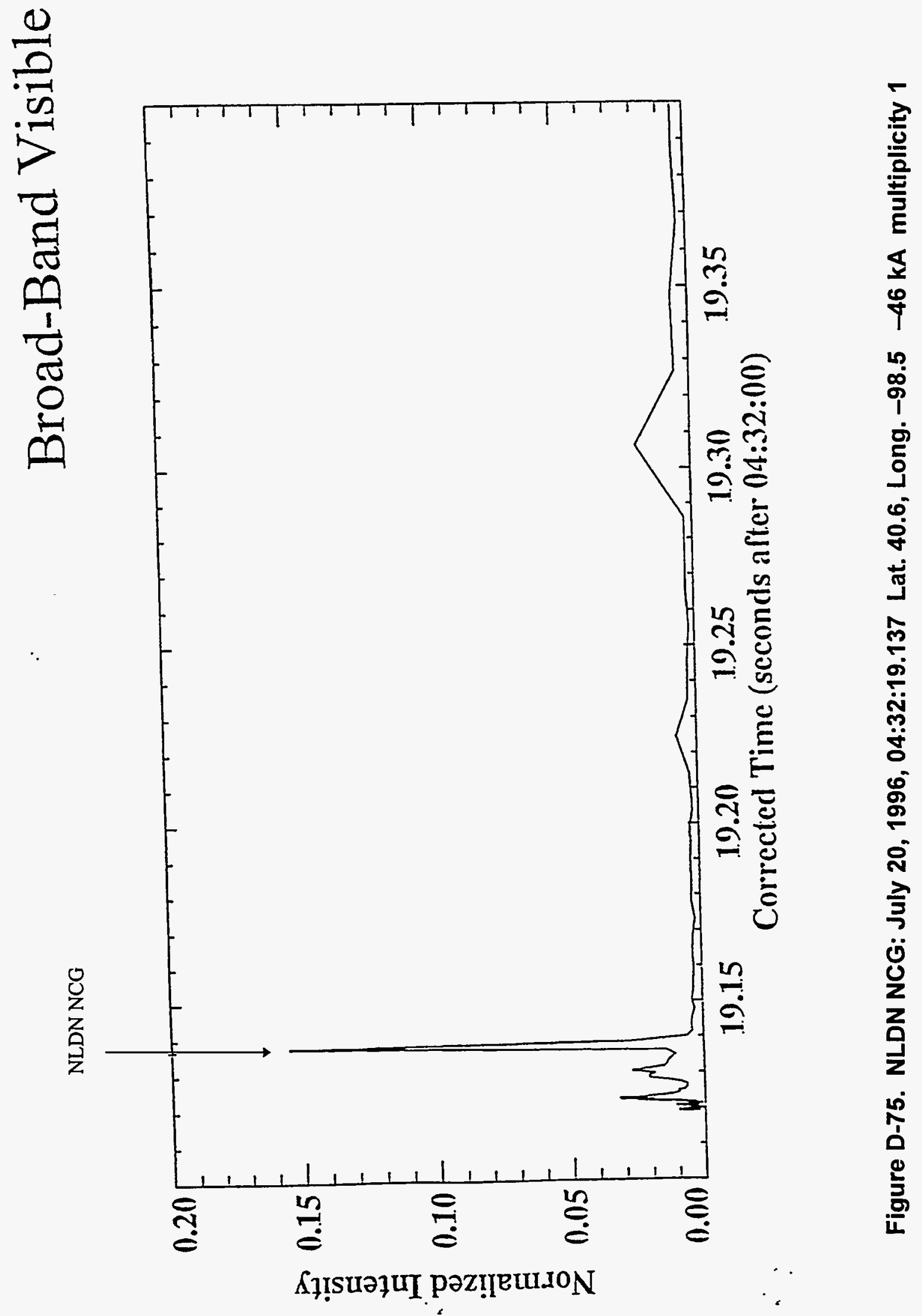




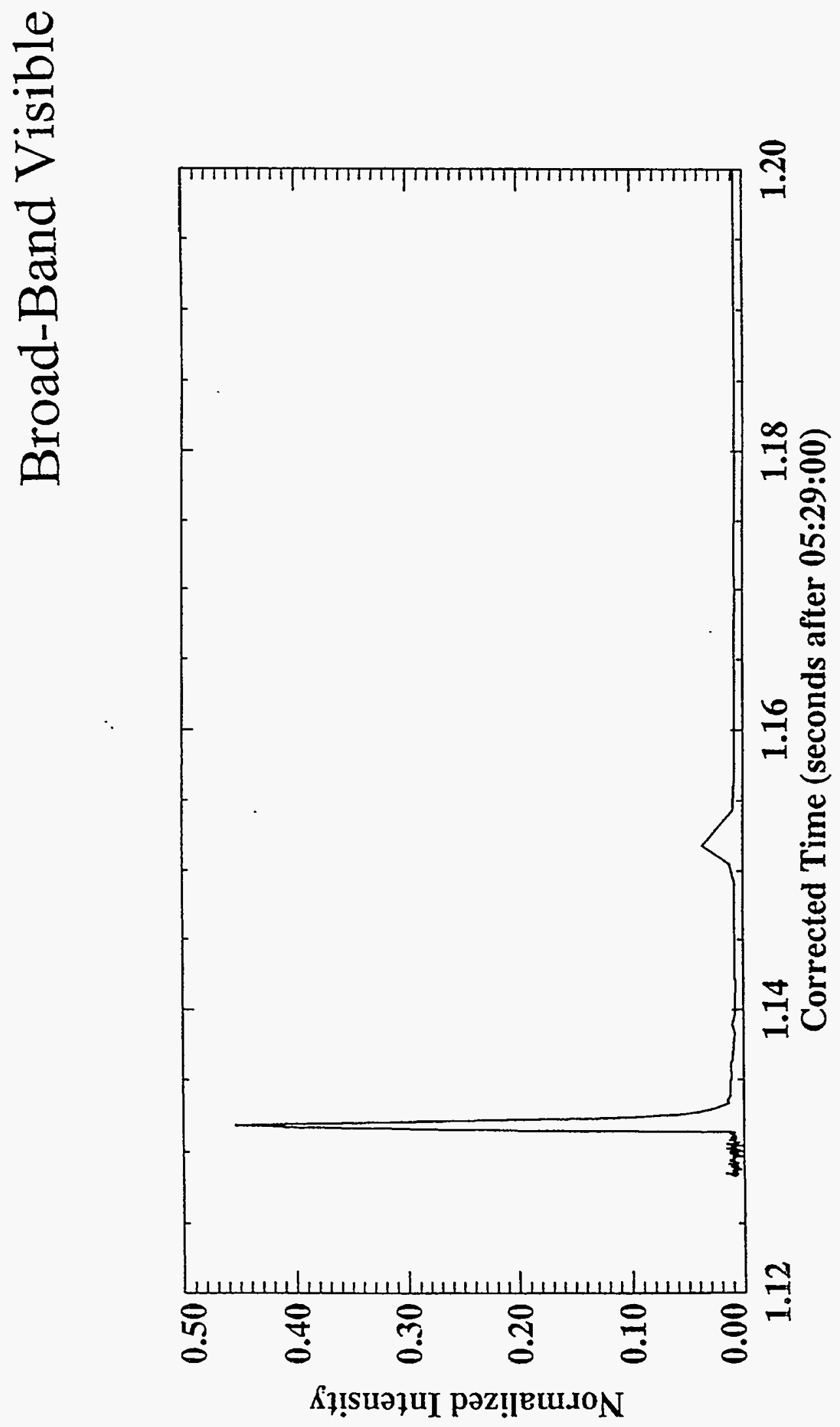

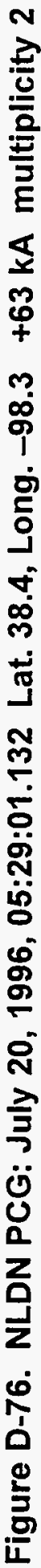




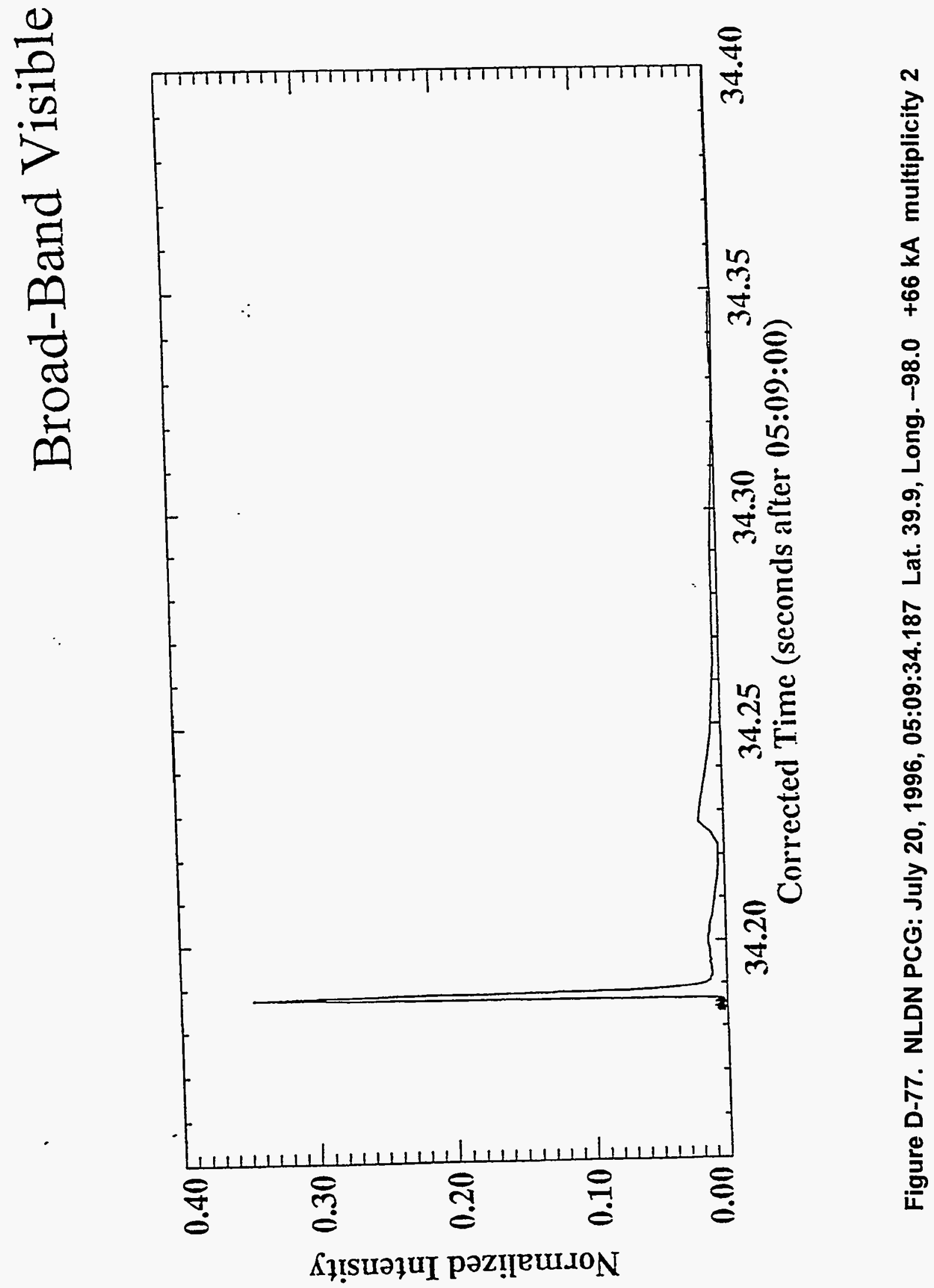




\section{Broad-Band Visible}

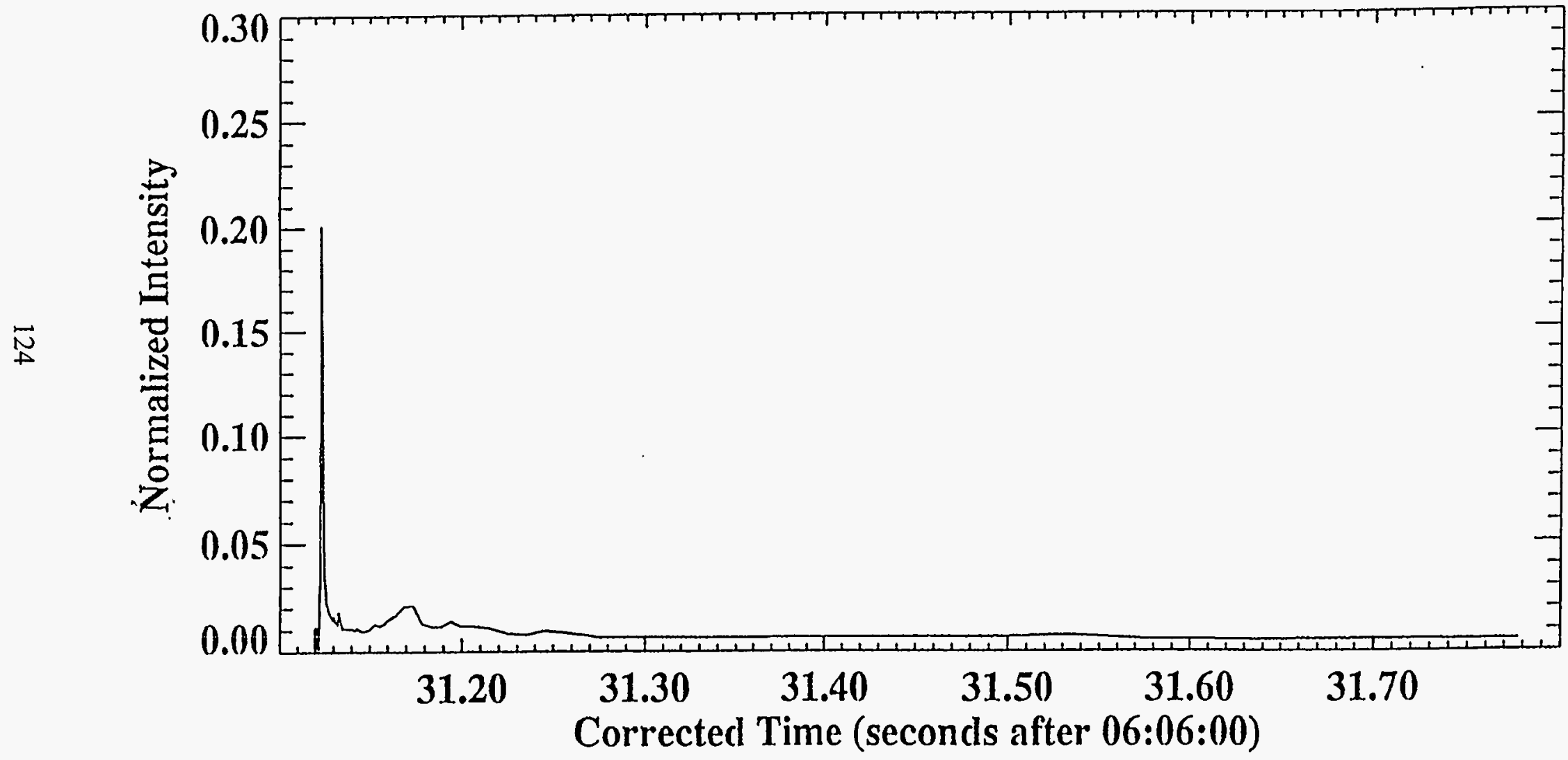

Figure D-78. NLDN PCG: July 20, 1996, 06:06:31.122 Lat. 40.6, Long. -98.0 +46 kA multiplicity 1 


\section{Broad-Band Visible}

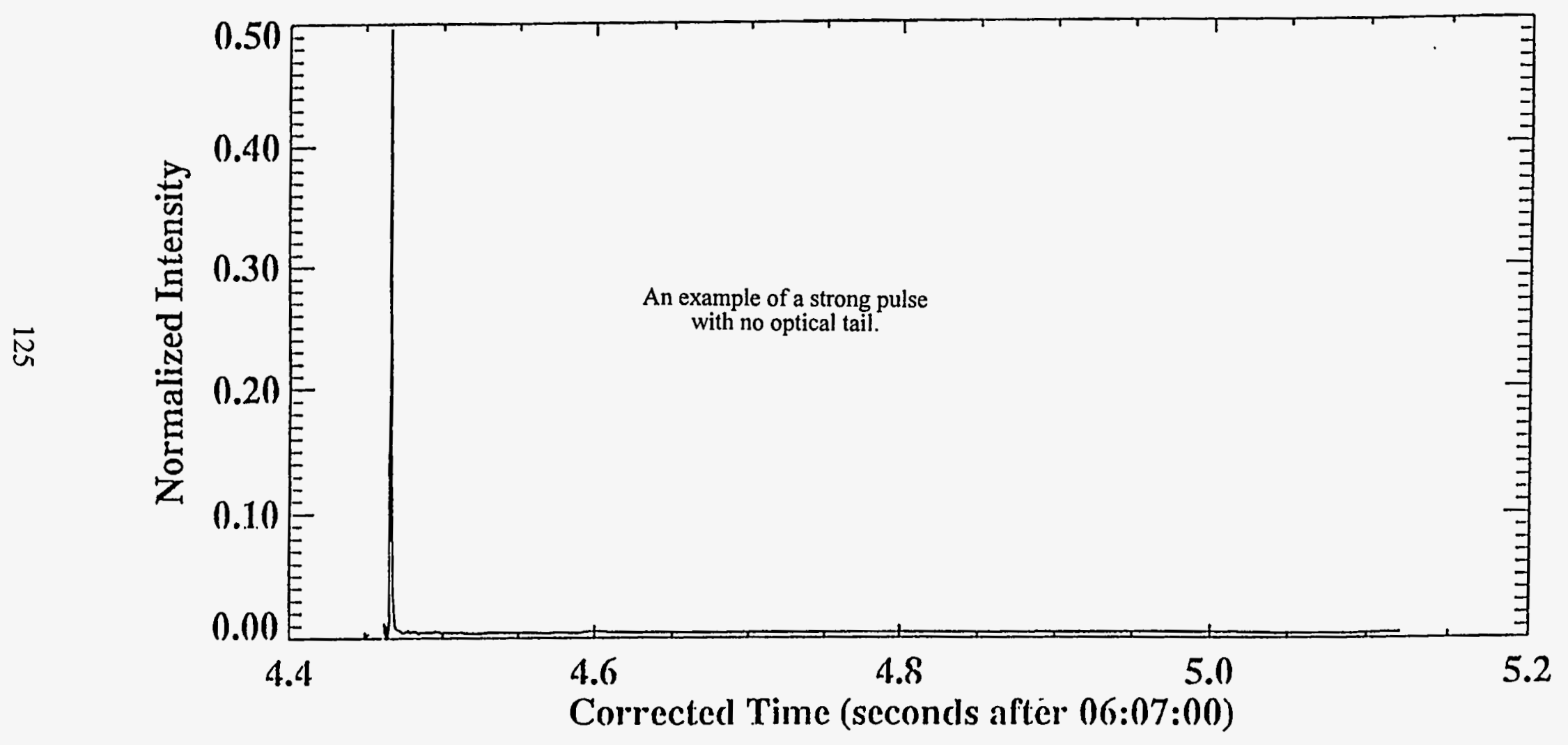

Figure D-79. NLDN PCG: July 20, 1996, 06:07:04.466 Lat. 40.8, Long. $-97.9+75$ kA multiplicity 1 


\section{Broad-Band Visible}

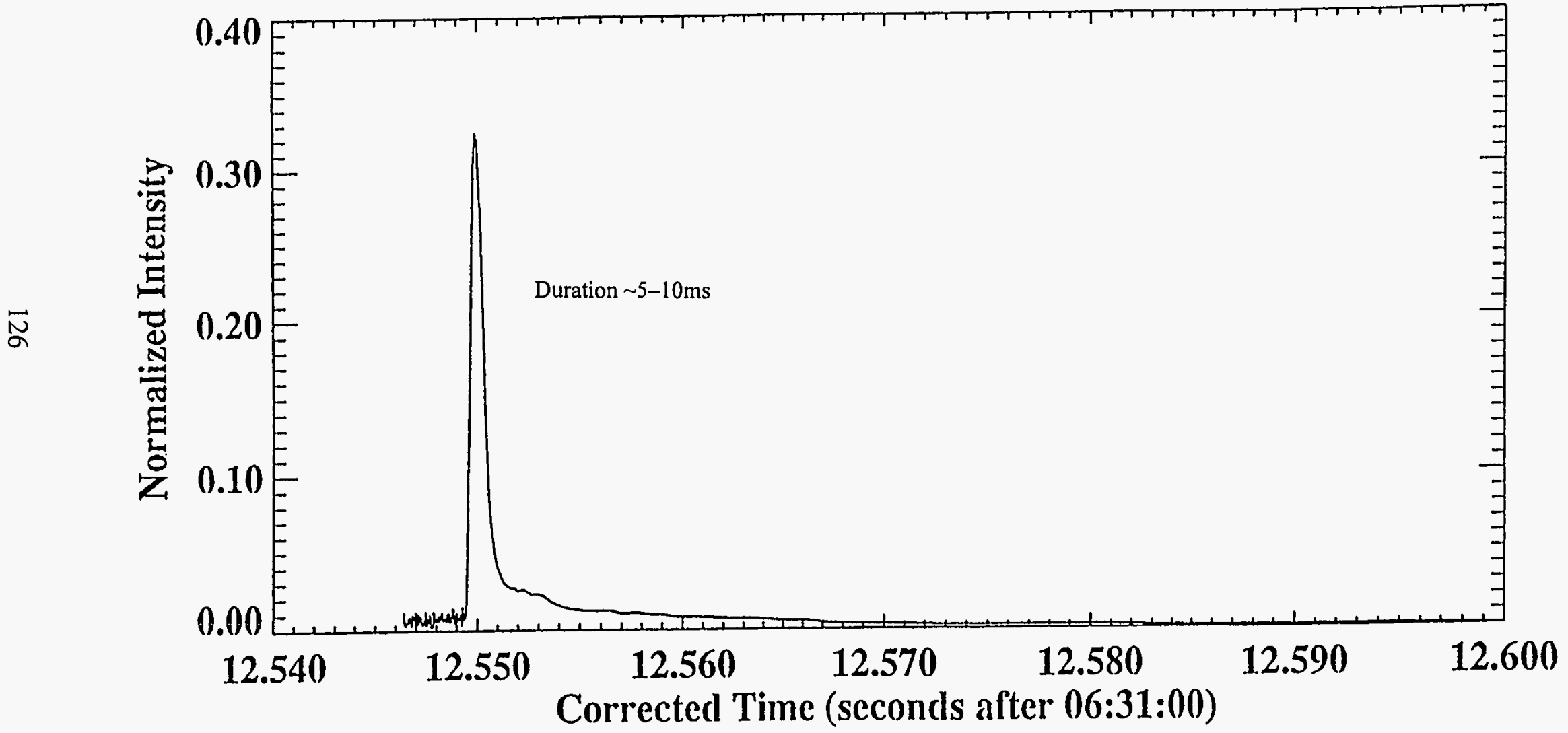

Figure D-80. NLDN PCG: July 20, 1996, 06:31:12.550 Lat. 39.4, Long. -96.5 +44 kA multiplicity 1 


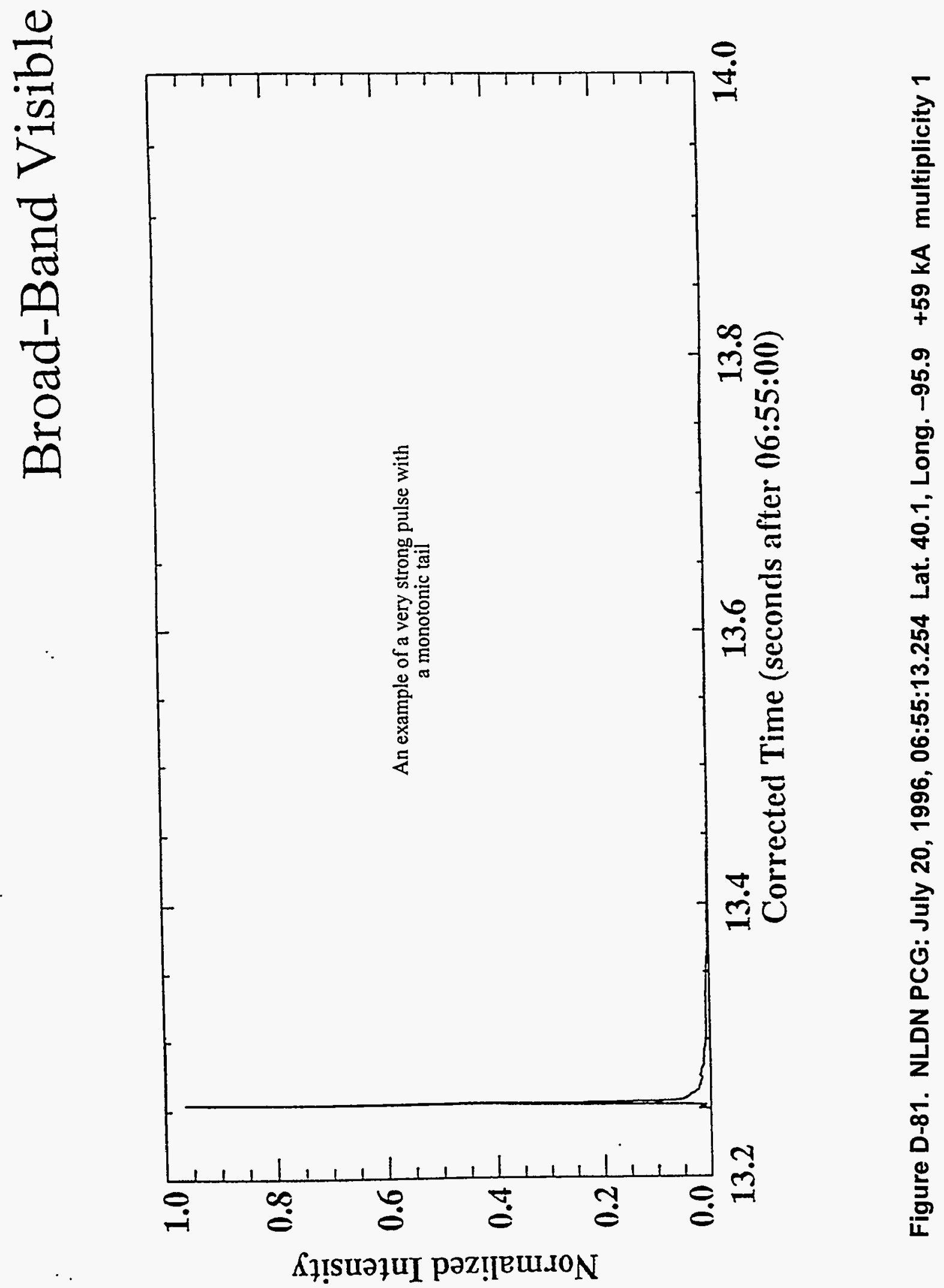


This page intentionally left blank. 


\section{Appendix E: Examples of M46 Optical Signal Ratio Calculations}

\section{Example 1. (04:13:44)}

Figure E-1 is an example of a calculation of a M46 optical signal ratio (for continuing current estimation) for a waveform with a monotonic optical tail. The background for this waveform was estimated to be between 0.006 and 0.010 in amplitude. The value of 0.010 was used for this calculation to form a conservative estimate of the optical ratio. The optical duration of this waveform was estimated to be from 20 to $40 \mathrm{~ms}$. Two-thirds of the minimum optical duration of $20 \mathrm{~ms}$ is about $13.3 \mathrm{~ms}$. This defined the measurement point for the optical tail amplitude. The background was subtracted from the optical peak amplitude and from the optical tail amplitude. Then the two values were ratioed to produce an optical signal ratio of 0.03 .

\section{Example 2. (03:46:32)}

Figure E-2 is an example of a calculation of a M46 optical signal ratio (for continuing current estimation) for a waveform with two secondary maximums. This calculation was performed in the same manner as the calculation in Example 1, except that the optical tail measurement points were taken at the secondary maximums.

Notice that the background level chosen for each example is different. This is because each background level was estimated independently for each waveform. A more rigorous study needs to be done.in order to determine a better approach to estimating the background. 
This page intentionally left blank. 


\section{Broad-Band Visible}

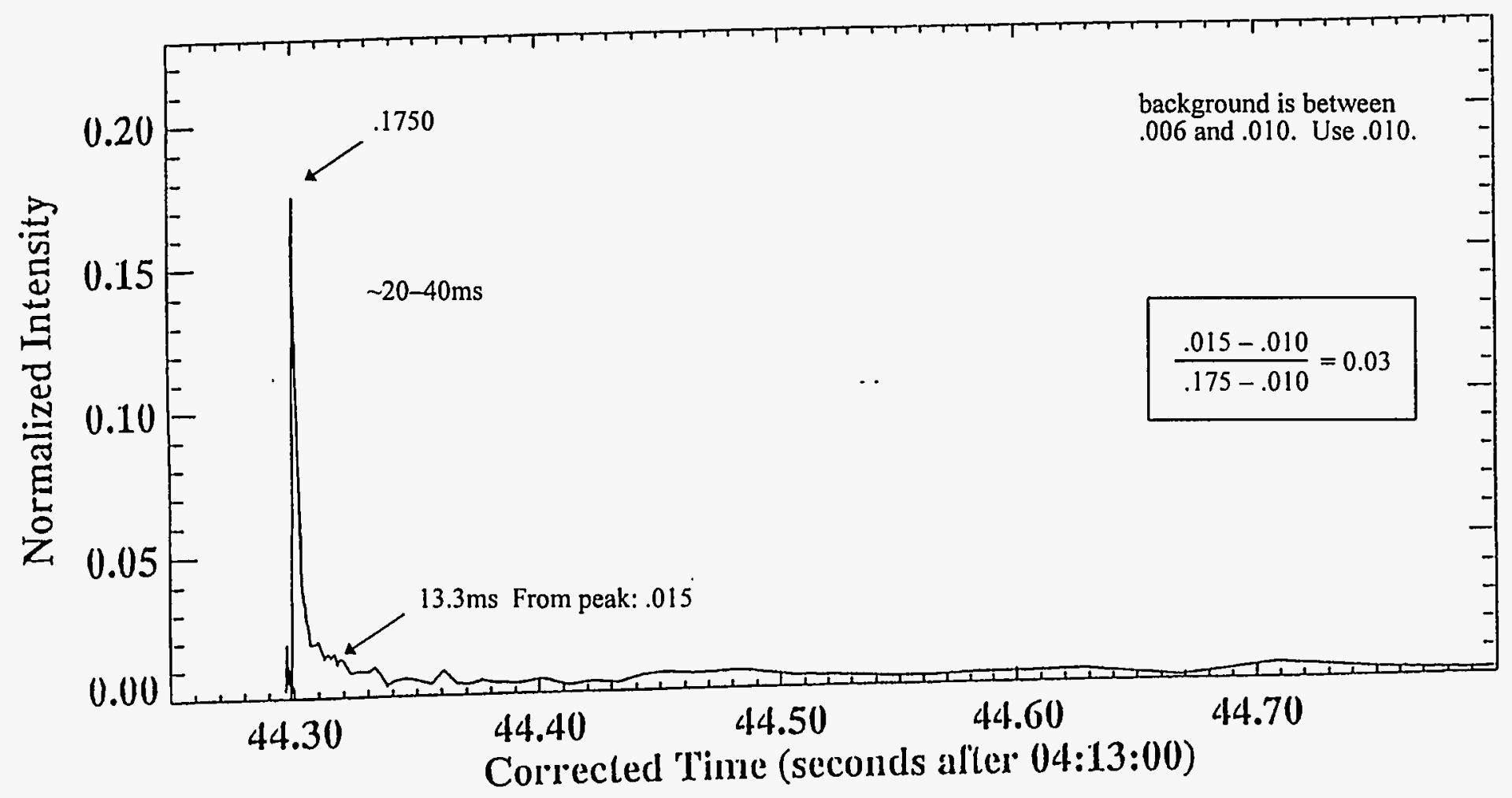

Figure E-1. NLDN PCG: July 11, 1996, 04:13:44.300 Lat. 48.4, Long. -98.3 +43 kA multiplicity 1 


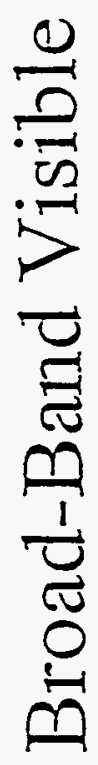

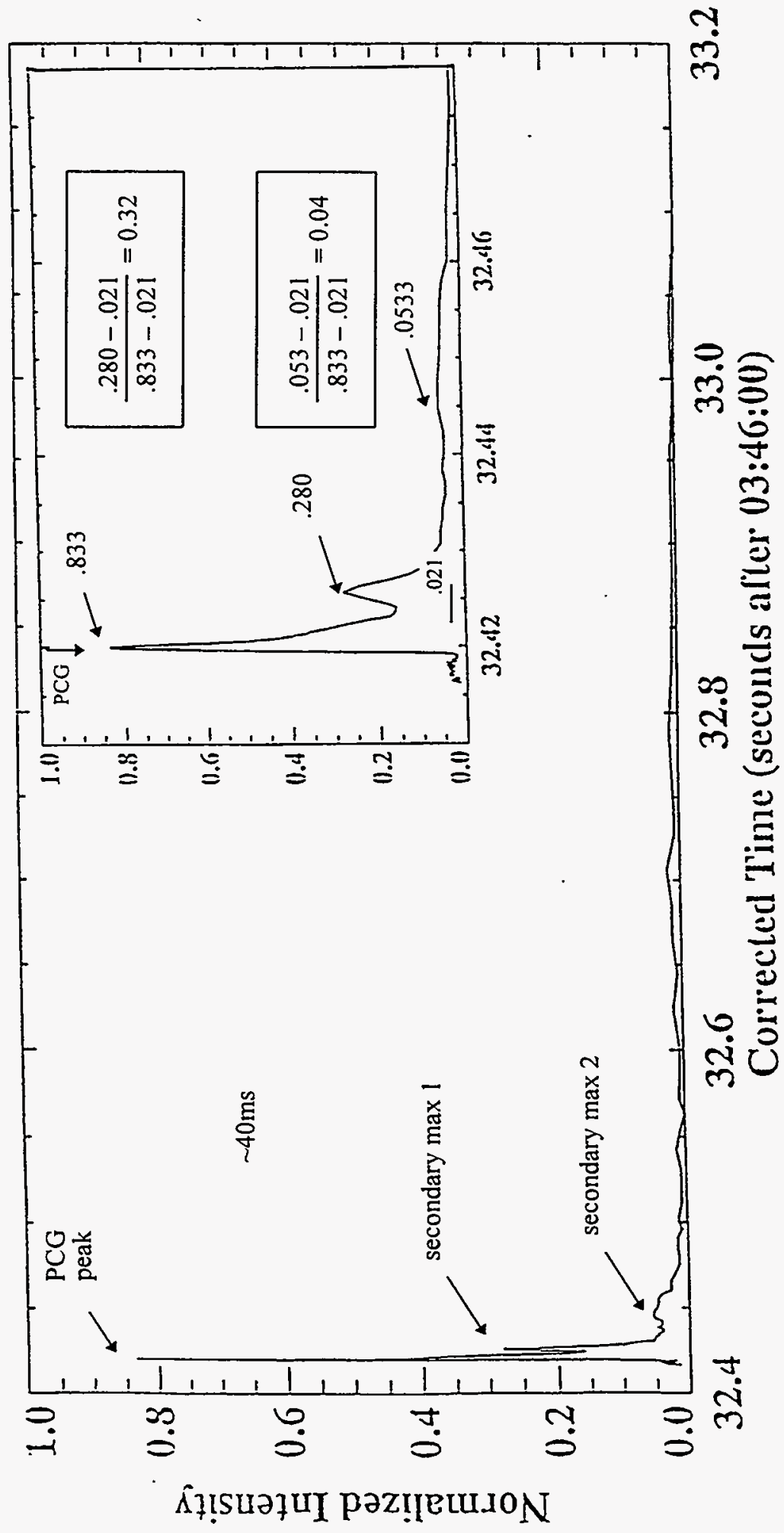

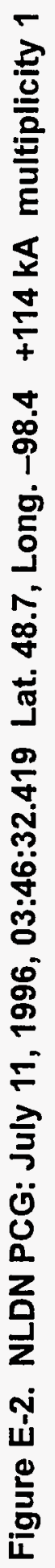




\section{DISTRIBUTION}

$1 \quad$ Laila Jeong

PL/GPOS

29 Randolph Road

Hanscom AFB, MA 01731

1 Earle Williams

MIT 48-211

Cambridge, MA 02139

$1 \quad$ Marx Brook

PO Box 1925

Socorro, NM 87801

2 Capt. R. Luce

AFTAC/TAOS

1030 S. Highway $1 \mathrm{~A}$

Patrick AFB, FL 32925-3002

1 John Shrum c/o Capt. R. Luce AFTAC/TAOS

$1030 \mathrm{~S}$. Highway $1 \mathrm{~A}$

Patrick AFB, FL 32925-3002

1 Joe Marchall c/o Capt. R. Luce AFTAC/TAOS

1030 S. Highway $1 \mathrm{~A}$

Patrick AFB, FL 32925-3002

10967 Norman Blocker, 5706

10972 Clinton A. Boye, 5705

50972 Duane Landa, 5705

10978 Dick Spalding, 5909

10980 Charley.Vittitoe, 5725

200980 Emily Mitchell, 5725

19018 Central Technical Files, 8940-2

50899 Technical Library, 4916

20619 Review \& Approval Desk, 12690 For DOE/OSTI 